\title{
POLITÉCNICA
}

"Ingeniamos el futuro"

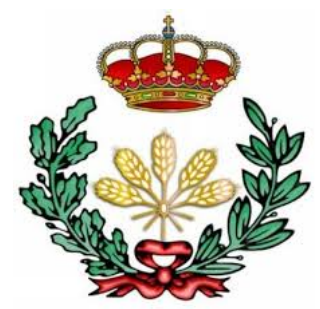

UNIVERSIDAD POLITÉCNICA DE MADRID

Escuela Técnica Superior de Ingeniería Agronómica, Alimentaria y de Biosistemas

\section{UTILIZACIÓN DEL COMPOST DE ORUJO DE VID COMO ENMIENDA ORGÁNICA Y FERTILIZANTE EN UNA ZONA VULNERABLE}

Tesis Doctoral

Raquel Villena Gordo

Licenciada En Ciencia y Tecnología de los Alimentos 

Departamento de Química y Tecnología de los Alimentos

Escuela Técnica Superior de Ingeniería Agronómica, Alimentaria y de Biosistemas

\section{UTILIZACIÓN DEL COMPOST DE ORUJO DE VID COMO ENMIENDA ORGÁNICA Y FERTILIZANTE EN UNA ZONA VULNERABLE}

Autora:

Raquel Villena Gordo

Licenciada En Ciencia y Tecnología de los Alimentos

Directora:

María Carmen Cartagena Causapé

Catedrática Universidad Politécnica de Madrid

Madrid

2019 

AGRADECIMIENTOS 

El desarrollo de esta tesis ha supuesto para mí un camino muy largo lleno de escoyos que he ido salvando, que pensé que nunca acabaría, en el cual he recibido la ayuda de muchas personas, en muy diversos campos y sin cuya colaboración, este trabajo no hubiera llegado a término. Con lo cual, este trabajo quedaría incompleto, sin agradecer su colaboración y apoyo a todos ellos.

En primer lugar, me gustaría agradecer todo el esfuerzo, la paciencia y las horas dedicadas a este trabajo de investigación a $M^{a}$ Carmen Cartagena mi tutora, que me ha animado constantemente y me ha enseñado a hacer las cosas adecuadamente, confiando en mí y trasmitiéndome sus amplios e inagotables conocimientos de valor incalculable para mí, sin cuya ayuda no hubiera sido posible este trabajo de investigación. iMuchas Gracias! ha sido un placer trabajar con ella.

También querría hacer una mención especial y darles las gracias, a María Requejo y a Mayte Castellanos que me han ayudado en todo momento, sobretodo en el desarrollo y control de los ensayos, por su paciencia y por todo lo que he aprendido de ellas, sin su ayuda incondicional esta tesis tampoco hubiera sido posible, como también agradecer su trabajo y ayuda a todo el personal de la finca "La Entresierra", porque sin su asistencia técnica durante el experimento de campo, no hubiera sido posible este trabajo.

Agradecer su colaboración inestimable y apoyo a Augusto Arce, Ana Obrador y Ana Tarquis.

Agradecer a Agricompost SL que nos haya facilitado el compost de orujo de uva desalcoholizado necesario para la realización de los ensayos.

No quiero olvidarme de agradecer su ayuda, a todas aquellas personas que de alguna manera han estado ahí y me han ayudado en la elaboración de esta tesis, aportando su granito de arena por pequeño que haya sido, sufriéndome con paciencia cuando solicitaba su ayuda, para mí en ese momento inestimable aunque a ellos no les haya parecido gran cosa.

Gracias también a todo el personal del laboratorio de Química y Análisis Agrícola que todos estos años han tenido tanta paciencia conmigo, cuando solicitaba su ayuda para poder desenvolverme cómodamente en su laboratorio y que siempre me han brindado amablemente. 
Y por último y no menos importante, gracias a mi familia que me ha apoyado y aguantado todos estos años, que han sufrido en primera persona mis cambios de humor y haberles robado tiempo para dedicarlo a este proyecto.

A Ginés, por quererme, tener paciencia, por su compresión y ayudarme en todo lo que ha podido para darme tiempo para trabajar en este proyecto que para mí era importante.

iMuchas Gracias a Todos!

Raquel 
A $M^{a}$ Carmen A mi familia A Gines 

NO IMPORTA LO LENTO QUE VAYAS MIENTRAS NO TE PARES TODO PARECE IMPOSIBLE HASTA QUE SE HACE

(Nelson Mandela) 

ÍNDICE 

Abreviaturas $\quad$ i

Índice de tablas vii

Índice de figuras xix

Resumen $\quad$ xix

Abstract $\quad$ xxiii

Capítulo 1: Introducción 1

1.1. Residuos producidos por la industria vitivinícola 4

1.2. La problemática del agua en Castilla la Mancha 17

1.3. Ciclo del Ny P en el suelo 19

1.4. Principales mecanismos que determinan el valor agronómico de un residuo orgánico $\quad 21$

1.5. Aprovechamiento del compost de orujo desalcoholizado de la industria vitivinícola en una zona vulnerable

1.6. Utilización de índices como herramienta para estudiar el comportamiento del compost de orujo en el cultivo del melón en una zona vulnerable

Capítulo 2: Objetivos

Capítulo 3: Materiales y métodos 35

3.1. Características generales 37

3.1.1. Localización y Características de la zona del ensayo 37

3.1.2. El suelo del ensayo 38

3.1.3. El clima 39

3.2. Experimento de campo 43

3.2.1. Cultivo de melón: Diseño experimental, tratamientos y riego 43

3.2.2. Cultivo de trigo: Diseño experimental 48 
3.3. Muestreo y análisis realizados

3.3.1. Análisis de planta

3.3.2. Análisis de suelo

3.3.3. Análisis del compost de orujo

3.3.4. Análisis del agua de riego

3.3.5. Análisis de Drenaje y lixiviados

3.3.6. Balance de nitrógeno y de fósforo en campo en el sistema suelo-planta

3.3.7. Índices utilizados para el estudio del comportamiento del compost de orujo en el cultivo de melón

3.3.7.1. Índices de crecimiento

3.3.7.2. Indices de eficiencia del uso del nitrógeno y del fósforo

3.3.7.3. Índices de eficiencia del uso del uso del agua

3.3.7.4. Indices ambientales en zonas vulnerables

\subsubsection{Análisis estadístico}

\section{Capítulo 4: Resultados}

4.1. Influencia de la aplicación de compost de orujo en la dinámica de crecimiento del cultivo de melón: Índices de crecimiento

4.2. Dinámica de la absorción de los nutrientes ( $N$ y $P$ ) y su distribución en el cultivo de melón

4.3. Producción y calidad del cultivo de melón. Influencia de la dosis de compost de orujo

4.4. Impacto ambiental del uso del compost de orujo en zonas vulnerables. Balances de nitrógeno y de fósforo

4.5. Índices de eficiencia del uso de nitrógeno y del fósforo para optimizar el uso del compost de orujo en un cultivo de melón industria vitivinícola en una zona vulnerable 
4.6. La aplicación del compost de orujo frente a la fertirrigación: Evaluación agronómica y medioambiental 106

4.7. Efecto residual de la aplicación del compost de orujo sobre un cultivo de trigo

Capítulo 5: Discusión general

5.1. Dinámica de crecimiento del cultivo de melón

5.2. Producción y calidad de melón

5.3. Comportamiento del nitrógeno y del fósforo aplicado

5.4. Consecuencias ambientales que tendría su aplicación en zonas vulnerables: comparación con fertirrigación

5.5. Efecto residual del nitrógeno procedente de compost de orujo

Capítulo 6: Conclusiones 

ABREVIATURAS 

AE Eficiencia agronómica de la aplicación de un nutriente

$A E_{N}$ Eficiencia agronómica de la aplicación de $N$

$A E_{p}$ Eficiencia agronómica de la aplicación de $P$

CGR Velocidad de crecimiento del cultivo

D Drenaje

DDT Días después del trasplante

EII Índice de impacto medioambiental

ETc Evapotranspiración cultivo

ETo Evapotranspiración de referencia

E (ס) Entropía relativa

FGR Velocidad de crecimiento del fruto

IE Eficiencia de utilización de un nutriente

$I E_{N}$ Eficiencia de utilización de $N$

$\mathrm{IE}_{\mathrm{N} 1}$ Eficiencia de utilización de $\mathrm{N}$ basado en la producción de fruto

IE Eficiencia de utilización de $P$

IE $E_{p 1}$ Eficiencia de utilización de $P$ basado en la producción de fruto

II Índice de impacto

IRRWUE Índice de uso del agua en función del agua de riego

LA Área foliar

LAD Duración de área foliar

LAI Índice de área foliar

LAR Razón de área Foliar

LGR Velocidad de crecimiento de la hoja

LWR Relación de la masa foliar

ME Eficiencia de gestión 
N Nitrógeno

$\mathbf{N}_{A}$ Nitrógeno aplicado

$N_{d}$ Nitrógeno disponible

$\mathrm{N}_{g}$ Nitrógeno gas

$N_{1}$ Nitrógeno lixiviado

n El período de tiempo (días) entre dos cosechas sucesivas

NAR Tasa de asimilación neta

NHI Índice de cosecha de un nutriente

$\mathrm{NHI}_{\mathrm{N}}$ Índice de cosecha de $\mathrm{N}$

$\mathrm{NHI}_{\mathrm{P}}$ Indice de cosecha de $\mathrm{P}$

NM N mineralizado

NMI Índice de mineralización de nitrógeno

NUE Eficiencia de uso de un nutriente

NUpE Eficiencia de la Absorción de un nutriente

$N U_{p} E_{N}$ Eficiencia de la Absorción de $N$

NUpE Eficiencia de la Absorción de P

P Fosforo

$P_{A}$ Fosforo aplicado

$P_{d}$ Fosforo disponible

PM Fosforo movilizado

PFP Factor parcial de productividad

$\operatorname{PFP}_{\mathrm{N}}$ Factor parcial de productividad del $\mathrm{N}$

PFP $_{\mathrm{N} 1}$ Factor parcial de productividad calculado con el $\mathrm{N}_{\text {Aplicado }}$

PFP $_{\mathrm{N} 2}$ Factor parcial de productividad calculado con el $\mathrm{N}_{\text {disponible }}$

PFP $_{\mathrm{P}}$ Factor parcial de productividad del $\mathrm{P}$ 
9 Longitud del segmento de los intervalos elegidos para el estudio en metros

RE Eficacia de recuperación aparente de un nutriente

$R E_{N}$ Eficiencia de recuperación aparente de $\mathrm{N}$

REP $_{\mathrm{P}}$ Eficiencia de recuperación aparente de $P$

RGR Velocidad de crecimiento relativa

Rb Riego bruto

$S$ Área que ocupa una planta $\left(\mathrm{m}^{2}\right)$

SLA Área foliar especifica

$S(\delta)$ Entropía

TBNUE Eficiencia del uso del nutriente $(x)$ basado en la biomasa total

TBNUE $_{N}$ Eficiencia del uso del $\mathrm{N}$ basado en la biomasa total

TBNUE E Eficiencia del uso del P basado en la biomasa total

Tm Temperaturas medias

TMA Temperaturas máximas

Tma Temperaturas mínimas

TSS Total de sólidos solubles

$U_{0}$ Cantidad de nutriente $(N$ y $P$ ) absorbido por el cultivo sin aplicación de compost

$U_{N}$ Cantidad de $\mathrm{N}$ absorbido por el cultivo con aplicación de compost

$U_{p}$ Cantidad $P$ absorbido por el cultivo con aplicación de compost

$U_{\mathrm{NF}}$ Nutriente total (nitrógeno y fosforo) absorbido por el fruto con aportación de compost

$U_{x}$ Nutriente absorbido por el cultivo

$U_{x F}$ Nutriente absorbido por la cosecha (fruto)

$W_{h t}$ Peso seco de la hoja en el momento de la cosecha (t)

$W_{f t}$ Peso seco de fruto en el momento de la cosecha $(t)$ 
$W_{\text {ptt }}$ Peso seco de la planta entera en el momento de la cosecha ( $\left.t\right)$

WEP P extraíble en agua

WSP P soluble en agua

WUE Eficacia de uso del agua en función de la Etc

$Y_{T A}$ Producción de biomasa total de la planta

$Y_{T x}$ Producción de biomasa total del cultivo

$V_{x}$ Kilogramos de producto obtenidos por kilogramo de nutriente aportado

УТ Producción de materia seca

$\mu_{i}(\delta)$ Distribución normalizada de la probabilidad de una variable

$\Delta E(\delta)$ Variación de la entropía

$\Delta S$ Variación en el contenido volumétrico de agua en el suelo 
ÍNDICE DE TABLAS 

Tabla 1.1 Tratamientos biotecnológicos de los residuos de la industria vitivinícola (Arvanitoyannis, I.S.a y b, 2006; Devesa-Rey, R., 2011).

Tabla 1.2 Subproductos obtenidos del orujo de vid (DevesaRey et al., 2011).

Tabla 1.3 Propiedades físico-químicas del orujo de uva y del compost y vermicompost de orujo de uva.

Tabla 1.4 Ventajas potenciales para la industria vitivinícola del compostaje in situ de sus residuos orgánicos.

Tabla 1.5 Efectos más destacados de la materia orgánica. (Labrador-Moreno, 1996).

Tabla 1.6 Superficies declaradas como zona Vulnerable según CC: AA (2009) (MAPAMA, 2013).

Tabla 3.1 Propiedades físico-químicas del suelo del ensayo en 2011, 2012 y 2013.

Tabla 3.2 Los datos climáticos mensuales, de la zona durante el período del experimento en 2011, 2012, 2013 y 2014.42

Tabla 3.3 Características del compost usado los tres años.

Tabla 3.4 Propiedades físico-químicas del agua de riego utilizada en el experimento (Años 2011, 2012, y 2013).

Tabla 3.5 Análisis realizados en el agua de riego utilizada en el experimento (Años 2011, 2012, y 2013).

Tabla 3.6 Índices de crecimiento (Hunt, 1982).

Tabla 3.7 Índices utilizados para el cálculo de la eficiencia del uso del $N$ y del $P$ en el sistema suelo planta en los años 2011, 2012 y 2013.

Tabla 4.1.1 Evolución de los índices morfológicos (SLA, LWR y LAR) durante los tres periodos definidos I, II y II del ciclo de cultivo del melón. 
Tabla 4.1.2 Evolución de los índices NAR $\left(\mathrm{g} \mathrm{m}^{-2}\right.$ día $\left.{ }^{-1}\right), \operatorname{LGR}\left(\mathrm{cm}^{2}\right.$ $\mathrm{m}^{-2}$ día $\left.{ }^{-1}\right)$, CGR $\left(\mathrm{g} \mathrm{m}^{-2}\right.$ día $\left.{ }^{-1}\right), R G R\left(m g g^{-1}\right.$ día $\left.^{-1}\right)$, y FGR ( $\mathrm{g} \mathrm{m}^{-2}$ día $^{-1}$ ) durante los periodos definidos I, II, III y IV del ciclo de cultivo del melón.

Tabla 4.3.1 Producciones, pesos medios, $n^{\circ}$ de frutos y eficiencia de manejo (ME) en función de la dosis de compost.

Tabla 4.3.2 Parámetros de calidad del melón en función de la dosis de compost aplicada.

Tabla 4.4.1 Balance de $\mathrm{N}$ en el sistema suelo-planta en los años 2011, 2012 y 2013 en $\mathrm{Kg} \mathrm{ha}^{-1}$.

Tabla 4.4.2 Datos de drenaje y $\mathrm{N}$ lixiviado acumulado en los años 2011, 2012 y 2013 en $\mathrm{Kg} \mathrm{ha}^{-1}$.

Tabla 4.4.3 Valores del índice de mineralización los años 2011, 2012 y 2013.

Tabla 4.4.4 Balance de $P$ en el suelo al final del ensayo en los años 2011, 2012 y 2013.

Tabla 4.5.1 Índices de eficiencia del uso del $N$ en el sistema suelo planta en los años 2011, 2012 y 2013.

Tabla 4.5.2 Índices de eficiencia del uso del $P$ en el sistema suelo planta en los años 2011, 2012 y 2013.

Tabla 4.6.1 Valores de los índices de la eficiencia del uso del agua en el sistema suelo planta en los años 2011, 2012 y 2013.

Tabla 4.7.1 Valores medios de producción de grano, $\mathrm{N}$ extraído por el grano de trigo y $\mathrm{N}$ inicial disponible en el suelo. 118 
ÍNDICE de FIGURAS 

Figura 1.1 La producción de vino (OIV, 2018).

Figura 1.2 Generación de residuos en el proceso de elaboración del vino (modificado de Muhlack et al., 2018).

Figura 1.3 Esquema del proceso de extracción del alcohol y del tartrato de calcio de los orujos y lías de vinificación (modificado de Bustamante, 2007).

Figura 1.4 Imágenes de distintos residuos de la industria enológica.

Figura 1.5 Esquema de la valorización del orujo de uva por procesos vía aerobia y anaerobia, con los efectos positivos (+) y negativos $(-)$ de los productos finales (compost, vermicompost $y$ digestato) en el suelo (Gómez-Brandon et al., 2019).

Figura 1.6 Pilas de compost en la planta de Agricompost S.L. (Socuéllamos, Ciudad Real).

Figura 1.7 Distribución de las Zonas Vulnerables) declaradas en el territorio español (MAPAMA, 2015).

Figura 1.8 Principales impactos en el agua, en el suelo y en el aire del exceso de los nutrientes nitrógeno y fósforo.

Figura 1.9 Procesos que rigen el valor fertilizante de un residuo orgánico;impactos ambientales asociados (INRA-CNRS 2014).

Figura 1.10 Diagrama conceptual de las distintas formas de $P$ inorgánico en suelos categorizadas en términos de accesibilidad, extractabilidad y disponibilidad para las plantas (Syers, J.K. et al., 2008).

Figura 1.11 Metodología de especiación de P según Xiao-Lan Huang (2008).

Figura 1.12 Melón piel de sapo.

Figura 1.13 Superficie dedicada al de melón en 2018 por comunidades autónomas en España (MAGRAMA, 2018).

Figura 1.14 Cultivo de trigo. 
Figura 1.15 Aprovechamiento circular de compost de la industria vitivinícola (Gestión agrícola sostenible).

Figura 3.1 En verde delimitación de la finca "La Entresierra" y en rojo delimitación de las parcelas donde se realizaron los ensayos. (Fotografía aérea de la finca experimental "La Entresierra" (Google maps).

Figura 3.2 Esquema temporal del ensayo en las tres parcelas en la finca experimental de "La Entresierra".

Figura 3.3 Perfil del suelo donde se realizaron los experimentos.

Figura 3.4 Temperaturas medias los años del ensayo.

Figura 3.5 Precipitación mensual los años del ensayo.

Figura 3.6 Esquema general de las precipitaciones años 2011, 2012, 2013 y 2014.

Figura 3.7 Aplicación del compost.

Figura 3.8 Acolchado plástico (polietileno transparente) densidad de 4.444 plantas ha $\mathrm{h}^{-1}(1,5 \times 1,5 \mathrm{~m})$.

Figura 3.9 Esquema del campo experimental del melón.

Figura 3.10 Compost de orujo.

Figura 3.11 Detalle del sistema de riego por goteo.

Figura 3.12 Esquema campo experimental. Transecto de estudio. 50

Figura 3.13 Toma de muestras del trigo a lo largo de todo el transecto. 51

Figura 3.14 Colocación de las sondas Diviner 200 (FDR) en las parcelas. 53

Figura 3.15 Ubicación de las cañas de succión en las parcelas.

Figura 3.16 Esquema de la estructura del análisis multiescala a través de la entropía relativa a lo largo del transecto de estudio.

Figura 4.1.1 Producción de materia seca $\left(\mathrm{g} \mathrm{m}^{-2}\right)$ de la hoja, tallo, fruto y la planta total durante la temporada de crecimiento en 2011. 
Figura 4.1.2 Producción de materia seca $\left(\mathrm{g} \mathrm{m}^{-2}\right)$ de la hoja, tallo, fruto y la planta total durante la temporada de crecimiento en 2012.

Figura4.1.3 Producción de materia seca $\left(\mathrm{g} \mathrm{m}^{-2}\right)$ de la hoja, tallo, fruta y la planta aérea total durante la temporada de crecimiento en 2013.

Figura 4.1.4 Distribución materia seca en hoja, tallo y fruto durante la temporada de crecimiento en 2011, 2012 y 2013.

Figura 4.1.5 Índice de área foliar (LAI) y Duración del área foliar (LAD) durante la temporada de crecimiento en 2011, 2012 y 2013.

Figura 4.1.6 Temperaturas medias y mínimas durante la temporada de crecimiento del cultivo en 2011, 2012 y 2013.

Figura 4.1.7 Precipitaciones, Temperaturas medias ( $\mathrm{Tm}$ ), temperaturas mínimas (tma) y temperaturas máximas (TMA) durante la temporada de crecimiento del cultivo en 2011, 2012 y 2013.

Figura 4.1.8 Relación entre la tasa de crecimiento relativo (RGR) y sus componentes: a) Razón de área foliar (LAR), b) Tasa de Asimilación neta (NAR), c) Área específica foliar (SLA) y d) Relación de peso foliar (LWR) durante la temporada de crecimiento en 2011, 2012 y 2013.

Figura 4.1.9 Matriz de correlación de los índices de crecimiento: LAI, LAD, SLA, LWR, LAR, LGR, NAR, RGR, CGR Y FGR (2011, 2012 y 2013).

Figura 4.2.1 Efecto de la dosis de compost aplicado en la acumulación de $N$ en las diferentes partes de la planta de melón: hoja ( $a, d y$ g), tallo ( $b$, e y $h$ ) y fruta (c, f y i) en el año 2011 ( $a, b$ y c), 2012 (d, e y f) y 2013 ( $g, h$ y $)$.

Figura 4.2.2 Efecto del compost aplicado en la absorción de $N\left(\mathrm{~g} \mathrm{~m}^{-2}\right)$ de las diferentes partes de la planta de melón: hoja ( $a$, e y i), tallo $(b, f y j)$, fruto $(c, g$ y $k$ ) y en la planta de melón completa (d, h y I) en 2011 ( $a, b, c$ y d), $2012(e, f, g$ y h) y $2013(i, j, k$ y $)$. 
Figura 4.2.3 Distribución de nitrógeno en las hojas, tallos y frutos durante la temporada de crecimiento en 2011, 2012 y 2013.

Figura 4.2.4 Efecto de la dosis de compost aplicado en la acumulación de $P$ en las diferentes partes de la planta de melón: hoja (a y d), tallo (b y e), fruto ( $c$ y f) en 2011 ( $a, b$ y c) y 2012 (d, e y f).

Figura 4.2.5 Efecto del compost aplicado en la absorción de $P\left(\mathrm{~g} \mathrm{~m}^{-2}\right)$ de las diferentes partes de la planta de melón: hoja (a y e), tallo (b y $f$ ), fruto ( $c$ y $g$ ) y en la planta de melón completa (d y h) en 2011 ( $a, b, c y d)$ y 2012 (e,f, gy h).

Figura 4.2.6 Distribución de fósforo en las hojas, tallos y frutos durante la temporada de crecimiento en 2011 y 2012.

Figura 4.2.7 Relación entre el N y P absorbido por la planta $\left(\mathrm{g} \mathrm{m}^{-2}\right)(2011$, 2012 y 2013).

Figura 4.2.8 Absorción de nutrientes ( $N$ y $P$ ) en función de la cantidad disponible: a) $\mathrm{N}$ absorbido frente a $\mathrm{N}$ disponible; b) Relación $N$ absorbido/ $N$ disponible frente a $N$ disponible; $c) P$ absorbido frente a $P$ disponible; $d$ ) Relación $P$ absorbido/ $P$ disponible frente a $P$ disponible.

Figura 4.3.1 Producción Total y comercial en las distintas cortas los tres años de ensayo 2011 (a), 2012 (b) y 2013 (c).

Figura 4.3.2 Relación entre la producción total y comercial del fruto del melón de los tres años de ensayo 2011, 2012 y 2013.

Figura 4.3.3 Producción relativa de fruto de melón frente a) al $\mathrm{N}$ aplicado $\left(N_{A}\right)$ y b) al $P$ aplicado $\left(P_{A}\right)$ c) al $N$ absorbido $\left(U_{N}\right)$ y d) al $P$ absorbido $\left(U_{P}\right)$.

Figura 4.4.1 Cantidad de $\mathrm{N}$ lixiviado $\left(\mathrm{kg} \mathrm{N} \mathrm{ha}^{-1}\right)$ en función del drenaje $(\mathrm{mm})$ en los distintos años de ensayo (2011,2012 y 2013) según los distintos tratamientos $\left(C, D_{1}, D_{2}\right.$ y $\left.D_{3}\right)$.

Figura 4.4.2 Índice de mineralización de nitrógeno (NMI) (fertirrigación y compost) versus $\mathrm{N}$ disponible. 
Figura 4.6.1 Relaciones entre el rendimiento relativo (rendimiento fruto /máxima rendimiento de fruta) y $\mathrm{N}$ total disponible con fertilización orgánica y fertirrigación, incluido el $\mathrm{N}$ mineralizado del suelo a lo largo del ciclo del cultivo.

Figura 4.6.2 Relaciones entre el rendimiento relativo (rendimiento de fruta/máxima rendimiento de fruta) y $\mathrm{N}$ total disponible con fertilización orgánica y fertirrigación.

Figura 4.6.3 Índices agronómicos, económicos y ambientales utilizados para comparar la fertirrigación y la fertilización orgánica (Castellanos et al., 2013)

Figura 4.6.4 Comparación de los índices de eficiencia relacionados con la producción de fruto en función de a) $\mathrm{N}$ aplicado $\left(\right.$ PFP $\left._{\mathrm{N1}}\right)$ y $\mathrm{N}$ disponible $\left(\right.$ PFP $\left.\left._{\mathrm{N} 2}\right) ; \mathrm{b}\right) \mathrm{N}$ disponible $\left(\mathrm{PFP}_{\mathrm{N} 2}\right)$ y $\mathrm{N}$ absorbido $\left(I E_{N 1}\right)$ obtenidos en fertirrigación y mediante la aplicación de compost.

Figura 4.6.5 Índices de eficiencia del agua, (fertirrigación y aplicación de compost) en función del nitrógeno disponible $\left(\mathrm{kg} \mathrm{ha}^{-1}\right)$ : a) (WUE) $\left(\mathrm{kg} \mathrm{m}^{-3}\right)$ y b) (IRRWUE) $\left(\mathrm{kg} \mathrm{m}^{-3}\right)$.

Figura 4.6.6 Índices ambientales en función de la dosis de compost aplicada los años 2011, 2012 y 2013 ( $\left(\mathrm{ha}^{-1}\right)$ : a) Índice de impacto (II) y b) Índice de impacto ambiental (EII).

Figura 4.6.7 Índices ambientales en función del nitrógeno disponible (kg $\mathrm{ha}^{-1}$ ) (fertirrigación y aplicación del compost): a) Índice de impacto (II), b) Índice de impacto ambiental (EII).

Figura 4.7.1 Nutrientes disponibles en el suelo después del periodo de cultivo ( $\mathrm{mg} \mathrm{kg}^{-1}$ ) en los distintos años de ensayo (2011, 2012 y 2013).

Figura 4.7.2 Datos originales de las dos variables estudiadas a) Producción de grano y b) $\mathrm{N}$ absorbido por el mismo en $\mathrm{Kg} \mathrm{ha}^{-1}$ a lo largo del transecto, incluyendo el $\mathrm{N}$ disponible en el suelo procedente del cultivo del melón en cada tratamiento en las tres campañas: 2011-2012, 2012-2013 y 2013-2014. 
Figura 4.7.3 Evolución de los datos de precipitación y temperaturas máximas durante el periodo del cultivo del trigo: a) 20112012 b) 2012-2013 y c) 2013-2014.

Figura 4.7.4 Valores medios de eficacia de producción de grano y eficacia de extracción de N por el grano.

Figura 4.7.5 Producción relativa de grano en relación al $\mathrm{N}$ extraído (kg $\mathrm{ha}^{-1}$ ) por el cultivo de trigo: 2011-2012, 2012-2013 y 20132014.

Figura 4.7.6 Estudio de la entropía: ( $a, c$ y e) Entropía relativa $E(\delta)$ de la producción de trigo; ( $b, d$ y f) Variación de la entropía relativa $\Delta E$ (ס). (a y b): 2011-2012; (c y d): 2012-2013; (e y f): 2013-2014

Figura 4.7.7 Estudio de la entropía: ( $a, c$ y e) Entropía relativa $E(\delta)$ del $N$ extraído por el trigo; (b, $d$ y f) Variación de la entropía relativa $\Delta E$ (d). (a y b): 2011-2012; (c y d): 2012-2013; (e y f): 2013-2014.

Figura 4.7.8 Estudio de la entropía: ( $a, c$ y e) Entropía relativa $E(\delta)$ del $N$ disponible en el suelo para el trigo; (b, d y f) Variación de la entropía relativa $\Delta E(\delta)$. ( $a$ y b): 2011-2012; ( c y d): 20122013; (e y f): 2013-2014. 
RESUMEN 

La importancia de la industria vitivinícola en las regiones mediterráneas, está acompañada de la generación de grandes cantidades de residuos. La utilización del compost derivado de estos residuos para mejorar la producción y la calidad de los cultivos en el área donde se generan, podría ser una opción sostenible en la gestión agrícola.

España es el principal productor europeo de melón con una producción total de 664.154 † (MAGRAMA, 2018). Las mayores áreas están localizadas en la mitad sur, especialmente en la región de Castilla La Mancha, con más de 6.000 ha dedicadas a este cultivo y con una producción de melón de $228.336 t$ y donde además se encuentra concentrada la mitad de la producción de vino del país.

En este trabajo se realizó un experimento en campo durante tres años en un cultivo de melón irrigado, que se cultiva tradicionalmente en esta área donde además, se generan estos residuos en condiciones de clima Mediterráneo. El área está declarada como "zona vulnerable" por la Directiva de nitratos (91/676/CEE). El objetivo, fue comparar el comportamiento de la fertilización orgánica frente a la fertirrigación desde el punto de vista ambiental y nutricional.

Los tratamientos consistieron en tres dosis de compost: 6,6 tha ${ }^{-1}\left(D_{1}\right)$, 13,2 tha $a^{-1}\left(D_{2}\right)$ y 19,8 tha $^{-1}\left(D_{3}\right)$ y un control $(C)$, para determinar la dosis óptima que asegure la demanda de nutrientes, maximizando el rendimiento $y$ minimizando las pérdidas. El diseño estadístico fue en bloques al azar con cuatro repeticiones de cada tratamiento.

La aplicación de compost, produjo un ligero aumento en la biomasa de la planta acompañado de cambios en la velocidad de crecimiento relativo (RGR) y en la tasa de asimilación neta (NAR), así como un incremento en la velocidad de crecimiento de las hojas (LGR), en la velocidad de crecimiento del cultivo (CGR) y en la velocidad de crecimiento del fruto (FGR). En consecuencia, se observó una mejora significativa del rendimiento de la fruta en las parcelas enmendadas. El mayor rendimiento, 56 tha $\mathrm{h}^{-1}$, se obtuvo en el año 2012 con la dosis $D_{3}$, unido a una mejora en la calidad de la fruta reflejado en un incremento en los grados Brix.

En general, la aplicación del compost de orujo disminuyó la cantidad de nitrógeno lixiviado entre un $20 \%-50 \%$ respecto al control, dependiendo de la dosis y el año. 
La cantidad de nitrógeno mineralizado (NM) en el suelo durante el cultivo, aumentó con la aplicación del compost de orujo de forma proporcional a la dosis, entre un $165 \%$ y un $310 \%$. Del mismo modo, aumentó el índice de mineralización (NMI) entre un $233 \%$ y un $300 \%$, dependiendo de la dosis y el año. El efecto de las diferentes dosis de compost sobre la movilización de fósforo no fue concluyente. En general, la aplicación de compost de orujo desalcoholizado procedente de la industria vitivinícola, produjo un aumento en el suelo de nutrientes que juegan un papel esencial en el crecimiento y desarrollo de la planta.

Al comparar la aplicación de compost de orujo con la fertirrigación tradicional de la zona, se observó, que desde el punto de vista de la eficacia del uso del nitrógeno, es más importante la cantidad disponible que la fuente de la que procede. Sin embargo, se obtuvieron mayores valores de los índices relacionados con la eficacia del uso del agua y del sistema de riego (WUE e IRRWUE) con la aplicación del compost de orujo (17\% y $29 \%$ respectivamente respecto a la fertirrigación), para el mismo valor de $\mathrm{N}$ disponible en el suelo $\left(248 \mathrm{~kg} \mathrm{ha}^{-1}\right.$ ). El riesgo mediambiental establecido por los índices ambientales (II y EII), disminuyó con la aplicación de compost, produciéndose al mismo tiempo un aumento considerable del índice de manejo (ME).

Posteriormente, para valorar el efecto residual del compost de orujo en el suelo, se cultivó trigo de ciclo largo (Triticum aestivum L. cv García) en las mismas parcelas experimentales, estudiando la variación espacial de la concentración de nitrógeno remanente en el suelo procedente de cada tratamiento.

El estudio de los datos de la biomasa de trigo de las diferentes campañas mostró, que existe una fuerte relación, tanto en la producción de trigo como en la extracción de $\mathrm{N}$ por parte del mismo, con respecto a la línea ocupada por el cultivo de melón y con la dosis de compost a la que había sido expuesto el cultivo anterior.

Como consecuencia de los resultados obtenidos en este estudio, el reciclaje de estos materiales, como fuente de materia orgánica y nutrientes en zonas vulnerables, es una buena opción de gestión y un claro ejemplo de Economía Circular. 
ABSTRACT 

The importance of the winery industry in Mediterranean regions is accompanied by the generation of big amounts of wastes. The utilization of compost derived from these wastes to improve the yield and quality of crops within the area where they are generated, could be a sustainable option of agricultural management.

Spain is the main European producer of melon with a total production up to 664.154 + (MAGRAMA, 2018). The largest areas are located in the southern half, especially in Castilla-La Mancha region, with more than 6.000 ha dedicated to this crop and 228.336 t of melon production and where also more than the half of the total wine production of the country is concentrated.

In this work a three years field experiment was carried out in a dripirrigated melon crop, traditionally grown in the area where also, these wastes are generated in Mediterranean climatic conditions. The area is designated as "vulnerable zone" by the Nitrates Directive (91/676/CEE). The objective, was to compare the behavior of organic fertilization versus fertirrigation from both the environmental and nutritional point of view.

The treatments consisting of three doses of compost: $6,6+\mathrm{ha}^{-1}\left(D_{1}\right)$, $13,2+h a^{-1}\left(D_{2}\right)$ and $19,8+h a^{-1}\left(D_{3}\right)$ and a control $(C)$, in order to determine the optimum dose to ensure nutrient demand, maximizing yield and minimizing losses. A randomized complete block design was used and each treatment was replicated four times.

The application of compost, produced a slight increase in the biomass of the plant accompanied by changes in the relative growth rate (RGR) and the net assimilation rate (NAR), as well as an increase in the leaves growth rate (LGR), the crop growth rate (CGR) and the fruit growth rate (FGR). As a result, a significant improvement in fruit yield was observed in the amended plots. The highest yield, 56 t ha ${ }^{-1}$, was obtained in 2012 with the $D_{3}$ dose, together with an improvement in the quality of the fruit shown by an increase in the Brix degrees.

In general, the application of the exhausted grape marc compost decreased the amount of nitrogen leached between $20 \%-50 \%$ depending on the dose and year.

The amount of mineralized nitrogen (NM) in the soil during cultivation, increases with the application of the exhausted grape marc compost, proportional to the dose, between $165 \%$ and $310 \%$. Likewise, the mineralization 
index (NMI) increased between $233 \%$ and $300 \%$, depending on both the dose and year. The effect of the different doses of compost on the phosphorus mobilization was not conclusive. In general, the application of exhausted grape marc compost from winery and distillery waste, produced an increase in the soil of nutrients that play an essential role in the growth and development of the plant.

When comparing the application of compost of exhausted grape marc with the traditional fertirrigation of the zone, it was observed that, from the point of view of the efficiency of the use of nitrogen, is more important the quantity available of it than the source it come from. However, higher values of the indexes related to the efficiency of the use of water and the irrigation system (WUE and IRRWUE) were obtained, through the application of the exhausted grape marc compost that with the fertirrigation (17\% and $29 \%$ ) respectively, for the same $N$ available in the soil (248 $\mathrm{kg} \mathrm{ha}^{-1}$ ). The environmental risk established by the environmental indexes (II and EII), decreased with the application of compost, while producing a considerable increase in the management index (ME).

Then, to analyze the residual effect of the wine-destillery waste compost in the soil, a long-cycle wheat (Triticum aestivum L. cv García) was cultivated in the same experimental plots, studying the spatial variation of the remaining nitrogen concentration of each treatment in the soil.

The study of wheat biomass data from the different campaigns showed, that there is a strong relationship, both in the production of wheat and in the extraction of $\mathrm{N}$ by it, between the position occupied by the melon crop and the dose of compost it had been exposed to.

As a consequence of the results obtained in this study, the recycling of these materials, as a source of organic matter and nutrients in vulnerable areas, is a good management option and an example of Circular Economy. 
Capítulo 1

INTRODUCCIÓN 

La gestión eficaz de los residuos es esencial en la Economía Circular. En julio de 2018 entró en vigor una nueva normativa sobre Residuos (Directiva UE2018/851) que abarca, entre otras cosas, nuevas y ambiciosas tasas de reciclado, un régimen jurídico clarificado de los materiales reciclados y medidas reforzadas de prevención y gestión de residuos, incluidas las relativas a los residuos alimentarios y a los productos que contienen materias primas fundamentales.

Las políticas actuales de la Unión Europea, están dirigidas a disminuir la cantidad de residuos orgánicos que van a vertedero e incineración, por lo que se está produciendo un incremento cada vez mayor del reciclado (Möller, 2016). Tanto la digestión anaerobia como el compostaje, son las estrategias más utilizadas para la gestión de los residuos orgánicos. La obtención de compost, producto estable biológicamente y sanitariamente seguro para su utilización en suelos agrícolas, es una opción muy interesante, ya que reduce el riesgo de fitotoxicidad, las emisiones de dióxido de carbono y óxido de nitrógeno, junto a la posible inmovilización del nitrógeno del suelo (Bernal et al., 1998; Grigatti et al., 2007). En la actualidad, dentro del paquete de Economía Circular de la UE, hay un gran interés en la utilización del compost con fines agrícolas como potencial sustituto de los fertilizantes químicos, asegurando al mismo tiempo, el mantenimiento del carbono orgánico del suelo y de la fertilidad biológica (Hamilton et al., 2017; Razza et al., 2018).

Se ha investigado mucho sobre la fertilidad biológica del suelo tras la aplicación de compost (Diacono and Montemurro, 2011), así como sobre la disponibilidad de nitrógeno procedente de la materia orgánica reciclada (Svensson et al., 2004; Bar-Tal et al., 2004). Sin embargo, la información sobre la cantidad de fósforo disponible procedente de estos materiales es escasa (Eghball and Power, 1999; Bar-Tal et al., 2004; Chen, 2006; Grigatti et al., 2017). Además, la composición de la materia orgánica compostada, puede no ser adecuada a los requerimientos de la planta, provocando a menudo cuando la dosis de aplicación se calcula únicamente en función de las necesidades de nitrógeno del cultivo, una sobre fertilización de fósforo (Eghball and Power, 1999; Diacono and Montemurro, 2011; Lemming et al., 2019, Glcesner et al., 2019). Esto puede representar un riesgo ambiental importante, $y$ al mismo tiempo, un potencial beneficio para el cultivo siguiente (Lemming et al., 2019).

La conversión en compost de los residuos producidos en la industria vitivinícola y alcoholera, representan un claro ejemplo de Economía Circular de gran importancia económica y ambiental, y su aplicación al suelo agrícola como 
fuente de materia orgánica y nutrientes, es de gran interés en zonas vulnerables, donde la dosificación no racional de fertilizantes, ha provocado una fertilización excesiva de dos de los nutrientes principales, como son el nitrógeno y el fósforo.

\subsection{RESIDUOS PRODUCIDOS POR LA INDUSTRIA VITIVINÍCOLA}

El vino es la bebida alcohólica más importante del mundo, con una demanda actual de 246 millones de hectólitros (Mill. hl). Aunque tradicionalmente la producción de vino y el consumo estaba concentrado en Europa, en la actualidad 67 países exportan, importan y consumen vino. Dentro de la Unión Europea, España es el país que tiene más superficie de viñedo (969.000 ha), seguido de China (875.000 ha), Francia (793.000 ha), Italia (705.000 ha) y Turquía (448.000 ha) (OIV 2019).

Según los últimos datos publicados por la Organización Internacional de la Viña y el Vino (OIV) sobre la producción de vino 2018, la producción mundial fue de 292 Mill. hl, confirmando Italia su liderazgo como primer productor con 54,8 Mill. hl, seguido de Francia con 48,6 Mill. hl, y en tercera posición en el ranking de producción mundial, España con 44,4 Mill. hl (Figura 1. 1). España, a pesar de ser el país con mayor superficie cultivada de viñas en el mundo, no es el mayor productor, debido a la baja productividad del suelo de sus regiones productoras.

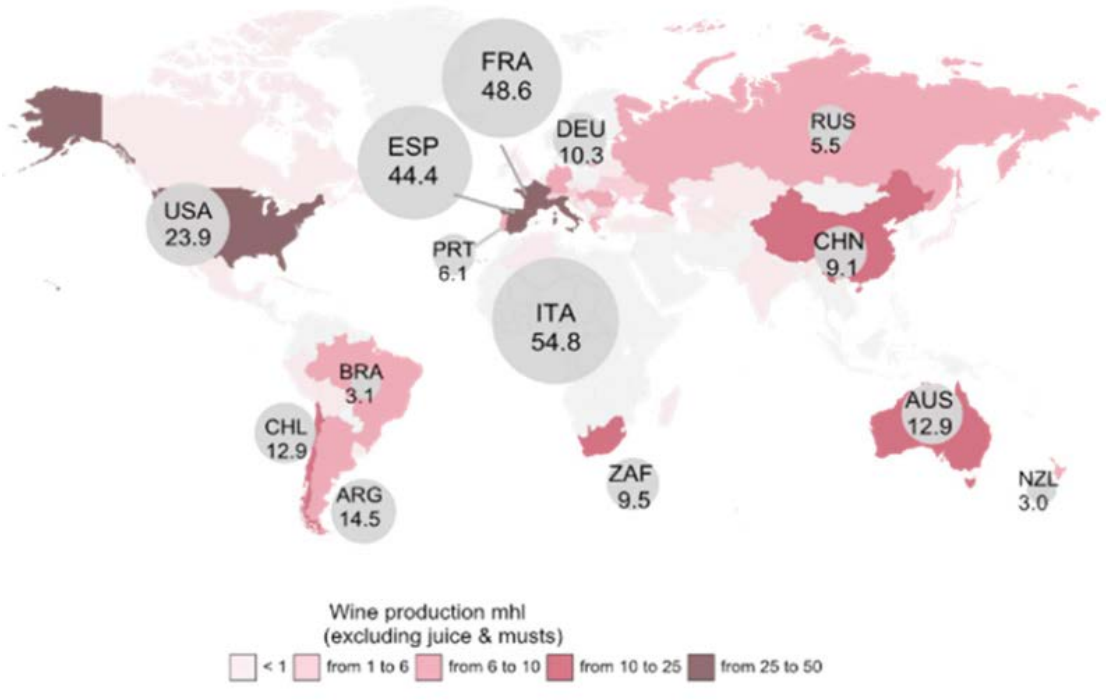

Figura 1.1 La producción de vino en 2018 (OIV, 2019). 
Según los datos provisionales 2018/19 del Sistema de Información de Mercados del Sector Vitivinícola (INFOVI), dentro de la península Ibérica, la región que más vino produce es Castilla-la Mancha, concentrando el $55 \%$ de la producción de vino.

La industria vitivinícola produce gran cantidad de residuos orgánicos. Se estima, que la industria española del vino genera de 2 a 3 millones de toneladas al año de residuos o subproductos, producidos fundamentalmente en la época de la vendimia. Los principales residuos sólidos producidos en esta actividad son: restos de poda de vides, orujo (compuesto por piel, semillas y raspones) y lías de vinificación, además de lodos producidos en la decantación de las aguas de lavado (Bustamante et al., 2009).

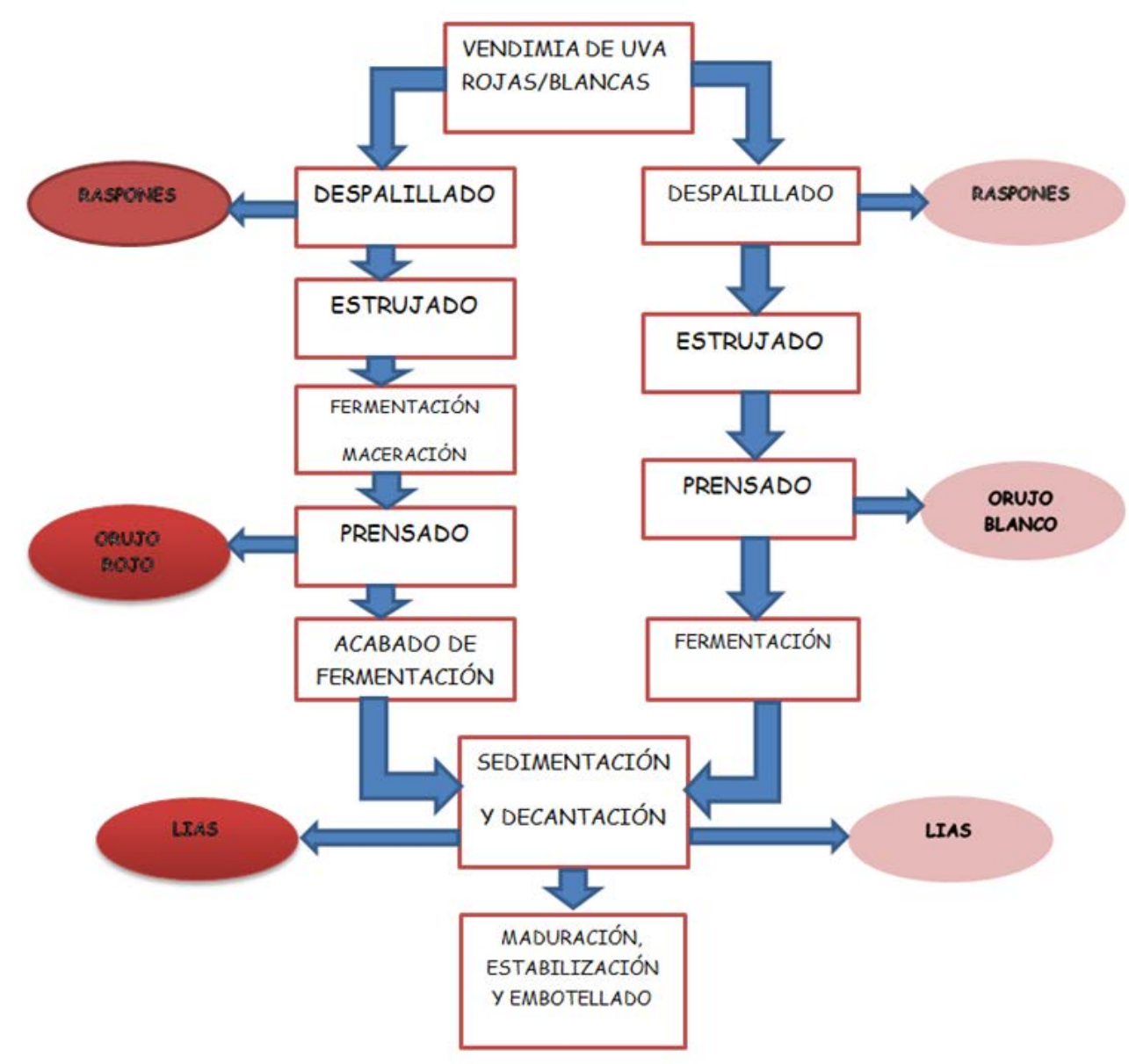

Figura 1.2 Generación de residuos en el proceso de elaboración del vino (modificado de Muhlack et al., 2018). 
El reglamento de la European Council Regulation 1493/1999 del Consejo de 17 de Mayo de 1999, establece la obligación de enviar los residuos sólidos (los orujos) a las alcoholeras o destilerías, que los usan como materia prima para obtener principalmente alcohol etílico, y como subproductos, un orujo agotado y un residuo líquido llamado vinaza, dándole así un primer uso a los residuos (Figura 1.3). Todas las actividades llevadas a cabo en la alcoholera, se basan en la extracción del alcohol y el tartrato que contienen los orujos, las lías y los excedentes de vino, generando así, un residuo sólido, el orujo desalcoholizado, un residuo líquido, la vinaza, y tartrato de calcio.

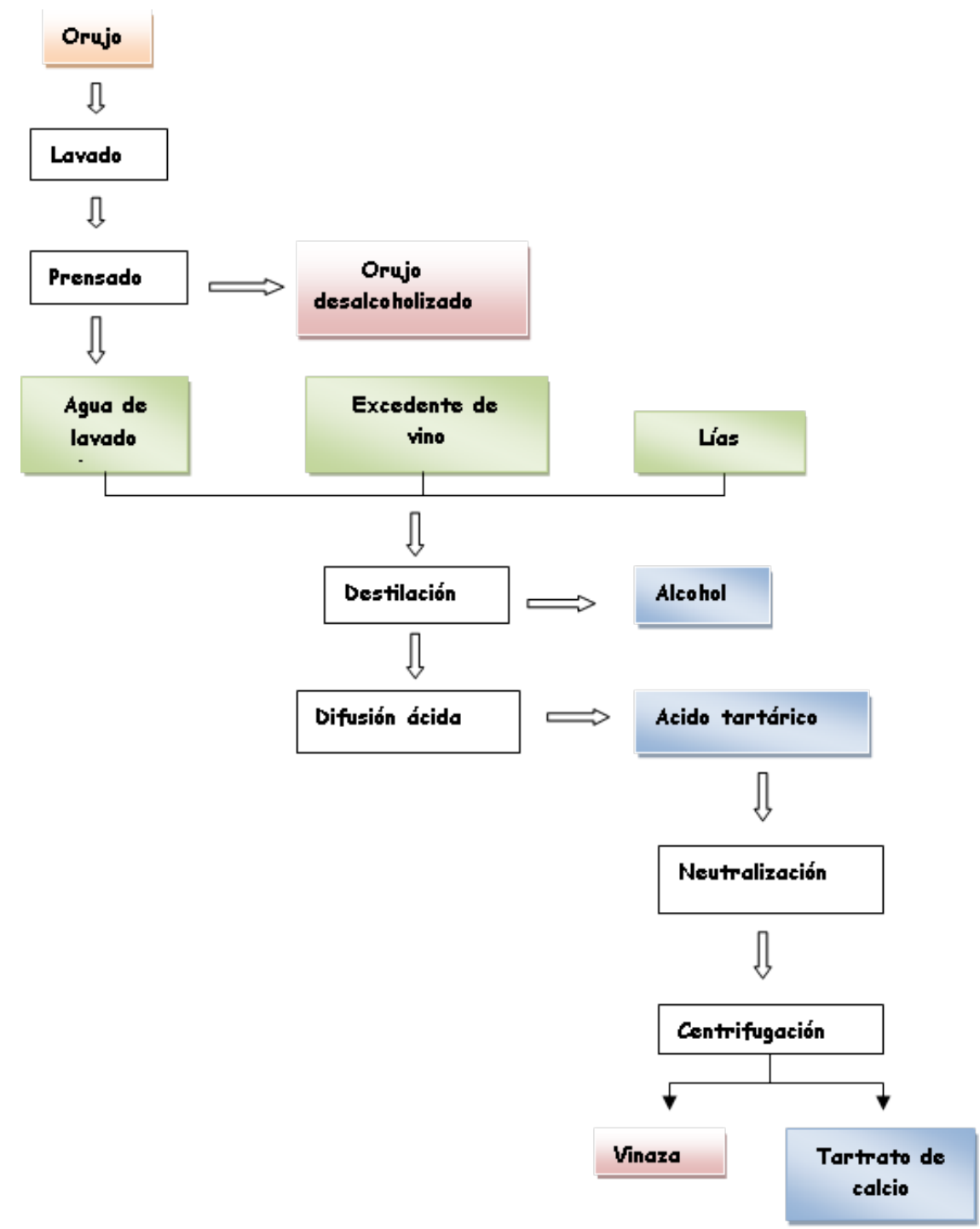

Figura 1.3 Esquema del proceso de extracción del alcohol y del tartrato de calcio de los orujos y lías de vinificación (modificado de Bustamante, 2007). 
Los orujos agotados de uva en las alcoholeras, son orujos desalcoholizados obtenidos del lavado a alta temperatura de estos. Contienen un menor contenido en sales y en compuestos orgánicos solubles que el orujo. La mayor parte de los compuestos fenólicos del orujo, se pierden durante el lavado (Moreno and Moral, 2008).

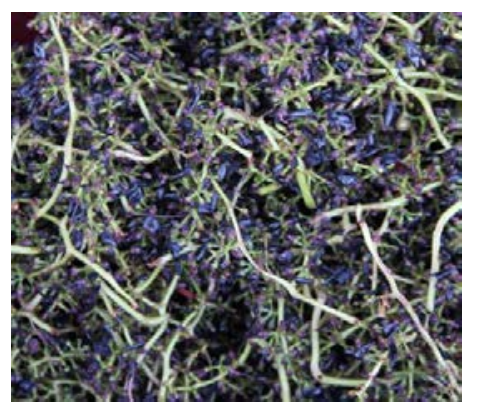

Raspón

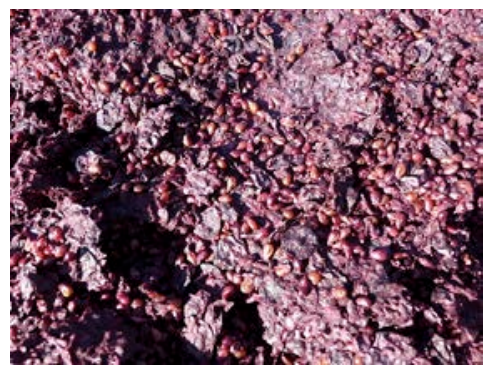

Orujo desalcoholizado

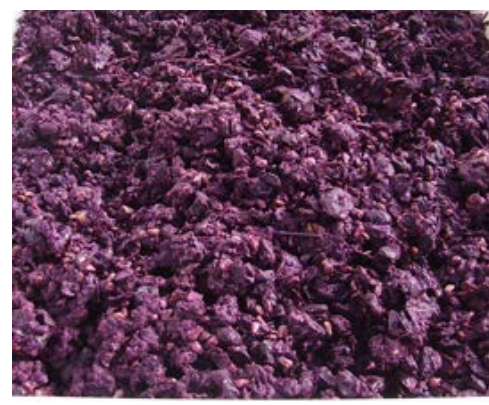

Orujo

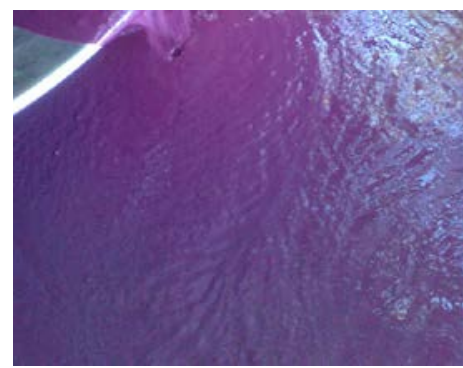

Lías

Figura 1.4 Imágenes de distintos residuos de la industria enológica.

Se estima (Bustamante, 2007) que por cada hectolitro de vino se producen los siguientes subproductos (Figura 1.4):

o Raspón: $7,1 \mathrm{~kg} / \mathrm{hl}$ vino.

o Orujo: $20 \mathrm{~kg} / \mathrm{hl}$ vino.

o Lías: $8,6 \mathrm{~kg} / \mathrm{hl}$ vino.

o Aguas residuales: $0,6 \mathrm{~m}^{3} / \mathrm{hl}$ vino. 
Todos estos residuos o subproductos, se producen principalmente durante el período de vendimia (septiembre-noviembre), lo que genera problemas de almacenamiento (Bustamante, 2007). A esto se une, que la mayoría de los residuos generados (80-85\%) tienen carácter orgánico, lo cual complica aún más el manejo de los mismos. En general, estos residuos se caracterizan por tener un pH bajo $(3,8-6,8)$, conductividad eléctrica comprendida entre 1,62 y $6,15 \mathrm{dS} \mathrm{m} \mathrm{m}^{-1}$, alto contenido en materia orgánica $\left(669-920 \mathrm{~g} \mathrm{~kg}^{-1}\right.$ ), altas concentraciones de nutrientes fundamentalmente potasio $\left(11,9-72,8 \mathrm{~g} \mathrm{~kg}^{-1}\right)$, altos niveles de polifenoles $\left(1,2-19,0 \mathrm{~g} \mathrm{~kg}^{-1}\right)$ y bajos contenidos de micronutrientes y metales pesados (Bustamante et al., 2008 a).

\section{* Composición química de los residuos vitivinícolas}

El orujo de vid es el subproducto solido más abundante en la elaboración del vino, y representa un $60 \%$ del peso total. Este complejo material, está compuesto por un $30 \%$ de polisacáridos neutros, $20 \%$ de ácido péctico, $15 \%$ de proantocianidinas, lignina, proteínas estructurales y fenoles. Los últimos dos componentes están entrecruzados a grupos ligninas-carbohidratos y representan la fuente orgánica valorable si se fracciona (Amendola et al., 2012; Minjares-Fuentes et al., 2014). La pulpa, constituye del 10 al 20\% del peso de la uva, e incluye piel, semillas y otros materiales solidos después de la extracción del zumo de uva por presión.

La piel es el mayor componente del orujo de vid, representando alrededor de la mitad de su masa (Mendes et al., 2013 a). Sin embargo, gran parte de la piel se retira junto con las semillas después de la producción del zumo (Kuck and Zapata Noreña, 2016). Aunque la composición fenólica de la piel varía en función de la variedad y de las condiciones de cultivo, en general, contiene una gran cantidad de antocianos y taninos con un alto grado de polimerización, y baja cantidad de galatos en comparación con otras partes de la uva. La pared celular de la piel está formada por un $20 \%$ de celulosa, $12 \%$ de hemicelulosa, sustancias de ácido péptico (20\%), alrededor de un $15 \%$ de proantocianidinas insolubles, $8 \%$ de cenizas, $5 \%$ de extracto soluble es diclorometano y menos de un $5 \%$ de proteínas estructurales (Mendes et al., 2013 b; Pinelo et al., 2006).

El raspón, el esqueleto del racimo y los tallos, se obtienen en grandes cantidades durante las operaciones de estrujado y despalillado. Representan del 3 al $6 \%$ de la materia cruda procesada (Carcela et al., 2010), y están constituidos por compuestos lignocelulósicos, como celulosa, hemicelulosa, 
taninos (6-7\%) y un alto contenido en lignina (22 al 47\%) (Spigno et al., 2008). La concentración de estos componentes, depende de muchos factores como el origen geográfico, clima, tiempo de cosecha y variedad (Spigno et al., 2013).

Las semillas, es el subproducto más importante de las industrias que obtienen zumo de uva y vino. Constituyen el $5 \%$ del peso de la uva, produciéndose anualmente $3 \mathrm{Mt}$. Contienen fibra, proteínas, lípidos (grasas y aceite), hidratos de carbono, minerales y entre un 5 y un $8 \%$ de compuestos fenólicos, dependiendo de la variedad y de otros factores.

Los restos de poda, representan el $93 \%$ de los residuos obtenidos en viticultura (Sanchez et al., 2002), y están compuestos por celulosa (34 g/100 g en peso seco), hemicelulosa (19 g/100 g en peso seco) y lignina (27 g/100 g en peso seco) (Max et al., 2010).

Las lías del vino, que se producen durante el proceso de fermentación y envejecimiento del vino, representan del 2 al $6 \%$ del volumen total de la producción. Consisten, en una fase sólida, compuesta fundamentalmente por microorganismos (levaduras y bacterias), carbohidratos insolubles de las fracciones celulósicas y hemicelulósicas, compuestos fenólicos, ligninas, proteínas, sales metálicas y orgánicas como tartratos, y una fase liquida, rica en etanol y ácidos orgánicos, como el ácido láctico y el acético.

\section{Valorización de los residuos procedentes de la industria vitivinicola}

Los residuos de la industria vitivinícola, se pueden valorizar por muchas vías dadas sus características químicas y la presencia de sustancias de alto valor añadido. (Rebecchi et al., 2013). Los principales tratamientos biotecnológicos de los residuos de la industria vitivinícola, se recogen en la tabla 1.1. 
Tabla 1.1 Tratamientos biotecnológicos de los residuos de la industria vitivinícola (Arvanitoyannis, I.S., 2006 a,b; Devesa-Rey, R., 2011).

\begin{tabular}{|c|c|c|}
\hline Tipo de residuo & Tratamiento & Producto \\
\hline \multirow[t]{2}{*}{ Lías de la vinificación } & - & $\begin{array}{l}\text { Suplemento nutricional para } \\
\text { Lactobacilos }\end{array}$ \\
\hline & $\begin{array}{l}\text { Extracción de ácido } \\
\text { tartárico }\end{array}$ & $\begin{array}{l}\text { Suplemento nutricional para } \\
\text { Debaromyces Hansenii }\end{array}$ \\
\hline \multirow[t]{3}{*}{ Vinazas } & $\begin{array}{l}\text { Tratamiento alcalino, } \\
\text { microondas, fermentación }\end{array}$ & Ácido láctico \\
\hline & $\begin{array}{l}\text { Solubilización y } \\
\text { precipitación }\end{array}$ & Ácido tartárico \\
\hline & Fermentación & $\begin{array}{l}\text { Proteína rica en biomasa } \\
\text { fúngica }\end{array}$ \\
\hline Lías, orujo de vid & $\begin{array}{l}\text { Fermentación inducida por } \\
\text { levaduras }\end{array}$ & Proteína \\
\hline Vinazas y orujo de vid & $\begin{array}{l}\text { Fermentación con } \\
\text { Trichoderma viride }\end{array}$ & Agente de biocontrol \\
\hline \multirow[t]{5}{*}{ Restos de poda } & $\begin{array}{l}\text { Hidrólisis, fermentación de } \\
\text { azucares hemicelulósicos } \\
\text { por L.pentosus }\end{array}$ & $\begin{array}{l}\text { Ácido láctico, } \\
\text { biosurfactantes }\end{array}$ \\
\hline & $\begin{array}{l}\text { Hidrólisis, deslignificación, } \\
\text { sacarificación simultánea y } \\
\text { fermentación de la fracción } \\
\text { celulósica }\end{array}$ & Ácido láctico \\
\hline & $\begin{array}{l}\text { Hidrólisis y fermentación } \\
\text { de azucares hemicelulósicos } \\
\text { por Lactobacillus y } \\
\text { Debaryomyces hansenii }\end{array}$ & $\begin{array}{l}\text { Ácido láctico; xilitol; } \\
\text { biosurfactantes }\end{array}$ \\
\hline & $\begin{array}{l}\text { Fermentación en estado } \\
\text { sólido con Pleurotus }\end{array}$ & $\begin{array}{l}\text { Fuente de microorganismos } \\
\text { y comida }\end{array}$ \\
\hline & $\begin{array}{l}\text { Hidrólisis, fermentación de } \\
\text { azucares hemicelulósicos } \\
\text { por L.pentosus }\end{array}$ & $\begin{array}{l}\text { Ácido láctico, } \\
\text { biosurfactantes }\end{array}$ \\
\hline \multirow[t]{5}{*}{ Orujo de vid } & $\begin{array}{l}\text { Hidrólisis, fermentación por } \\
\text { L.pentosus }\end{array}$ & $\begin{array}{l}\text { Ácido láctico, } \\
\text { biosurfactantes }\end{array}$ \\
\hline & Extracción & Taninos, polifenoles \\
\hline & $\begin{array}{l}\text { Fermentación en estado } \\
\text { sólido }\end{array}$ & Enzimas hidrolíticos \\
\hline & $\begin{array}{l}\text { Fermentación con } \\
\text { lactobacilos }\end{array}$ & Anti alérgicos \\
\hline & $\begin{array}{l}\text { Fermentación en estado } \\
\text { sólido }\end{array}$ & $\begin{array}{l}\text { Enzimas hidrolíticos, } \\
\text { bioetanol }\end{array}$ \\
\hline Orujo de vid, lías & Fermentación por levaduras & Proteínas \\
\hline Aceite de semillas de uva & $\begin{array}{l}\text { Fermentación con } \\
\text { Pseudomonas aeruginosa }\end{array}$ & Surfactantes \\
\hline Semillas de uva & Extracción & Aceite \\
\hline
\end{tabular}


Durante el proceso de producción del vino, alrededor del $25 \%$ de la masa de uvas se convierte en orujo formado por tallos, pieles y células rotas de la pulpa, así como semillas que quedan después del proceso de estrujado y prensado para obtener el zumo de uva (Devesa-Rey et al., 2011, GonzalezCenteno et al., 2010 y Domínguez et al., 2016). Se estima, que la producción mundial de este residuo, puede suponer anualmente de 10,5 a 13,1 millones de toneladas. Dadas las características químicas del orujo de vid, son muchos los productos que se pueden obtener a partir del mismo (Tabla 1.2).

Tabla 1.2 Subproductos obtenidos del orujo de vid (Devesa-Rey et al., 2011).

\begin{tabular}{|c|c|c|c|}
\hline Residuo & Tratamiento & Producto & Referencias \\
\hline \multirow[t]{2}{*}{ Orujo de uva } & \multirow{2}{*}{$\begin{array}{l}\text { Hidrolisis, } \\
\text { fermentación con } \\
\text { L. pentosus }\end{array}$} & $\begin{array}{l}\text { Ácido láctico } \\
\text { biosurfactantes }\end{array}$ & Portilla et al. $(2007,2008,2009)$ \\
\hline & & Bioemulsificantes & Portilla et al. (2010) \\
\hline Aceite de semilla de uva & $\begin{array}{l}\text { Fermentación } \\
\text { con Pseudomana } \\
\text { aeruginosa }\end{array}$ & Biosurfactantes & Wei et al. (2005) \\
\hline \multirow[t]{2}{*}{ Orujo de uva } & \multirow[t]{2}{*}{ Extracción } & $\begin{array}{l}\text { Taninos } \\
\text { como } \\
\text { adhesivos }\end{array}$ & Jiang et al. (2011) \\
\hline & & Polifenoles & $\begin{array}{l}\text { Vatai et al. (2009); Conde et al. (2011); Ping } \\
\text { et al. (2011) }\end{array}$ \\
\hline Semilla de orujo de uva & Extracción & Aceite & Molero Gómez et al. (1996); Fiori (2010) \\
\hline Orujo de uva & $\begin{array}{l}\text { Fermentación con } \\
\text { Lactobacillus }\end{array}$ & Antialérgicos & Tominaga et al. (2010) \\
\hline Orujo de uva & $\begin{array}{l}\text { Fermentación en estado } \\
\text { sólido }\end{array}$ & Enzimas hidrolíticos & Botella et al. (2005); Díaz et al. $(2009,2011)$ \\
\hline Orujo de uva & $\begin{array}{l}\text { Fermentación en estado } \\
\text { sólido }\end{array}$ & Bioetanol & Rodriguez et al. (2010) \\
\hline \multirow[t]{2}{*}{ Orujo de uva } & \multirow[t]{2}{*}{ Compostaje } & Sustrato para plantas & $\begin{array}{l}\text { Díaz et al. (2002); Nogales et al. (2005), } \\
\text { Bustamante et al. (2007, 2009, 2010); } \\
\text { Manios et al. (2007); Moldes et al. (2007a), } \\
\text { Pardo et al. (2007); García-Martínez et al. } \\
\text { (2009) }\end{array}$ \\
\hline & & $\begin{array}{l}\text { Sustrato para cultivo de } \\
\text { Levaduras }\end{array}$ & Pardo et al. (2007) \\
\hline Orujo de uva & Vermicompostaje & Sustrato para plantas & $\begin{array}{l}\text { Paradelo et al. (2009b); Gómez-Brandón et } \\
\text { al. (2011), }\end{array}$ \\
\hline $\begin{array}{l}\text { Orujo de uva } \\
\text { hidrolizado, lías }\end{array}$ & Compostaje & Sustrato para plantas & Paradelo et al. (2010a) \\
\hline $\begin{array}{l}\text { Orujo de uva, restos de } \\
\text { poda }\end{array}$ & $\begin{array}{l}\text { Fermentación en estado } \\
\text { sólido con Pleurotus }\end{array}$ & $\begin{array}{l}\text { Fuente de } \\
\text { microorganismos y comida }\end{array}$ & Sánchez et al. (2002) \\
\hline Orujo de uva & Compostaje & $\begin{array}{l}\text { Adsorbentes para } \\
\text { compuestos coloreados }\end{array}$ & Paradelo et al. (2009c) \\
\hline Orujo de uva & Sin tratamiento & $\begin{array}{l}\text { Adsorbente de metales } \\
\text { para descontaminación de } \\
\text { efluentes }\end{array}$ & Farinella et al. (2008) \\
\hline Orujo de uva, lías & $\begin{array}{l}\text { Fermentación inducida por } \\
\text { levaduras }\end{array}$ & Proteínas & Silva et al. (2011) \\
\hline Vinaza de orujo de vid & $\begin{array}{l}\text { Fermentación con } \\
\text { Trichoderma viride }\end{array}$ & Agente de biocontrol & Bai et al. (2008); Santos et al. (2008) \\
\hline
\end{tabular}




\section{Valorización agrícola del orujo de vid}

El uso de orujo de uva como enmienda del suelo, es una de las principales opciones para su valorización, ya que contiene una cantidad importante de materia orgánica y macronutrientes (Bustamante et al., 2010; Domínguez et al., 2017). Sin embargo, su aplicación directa al suelo, puede causar fitotoxicidad y efecto antimicrobiano debido al aporte de taninos y polifenoles, produciendo efectos adversos en el crecimiento de las plantas (Fontana et al., 2013), además de contaminación del agua y emisión de gases de efecto invernadero.

Los riesgos ambientales de su aplicación al suelo, se pueden reducir utilizando diversas tecnologías (Figura 1.5). Así, los tratamientos biológicos del orujo de vid utilizando su biodegradación vía aerobia o anaerobia, darían lugar a productos comercializables, lo que supondría además beneficios ambientales y económicos (Muhlack et al., 2018).

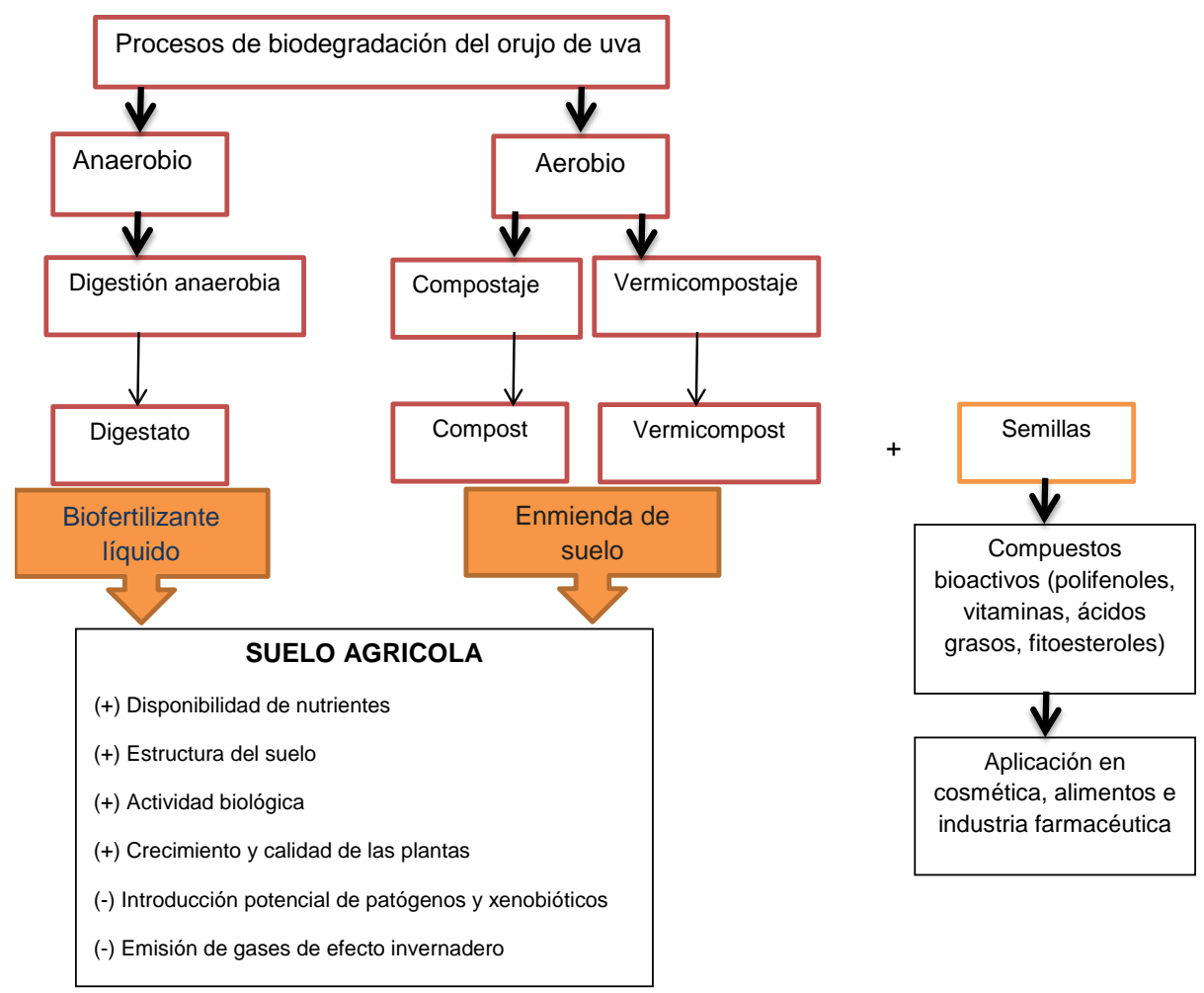

Figura 1.5 Esquema de la valorización del orujo de uva por procesos vía aerobia y anaerobia, con los efectos positivos (+) y negativos (-) de los productos finales (compost, vermicompost y digestato) en el suelo (Gómez-Brandon et al., 2019). 
Las principales propiedades físico-químicas del orujo de uva, compost y vermicompost, se recogen en la tabla 1.3.

Tabla 1.3 Propiedades físico-químicas del orujo de uva y del compost y vermicompost de orujo de uva.

\begin{tabular}{|c|c|c|c|}
\hline & Orujo de uva* & Compost* & Vermicompost $^{\star \star}$ \\
\hline $\mathrm{pH}$ & $4,4 \pm 0,04$ & $6,9 \pm 0,04$ & $7,1 \pm 0,03$ \\
\hline Conductividad eléctrica ( $\left.\mathrm{mS} \mathrm{cm}^{-1}\right)$ & $1,3 \pm 0,15$ & $1,8 \pm 0,08$ & $0,3 \pm 0,009$ \\
\hline Materia orgánica (\%) & $91 \pm 0,30$ & $93 \pm 0,4$ & $75 \pm 0,34$ \\
\hline$C$ total (g kg ${ }^{-1}$ sms $)$ & $484 \pm 1,60$ & $539 \pm 0,2$ & $376 \pm 1,47$ \\
\hline$N$ total ( $\left.\mathrm{kg}^{-1} \mathrm{sms}\right)$ & $20 \pm 0,62$ & $19 \pm 0,02$ & $30 \pm 0,13$ \\
\hline$C / \mathrm{N}$ & $24 \pm 0,72$ & $28 \pm 0,4$ & $13 \pm 0,07$ \\
\hline$P$ total ( $\left.\mathrm{g} \mathrm{kg}^{-1} \mathrm{sms}\right)$ & $4 \pm 0,08$ & n.d. & $8 \pm 0,32$ \\
\hline$K$ total ( $\left.\mathrm{g} \mathrm{kg}^{-1} \mathrm{sms}\right)$ & $31 \pm 0,56$ & n.d & $11 \pm 0,65$ \\
\hline Lignina ( $\left.\mathrm{kg}^{-1} \mathrm{sms}\right)$ & $516 \pm 9,56$ & $581 \pm 3,0$ & $323 \pm 2,36$ \\
\hline Celulosa ( $\left.\mathrm{g} \mathrm{kg}^{-1} \mathrm{sms}\right)$ & $225 \pm 10,39$ & $43 \pm 0,2$ & $58 \pm 10,48$ \\
\hline Hemicelulosa (g kg-1 sms) & $101 \pm 1,39$ & $43 \pm 0,2$ & $30 \pm 0,54$ \\
\hline Polifenoles totals ( $\mathrm{mg} \mathrm{g}^{-1} \mathrm{sms}$ ) & $58 \pm 10$ & nd & $12,5 \pm 0,7$ \\
\hline Antocianos ( $\mathrm{mg} \mathrm{g}^{-1} \mathrm{sms}$ ) & $1,25 \pm 0,04$ & nd & $0,17 \pm 0,01$ \\
\hline
\end{tabular}

n.d.: no disponible. Los datos correspondientes al digestato de orujo de vid no están disponibles ya que este se emplea como co sustrato en digestión anaerobia. * Domínguez et al (2016); ** Paradelo et al (2013).

En varios países se han compostado los orujos de uva para su estudio: Francia (Faure, 1991; Faure and Deschamps, 1990 a, b), Alemania (Dittmer et al., 1990) Yugoslavia (Stojanovic et al., 1989), Israel (Inbar et al., 1988; Mandelbaum et al., 1988), Argentina (Del Toro, 1988), Venezuela (Ferrer et al., 1993: Santiago et al., 1993; Sánchez and Ferrer, 1994) y España (Costa et al., 1989: García et al., 1990, 1992). Se ha investigado principalmente el desarrollo de sus características físico - químicas y microbiológicas durante el compostaje (Faure and Deschamps, 1990 a, b; Faure, 1991; Mandelbaum et al., 1988), su influencia sobre organismos patógenos (Mandelbaum et al., 1988; Dittmer et al., 1990; Shuval et al., 1991), así como su capacidad de extracción de metales pesados (Costa et al., 1989; García et al., 1990).

La industria vinícola se encuentra principalmente en los agrosistemas mediterráneos, caracterizados por condiciones semiáridas. Los cultivos 
hortícolas han sido tradicionalmente cultivados en estas zonas, con altos aportes de agua y fertilizantes. La utilización de compost derivado de los residuos de la bodega y de la destilería para mejorar el rendimiento y la calidad de los cultivos, dentro de la zona donde se generan, podría ser una opción sostenible de gestión agrícola (Tabla 1.4).

Tabla 1.4 Ventajas potenciales para la industria vitivinicola del compostaje in situ de sus residuos orgánicos.

\begin{tabular}{|l|l|}
\hline \multicolumn{1}{|c|}{ Tipo } & \multicolumn{1}{c|}{ Ventaja } \\
\hline Ambientales & $\begin{array}{l}\text { Disminución del impacto ambiental asociado al } \\
\text { transporte de residuos } \\
\text { Minimización de residuos } \\
\text { Cierre del ciclo de la materia orgánica } \\
\text { Disminución de aplicación de fertilizantes }\end{array}$ \\
\hline Agronómicas & $\begin{array}{l}\text { Control de los fertilizantes orgánicos } \\
\text { Facilidad de transporte y aplicación al suelo } \\
\text { Supresión de malas hierbas } \\
\text { Mejora propiedades del suelo }\end{array}$ \\
\hline Económicas & $\begin{array}{l}\text { Disminución de costes } \\
\text { Posibilidad de obtención de ayudas públicas } \\
\text { Mejora de la imagen de la empresa y de su } \\
\text { percepción social }\end{array}$ \\
\hline
\end{tabular}

Los diversos residuos producidos en la industria vitivinícola, restos de poda de la vid, escobajo y orujo de vid, se pueden mezclar para obtener compost de calidad (Pardo et al., 2007; Nogales et al., 2005; Gómez-Brandon et al., 2011) mediante vermicompostaje, consiguiendo una reducción de la relación $C: N$, de la conductividad, de la fitotoxicidad, y un aumento de los compuestos húmicos, contenido en nutrientes y pH. Manios (2004), incorpora al proceso de compostaje las pieles de la uva, produciendo un compost de elevada calidad. Paradelo et al. (2010 b), compostando orujo de uva hidrolizado con lías de la vinificación,valoraron el efecto de la temperatura, la concentración de las lías y la concentración de $\mathrm{CaCO}_{3}$, en las propiedades del compost obtenido.

Diversos autores han estudiado el efecto de la aplicación directa del orujo al suelo (Sorlini Y col., 1998), y han podido constatar, la necesidad de realizar un tratamiento previo de estabilización al orujo antes de su aplicación al mismo. Otros trabajos, han demostrado cómo la fuerte fitotoxicidad de este residuo desaparece tras un pequeño periodo de compostaje (Moldes y col., 2007 
b; Paradelo, 2009). En la tabla 1.5 se recogen los principales efectos beneficiosos de la aplicación de materia orgánica humificada al suelo.

Tabla 1.5 Efectos más destacados de la materia orgánica humificada. (LabradorMoreno, 1996).

\begin{tabular}{|l|l|}
\hline $\begin{array}{c}\text { Propiedades del } \\
\text { suelo }\end{array}$ & \multicolumn{1}{c|}{ Efectos de la materia orgánica humificada } \\
\hline & $\begin{array}{l}\text { Aumenta la capacidad calorífica } \\
\text { Suelos más calientes en primavera } \\
\text { Reduce las oscilaciones térmicas } \\
\text { Agrega las partículas elementales } \\
\text { Aligera suelos arcillosos y cohesiona los arenosos } \\
\text { Aumenta la estabilidad estructural } \\
\text { aumenta la permeabilidad hídrica y gaseosa } \\
\text { Facilita el drenaje y las labores } \\
\text { Reduce la erosión } \\
\text { Aumenta la capacidad de retención hídrica } \\
\text { Reduce la evaporación } \\
\text { Mejora el balance hídrico }\end{array}$ \\
\hline Aumenta el poder tampón \\
Regula el pH \\
Aumenta la capacidad de intercambio catiónico la rizogénesis \\
Mantiene los cationes en forma asimilable \\
Forma quelatos y fosfohumatos \\
Mantiene las reservas de nitrógeno \\
Favorece la respiración radicular \\
Favorece la germinación de semillas \\
\hline
\end{tabular}

En España, la pérdida de materia orgánica, es un problema que afecta a la fertilidad de sus suelos, lo que los hace más propensos a la degradación (Paradelo et al, 2010 a). El uso del orujo agotado y compostado como enmienda orgánica, es una buena opción por varias razones: se produce en gran cantidad, 
tiene alta concentración de materia orgánica y nutrientes, especialmente potasio y bajo contenido en metales pesados y micronutrientes, comparado con otros residuos (Bustamante et al, 2007). Varios autores han hablado de la idoneidad de enmendar el suelo con compost de orujo agotado para diferentes propósitos en agricultura y horticultura (Ferrer et al., 2001; Bertran et al., 2004; Flavel et al., 2005; Bustamante et al., 2008 b; Paradelo et al., 2007; 2009 $a, b)$.

En el proceso de fabricación de compost procedente de la industria vinícola, los materiales disponibles han ido variando a lo largo del tiempo en Castilla La Mancha. Hace unos años, se trabajaba exclusivamente con orujo desalcoholizado procedente de las alcoholeras de la zona, sin embargo, hoy día, este material se ha valorizado, usándose como materia prima para otros procesos como en plantas de cogeneración de energía, obtención de aceites etc..., por lo que las alcoholeras, sólo proporcionan una pequeña cantidad y a muy elevado precio de orujo desalcoholizado para la elaboración de enmiendas orgánicas.

El compost utilizado en este estudio (Agricompost S.L.), contiene escobajos de las bodegas y un $15 \%$ de orujo desalcoholizado. Ambos residuos se compostan separadamente debido a la diferente duración de cada proceso (1 año y 2-3 meses respectivamente). La mezcla se realiza al final del proceso de compostaje.

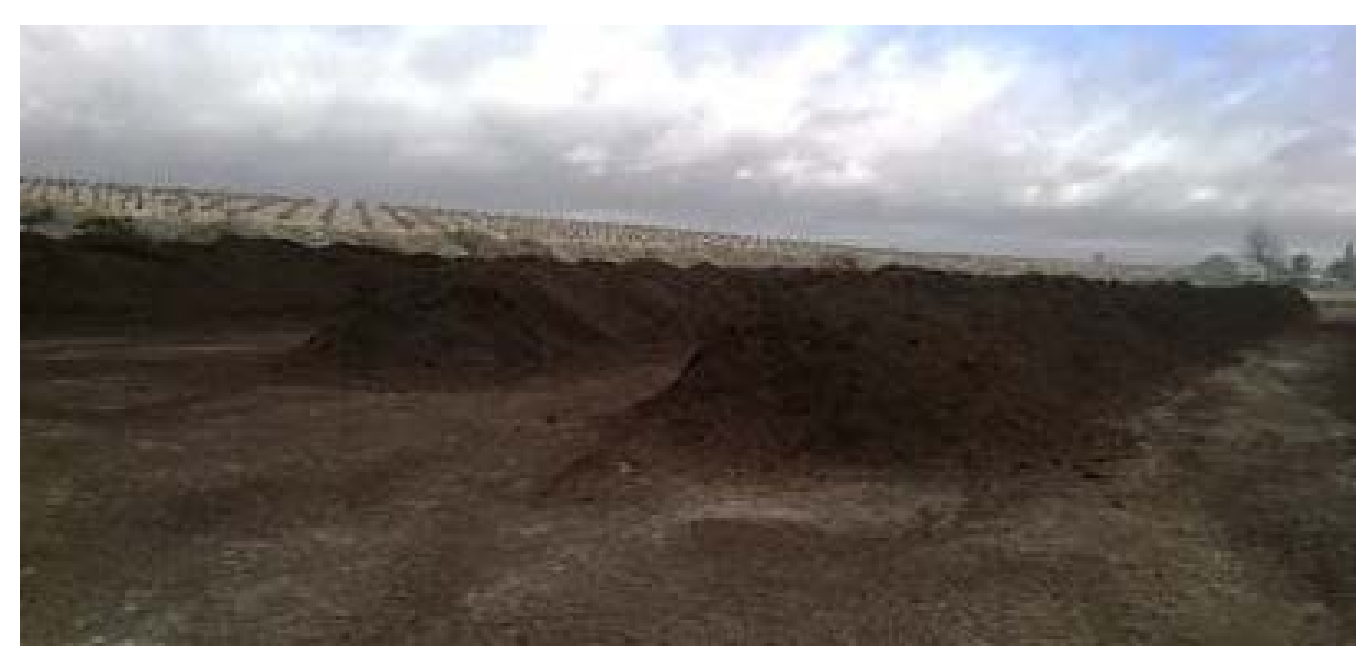

Figura 1.6 Pilas de compost en la planta de Agricompost S.L. (Socuéllamos, Ciudad Real). 
En general, el compost de residuos de bodega, presenta una salinidad baja, un porcentaje de materia orgánica elevado, altos niveles de nutrientes (proporcionando una lenta fertilización a lo largo del tiempo) y además podría incrementar la biomasa microbiana del suelo mejorando sus propiedades físicas (aireación, capacidad de retención de agua, etc...). Una vez elaborado el compost, es importante tener en cuenta su calidad y capacidad para aportar nitrógeno al suelo cuando se utiliza con fines agrícolas, ya que al haber sufrido un proceso de estabilización, presenta una mineralización más lenta, y a corto plazo presenta una baja disponibilidad de nitrógeno. Por ello, este producto se considera un fertilizante de liberación lenta, aspecto a tener en cuenta como forma de evitar la contaminación por exceso de nutrientes.

\subsection{LA PROBLEMÁTICA DEL AGUA EN CASTILLA LA MANCHA}

El uso eficiente del abonado junto con el riego, es fundamental para un manejo óptimo de los recursos en rotaciones hortícolas. Esto es especialmente

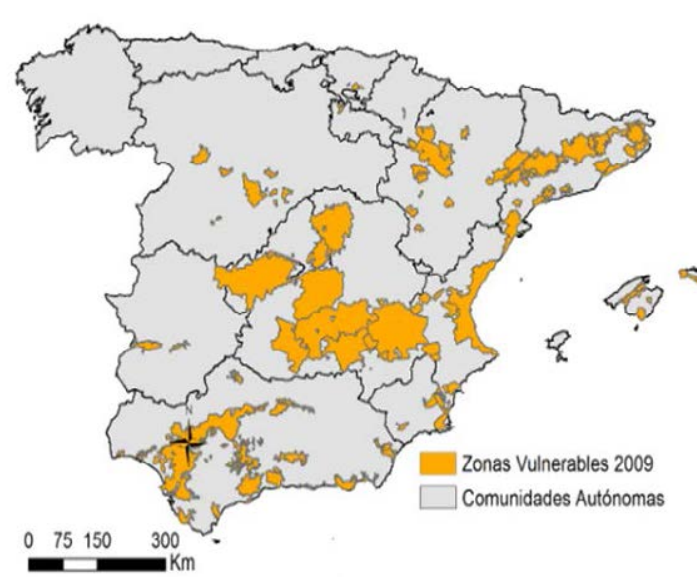

Figura 1.7 Distribución de las Zonas Vulnerables) declaradas en el territorio español (MAPAMA, 2015). importante en zonas declaradas vulnerables a la contaminación por nitratos, como es el caso que nos ocupa (Figura 1.7). Ciudad Real es una zona de gran tradición agrícola, se cultiva intensamente con gran aporte de agua y fertilizantes. Además, la contaminación de acuíferos por nitratos ha recibido una atención especial por la normativa de la Unión Europea (Directiva 91/676/CEE, de 12 de Diciembre), que establece un marco para la protección de las aguas contra la contaminación producida por nitratos procedentes de fuentes agrarias y su uso sostenible.

La integración de la citada Directiva en ordenamiento jurídico español, se llevó a cabo por el Estado mediante Real Decreto 261/1996. La aplicación de esta normativa ha hecho de Castilla la Mancha la región de España con más superficie declarada vulnerable a la contaminación de nitratos (45\%) de su territorio (Tabla 1.6). 
Tabla 1.6 Superficies declaradas como zona Vulnerable según CC.AA (2009)

(MAPAMA, 2013).

\begin{tabular}{l|rrr}
\hline \multicolumn{1}{c|}{$\begin{array}{c}\text { Comunidades } \\
\text { Autónomas }\end{array}$} & \multicolumn{1}{c}{$\begin{array}{c}\text { Zonas } \\
\text { Vulnerables (ha) }\end{array}$} & $\begin{array}{c}\text { superficie Vulnerable } \\
\text { CCAA/superficie total CCAA }\end{array}$ & $\begin{array}{c}\text { superficie Vulnerable } \\
\text { CCAA/superficie } \\
\text { Vulnerable total España }\end{array}$ \\
\hline Andalucía & 1.529 .831 & $17,5 \%$ & $18,9 \%$ \\
Aragón & 481.685 & $10,1 \%$ & $5,9 \%$ \\
Baleares & 121.539 & $24,2 \%$ & $1,5 \%$ \\
Canarias & 23.286 & $3,0 \%$ & $0,3 \%$ \\
Castilla-la Mancha & 3.634 .370 & $45,8 \%$ & $44,9 \%$ \\
Castilla y León & 229.506 & $2,4 \%$ & $2,8 \%$ \\
Cataluña & 1.082 .154 & $33,6 \%$ & $13,4 \%$ \\
Extremadura & 64.645 & $1,6 \%$ & $0,8 \%$ \\
La Rioja & 11.075 & $2,2 \%$ & $0,1 \%$ \\
Madrid & 130.346 & $16,2 \%$ & $1,6 \%$ \\
Murcia & 82.314 & $7,3 \%$ & $1,0 \%$ \\
Navarra & 18.773 & $1,8 \%$ & $0,2 \%$ \\
Pais Vasco & 15.029 & $2,1 \%$ & $0,2 \%$ \\
Valencia & 671.497 & $28,9 \%$ & $8,3 \%$ \\
\hline \multicolumn{1}{c}{ Total España } & $\mathbf{8 . 0 9 6 . 0 5 6}$ & $16,0 \%$ & $100,0 \%$ \\
\hline
\end{tabular}

Los datos sobre el efecto de la aplicación de fertilizantes orgánicos sobre las pérdidas de nitrógeno por lixiviación de nitratos son dispares. En la bibliografía hay trabajos que demuestran que producen menos pérdidas (Kirchman and Bergstróm, 2001), mientras que otros, no encuentran diferencias (DuFault et al., 2008) o incluso algunos, indican que la lixiviación de nitratos y otros nutrientes, es mayor cuando solo se aporta materia orgánica.

Optimizar la adición de nutrientes, sobre todo de nitrógeno y fosforo, maximizando la producción y minimizando el impacto medioambiental, es uno de los objetivos más importantes de la agricultura actual.

Para diseñar un programa de fertilización, es necesario conocer las pautas de extracción de los principales nutrientes por el cultivo (sobre todo de $N$ y $P$ ), a fin de ajustar las necesidades de éstos a la disponibilidad, minimizando de esta forma el riesgo por lixiviación en el caso del $\mathrm{N}$ y de eutrofización en el caso del P. 


\subsection{CICLO DEL N Y P EN EL SUELO}

Con el fin de poder conseguir resultados adecuados a la hora de realizar prácticas agronómicas, que resulten sostenibles para el medio ambiente, es importante conocer los ciclos biogeoquímicos de los principales macronutrientes esenciales para el crecimiento vegetal, el $N$ y el $P$, a escala de sistema suelocultivo, lo que permite conocer la estructura y funcionamiento de los nutrientes en dicho sistema, algo fundamental para la compresión y la toma de decisiones de manejo agronómico. También es importante, conocer los procesos en el suelo que pueden afectar a su disponibilidad para las plantas, y las pérdidas de estos que afectarían al medio ambiente.

En la figura 1.8 se recogen los principales impactos en el agua, en el suelo y en el aire del exceso de los nutrientes, nitrógeno y fósforo.

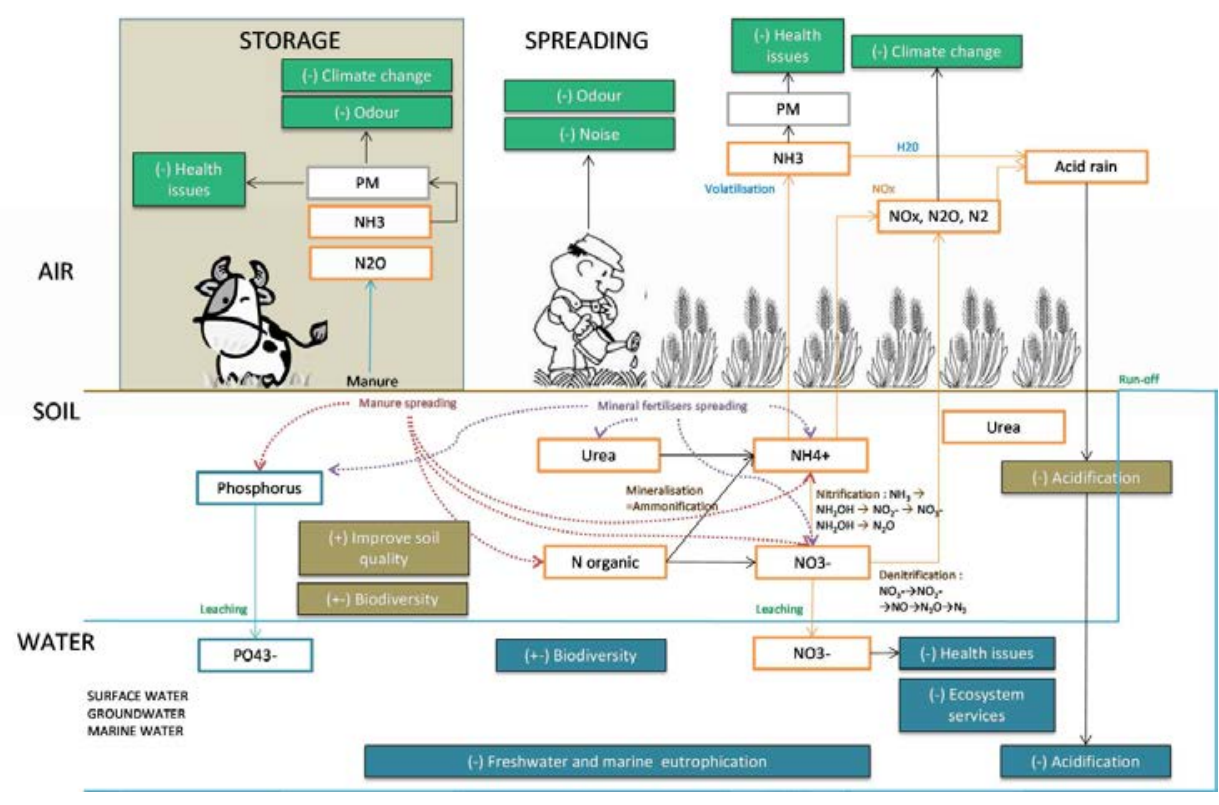

Figura 1.8 Principales impactos en el agua, en el suelo y en el aire del exceso de los nutrientes, nitrógeno y fósforo (Resource Efficiency in Practice - Closing Mineral Cycles /Final report).

\section{* Factores que afectan a los ciclos de nutrientes}

La elevada complejidad de los ciclos de nutrientes, se debe a que son muchos los factores o actividades que pueden intervenir en su modificación, como son las condiciones ambientales o la incorporación al medio de determinadas sustancias. 
El tipo de suelo, su textura, su estructura y su contenido en materia orgánica, influyen en la transformación de nutrientes y en su transferencia a los ecosistemas terrestres. Destaca la materia orgánica del suelo, compuesta por fracciones de diferente grado de descomposición y que es capaz de enlazar determinados nutrientes. Así, la capacidad de intercambio catiónico de la materia orgánica es 40 a 50 veces superior al de las arcillas, y la mineralización de la materia orgánica, produce nitrógeno y fósforo disponible para las plantas.

El contenido en MO del suelo, influye también en las pérdidas potenciales de nutrientes. Si a la hora de calcular la dosis de fertilizante, no se tiene en cuenta la cantidad que aporta el suelo, se produce una sobre fertilización con el consiguiente riesgo de contaminación. En Europa, el 45\% de los suelos, tienen un bajo contenido en materia orgánica (0-2\% de $C$ orgánico).

La erosión del suelo, consiste en la pérdida de partículas de suelo que contienen nutrientes por la lluvia, el viento o las prácticas agrícolas, como el laboreo (Eckelmann et al., 2006; Velthofa et al., 2011). Las actividades humanas y la agricultura en particular, pueden acelerar la erosión y la pérdida de suelo que afecta a los ciclos de nutrientes.

La escorrentía superficial, que se produce en zonas con excesiva precipitación y con pendiente elevada, causa pérdidas importantes de suelo conteniendo N, P y K. En particular, la erosión, es una importante fuente de pérdidas de fósforo.

La disponibilidad de agua en el suelo, es fundamental en los ciclos de nutrientes y en el crecimiento de los cultivos, ya que los nutrientes solamente son disponibles para las plantas cuando se encuentran en forma disuelta, $\mathrm{NH}_{4}{ }^{+} \mathrm{Y}$ $\mathrm{NO}_{3}{ }^{-}$en el caso del nitrógeno y $\mathrm{H}_{2} \mathrm{PO}_{4}^{-}$y $\mathrm{HPO}_{4}{ }^{2-}$ en el caso del fósforo. Esto hace que las plantas no puedan asimilar los nutrientes bajo condiciones de estrés hídrico, y como consecuencia, que queden en el suelo con el consiguiente riesgo de pérdidas por lixiviación.

El contenido en agua del suelo, es uno de los factores que determinan la concentración de nutrientes en la disolución del mismo y su disponibilidad para las plantas. La capacidad de retención de agua, es un parámetro clave del contenido de agua del suelo, al asegurar la captura, almacenamiento y aporte de agua en el mismo. La textura del suelo, su estructura y su contenido en materia orgánica, juegan un importante papel en los mecanismos de la capacidad de retención de agua, influyendo en la porosidad total, distribución del tamaño de poros y en el área de superficie especifica. 
La humedad del suelo, es también un factor determinante de la cantidad de emisiones producidas, debido a la influencia en la concentración de oxígeno disuelto que condiciona la actuación, bien de las bacterias nitrificantes que actúan sobre los iones $\mathrm{NH}_{4}^{+}$y $\mathrm{NO}_{2}{ }^{-}$o bien de las desnitrificantes que actúan sobre el $\mathrm{NO}_{3}^{-}$y $\mathrm{NO}_{2}{ }^{-}$.

En lo que se refiere a las condiciones climáticas, la temperatura y la precipitación son dos parámetros clave en el ciclo de nutrientes.

La temperatura, afecta por una parte al proceso de evapotranspiración por el que se pierde agua a la atmósfera, no estando disponible para las plantas, y por otra, a la degradación de la materia orgánica del suelo, que es mayor en climas Mediterráneos, incrementando las emisiones a la atmósfera.

La cantidad de agua de lluvia, su duración y su frecuencia, afectan de forma directa. En invierno, donde las precipitaciones son altas, el riesgo de pérdidas por lixiviación y escorrentía superficial de fertilizantes es elevado. Esta es una de las razones por la que en la Directiva de Nitratos, se definen periodos en los que la aplicación al suelo de determinados tipos de fertilizantes está prohibida. Si el suelo se satura de agua, además de las pérdidas por lixiviación, se produce desnitrificación, con la consecuente emisión a la atmósfera de óxidos de nitrógeno y pérdidas de nutrientes del suelo.

\subsection{PRINCIPALES MECANISMOS QUE DETERMINAN EL VALOR AGRONÓMICO DE UN RESIDUO ORGÁNICO}

Los residuos orgánicos estan constituidos por una fracción orgánica y una mineral. Tanto el contenido en materia orgánica como de las formas organicas y minerales del $N$ y del $P$, es muy variables. El nitrógeno se encuentra mayoritariamente en forma orgánica, el fósforo dependiendo del residuo se puede encontrar en forma predominantemente mineral, mientras que la totalidad del potasio, se encuentra en forma mineral. El valor fertilizante de un residuo orgánico va a depender de las cantidades totales de estos elementos, pero también de la proporción en que se encuentran en forma orgánica y mineral. En el caso del N, las especies más demandadas para el crecimiento por las plantas son las inorgánicas, de las cuales, las formas predominantes son los iones amonio $\left(\mathrm{NH}_{4}{ }^{+}\right)$y nitrato $\left(\mathrm{NO}_{3}{ }^{-}\right)$(Harrison et al., 2007), aunque también toman aminoácidos y monómeros orgánicos. La forma química en la que las 
plantas absorben el $\mathrm{P}$ es como ión mono hidrógeno fosfato $\left(\mathrm{HPO}_{4}{ }^{2-}\right)$ o como dihidrógeno fosfato $\left(\mathrm{H}_{2} \mathrm{PO}_{4}{ }^{2-}\right)$.

En la figura 1.9 se representa un esquema de los procesos que se producen al aplicar un residuo orgánico en el suelo. El valor como enmienda orgánica, va a depender de la incorporación de materia orgánica al suelo y de la velocidad de degradación. Su valor fertilizante, depende de la velocidad de transformacion de los elementos nutritivos a formas disponibles para la planta: nitrogeno mineral, fósforo y potasio en disolución. La cantidad de $\mathrm{N}$ mineral, es función del contenido inicial en el residuo orgánico y de la velocidad de mineralización de la materia orgánica en el suelo, mientras que en el caso del P y $K$, la cantidad disponible en disolución, depende de las condiciones fisico químicas del suelo donde se aplica el residuo.

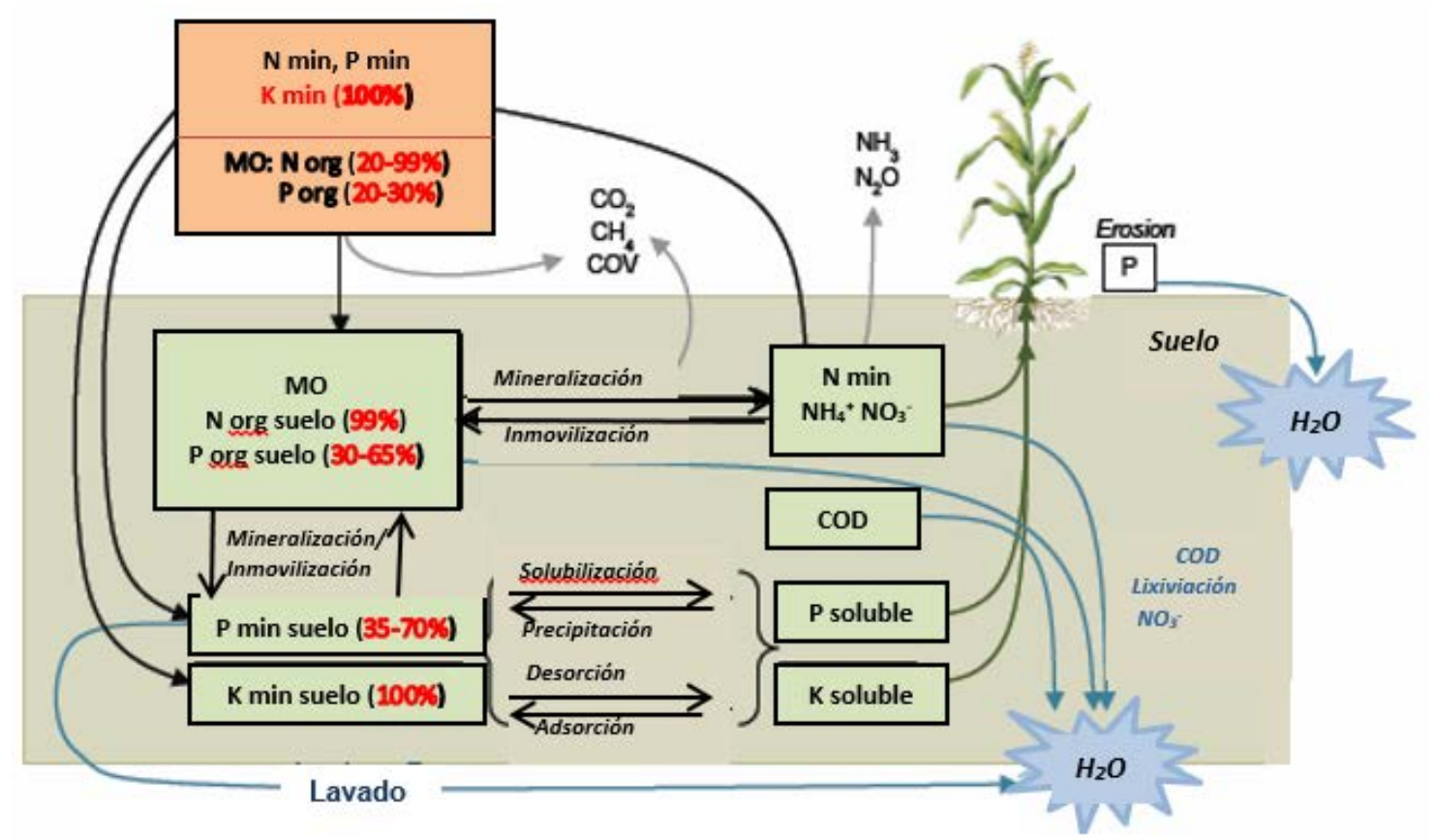

Figura 1.9 Procesos que rigen el valor fertilizante de un residuo orgánico: impactos ambientales asociados (INRA-CNRS, 2014).

La biodegradación microbiana más o menos rápida de la materia orgánica del residuo cuando se incorpora en el suelo, depende de su naturaleza química (la lignina por ejemplo es recalcitrante) y de la estabilización de esa MO a lo largo 
del proceso de tratamiento del residuo orgánico, como es la humificación en el caso del compostaje. En este caso, la MO lentamente biodegradable, actúa como un excelente enmendante. El valor enmendante y fertilizante están ligados, ya que dependen de fracciones complementarias, biodegradable y estable, de la MO. Por otra parte, el valor fertilizante y los riesgos ambientales asociados al $N$, dependen del contenido de $N$ mineral inicial en el residuo y de la mineralización de la MO fácilmente degradable. Para reducir estas pérdidas, es importante tener un adecuado manejo del sistema de explotación y mantenimiento de los suelos agrícolas

La forma en que el $\mathrm{N}$ es absorbido por las plantas y sus necesidades va a depender de muchos factores como la especie, la variedad, el rendimiento potencial, la temperatura, el pH, etc... (Jackson et al., 2008).

En los ecosistemas agrícolas, el $\mathrm{N}$ es transformado de una forma a otra dependiendo de las condiciones ambientales ( $\mathrm{pH}$, temperatura, humedad, etc...). El balance de todos estos procesos, nos indica la cantidad de nitrógeno disponible y asimilable por las plantas.

En el suelo, el $P$ esta en distintas formas químicas que se pueden incluir dentro de dos grandes grupos: $P$ inorgánico (35-70\% del $P$ total) y $P$ orgánico (30-65\% del $P$ total).

El ciclo del fósforo en el suelo es complejo por su interacción entre las plantas, animales, microorganismos y las fases solidas del suelo (Lyamuremye and Dick, 1996). El P orgánico se encuentra tanto en formas activas (diesteres, monoesteres, ortofosfatos lábiles y polifosfatos orgánicos), como en formas estables (inositol fosfato y fosfonatos) (Turner et al., 2002; Condron et al., 2005). Se trata de un nutriente poco móvil en el suelo, que es tomado por el sistema radicular de las plantas, por difusión e intercepción radicular. La velocidad del proceso de difusión, depende de múltiples factores entre los que se encuentran, la diferencia de concentración de $P$ en el área de difusión, la temperatura, la humedad edáfica y la tortuosidad del suelo.

Johnston (2001) sugirió que se podría considerar que existen cuatro pools de $P$ inorgánico en el suelo, que se caracterizan por la diferente disponibilidad del $P$ para las raíces de las plantas (Figura 1.10) y que están relacionados con su extractabilidad mediante diferentes reactivos. Syers et al. (2008), desarrollaron esta idea, considerando que la cantidad de P en cada pool, está relacionada con la cantidad de energía con la que el $P$ se vincula con la 
superficie del suelo, con la matriz interna del mismo, así como con su relación con otros constituyentes del suelo.

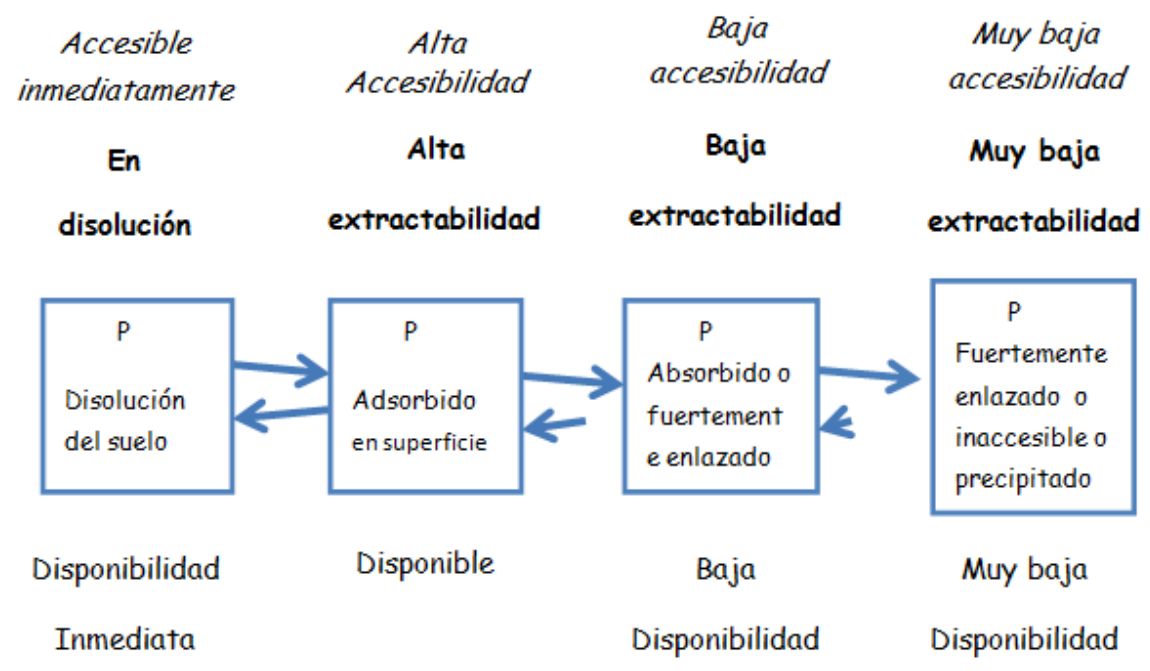

Figura 1. 10 Diagrama conceptual de las distintas formas de $P$ inorgánico en suelos categorizadas en términos de accesibilidad, extractabilidad y disponibilidad para las plantas (Syers, J.K. et al., 2008).

El P de los dos primeros pools, es el que se mide en el suelo con los métodos analíticos normalmente utilizados, pero el valor obtenido depende del extractante utilizado. EI P del tercer pool está fuertemente enlazado a los componentes del suelo, aunque puede estar a disposición de las plantas en semanas o meses. EI P del pool menos accesible, es parte del complejo mineral del suelo y únicamente puede llegar a estar disponible para las plantas pasados muchos años (Roberts et al., 2015). Según Johnston et al. (2014), hay un nivel crítico de $P$ disponible entre el pool 1 y 2, óptimo para alcanzar la máxima producción del cultivo, sin necesidad de aplicar $P$ de forma externa, ya que sería ineficaz. Esto implica que para poder determinar el nivel crítico de $P$ disponible para el cultivo, sea necesario usar relaciones entre la producción del cultivo y el $P$ añadido o bien, el $P$ disponible determinado analíticamente.

Hoy en día, se utiliza como indicador del $P$ disponible de los residuos, la determinación de $P$ soluble en agua (WSP), también denominado $P$ extraíble en agua (WEP), ya que se sabe que el $P$ total que se aporta al suelo no es indicativo del $P$ disponible. Sin embargo, según se va conociendo más el comportamiento de 
este elemento, muchos científicos consideran, que la medida de P total y WSP aportan información limitada sobre el comportamiento de los residuos en suelos enmendados. El empleo de metodologías de análisis como técnicas de Resonancia Magnética Nuclear (RMN) (Hunger et al., 2005; Maguire et al., 2004; Toor et al., 2005 a) y espectroscopía de absorción por rayos-x (XANES) (Peak et al., 2002; Toor et al., 2005 b) ayudan al conocimiento del comportamiento del $P$, pero su empleo es limitado debido a su complejidad.

Actualmente, hay un elevado número de métodos químicos de fraccionamiento secuencial, que se aplican con perspectivas tanto agronómicas como medioambientales, y que permiten caracterizar las formas de $P$ en diferentes tipos de residuos orgánicos. En este trabajo, se ha utilizado el método de fraccionamiento de Hedley (1982) y sus posteriores modificaciones (Sui et al., 1999; Huang et al., 2008) (Figura 1.11), ya que ha sido empleado en numerosas ocasiones en suelos, sedimentos, estiércoles animales, lodos y compost (Sharpley and Sisak, 1997; Dou et al., 2000; Dao et al., 2001).

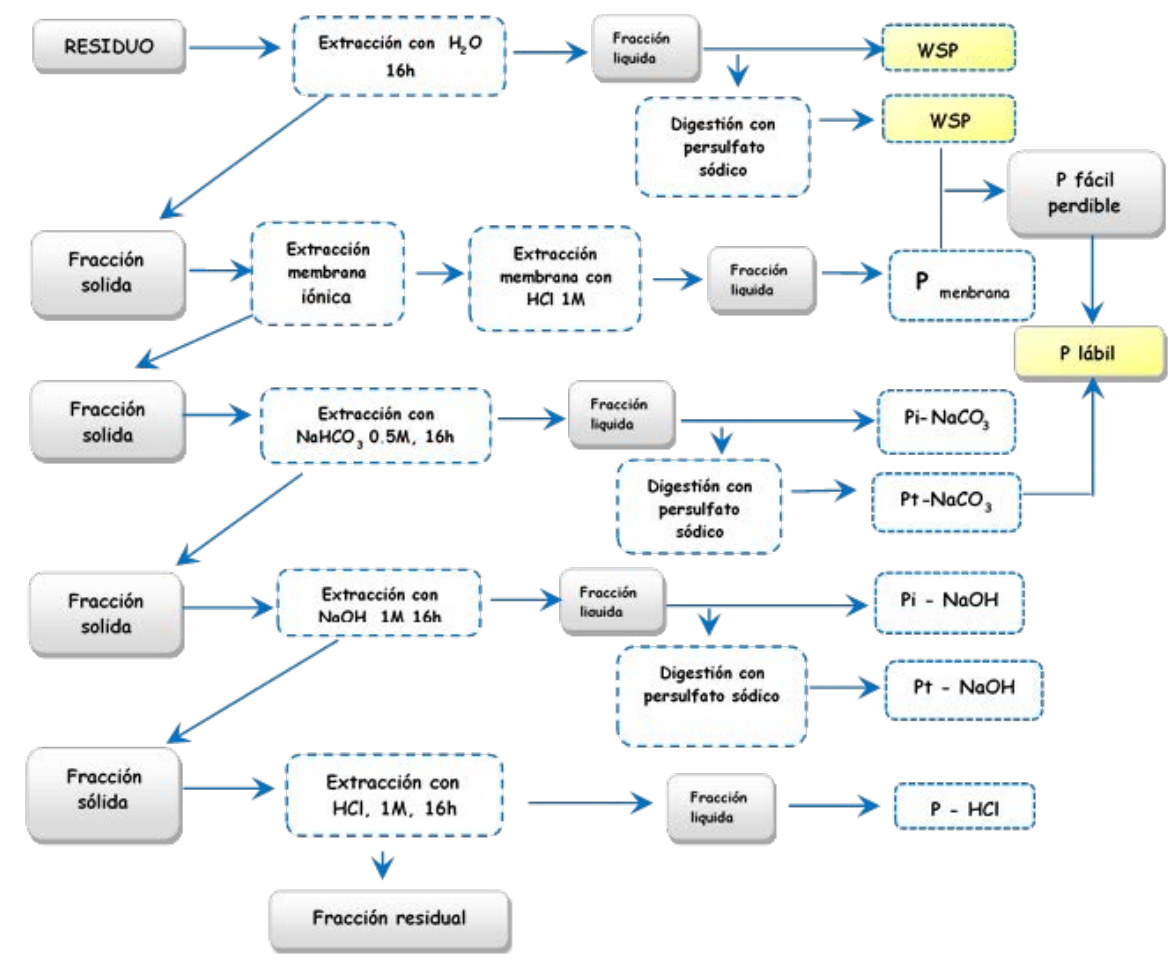

Figura 1. 11 Metodología de especiación de P según Xiao-Lan Huang (2008).

La absorción de fósforo por los cultivos, es aproximadamente de 10 a 30 $\mathrm{kg} \mathrm{ha}^{-1}$. Debido a la baja movilidad de este elemento en el suelo, sus pérdidas por 
lixiviación son insignificantes normalmente $\left(0,2-0,5 \mathrm{~kg} \mathrm{ha}^{-1}\right)$, siendo el principal peligro para el medio ambiente, las pérdidas por escorrentía superficial.

\subsection{APROVECHAMIENTO DEL COMPOST DE ORUJO DESALCOHOLIZADO DE LA INDUSTRIA VITIVINÍCOLA EN UNA ZONA VULNERABLE}

La necesidad de reducir la contaminación producida por la aplicación de grandes cantidades de fertilizantes, sobre todo nitrogenados, está reforzando la importancia de usar otras alternativas como la aplicación de residuos orgánicos como fuente de nutrientes además de como enmienda orgánica. Para una correcta gestión de este tipo de residuos, se requiere el conocimiento de la dinámica de absorción y distribución de nutrientes por parte la planta cuando se aplica, como en este caso, compost de orujo en diferentes dosis.

El compost de orujo es un residuo del que existen pocos antecedentes de aplicación en zonas vulnerables. Su utilización dada su alta calidad, puede ser una vía alternativa rentable desde el punto de vista económico y ambiental, debido a que se genera en grandes cantidades en la zona de Castilla la Mancha. Sin embargo, es necesario probar su eficacia en condiciones de campo, y comparar los resultados obtenidos con la fertirrigación tradicional, valorando además, el efecto residual que tiene en el suelo. Se ha elegido un cultivo de melón para valorar el efecto de la aplicación del compost, ya que España, es el principal productor europeo de melón (46\%), principalmente tipo piel de sapo (Figura 1.12).

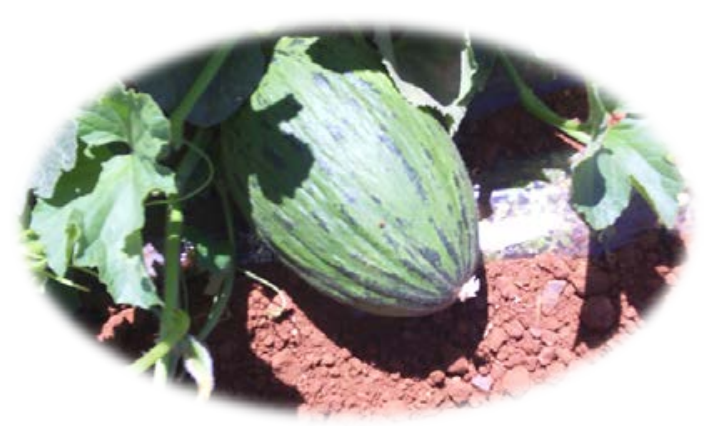

Figura 1.12 Melón piel de sapo.

El melón se cultiva en la mitad sur de España, especialmente en CastillaLa Mancha (Figura 1.13) (MAGRAMA, 2018), con 6000 ha (34\% de la superficie nacional), siendo Ciudad Real, la provincia que mayor superficie destina a este 
cultivo, con 4.776 ha (32\% de la superficie nacional) y la segunda provincia con mayor producción a nivel nacional, con 215.007 † producidas, la mayoría en regadío y al aire libre, donde se concentra más de la mitad de la producción total de vino del país (MAGRAMA, 2018).

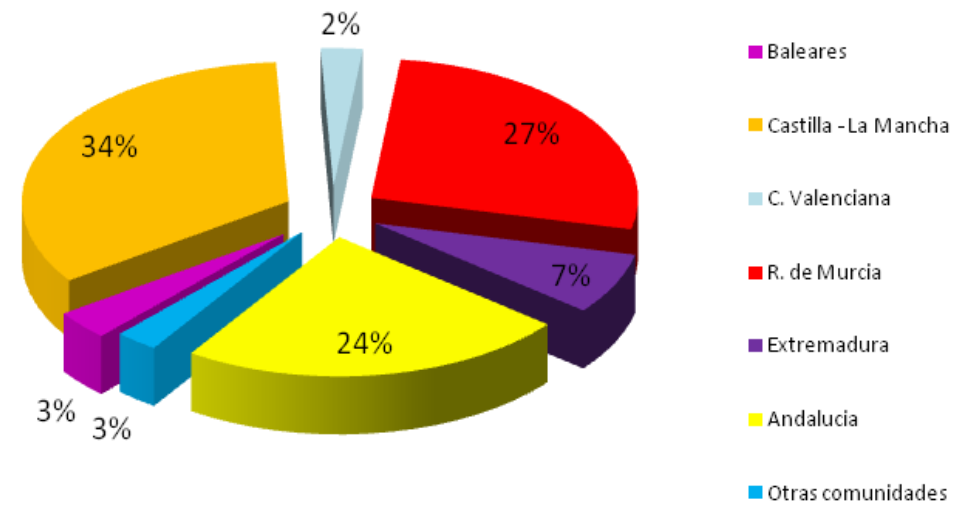

Figura 1.13 Superficie dedicada al de melón en 2018 por comunidades autónomas en España (MAGRAMA, 2018).

Dada la baja velocidad de mineralización del compost de orujo, es necesario conocer para su correcta dosificación, el efecto residual en el suelo. Para ello y posteriormente al cultivo de melón, se sembró un cultivo captura muy ávido por el nitrógeno, como es el trigo blando.

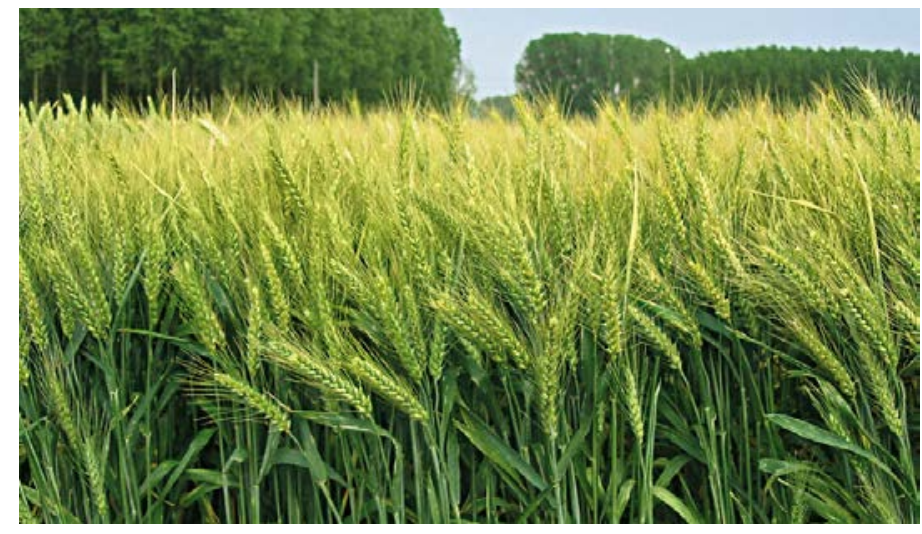

Figura 1.14 Cultivo de trigo. 
Este planteamiento, permitiría desarrollar una agricultura sostenible, compatible con el medio ambiente, favoreciendo la conservación del suelo y una utilización racional de los fertilizantes, reduciendo al mismo tiempo, los costes de producción, manteniendo los rendimientos, la calidad de los productos y reduciendo la contaminación de origen agrario en el medio. Para conseguir todo esto, es necesario conocer, cómo afecta la aplicación del compost de orujo desalcoholizado de la industria vitivinícola, en condiciones de campo, a la disponibilidad de los principales nutrientes para las plantas (nitrógeno y fosforo), para poder afrontar sus requerimientos nutricionales. Además, es necesario obtener información, sobre la cantidad de nutrientes remanentes que queda en el suelo. Con estos conocimientos, se podrán poner en marcha distintas políticas de mantenimiento de los sistemas agrarios, que frenen la contaminación por nitratos de las aguas subterráneas, como consecuencia del lavado de los suelos a causa de la lluvia o el riego y la eutrofización de las aguas superficiales.

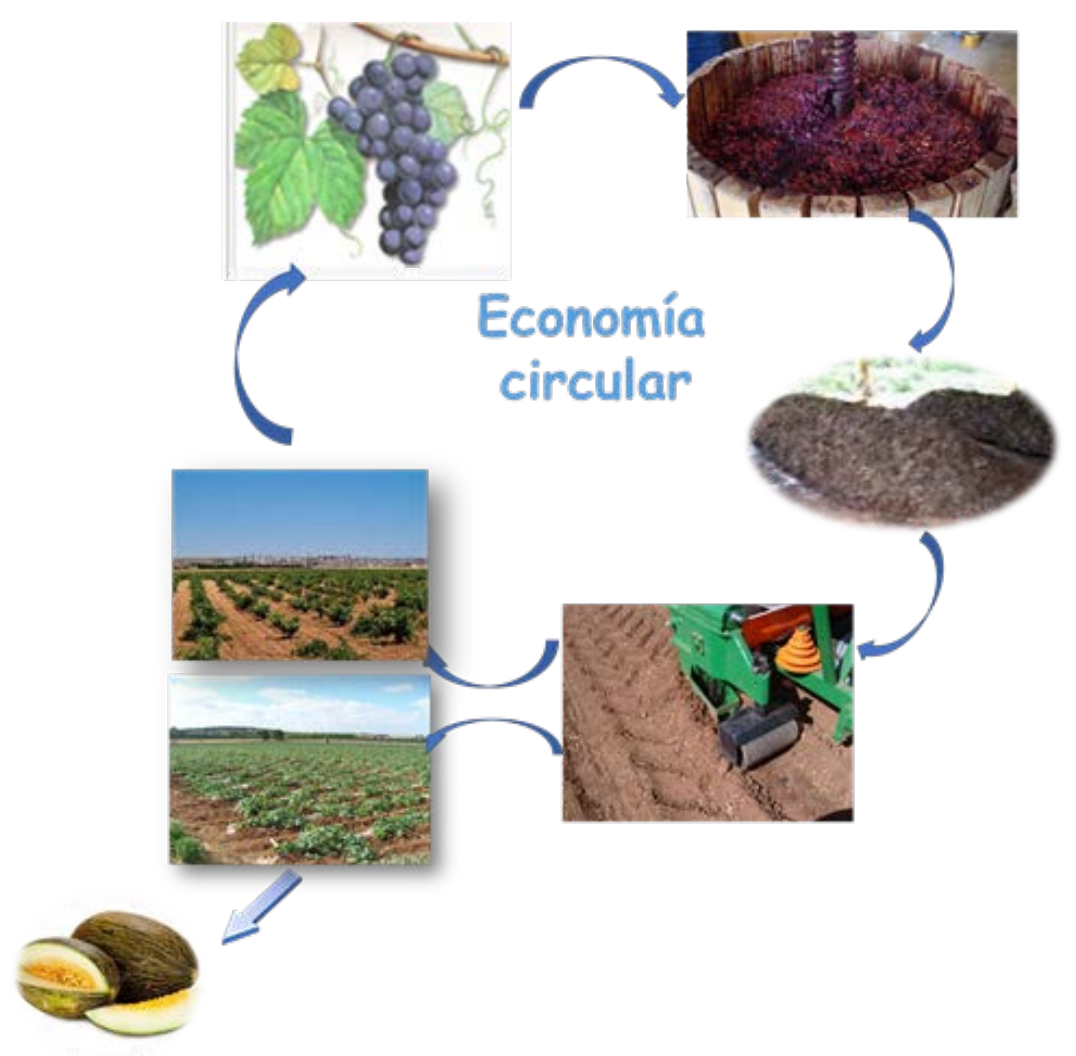

Figura 1.15 Aprovechamiento circular de compost de la industria vitivinícola (Gestión agrícola sostenible). 


\subsection{UTILIZACIÓN DE ÍNDICES COMO HERRAMIENTA PARA ESTUDIAR EL COMPORTAMIENTO DEL COMPOST DE ORUJO EN EL CULTIVO DEL MELÓN EN UNA ZONA VULNERABLE}

La correcta utilización de residuos orgánicos, en nuestro caso compost de orujo desalcoholizado, en un cultivo hortícola como el melón y en una zona vulnerable, implica conocer su comportamiento bajo diferentes aspectos tanto agronómicos como ambientales. Por una parte, es interesante saber, cómo afectará su aplicación al suelo, al desarrollo del cultivo desde el punto de vista morfológico, fisiológico y a la dinámica de crecimiento de las diferentes partes de la planta. Por otra, que efecto tendría su aplicación, en el comportamiento de los nutrientes en el sistema suelo-planta, la ventajas económicas de su empleo y por último su influencia en aspectos ambientales, como son el uso del agua o la contaminación por nitratos, conocimientos muy importantes en una zona vulnerable.

El análisis del crecimiento, permite investigar el efecto de las prácticas agronómicas que modifican el medio, en el desarrollo de un cultivo. Tanto la producción de materia seca, como el índice de área foliar (LAI), se han usado sistemáticamente como índices fisiológicos para evaluar diferencias en el crecimiento del cultivo en distintas condiciones. El mantenimiento de un adecuado equilibrio entre el crecimiento y el rendimiento, es básico a la hora de lograr el desarrollo correcto de un cultivo. Son muchos los índices de crecimiento que aparecen en la bibliografía. Alguno de ellos: la razón de área foliar (LAR), el área foliar especifica (SLA) y la relación de masa foliar (LWR), nos proporcionan información sobre los cambios morfológicos que se producen en la planta si se aplica compost de orujo. Otros, como la tasa de asimilación neta (NAR) y la duración de área foliar (LAD), proporcionan información de los cambios producidos en los aspectos fisiológicos de la planta. Por último se encuentran los índices que representan la velocidad de crecimiento: de la hoja $(L G R)$, del cultivo (CGR), relativa ( $R G R)$ y del fruto ( $F G R$ ).

El conjunto de todos ellos nos permiten obtener información del efecto de la aplicación del compost sobre el crecimiento vegetativo del cultivo y de los frutos simultáneamente.

La eficiencia del uso de un nutriente (NUE), comprende tres aspectos claves: la eficiencia de absorción, la eficiencia de utilización para producir biomasa y el índice de cosecha (Lammerts and Struik, 2017). El conocimiento de 
la eficiencia permite optimizar la fertilización, lo que conlleva tanto importantes ventajas económicas como ambientales.

EI NUE es un término complejo que engloba muchos componentes. De forma simple, la cuantificación del NUE se obtiene como una relación entre un output (rendimiento biológico o rendimiento económico) y un input (nutriente suministrado), siendo numerosos los índices de eficiencia del uso de nutrientes que se encuentran en la bibliografía (Novoa and Loomis, 1981; Cassman et al., 2002; Dobermann, 2005 y 2007; Fageria et al., 2005; Morris et al., 2018; Ramesh, 2018; Syers et al., 2008; Roberts et al., 2015; Gourley et al., 1993; Huggins and Pan, 1993).

La eficiencia del uso del agua, definida como la relación entre la producción de fruto y el agua utilizada para conseguir ese rendimiento (Castellanos et al., 2013), es un dato clave tanto desde el punto de vista económico como ambiental, fundamentalmente en zonas vulnerables y en donde la escasez de fuentes de agua de buena calidad, es un problema importante sobre todo, en zonas áridas y semiáridas.

Reducir los riesgos de contaminación de los acuíferos, sin reducir la producción debería ser el principal objetivo cuando se gestiona de forma correcta los residuos orgánicos. Castellanos et al., 2013, definió varios índices relacionados con este objetivo: índice de impacto (II) e índice de impacto ambiental (EII), ambos relacionados con el contenido en nitratos en el lixiviado y la eficiencia de manejo (ME), que incluye aspectos económicos y ambientales. 
Capítulo 2

OBJETIVOS 

El compost de orujo desalcoholizado procedente de la industria vitivinícola se pueden valorizar de muchas formas, pero teniendo en cuenta el nuevo punto de vista de la UE de conservar los recursos naturales sin contaminar el medio ambiente, la utilización de estos residuos para su aplicación a los suelos de las zonas donde se producen, mejorando su fertilidad, puede ser una opción sostenible de gestión agrícola encuadrada dentro del concepto de Economía Circular que promulga la UE. Esta práctica, podría ser una buena alternativa a la fertirrigación tradicional que se utiliza en esas zonas, muchas de ellas declaradas vulnerables a la contaminación por nitratos con la aplicación de la Normativa europea (91/676/ CEE).

Existe poca información sobre la aplicación de este residuo orgánico con fines agronómicos en experimentación en campo, lo que suscita muchas preguntas que deben ser contestadas:

1- ¿Cómo afecta la aplicación de este residuo al desarrollo vegetativo del cultivo de melón dependiendo de la dosis aplicada del mismo?

2- ¿Cómo afecta la aplicación del compost de orujo a la producción y calidad del melón?

3- ¿Cómo influye la aplicación de este residuo en el comportamiento de los macronutrientes ( $\mathrm{Y} P$ ) durante el desarrollo del cultivo en el sistema suelo planta?

4- ¿Qué consecuencias medioambientales tendría su aplicación en zonas vulnerables?

5- ¿Podría sustituir la aplicación de este residuo orgánico en las zonas vulnerables a la fertilización tradicional?

6- ¿Qué efecto residual en el suelo tiene el $\mathrm{N}$ procedente del compost de orujo en cultivos posteriores?

Con el fin de poder dar respuestas a estas preguntas en esta tesis se han fijado los siguientes objetivos: 
1. Evaluar el comportamiento como enmienda orgánica y fertilizante del compost de orujo desalcoholizado procedente de la industria vitivinícola en un cultivo de melón en una zona vulnerable, comparando los resultados con los obtenidos mediante fertirrigación tradicional.

2. Estudiar la dinámica de crecimiento del cultivo, cuantificando la producción de biomasa, su distribución en los distintos órganos aéreos y analizando diversos tipos de índices de crecimiento.

3. Evaluar la influencia de la incorporación al suelo del compost de orujo en la producción de melón y en los diferentes parámetros de calidad.

4. Determinar la dinámica de extracción de los nutrientes en condiciones de campo de un cultivo de melón piel de sapo y su distribución entre los diferentes órganos de la planta, según los distintos tratamientos aplicados.

5. Determinar la influencia de la dosis de aplicación del residuo en el grado de mineralización del $\mathrm{N}$ y movilización del $\mathrm{P}$ en un suelo enmendado con compost de orujo, en comparación con el suelo sin enmendar.

6. Comparar la eficacia agronómica y medioambiental de la aplicación de compost de orujo frente al sistema de fertirrigación tradicional.

7. Valorar el efecto residual en el suelo de la aplicación de este residuo en un cultivo posterior (trigo). 
Capítulo 3

MATERIALES Y MÉTODOS 

En este capítulo, se recoge en primer lugar, la metodología experimental general utilizada en los ensayos en campo. Se incluyen las características del lugar del experimento, del suelo y climáticas de la zona. En segundo lugar, se describe la metodología utilizada en el experimento del melón y del trigo, y por último, se describen las diferentes metodologías y análisis realizados.

\subsection{Características generales}

\subsubsection{Localización y características de la zona del ensayo}

Los ensayos de campo se realizaron durante las campañas 2011-2012, 2012-2013 y 2013-2014 en la finca experimental "La Entresierra", del Centro de Investigación Agroambiental-IRIAF "El Chaparrillo", propiedad de la Consejería de Agricultura y Medio Ambiente de la Junta de Comunidades de Castilla-La Mancha en Ciudad Real, situada en la zona regable de "El Vicario", a $3 \mathrm{Km}$ de la capital, entre las carreteras $\mathrm{N}-401$ y $\mathrm{CM}-414$, cuyas coordenadas geográficas son: $3^{\circ} 56^{\prime} \mathrm{W}, 39^{\circ} \mathrm{O}^{\prime} \mathrm{N}, \mathrm{y}$ con $640 \mathrm{~m}$ de altitud.

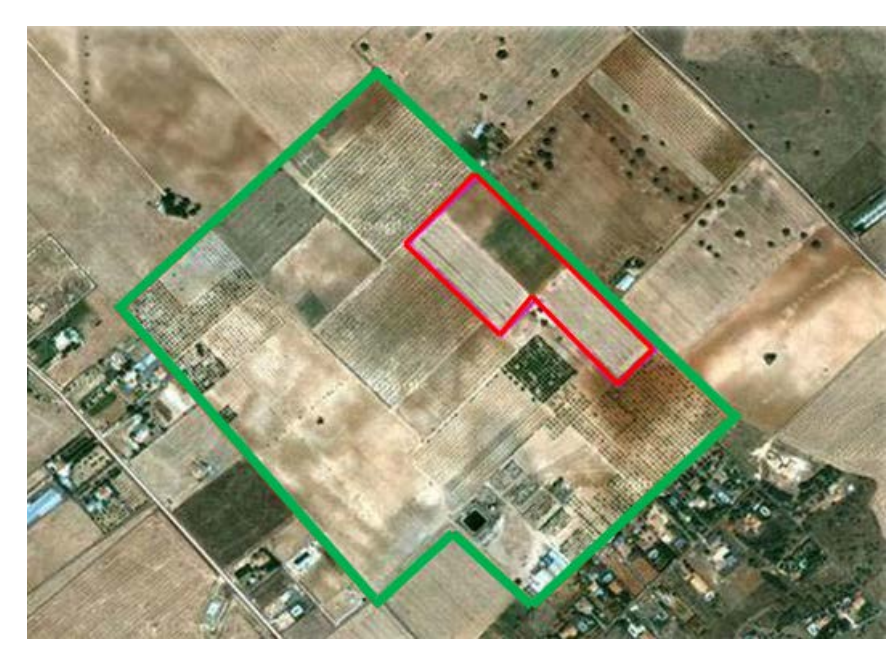

Figura 3.1 En verde delimitación de la finca "La Entresierra" y en rojo delimitación de las parcelas donde se realizaron los ensayos. (Fotografía aérea de la finca experimental "La Entresierra" (Google maps).
Los experimentos tuvieron lugar en tres parcelas independientes $y$ contiguas, lo que hizo posible la rotación de un cultivo de melón seguido de uno de trigo durante tres años consecutivos (Figura 3.1). En estas parcelas, los tres años anteriores al experimento de melón, se cultivó trigo (Triticum aestivum L.) y en esos años, no recibieron ni riego ni materia orgánica ni fertilizantes. El cultivo de trigo (Triticum aestivum L. cv. García), se eligió como cultivo captura, para poder apreciar el efecto residual del nitrógeno procedente de la adición de las distintas dosis de compost al cultivo de melón. 
Figura 3.2 Esquema temporal del ensayo en las tres parcelas en la finca experimental de "La Entresierra".

\begin{tabular}{||l||l||}
\hline $\begin{array}{l}\text { Cultivo de melón 2011 } \\
\text { Cultivo de trigo 2011-2012 }\end{array}$ & $\begin{array}{l}\text { Cultivo de melón 2012 } \\
\text { Cultivo de trigo 2012-2013 }\end{array}$ \\
\hline \hline $\begin{array}{l}\text { Cultivo de melón 2013 } \\
\text { Cultivo de trigo 2013-2014 }\end{array}$ & \\
\hline
\end{tabular}

La finca utilizada para el ensayo, se encuentra en una pequeña depresión de fondo plano, cercana al límite de unos pequeños relieves que no exceden los $714 \mathrm{~m}$, mostrando un paisaje plano y débilmente accidentado (Varela and Castaño, 1995). Las parcelas se encuentran dentro de la zona más septentrional del sector volcánico del Campo de Calatrava (Varela and Castaño, 1995).

\subsubsection{El suelo del ensayo}

Las características del suelo (horizonte Ap) de las parcelas correspondientes a cada año del experimento, se recogen en la Tabla 3.1.

Tabla 3.1 Propiedades físico-químicas del suelo del ensayo en 2011, 2012 y 2013.

\begin{tabular}{|c|c|c|c|}
\hline Propiedades & 2011 & 2012 & 2013 \\
\hline $\mathrm{pH}$ & 8,4 & 8,4 & 8,4 \\
\hline$C E\left(\mathrm{~ms} \mathrm{~cm}^{-1}\right)$ & 0,2 & 0,2 & 0,2 \\
\hline Materia orgánica $\left(\mathrm{g} \mathrm{kg}^{-1}\right)$ & 22,2 & 22,6 & 24.1 \\
\hline$P$ disponible $\left(m g \mathrm{~kg}^{-1}\right)$ & 28,3 & 16,9 & 22,1 \\
\hline$K$ disponible $\left(m g \mathrm{~kg}^{-1}\right)$ & 479,3 & 325,6 & 410,7 \\
\hline Ca disponible $\left(\mathrm{mg} \mathrm{kg}^{-1}\right)$ & 1648,3 & 1343,3 & 1649,3 \\
\hline Mg disponible $\left(\mathrm{mg} \mathrm{kg}^{-1}\right)$ & 396,0 & 622,3 & 461,2 \\
\hline$N$ kjeldahl $\left(\mathrm{g} \mathrm{kg}^{-1}\right)$ & 0,8 & 0,9 & 1,1 \\
\hline $\mathrm{N}-\mathrm{NO}_{3}^{-}\left(m g \mathrm{~kg}^{-1}\right)$ & 14,1 & 11,2 & 15,3 \\
\hline $\mathrm{N}-\mathrm{NH}_{4}^{+}\left(\mathrm{mg} \mathrm{kg}^{-1}\right)$ & 0,8 & 0,9 & 1,7 \\
\hline
\end{tabular}


Se trata de un suelo con aproximadamente $21,6 \%$ de Arcilla, $8,0 \%$ de Limo y $70,4 \%$ de Arena, por lo que según la USDA, se podría considerar que la textura de este suelo sería Textura franco arcillo arenosa y fue clasificado como Petrocalcic Palexeralfs (Soil Survey Staff, 2014), con una capa petrocalcica discontinua y fragmentada por debajo de los primeros 0,60 $\mathrm{m}$. En esta capa, existen grietas que proporcionan una mayor permeabilidad vertical a nivel local. (Figura 3.2).

Este suelo presenta los siguientes horizontes genéricos: Ap $(0-0,3 \mathrm{~m})$, Bck $(0,3-0,6 \mathrm{~m}), C \mathrm{~km}(0,6-1,0 \mathrm{~m})$, Cck $(1,0 a>1,5 \mathrm{~m})$ (Figura 3.3).

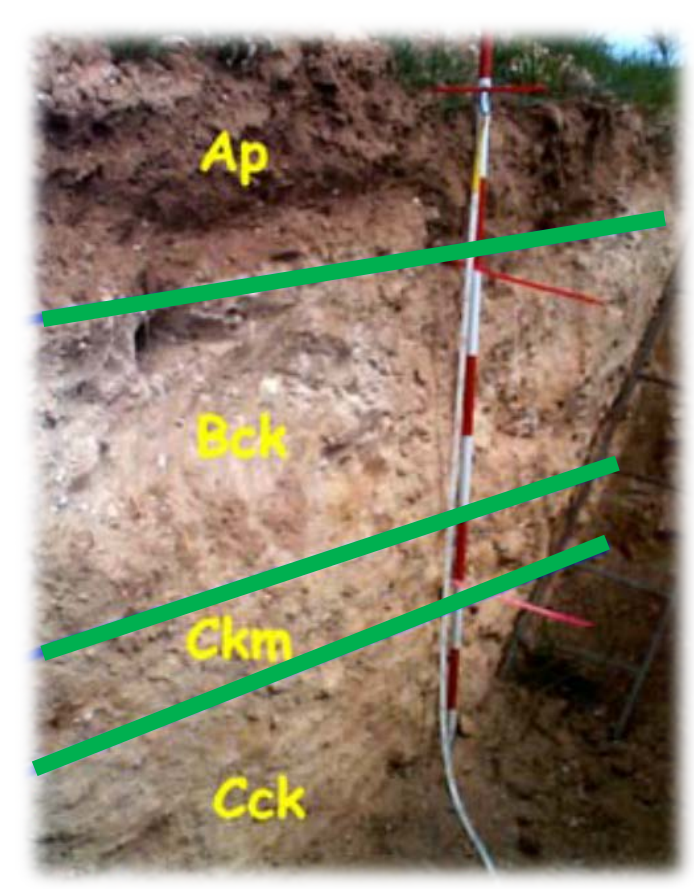

Figura 3.3 Perfil del suelo donde se realizaron los experimentos.

$0,211 \mathrm{~m}^{3} \mathrm{~m}^{-3}$ respectivamente.
Ligeramente básico (pH 8,4), con un contenido medio de materia orgánica de $2,2 \%$, poco profundo, con un contenido total de nitrógeno de $0,1 \%$ (Kjeldahl), rico en potasio $(405,2$ $\mathrm{mg} \mathrm{kg}^{-1}$ y con un nivel medio de fósforo (22,43 $\mathrm{mg} \mathrm{kg}^{-1}$ Olsen).

La presencia de agua disponible para la planta está restringida en los primeros 0,60 m. El contenido volumétrico de los primeros 0,3 $\mathrm{m}$. fue $0,228 \mathrm{~m}^{3} \mathrm{~m}^{-3}$ a capacidad de campo (potencial matricial del suelo $-0,03$ $\mathrm{MPa}), 0,121 \mathrm{~m}^{3} \mathrm{~m}^{-3}$ en el punto de marchitamiento (potencial matricial del suelo $-1,5 \mathrm{MPa}$ ) y de 0,3-0,7 m, 0,430-

\subsubsection{El clima}

El clima de esta zona es de tipo mediterráneo continental. Caracterizado principalmente por la existencia de una estación seca bien definida, y una fuerte fluctuación diaria de las temperaturas. En esta zona, la climatología está caracterizada por tener pocas precipitaciones y altas temperaturas estivales. La temperatura promedio durante el verano, fue alrededor de los $25^{\circ} \mathrm{C}$, las máximas temperaturas se registraron en julio y agosto (Figura 3.4). La 
precipitación media durante el cultivo del trigo (de noviembre a julio), fue entre 170,10 y $499,90 \mathrm{~mm}$, existiendo meses secos (Figura 3.5). El verano fue la estación más seca que representó sólo el $10 \%$ de la precipitación anual, y el resto de la precipitación se centró de septiembre a abril. La evapotranspiración de referencia acumulada (ETo) estuvo comprendida entre 393,9 y 585,8 mm.

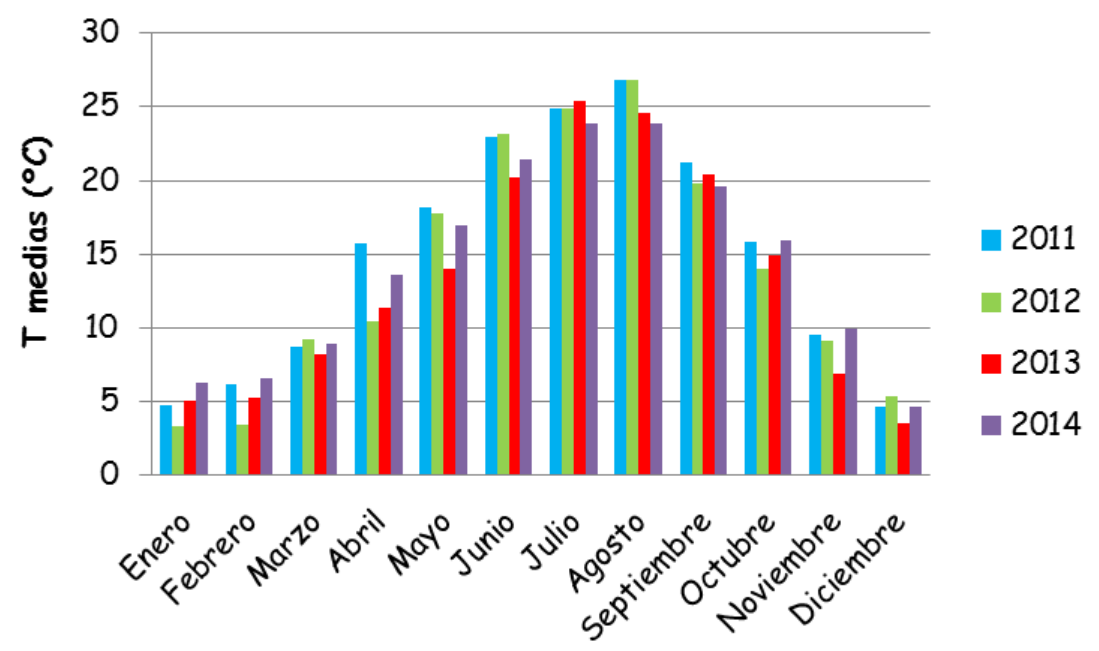

Figura 3.4 Temperaturas medias los años del ensayo.

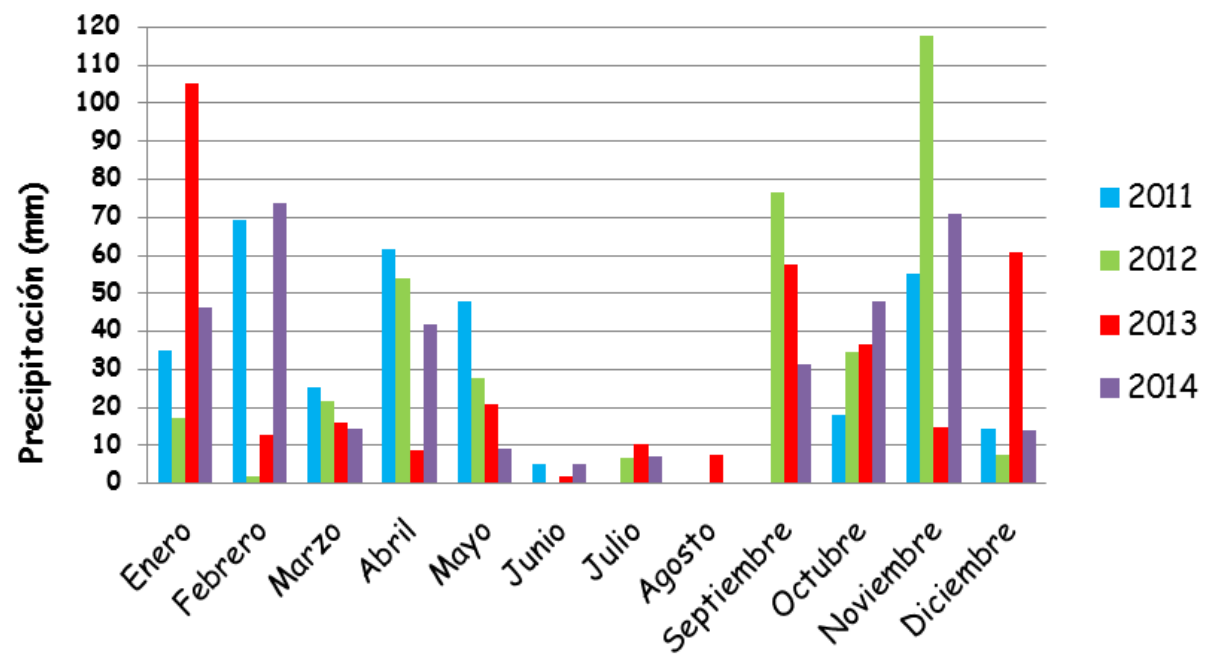

Figura 3.5 Precipitación mensual los años del ensayo. 


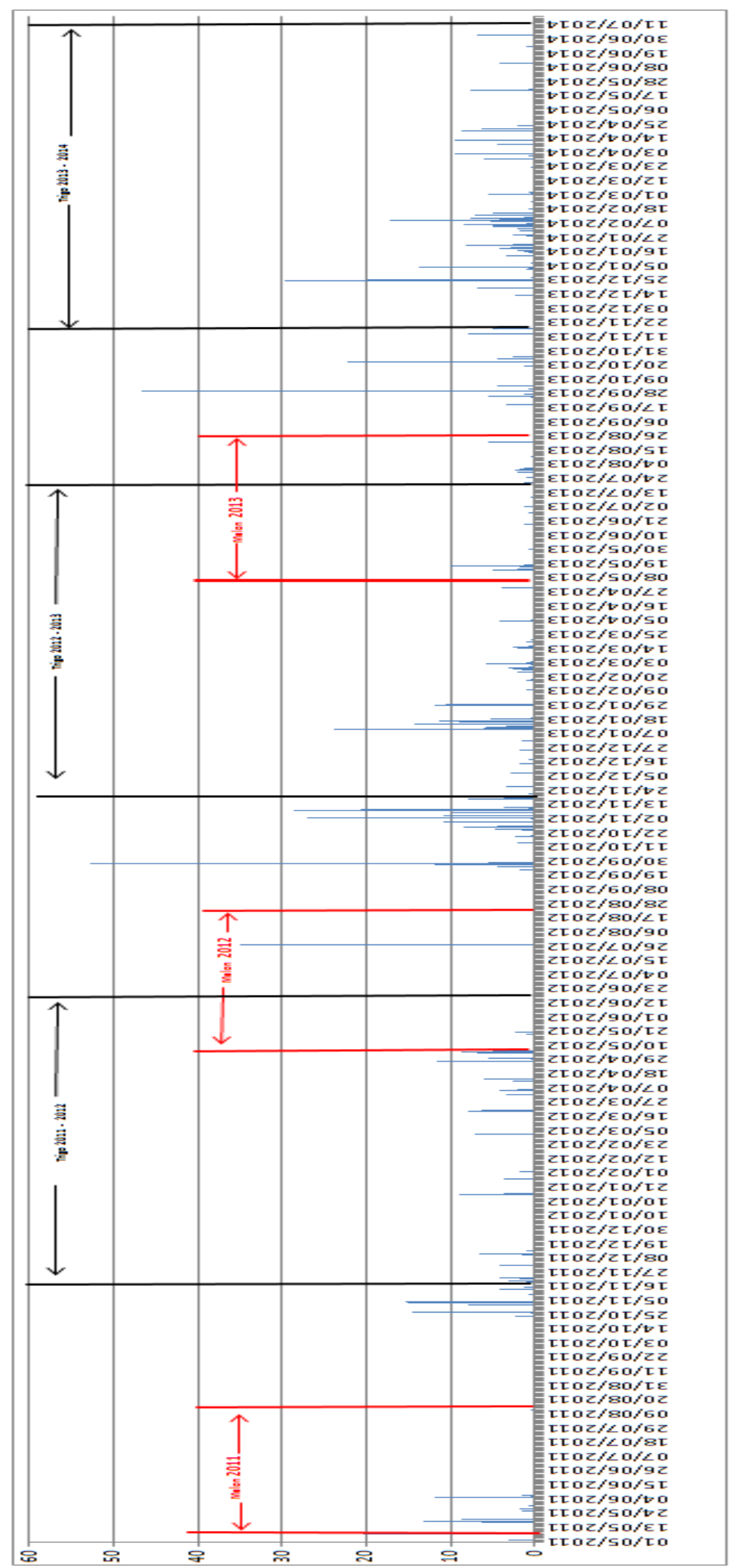

Figura 3.6 Esquema general de las precipitaciones años 2011, 2012, 2013 y 2014. 
Los datos climáticos de los años en los que se realizaron los experimentos, se recogen en la Tabla 3.2.

Tabla 3.2 Los datos climáticos mensuales, de la zona durante el período del experimento en 2011, 2012, 2013 y 2014.

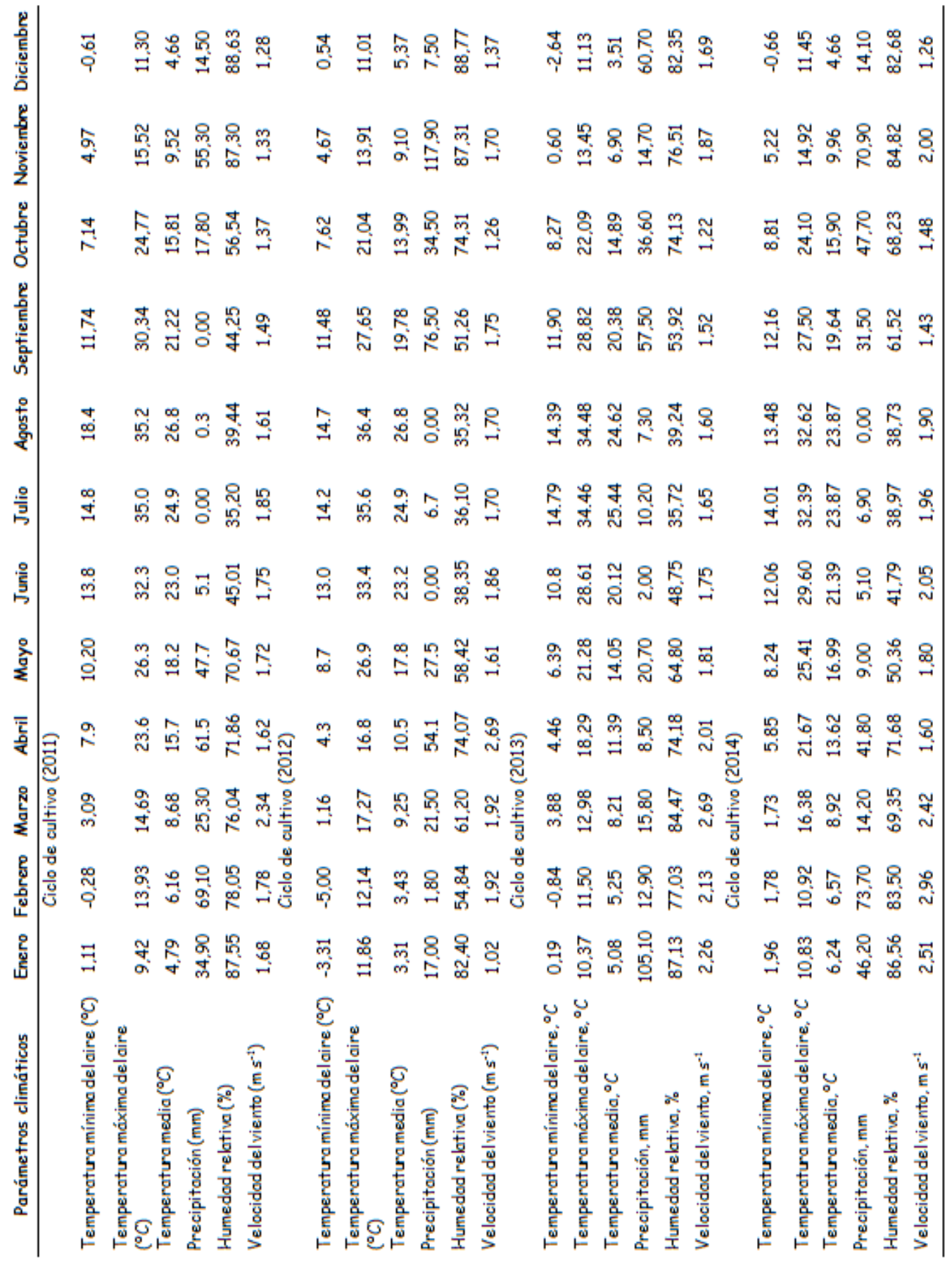




\subsection{Experimentos de campo}

\subsubsection{Cultivo de melón: Diseño experimental, tratamientos y riego}

En el experimento se utilizó la especie de melón más ampliamente cultivada en España, tipo "Piel de sapo" (Cucumis melo L., var. cv Trujillo). Las semillas de melón fueron germinadas en invernadero, a finales de marzo de los tres años, hasta que brotaron dos o tres hojas verdaderas. Posteriormente, fueron trasplantadas al campo experimental y al aire libre, aproximadamente 20 días después de la aplicación del compost al suelo, con una abonadora en la línea de cultivo (Figura 3.7) (11 de mayo de 2011, 9 de mayo de 2012 y el 10 de mayo de 2013), sobre acolchado plástico (polietileno transparente, $20 \mathrm{~mm}$ de espesor y $110 \mathrm{~cm}$ de ancho), a una densidad de 4.444 plantas ha $^{-1}(1,5 \times 1,5 \mathrm{~m})$ (Figura 3.8).
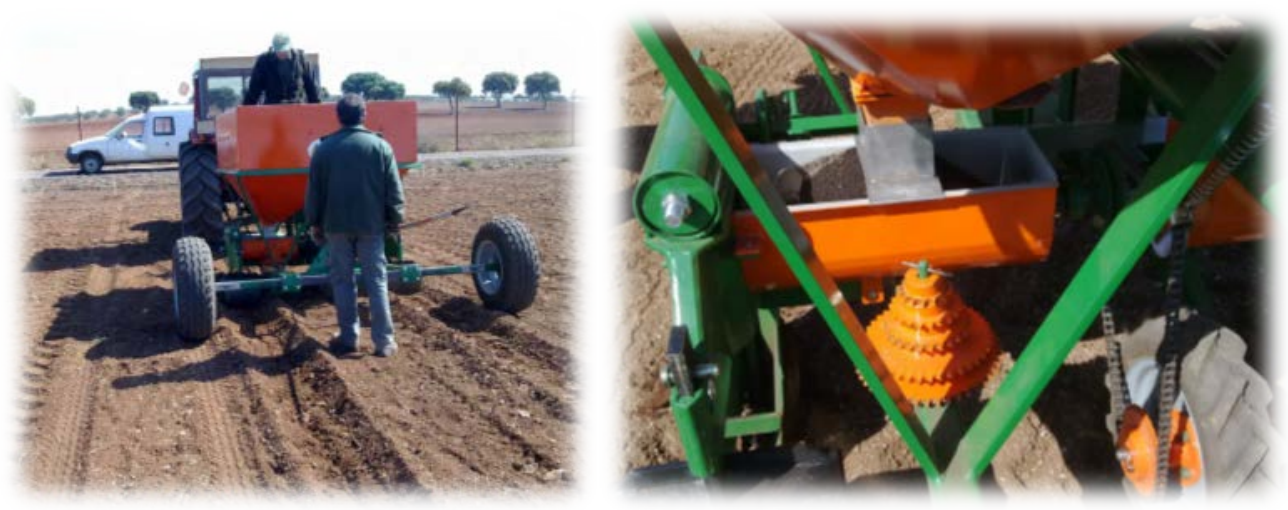

Figura 3.7 Aplicación del compost.

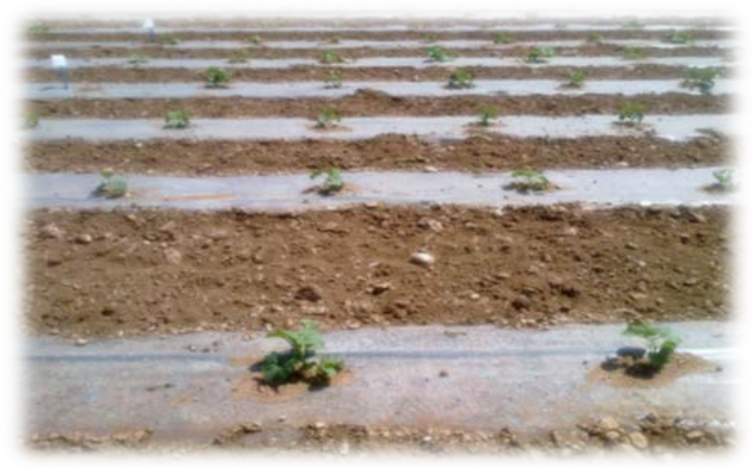

Figura 3.8 Acolchado plástico (polietileno transparente) densidad de 4.444 plantas $h a^{-1}(1,5 \times 1,5 \mathrm{~m})$. 
Se utilizó un diseño de bloques al azar, con cuatro tratamientos, un suelo testigo o control $(C)$ en el que no se aplica enmienda orgánica y suelo con tres dosis diferentes de compost de orujo: Dosis $1\left(D_{1}\right)\left(1 \mathrm{~kg} \mathrm{~m}\right.$ lineal $\left.^{-1}\right)$, Dosis 2 $\left(D_{2}\right)\left(2 \mathrm{~kg} \mathrm{~m}_{\text {lineal }}{ }^{-1}\right)$, y Dosis $3\left(D_{3}\right)\left(3 \mathrm{~kg} \mathrm{~m}\right.$ lineal $\left.{ }^{-1}\right)$, equivalentes a $6,6 \mathrm{tha}^{-1}$, $13,2+h^{-1}$ y $19,8+$ ha $^{-1}$ respectivamente. Cada tratamiento fue repetido cuatro veces en parcelas de $15 \times 12 \mathrm{~m}$. En cada parcela hubo diez filas de plantación con 1,5 $\mathrm{m}$ de separación, con 12 plantas por fila, separadas entre sí por una distancia de 1,5 m (Figura 3.9).

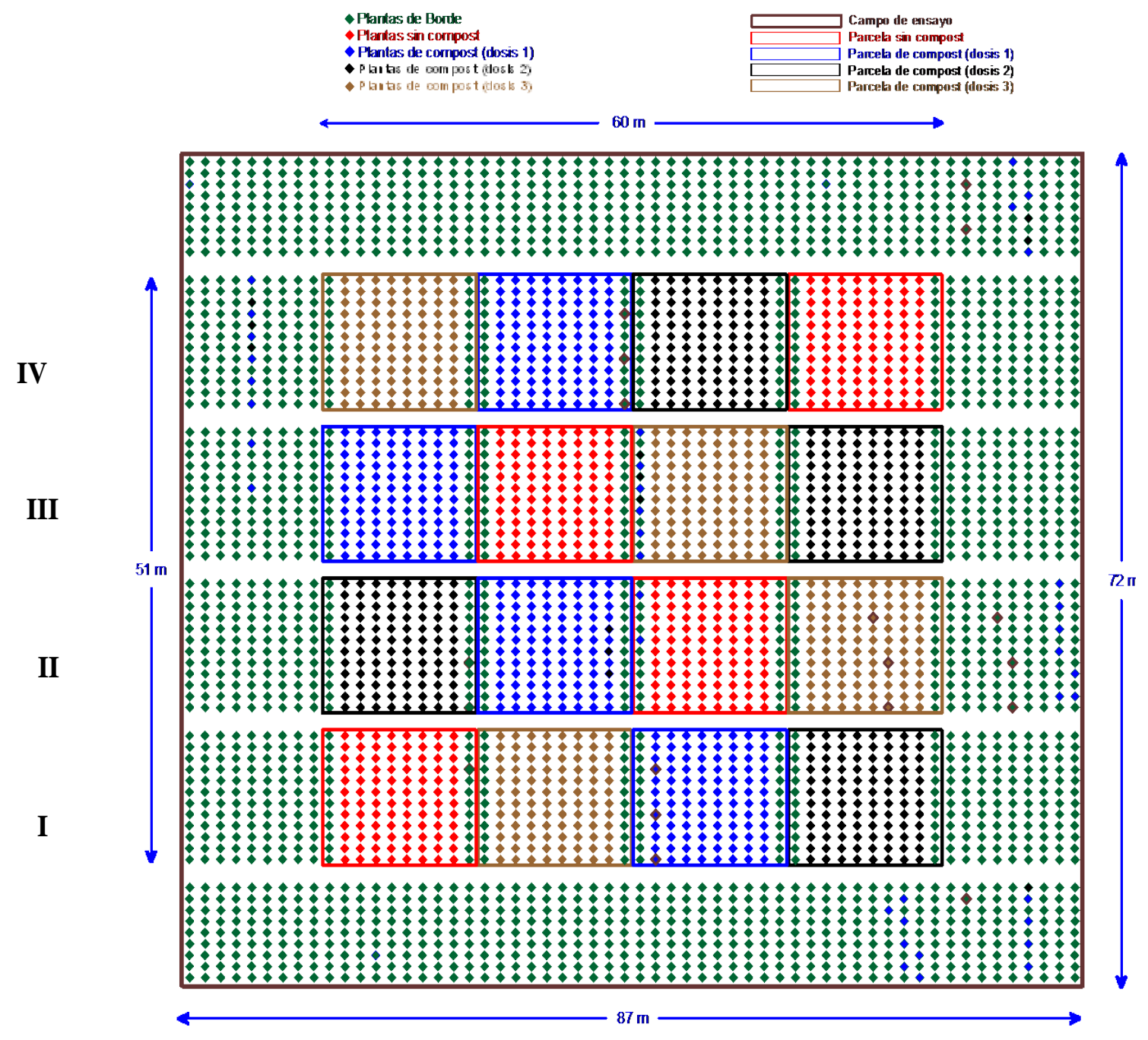

Figura 3.9 Esquema del campo experimental del melón.

El compost utilizado en el experimento es un producto comercial (Agricom Nature) obtenido en una planta de compostaje situada en Socuéllamos 
(Ciudad Real), la cual se abastece de los residuos de las destilerías de todos los alrededores (raspones y orujos agotados) y produce un compost de orujo a través de una degradación aerobia (Figura 3.10).
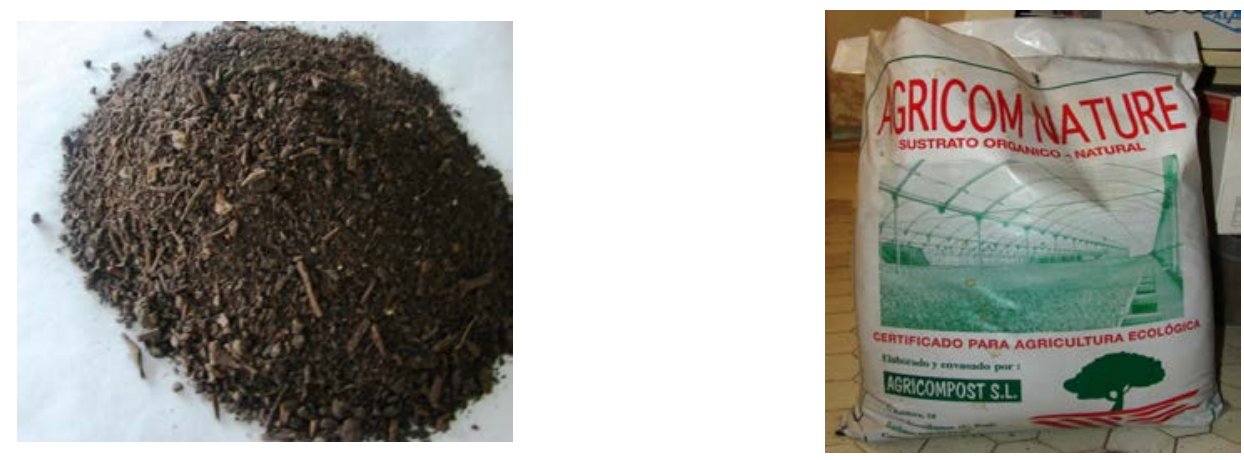

Figura 3.10 Compost de orujo.

Este abono cumple los criterios establecidos por la Legislación española sobre el uso de materiales orgánicos en agricultura. Las principales propiedades del compost utilizado cada año se muestran en la Tabla 3.3.

Tabla 3.3 Características del compost usado los tres años.

\begin{tabular}{|c|c|c|c|}
\hline Parámetros & 2011 & 2012 & 2013 \\
\hline $\mathrm{pH}$ & 9,2 & 9,8 & 9,2 \\
\hline$C E\left(m S \mathrm{~cm}^{-1}\right)$ & 1,2 & 1,0 & 1,2 \\
\hline Materia Orgánica $\left(g \mathrm{Kg}^{-1}\right)$ & 545,0 & 600,0 & 495,0 \\
\hline Relación C/N & 10,1 & 11,2 & 13,5 \\
\hline$N($ kjeldahl $)\left(g \mathrm{Kg}^{-1}\right)$ & 32,9 & 33,0 & 23,0 \\
\hline$N O^{3-}-N\left(g \mathrm{Kg}^{-1}\right)$ & 0,2 & 0,3 & 0,3 \\
\hline $\mathrm{NH}^{4+}-\mathrm{N}\left(m g \mathrm{~kg}^{-1}\right)$ & 1,5 & 1,8 & 1,3 \\
\hline P Total $\left(\mathrm{g} \mathrm{kg}^{-1}\right)$ & 6,8 & 7,6 & 7,6 \\
\hline K Total $\left(\mathrm{g} \mathrm{kg}^{-1}\right)$ & 33,7 & 21,1 & 57,6 \\
\hline Ca Total $\left(\mathrm{g} \mathrm{kg}^{-1}\right)$ & 0,1 & 0,3 & 1,5 \\
\hline Mg Total $\left(g \mathrm{~kg}^{-1}\right)$ & 0,7 & 0,6 & 0,7 \\
\hline Na Total $\left(g \mathrm{~kg}^{-1}\right)$ & 8,3 & 13,0 & 13,9 \\
\hline
\end{tabular}


El agua utilizada fue procedente del sondeo, con las características propias de aguas subterráneas de la zona, por lo que solo con el agua de riego se aplicaron cantidades importantes de nitrógeno $\left(89,132\right.$, y $140 \mathrm{~kg}$ de $\mathrm{N} \mathrm{ha}^{-1}$ los años 2011, 2012 y 2013 respectivamente).

La composición química del agua de riego, se midió semanalmente, y los datos medios anuales obtenidos se recogen en la tabla 3.4 .

Tabla 3.4 Propiedades físico-químicas del agua de riego utilizada en el experimento (Años 2011, 2012, y 2013).

\begin{tabular}{lccc}
\hline $\begin{array}{l}\text { Propiedades del } \\
\text { agua de riego }\end{array}$ & 2011 & 2012 & 2013 \\
\hline $\mathrm{pH}$ & 7,9 & 7,9 & 7,9 \\
$\mathrm{CE}\left(\mathrm{mS} \mathrm{cm}^{-1}\right)$ & 3,1 & 2,9 & 3,3 \\
$\mathrm{NO}_{3}{ }^{-}\left(\mathrm{mg} \mathrm{L}^{-1}\right)$ & 116,0 & 125,0 & 134,5 \\
$\mathrm{NH}_{4}{ }^{+}\left(\mathrm{mg} \mathrm{L}^{-1}\right)$ & 0,1 & 0,1 & 0,1 \\
$\mathrm{SO}_{4}^{-2}\left(\mathrm{mg} \mathrm{L}^{-1}\right)$ & 1233,7 & 1195,5 & 1214,6 \\
$\mathrm{~K}^{+}\left(\mathrm{mg} \mathrm{L}^{-1}\right)$ & 3,6 & 3,5 & 3,5 \\
$\mathrm{Mg}^{2+}\left(\mathrm{mg} \mathrm{L}^{-1}\right)$ & 172,0 & 169,0 & 168,0 \\
$\mathrm{Ca}^{2+}\left(\mathrm{mg} \mathrm{L}^{-1}\right)$ & 300,0 & 275,0 & 270,0 \\
$\mathrm{Cl}^{-}\left(\mathrm{mg} \mathrm{L}^{-1}\right)$ & 203,5 & 188,8 & 194,6 \\
\hline
\end{tabular}

El sistema de riego, consistió en una línea de riego por goteo por cada fila del cultivo, con goteros cada 0,5 $\mathrm{m}$ y un caudal de $2 \mathrm{~L} \mathrm{~h}^{-1}$, similar al utilizado por los agricultores de la zona (Figura 3.11). 


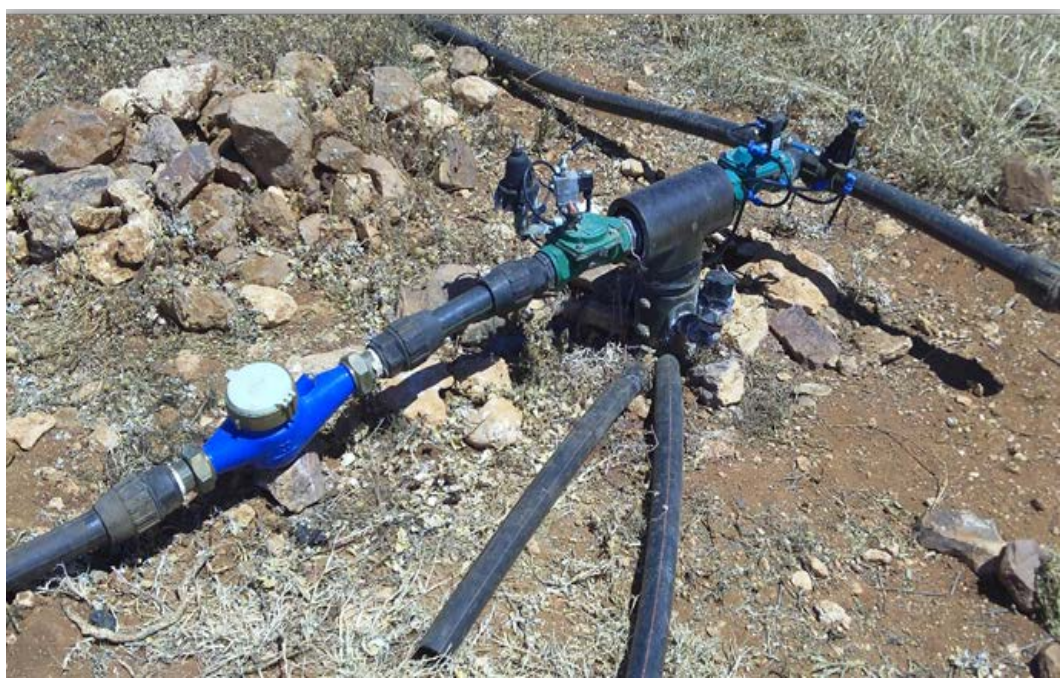

Figura 3.11 Detalle del sistema de riego por goteo.

Inicialmente después del trasplante, todas las parcelas recibieron $28 \mathrm{~mm}$ de agua para facilitar el establecimiento del cultivo. La programación de riego, se calculó desde los 27 hasta los 90 días después del trasplante (DDT) en 2011, desde 20 hasta 97 DDT en 2012, y de 27 a 111 DDT en 2013, con un riego único diario. El agua que se aplicó en cada riego, se calculó semanalmente como la evapotranspiración del cultivo (ETc) de la semana anterior, dividida por la eficacia del sistema que en nuestras condiciones, considerando la tolerancia salina del cultivo, la textura del suelo y la homogeneidad del sistema de riego, se consideró en 0,81 (Rincón and Giménez, 1989). El resultado se dividió por el número de días, para obtener las necesidades de riego diarias. Para asegurar la eficiencia del sistema, todos los riegos fueron incrementados un $23 \%$. Las dosis de riego fueron iguales para todos los tratamientos.

La ETc se calculó diariamente como $E T c=K c \times E T o$ (método de la FAO; Doorenbos and Pruitt, 1977); donde la Kc, es el coeficiente de cultivo, determinada en estudios anteriores en la misma zona para el melón (Ribas et al, 1995), y la ETo es la evapotranspiración de referencia, calculada por el método Penman-Monteith de la FAO (Allen, Pereira, Raes, and Smith, 2002), usando datos diarios de la estación meteorológica que se encuentra a $500 \mathrm{~m}$ del campo experimental. Los datos obtenidos para el ciclo del cultivo fueron $282,1 \mathrm{~mm}$, $386,6 \mathrm{~mm}$ y $410,35 \mathrm{~mm}$ en 2011, 2012 y 2013 respectivamente.

La lluvia efectiva durante el período de crecimiento fue insignificante. El riego total aplicado fue de $341,30 \mathrm{~mm}$ en el primer año, 461,00 mm en el segundo y $487,70 \mathrm{~mm}$ en el tercero. 
Todos los tratamientos también recibieron $120 \mathrm{~kg}$ de $\mathrm{P}_{2} \mathrm{O}_{5} \mathrm{ha}^{-1}$, en forma de ácido fosfórico, que se les inyectó diariamente a través del sistema de riego por goteo, para evitar el atasco de los goteros, desde la tercera semana después del trasplante hasta la última semana de agosto en los tres años. No fue necesaria la aplicación de potasio, debido al alto contenido de este elemento en el suelo (Tabla 3.1).

De forma complementaria, se llevó a cabo durante el período de crecimiento, un programa de control de enfermedades y de insectos de acuerdo con la práctica habitual de gestión, para asegurar que la respuesta a la dosis de $\mathrm{N}$ no se viera afectada por otros factores.

\subsubsection{Cultivo de trigo: Diseño experimental}

En las mismas parcelas donde se realizó el experimento del melón, se sembró trigo (Triticum aestivum L., cv Garcia) de ciclo largo el 20 de noviembre de cada campaña, en líneas espaciadas $0,15 \mathrm{~m}$ y con una densidad de siembra de 400 semillas $\mathrm{m}^{-2}$. Para controlar la aparición de malas hierbas, se utilizaron herbicidas. No se aplicaron fertilizantes ni enmiendas orgánicas, a excepción de la campaña de trigo 2012-2013 en el que se incorporó al suelo, con una abonadora centrifuga $100 \mathrm{~kg} \mathrm{ha}^{-1}$ de urea, con una riqueza del $47 \%$, en nitrógeno para valorar el efecto de la aplicación de un fertilizante inorgánico sobre el efecto residual del compost de orujo.

Debido a las escasas precipitaciones durante los meses del crecimiento del trigo el año 2012 (Figura 3.5), se hizo necesario un riego de apoyo de 130 mm (marzo-abril), para favorecer la fase de encañado y la formación de la espiga. Debido a la alta concentración de nitratos del agua utilizada, esto supuso un aporte de nitrógeno adicional de $34,05 \mathrm{~kg} \mathrm{ha}^{-1}$.

El resto de los años del ensayo, no hizo falta ningún riego adicional al trigo. Por tanto los resultados obtenidos en la campaña 2013-2014, corresponden únicamente al efecto residual del compost de orujo aplicado en el cultivo de melón, sin interferencias de ninguna otra actuación. 


\subsection{Muestreo y análisis realizados}

\subsubsection{Análisis de planta}

\section{> MUESTREO y ANÁLISIS DE PLANTAS DE MELÓN}

Durante la temporada de crecimiento, cuatro plantas de cada tratamiento se muestrearon al azar en cada una de las parcelas experimentales. La recogida se realizó a los 34,41,48,55, 62, 69,76 y 90 días después del trasplante (DDT) en 2011, a los 21, 34, 41, 48, 55, 62, 69, 76, 83 y 90 DDT en 2012 y en $32,39,46,53,60,67,74,81,88$ y 95 DDT en 2013. Las plantas seleccionadas, estuvieron rodeadas en el momento del muestreo, por plantas en cada una de las posiciones colindantes para evitar el efecto frontera. Las hojas, tallos y frutos (cuando estaban presentes) se separaron y se pesaron para obtener el peso fresco. Los pesos secos de hojas, tallos y frutos, se determinaron después de secar a $80^{\circ} \mathrm{C}$ durante $48 \mathrm{~h}$ hasta peso constante

Se midió el área foliar total con un medidor de área foliar (LI-3100C, LICOR, Lincoln, NE).

Se tomaron submuestras del material seco, que fueron molidas, y en las que se determinó el contenido de los distintos nutrientes en las diferentes partes de la planta y fruto en fechas alternas, los tres años.

El nitrógeno se determinó utilizando el método de Kjeldahl (AOAC, 1990). Para la determinación del fósforo y del potasio, las muestras secas se digirieron con ácido nítrico (Havlin and Soltanpour, 1989). En el extracto de las muestras digeridas, se analizó el fósforo por espectrometría de plasma acoplado (ICP), y el potasio por espectrofotometría de absorción atómica de llama. La absorción de $N$ y $P$ por cada órgano, se obtuvo como el producto de la concentración de $N$ y $P$ por la biomasa seca. La absorción de $N$ y $P$ de la planta de melón, se calculó como la suma de las absorciones de $\mathrm{N}$ y $\mathrm{P}$ de cada órgano.

Los melones se cosecharon cuando había una cantidad significativa de fruta madura en el campo, lo que ocurrió los dos primeros años a mediados de agosto, y a finales de éste mes el año 2013.

Las cosechas se realizaron semanalmente y comenzaron a los 75, 78 y 91 días después del trasplante (DDT), en 2011, 2012 y 2013, respectivamente, cuando los frutos estaban totalmente maduros. En cada cosecha, los frutos de melón se pesaron individualmente y se calculó el rendimiento total por hectárea. 
Para cada cosecha, se analizaron cuatro frutos comerciales representativos de cada repetición, para medir los parámetros de calidad de la fruta. La firmeza de la carne,se midió en cuatro zonas de la superficie ecuatorial en un corte usando un Penefel (Agro-Technologie, Tarascón, Francia), con una punta de $0,5 \mathrm{~cm}^{2}$ de diámetro. El índice de pulpa (IP), se calculó utilizando la fórmula: $2 \times$ grosor de pulpa $\times$ Anchura $^{-1}$. En el extracto líquido obtenido al licuar el mesocarpio de cada fruta, se determinó el contenido total de sólidos solubles (TSS), mediante un refractómetro Atago de mano, siendo expresado como ${ }^{\circ} \mathrm{Brix}$.

\section{> MUESTREO y ANÁLISIS DE LAS PLANTAS DE TRIGO}

El trigo fue sembrado en las parcelas anteriormente ocupadas por el melón. Cada año, se seleccionó un transecto (Figura 3.12) del campo de trigo perpendicular a las líneas de riego, que incluía cuatro parcelas con los distintos tratamientos utilizados en el cultivo de melón, marcando su posición con una estaca al inicio del cultivo, con un historial de tratamiento diferente cada año.

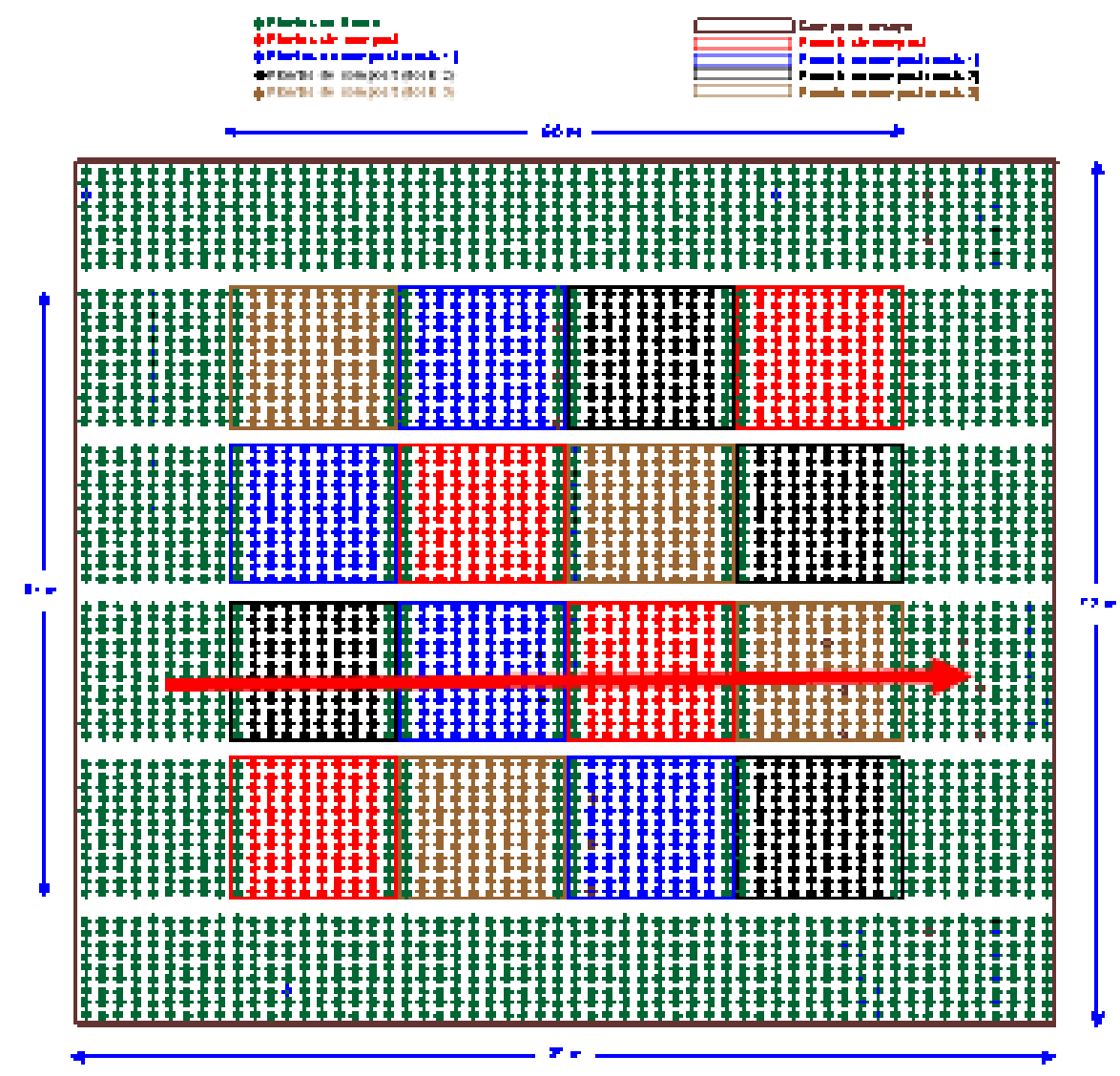

Figura 3.12 Esquema campo experimental. Transecto de estudio. 
El trigo se cosechó, el 20 de junio de 2012, el 22 de julio de 2013 y el 14 de julio de 2014, respectivamente, en secciones consecutivas a lo largo del transecto. Cada $0,5 \mathrm{~m}$ se colocó un septo de $(0,5 \times 0,5) \mathrm{m}^{2}$ (Figura 3.13), recogiendo un total de 128 muestras. Las bolsas conteniendo el trigo de cada septo, se guardaron debidamente etiquetadas para su posterior análisis en el laboratorio del Dpto. de Química y Tecnología de Alimentos de la E.T.S.I.A.A.B.

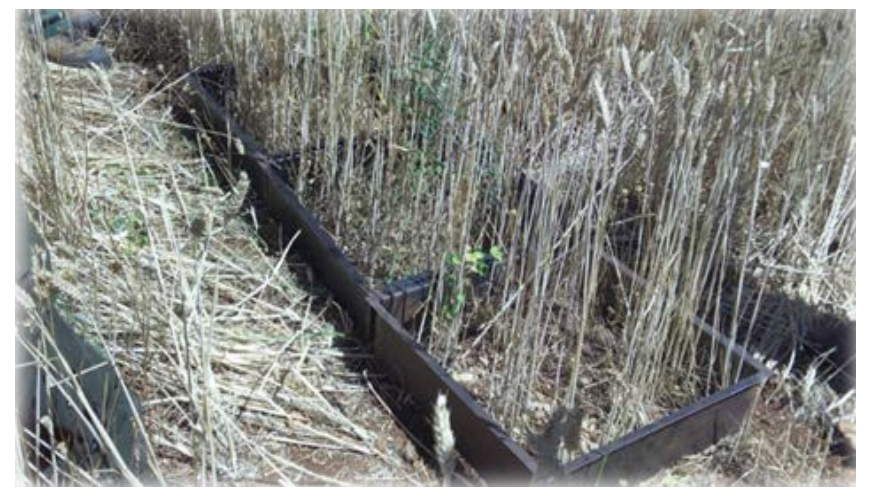

Figura 3.13 Toma de muestras del trigo a lo largo del transecto.

En cada una de las muestras obtenidas, se separó el grano de la planta, obteniéndose el peso seco de grano y de biomasa, tras secar en horno a $80^{\circ} \mathrm{C}$ hasta peso constante. El nitrógeno absorbido por el grano se determinó por el método Kjeldahl (Association of oficial Analytical Chemists, 1990).

\subsubsection{Análisis de suelo}

Las muestras de suelo fueron tomadas al inicio, antes de la aplicación de compost, y después de la aplicación de éste, así como al final del ensayo, en cada una de las parcelas elementales de abonado en la capa arable del suelo (0-30 $\mathrm{cm}$ ).

Después de cosechar el melón, se recogieron un total de 16 muestras; una muestra por parcela que está compuesta de 4 submuestras recogidas en diferentes puntos de la parcela (siempre en la línea de riego del melón). A continuación, se preparó el suelo removiéndolo con un cultivador antes de sembrar el trigo y se hizo el muestreo del suelo. 
Las caracterizaciones de cada muestra de suelo se realizaron por triplicado. Para determinar su contenido en $N$ mineral y $P$ en sus diferentes formas, se secaron al aire, molieron, tamizaron ( $<2 \mathrm{~mm}$ ) y cuartearon, con el fin de obtener una submuestra lo más homogénea posible.

Para la determinación de $\mathrm{NO}_{3}^{-}$y $\mathrm{NH}_{4}{ }^{+}$, las muestras se extrajeron con agua desionizada y $\mathrm{KCl} 1 \mathrm{M}$ respectivamente, y en los extractos se analizó el $\mathrm{NO}_{3}{ }^{-}$con electrodo selectivo y la concentración de $\mathrm{NH}_{4}{ }^{+}$por colorimetría. EI $\mathrm{P}$ disponible del suelo ( $P$ Olsen) se determinó mediante extracción con $\mathrm{NaHCO}_{3}$ $(0,5 \mathrm{M})$ a pH 8,5, (Olsen et al., 1954) y posterior detección por el método espectrofotométrico de Murphy and Riley (1962). La materia orgánica usando el método descrito por Hesse (1971), el N Kjeldahl por el método descrito por Bremer (1996), el potasio y sodio por fotometría de llama (Emisión) (Pratt, 1965), el calcio y magnesio por espectrofotometría de absorción atómica (MAPA, 1994), el pH en extracto acuoso (1:2,5, p/v) (MAPA, 1994) y la Conductividad eléctrica en extracto acuoso (1:5, p/v) (MAPA, 1994).

\subsubsection{Análisis del compost de orujo}

El contenido del compost de orujo de $\mathrm{N}$ total, nitrógeno disponible (nitratos y amonio), la materia orgánica, $\mathrm{K}, \mathrm{Na}, \mathrm{Ca}$ y $\mathrm{Mg}$, se determinó siguiendo la misma metodología que la utilizada en suelos, al igual que el $\mathrm{pH}$ y conductividad eléctrica (apartado 3.3.2).

El contenido en carbono orgánico soluble (COS) se determinó por oxidación con dicromato y valoración con sulfato amónico ferroso.

El contenido en $P$ total, $P$ inorgánico y orgánico del compost de orujo, se determinó por el método SMT (Ruban et al., 2011). El $P$ disponible ( $P$ labil), aplicando el protocolo secuencial de extracción de Huang et. al., (2008) a partir de una única muestra inicial, analizando el $P$ contenido en las primeras fracciones extraídas: P extraído con agua, con membrana iónica y con $\mathrm{NaHCO}_{3}$.

La determinación de fósforo en los extractos recogidos en cada fase de los procesos de extracción, se realizó mediante el método de azul de molibdeno de Murphy and Riley (1962) empleando un espectrofotómetro Ultra-violeta Visible de doble haz (Lambda 2000, Perkin Elmer). 


\subsubsection{Análisis del agua de riego}

El contenido en nutrientes del agua de riego, se midió semanalmente para su cuantificación. Los parámetros analizados en el agua de riego así como la metodología empleada, se muestran en la Tabla 3.5.

Tabla 3.5 Análisis realizados en el agua de riego utilizada en el experimento (Años 2011, 2012, y 2013).

\begin{tabular}{|l|l|}
\hline Parámetro & Metodología \\
\hline $\mathrm{pH}$ y Conductividad eléctrica & APHA; AWWA; WPCF, 1989 \\
\hline $\mathrm{NO}_{3}{ }^{-}$ & Electrodo selectivo \\
\hline $\mathrm{NH}_{4}{ }^{+}$ & Colorimetría \\
\hline $\mathrm{Cl}^{-}$ & Método de Mohr (APHA, 1998) \\
\hline $\mathrm{SO}_{4}{ }^{2-}$ & Gravimetría (AENOR, 1998) \\
\hline $\mathrm{Ca}^{2+}$ y Mg & \\
\hline $\mathrm{K}^{+}$ & Volumetría (APHA; AWWA; WPCF, 1989). \\
\hline
\end{tabular}

\subsubsection{Análisis de drenaje y lixiviados}

En cada parcela elemental de abonado, se instaló un tubo de $60 \mathrm{~cm}$ de

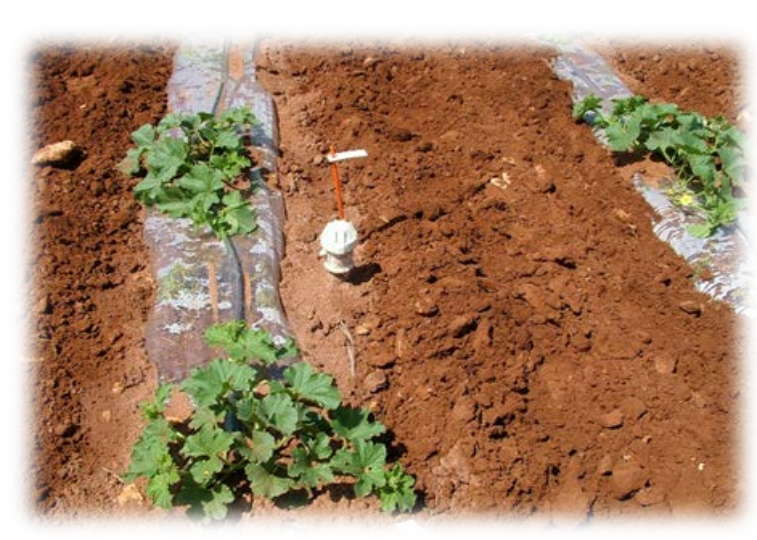

Figura 3.14 Colocación de las sondas Diviner 200 (FDR) en las parcelas. profundidad para el acceso a la sonda Diviner 200 (FDR). Los tubos se colocaron en el centro de cada parcela, entre dos plantas consecutivas y trasversales a la línea de riego, a una distancia de $37,5 \mathrm{~cm}$ (Figura 3.14).

Las medidas se realizaron semanalmente, midiéndose el contenido volumétrico del agua del suelo a intervalos de $10 \mathrm{~cm}$ de 
profundidad, cuantificando la reserva de agua, para finalmente determinar el drenaje mediante el siguiente balance de agua (Doorenbos and Pruitt, 1977).

$$
D=R b+P-E T c-R f \pm \Delta S
$$

Donde $D$ es el drenaje, $R b$ es el riego bruto, $P$ la precipitación, $R f$ es la escorrentía superficial, la cual fue despreciable y $\Delta S$ es la variación en el contenido volumétrico de agua en el suelo, entre dos semanas consecutivas a $0,60 \mathrm{~m}$ de profundidad.

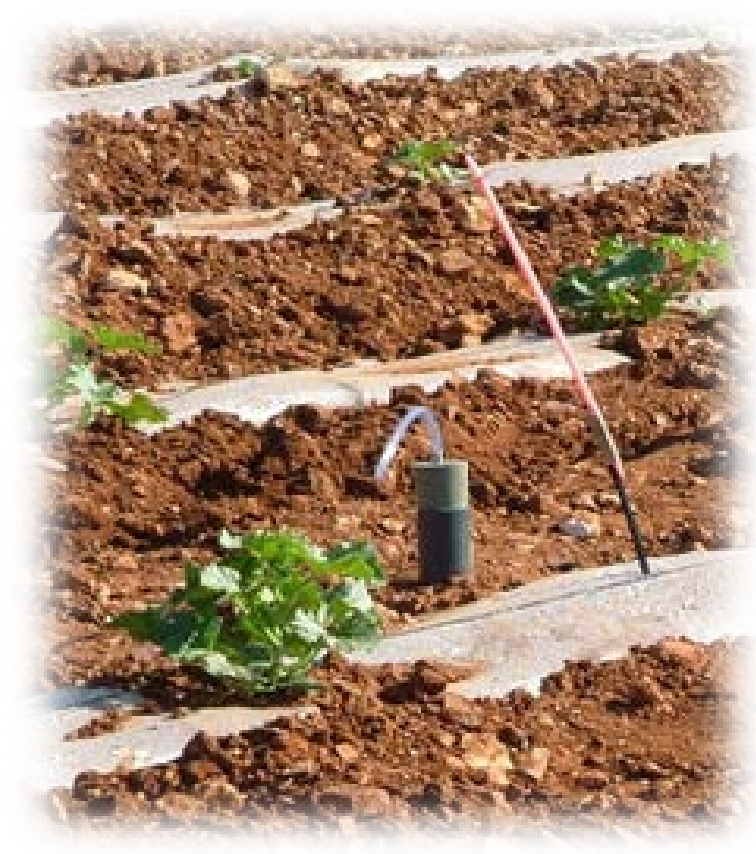

Figura 3.15 Ubicación de las cañas de succión en las parcelas.

Del mismo modo en cada parcela, se instaló una caña de succión (Figura 3.15) en el centro, entre dos plantas consecutivas y a $0,375 \mathrm{~m}$ de la línea de riego (Castellanos et al., 2013), provista de una cápsula cerámica para la recogida de muestras de solución líquida del suelo, a $60 \mathrm{~cm}$ de profundidad. Semanalmente, se recogió la solución del suelo con una bomba, aplicando 0,7 bar de succión, y se analizó, su contenido en nitratos y amonios.

El lavado de nitratos por debajo de $60 \mathrm{~cm}$ de profundidad se calculó, multiplicando el drenaje por la concentración media de nitratos en cada fecha en la solución del suelo. El lavado de $\mathrm{P}$ se desestimó, debido a las características del suelo ( $\mathrm{pH}$ básico) que hacen que el $P$ tienda a fijarse en la matriz del suelo ligándose al hierro, al aluminio y al calcio, no produciéndose perdidas por lixiviación.

\subsubsection{Balance de nitrógeno y de fósforo en campo en el sistema suelo-planta}

Para aumentar la información de la biodisponibilidad del $N$ y $P$ en el suelo tras la aplicación de las diferentes dosis de compost, se han llevado a cabo los balances de ambos elementos en el sistema suelo-planta, teniendo en cuenta las cantidades de estos nutrientes que entran en el sistema por las distintas 
fuentes: contenido inicial del suelo $\left(N_{\text {suelo inicial }}, P_{\text {suelo inicial }}\right)$, nutrientes aportados por el compost(en el caso del $P$, el fósforo lábil disponible para el cultivo) y el agua de riego $\left(N_{A}, P_{A}\right)$ y las cantidades que salen: cantidad extraída por el cultivo $\left(U_{N}, U_{P}\right)$, lo que queda en el suelo al final del ciclo del cultivo $\left(N_{\text {suelo final, }}\right.$ $P_{\text {suelo final }}$ ) y las pérdidas por lixiviación $\left(N_{1}\right)$, todos ellos expresados en $\mathrm{Kg} \mathrm{ha}^{-1}$.

$$
\Delta=U_{N}+N_{1}+N_{g}+N_{\text {suelo final }}-N_{A}-N_{\text {suelo inicial }}
$$

En el caso del nitrógeno, las pérdidas gaseosas producidas por desnitrificación $\left(\mathrm{N}_{g}\right)$ se han considerado despreciables (Sánchez-Martín et al., 2008). En el caso del P, se han despreciado las pérdidas producidas por lixiviación.

A partir de los balances, se ha obtenido el nitrógeno orgánico mineralizado durante el ciclo del cultivo (NM) y en el caso del fosforo, la cantidad de este elemento que queda disponible al final del ciclo del cultivo en el suelo, como consecuencia de su movilización e interconversión (PM). Se ha calculado el índice de mineralización de nitrógeno (NMI) (Castellanos et al., 2013) como la relación entre el nitrógeno mineralizado y el nitrógeno disponible.

$$
N M I=\frac{N M}{N d}
$$

3.3.7. Indices utilizados para el estudio del comportamiento del compost de orujo en el cultivo de melón

\subsubsection{Indices de crecimiento}

Los índices de crecimiento utilizados se recogen en la tabla 3.6. 
Tabla 3.6 Índices de crecimiento (Hunt, 1982).

\begin{tabular}{|c|c|c|c|c|}
\hline \multicolumn{2}{|l|}{ Tipo de indice } & $N^{0}$ & Ecuaciones & Unidades \\
\hline $\begin{array}{l}\text { índice de área foliar } \\
\text { "Leaf area index" }\end{array}$ & LAI & 1 & $L A I=\frac{L A}{S}$ & $m^{2} m^{-2}$ \\
\hline $\begin{array}{l}\text { la duración del área foliar } \\
\text { "Leaf area duration" }\end{array}$ & LAD & 2 & $L A D_{t}=L A D_{t-1}+\frac{\left(L A I_{t}+L A I_{t-1}\right) * n}{2}$ & días \\
\hline $\begin{array}{l}\text { El área foliar específica } \\
\text { "Specific leaf area" }\end{array}$ & SLA & 3 & $S L A_{t}=\frac{L A}{W_{h}}$ & $\mathrm{~cm}^{2} \mathrm{~g}^{-1}$ \\
\hline $\begin{array}{l}\text { la relación de peso Foliar } \\
\text { "Leaf weight relation" }\end{array}$ & LWR & 4 & $L W R_{t}=\frac{W_{h}}{W_{p t}}$ & $g$ hoja $g$ planta $^{-1}$ \\
\hline \multirow{2}{*}{$\begin{array}{l}\text { la razón de área foliar } \\
\text { "Leaf area ratio" }\end{array}$} & \multirow[t]{2}{*}{ LAR } & 5 & $L A R_{t}=\frac{L A}{W_{p t}}$ & \multirow[t]{2}{*}{$\mathrm{cm}^{2} \mathrm{~g}^{-1}$} \\
\hline & & 6 & $L A R_{t}=S L A_{t}^{*} L W R_{t}$ & \\
\hline $\begin{array}{l}\text { la velocidad del crecimiento } \\
\text { de la hoja "Leaf growth rate" }\end{array}$ & LGR & 7 & $L G R_{t}=\frac{S L A * W_{h}}{t}$ & $\mathrm{~cm}^{2} \mathrm{~m}^{-2} \mathrm{di}^{-1}$ \\
\hline $\begin{array}{l}\text { la tasa de asimilación neta } \\
\text { "Net assimilation rate" }\end{array}$ & NAR & 8 & $N A R_{t}=\frac{\left(W_{t}-W_{t-1}\right)}{t-(t-1)} * \frac{\left(L n L A_{t}-L n L A_{t-1}\right)}{L A_{t}-L A_{t-1}}$ & $g m^{-2} d i^{-1}$ \\
\hline \multirow{2}{*}{$\begin{array}{c}\text { la velocidad de crecimiento } \\
\text { relativo "Relative growth } \\
\text { rate" }\end{array}$} & \multirow[t]{2}{*}{ RGR } & 9 & $R G R_{t}=\frac{\left(\ln W_{t}-\ln W_{t-1}\right)}{t-(t-1)}$ & \multirow[t]{2}{*}{$m g g^{-1} d^{d i} a^{-1}$} \\
\hline & & 10 & $R G R_{t}=L A R_{t}^{*} N A R_{t}$ & \\
\hline \multirow{2}{*}{$\begin{array}{l}\text { la velocidad de crecimiento } \\
\text { del cultivo "Crop growth } \\
\text { rate" }\end{array}$} & \multirow[t]{2}{*}{ CGR } & 11 & $\operatorname{CQR}_{t}=\frac{\left(W_{t}-W_{t-1}\right)}{t-(t-1)} * \frac{1}{S}$ & \multirow[t]{2}{*}{$g m^{-2} d i a^{-1}$} \\
\hline & & 12 & $C G R_{t}=L A I_{t} * N A R_{t}$ & \\
\hline $\begin{array}{l}\text { la velocidad de crecimiento } \\
\text { del fruto "Fruit growth rate" }\end{array}$ & FGR & 13 & $F G R_{t}=\frac{\left(W_{t}-W_{t-1}\right)}{t-(t-1)}$ & $g m^{-2} d i a^{-1}$ \\
\hline
\end{tabular}

El índice de área foliar (LAI o IAF) fue calculada, dividiendo el área foliar total por el área de suelo disponible para una planta $\left(2,25 \mathrm{~m}^{2}\right)$. La duración del área foliar en todo el intervalo de cosecha (LAD) ( $t-1$ a $t$ ), se calculó mediante la ecuación (1), donde: $L A D_{+}$es $L A D$ calculado en el momento de la cosecha ( $t), L A D_{t-1}$ es LAD calculado en el momento de la cosecha anterior $(t-1), n$ es el período de tiempo (días) entre dos cosechas sucesivas [ $t-(t-1)]$.

Se calcularon: el área foliar específica (SLA), como la relación entre el área foliar y el peso de hoja expresado en $\left(\mathrm{cm}^{2} \mathrm{~g}^{-1}\right)$, la relación de peso foliar (LWR), como la relación entre la biomasa de las hojas y la de la planta expresado en (g hoja $g$ planta $^{-1}$ ) y la razón de área foliar (LAR), como la relación entre el área foliar y el peso total de la planta expresado en $\left(\mathrm{cm}^{2} \mathrm{~g}^{-1}\right)$ 
aunque este último parámetro también se puede calcular como relación de (SLA) $y$ (LWR) mediante la ecuación (6).

La velocidad de crecimiento de la hoja ( $L G R$ ), se calculó para todo el intervalo de cosecha mediante la ecuación (7), donde: SLA es SLA calculado en el momento de la cosecha ( $t), W_{h t}$ es el peso seco de la hoja en el momento de la cosecha $(t)$ en $\left(\mathrm{g} \mathrm{m}^{-2}\right), W_{h t-1}$ es el peso seco de la hoja a en la cosecha anterior, $t$ es el período de tiempo (días) entre dos cosechas sucesivas [t-(t-1)]. Se expresa en $\left(\mathrm{cm}^{2} \mathrm{~m}^{-2}\right.$ día $\left.^{-1}\right)$.

EI NAR o tasa de asimilación neta, representa la eficacia fotosintética de las hojas, y se define como el incremento en peso de la planta por unidad de área foliar, ( $\mathrm{g} \mathrm{m}^{-2} \mathrm{di}^{-1}$ ). Se calculó mediante la ecuación (8), donde: LA+ es LA medido en el momento de la cosecha $(t), L A_{t-1}$ es $L A$ medido en el momento de la cosecha anterior ( $t-1), W_{\mathrm{ptt}}$ es el peso seco de la planta entera en el momento de la cosecha ( $t), W_{\text {ptt-1 }}$ es el peso seco de la Planta entera en la cosecha anterior, $Y[t-(t-1)]$ es el período de tiempo (días) entre dos cosechas sucesivas.

La velocidad de crecimiento del cultivo, se puede calcular con dos índices distintos: La velocidad de crecimiento relativo (RGR), que es la ganancia de biomasa por unidad de biomasa y tiempo ( $m g g^{-1}$ día $^{-1}$ ) y que a la vez, se puede calcular de dos maneras distintas (ecuaciones 9 y 10) o la velocidad de crecimiento del cultivo (CGR), que se expresa en ( $\mathrm{g} \mathrm{m}^{-2} \mathrm{dia}^{-1}$ ) (ecuaciones 11 y 12). En nuestro caso se han utilizado las ecuaciones 9 y 11.

La velocidad de crecimiento del fruto $(F G R)\left(\mathrm{g} \mathrm{m}^{-2}\right.$ día $\left.{ }^{-1}\right)$, se calculó para todo el intervalo de cosecha mediante la ecuación (13), donde: $W_{f t}$ es el peso seco de fruto en el momento de la cosecha ( $t), W_{f t-1}$ es el peso seco de fruto en la cosecha anterior, $[t-(t-1)]$ es el período de tiempo (días) entre dos cosechas sucesivas y $S$ el área que ocupa una planta $\left(\mathrm{m}^{2}\right)$.

\subsubsection{2. Índices de eficiencia del uso del nitrógeno y del fósforo}

La cantidad de nutriente suministrado, se puede expresar en forma de nutriente aplicado $\left(N_{A}, P_{A}\right)$ o bien disponible $\left(N_{d}, P_{d}\right)$. El término de nutriente aplicado, es la suma del aportado por el agua de riego y por el fertilizante, en nuestro caso el compost de orujo. El nutriente disponible para el cultivo de melón, se calcula como suma del nutriente aplicado en forma disponible, más el mineral que aporta el suelo al inicio del experimento. 
La evaluación de la eficiencia de uso del fósforo es complicada, debido fundamentalmente, a la complejidad de las diferentes formas de $P$ disponible en el suelo y su interconversión. Para el cálculo de los índices de eficiencia de $P$, se han utilizado las mismas ecuaciones que en el caso del nitrógeno (Tabla 3.7).

En la tabla 3.7, se muestra un resumen de los índices utilizados en este trabajo y que proporcionan información de cómo el cambio de una variable externa al cultivo, en nuestro caso la aplicación de compost de orujo, puede afectar a la eficiencia del uso de los nutrientes.

Tabla 3.7 Índices utilizados para el cálculo de la eficiencia del uso del $N$ y del $P$ en el sistema suelo planta en los años 2011, 2012 y 2013.

\begin{tabular}{|l|c|}
\hline \multicolumn{1}{|c|}{ Tipo de indice } & Ecuaciones \\
\hline Factor parcial de productividad de aplicación del nutriente (PFP) & $P F P=\frac{Y_{A}}{N_{A}}$ \\
\hline Eficacia agronomica de aplicación del nutriente (AE) & $A E=\frac{Y_{A}-Y_{0}}{N_{A}}$ \\
\hline Eficiencia de Utilización interna del nutriente (IE) & $\mathrm{IE}=\frac{\mathrm{Y}_{\mathrm{A}}}{\mathrm{U}_{N}}$ \\
\hline La eficacia de uso de un nutriente basado en la biomasa total (TBNUE) & $T B N U E=\frac{Y_{T A}}{N_{d}}$ \\
\hline Eficiencia de la absorcion del nutriente (NUpE) & $N U_{p E}=\frac{U_{N}}{N_{d}}$ \\
\hline La eficacia de recuperación de la aplicación del nutriente (RE) & $R E=\frac{U_{N}-U_{0}}{N_{A}} * 100$ \\
\hline Indice de cosecha de un nutriente (NHI) & $N H I=\frac{U_{N F}}{U_{N}} * 100$ \\
\hline
\end{tabular}

Donde $\mathrm{Y}_{\mathrm{A}}$ es la producción de melón obtenida con los distintos tratamientos, $Y_{O}$ es la producción de melón obtenida con el control, $Y_{T A}$ es la producción de biomasa total de la planta, $N_{A}$ es la cantidad total de nutriente aplicado ( $N$ y $P$ ), Nd es la cantidad total de nutriente disponible ( $N$ y $P$ ) aportado por las diferentes fuentes, $U_{N}$ y $U_{0}$ son la cantidad de nutriente ( $N$ y $P$ ) absorbido por el cultivo con y sin aplicación de compost, $U_{N F}$ nutriente total (nitrógeno y fosforo) absorbido por el fruto con aportación de compost. Todos los datos se expresan en $\mathrm{kg} \mathrm{ha}^{-1}$, por lo que las unidades de los índices son $\mathrm{kg}$ $\mathrm{kg}^{-1}$ excepto RE y NHI que se expresan en porcentaje. 
El factor parcial de productividad de un nutriente ( $x$ ) (PFP), también llamado por Moll et al. (1982) eficiencia agronómica del uso del nutriente (AgNUE), se calcula como los kilogramos de producto obtenidos $\left(Y_{X}\right)$ por kilogramo de nutriente aportado $\left(N_{A}\right)$ (Dobermann, 2005 y 2007; Roberts, 2015; Syers et al., 2008).

$$
P F P=\frac{Y_{X}}{N_{A}}
$$

La eficiencia agronómica de la aplicación de un nutriente $(x)(A E)$, se define como: los $\mathrm{Kg}$ incrementados de producción con respecto al control, por $\mathrm{Kg}$ de nutriente aportado (Dobermann, 2005 y 2007; Roberts, 2015; Syers et al., 2008).

$$
N U E=\frac{Y_{A}-Y_{0}}{N_{A}-N_{0}}
$$

La eficiencia de utilización de un nutriente (IE) (Dobermann, 2007), se calcula como la razón entre la producción total del cultivo y el nutriente absorbido por el cultivo $\left(U_{x}\right)$, y nos informa de la habilidad de la planta para transformar los nutrientes adquiridos de las diversas fuentes (suelo, fertilizante y conpost), consiguiendo un rendimiento económico (Dobermann, 2007).

$$
I E=\frac{Y_{x}}{U_{x}}
$$

Si el valor de este índice es muy alto, se podría estar produciendo un déficit de ese nutriente, y si por el contrario su valor es bajo, la conversión interna del nutriente en la planta no está siendo la adecuada, seguramente debido a algún tipo de estrés (sequia, exceso de calor, exposición a algún mineral toxico, deficiencia en algún nutriente etc...) (Dobermann, 2007).

La eficiencia del uso del nutriente $(x)$ basado en la biomasa total (TBNUE), se define como la producción de biomasa total del cultivo por unidad de nitrógeno disponible (Craswell and Godwin, 1984 y Lammerts and Struik, 2017). 


$$
N F P=\frac{Y_{A}}{N_{A}} * 100
$$

La eficiencia de la Absorción de un nutriente (NUpE), se calcula como el total del nutriente absorbido por el cultivo por unidad de nutriente disponible en el suelo (Lammerts and Struik, 2017).

$$
N U p E=\frac{U_{x}}{N_{d}}
$$

La eficiencia de recuperación aparente de un nutriente $(x)(R E)$, se define como el incremento en la absorción del nutriente por kg de nutriente aplicado (Dobermann, 2005 y 2007; Roberts, 2015; Syers et al., 2008 y Fageria et al., 2005). Este índice depende de la congruencia entre la demanda de $\mathrm{N}$ por la planta, y la cantidad de nitrógeno disponible del $\mathrm{N}$ aplicado. Su valor se ve afectado tanto por el método de aplicación (cantidad, distribución colocación y forma del $\mathrm{N}$ aplicado), como por factores que dependen del cultivo (Dobermann, 2005 y 2007 y Fageria et al., 2005).

$$
R E=\frac{U_{N}-U_{0}}{N_{A}} * 100
$$

El índice de cosecha de un nutriente (NHI), es la relación entre el nutriente absorbido por la cosecha (fruto) respecto al nutriente absorbido por la planta completa (Masclaux-Daubresse et al., 2010; Ciampitti and Vyn, 2013 and Lammerts and Struik, 2017).

$$
N H I=\frac{U_{x F}}{U_{x}} * 100
$$




\subsubsection{3. Índices de eficiencia del uso del uso del agua}

La eficiencia del uso del agua (WUE), es la relación entre la producción de fruto (FY) y el agua utilizada para conseguir dicha producción. Para estimar el agua gastada durante el cultivo, se usa la ETc, como valor estimado del riego.

$$
W U E=\frac{F Y}{E T c}
$$

El sistema de riego, afecta a la homogeneidad y a la cantidad de agua que finalmente está disponible para el cultivo. Además, en esta zona, el alto contenido en sales hace que sea necesaria la aplicación de un exceso de agua para lavar las mismas. Se define la eficiencia de uso del agua de riego como

$$
\text { IRRWUE }=\frac{F Y}{\text { Riego }}
$$

Aunque este índice se puede calcular en función de la cantidad de agua de riego más la precipitación, en nuestro caso dicha precipitación fue despreciable.

\subsubsection{4. Índices ambientales en zonas vulnerables}

El índice de impacto (II) e índice de impacto ambiental (EII), están relacionados con el contenido en nitratos en el lixiviado (Castellanos et al., 2013). El primero de ellos, indica el exceso de la concentración de nitratos respecto al valor límite establecido por la Normativa Europea, $50 \mathrm{mg} \mathrm{L}^{-1}$.

$$
I I=\frac{[\text { Nitratos }] \text { lixiviado }}{50}
$$

El segundo índice de impacto ambiental (EII), indica como en nuestro caso la aplicación del compost minimiza o no la contaminación existente en el agua subterránea. 


$$
\mathrm{EII}=\frac{[\text { Nitratos }] \text { lixiviado }}{[\text { Nitratos] agua de riego }}
$$

Por último, la eficiencia de manejo (ME), que incluye aspectos económicos y ambientales, se calcula como la relación entre la producción de fruto y la cantidad de $\mathrm{N}$ lixiviado a lo largo del ciclo del cultivo.

$$
M E=\frac{F Y}{\text { Nlix }}
$$

\subsubsection{Análisis estadístico}

Los datos obtenidos en el experimento de melón fueron analizados estadísticamente, cada año por separado, usando el test de ANOVA. En el caso de obtener diferencias significativas $(p \leq 0,05)$ y $(p \leq 0,01)$, se utilizó el Test Tukey de comparación de medias. Las regresiones lineales y cuadráticas, se representaron usando el software de análisis estadístico SPS. Para determinar las relaciones existentes entre los diversos índices de crecimiento, calculados para el cultivo de melón, se usaron los coeficientes de correlación de Pearson.

Para poder dilucidar la influencia del tratamiento previo del compost de orujo a diferentes dosis en el cultivo de melón, en la distribución espacial y la dependencia espacial y de escala del trigo, se siguió la metodología propuesta por Tarquis et al. (2017), que estudió la dependencia de escala y espacial de la variabilidad del nitrógeno del suelo, utilizando entropías relativas $E(\delta)$ por su simplicidad (ecuación 1).

$$
E(\delta)=-\sum_{i=1}^{n(\delta)} \mu_{i}(\delta) \ln \left[\mu_{i}(\delta)\right]+\ln \frac{\delta}{L}
$$

El primer término representa la entropía $S(\delta)$ (ecuación 2 ) siendo $\mu_{i}(\delta)$ la distribución normalizada de la probabilidad de una variable, que varía con la escala (ecuación 3).

$$
S(\delta)=-\sum_{i=1}^{n(\delta)} \mu_{i}(\delta) \ln \left[\mu_{i}(\delta)\right]
$$




$$
\mu_{i}(\delta)=\frac{\sum_{j=(i-1) \delta+1}^{i \delta} x_{j}}{\sum_{i=1}^{L} x_{j}}
$$

El segundo término es la entropía de una media uniforme (ecuación 4)

$$
\ln \frac{\delta}{L}
$$

siendo $\delta=2^{k}, \quad$ donde $k=1,2, \ldots, n \quad y L=2^{n}$

Se realizó un análisis multiescala a través de la entropía relativa $(E(\delta))$ para normalizar las diferencias existentes en la entropía, considerando un segmento de cuadrícula de longitud que cubre una parte del transecto $(\delta)$ para el segmento de longitud elegido o distancia equivalente ( $q$ ) del total de la longitud del transecto $(64 \mathrm{~m})$, de manera que los intervalos consecutivos sean la mitad que el anterior (figura 3.16) (Tarquis et al., 2008).
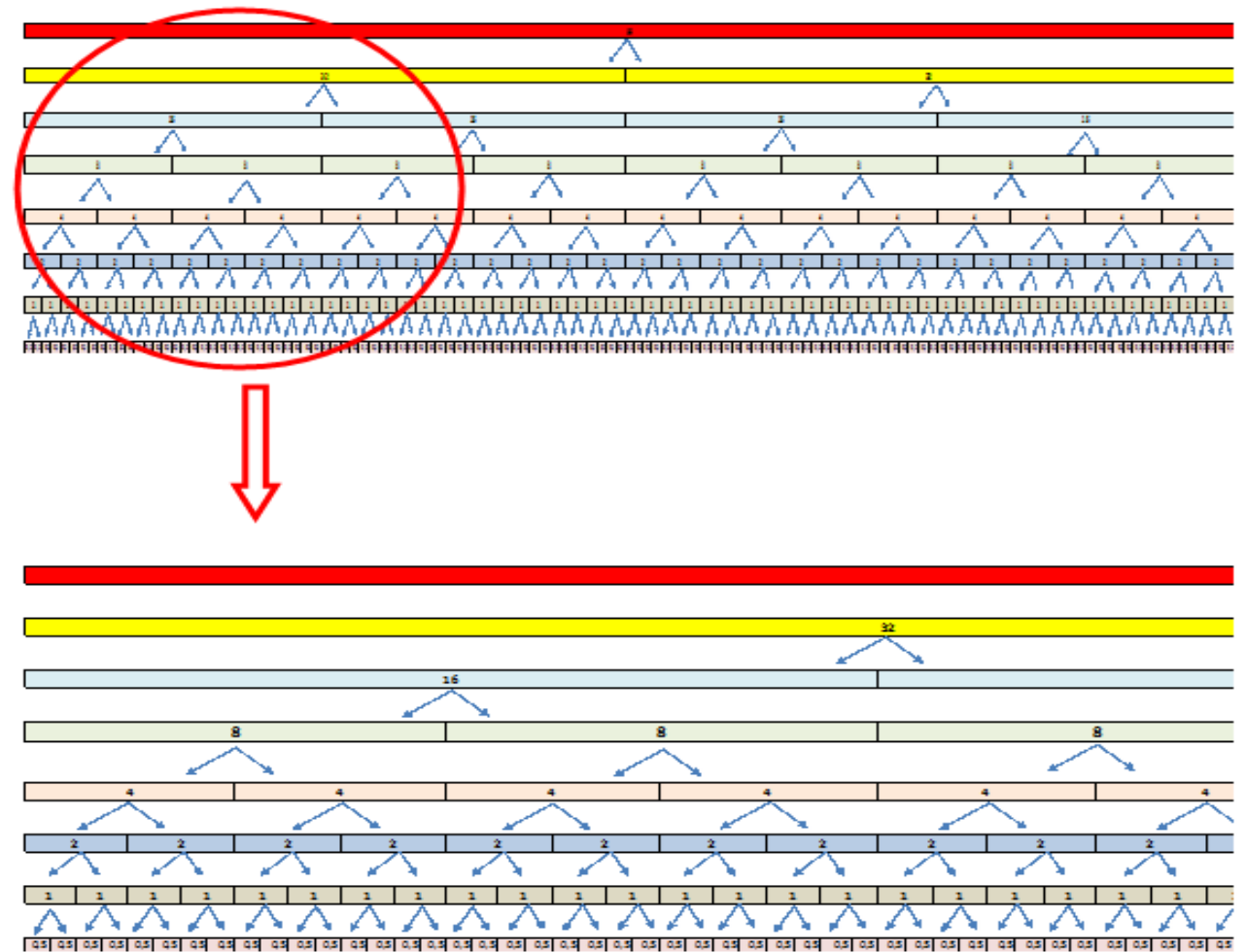

Figura 3.16 Esquema de la estructura del análisis multiescala a través de la entropía relativa a lo largo del transecto de estudio.

${ }^{*} q=$ Longitud del segmento de los intervalos elegidos para el estudio en metros. $(0,5,1,2,4,8,16$, 32 y 64$)$. 

Capítulo 4

RESULTADOS 

Este capítulo, se ha estructurado, valorando el efecto de la aplicación como enmienda orgánica y fertilizante de diferentes dosis del compost de orujo en un cultivo de melón, desde diferentes aspectos: económico, nutricional y ambiental, centrando el estudio en el nitrógeno y en el fósforo.

\subsection{Influencia de la aplicación de compost de orujo en la dinámica} de crecimiento del cultivo de melón: Índices de crecimiento

\section{$>$ ACUMULACIÓN DE MATERIA SECA}

La aplicación del compost de orujo, tuvo efecto en la acumulación de materia seca de las diferentes partes de la planta en los tres años de ensayo respecto al control, como se muestra en las figuras 4.1.1, 4.1.2 y 4.1.3.

En 2011, la dosis de compost aplicado no tuvo un efecto claro sobre la acumulación de materia seca en general (Figura 4.1.1). La materia seca de la hoja y tallo aumentó hasta los 62 DDT y a partir de esta fecha se mantuvo más o menos constante, independientemente del tratamiento aplicado, obteniendo diferencias significativas $(p \leq 0,05)$ únicamente a los 48 DDT con los tratamientos $D_{3}$ y $D_{2}$. En esa fecha, se obtuvo un incremento de la biomasa con la dosis $D_{2}$ del $33 \%$ en hoja, del $42 \%$ en tallo y del $37 \%$ en planta completa respecto al control.
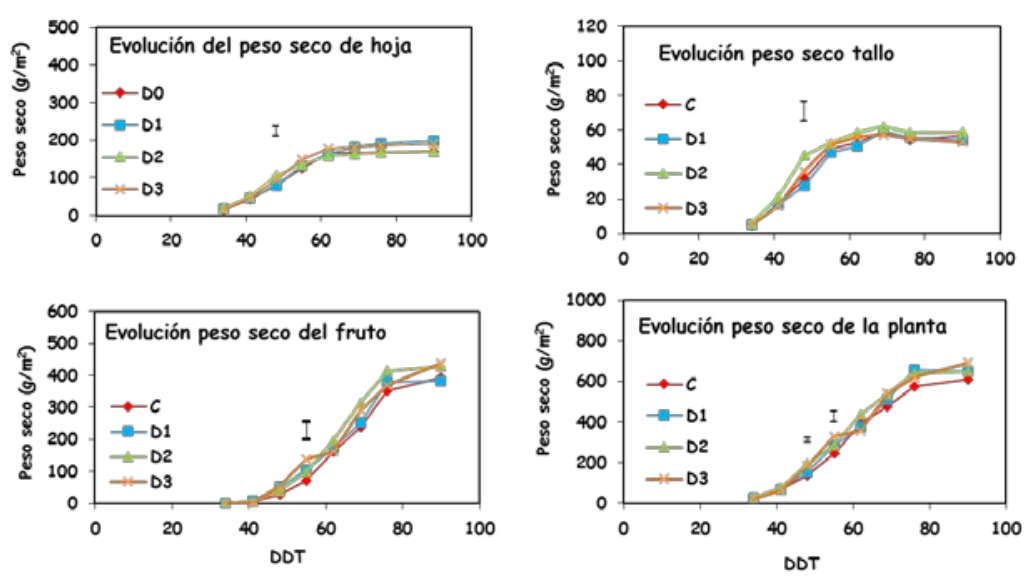

Figura.4.1.1 Producción de materia seca $\left(\mathrm{g} \mathrm{m}^{-2}\right)$ de la hoja, tallo, fruto y la planta total durante la temporada de crecimiento en 2011.

*Cada punto es la media de las cuatro réplicas. Las barras representan la menor diferencia significativa $(p \leq 0,05)$. 
La biomasa del fruto y de la planta entera siguió la misma tendencia, produciéndose un aumento continuado a lo largo de todo el periodo. En el caso de la biomasa del fruto, se observó un efecto significativo $(p \leq 0,05)$ con la aplicación del compost $\left(D_{3}\right)$ a los 55 DDT. En esa fecha, se obtuvo un incremento de la biomasa del fruto con $D_{3}$ del $96 \%$. En el caso de la planta entera se observaron diferencias significativas $(p \leq 0,05)$ a los 48 DDT y 55 DDT entre el tratamiento $D_{3}$ y resto de tratamientos.

En 2012, la aplicación de compost, produjo un efecto significativo en el peso seco de hoja, fruto y planta completa al final del ciclo vegetativo. (Figura 4.1.2) Se encontraron diferencias significativas $(p \leq 0,05)$ entre el control y los tratamientos de compost de orujo a los 76 DDT en el caso de las hojas, y a los 76 y 90 DDT en el caso del fruto, obteniéndose en este caso, un incremento significativo del $23 \%$ en la acumulación de biomasa en la primera corta.
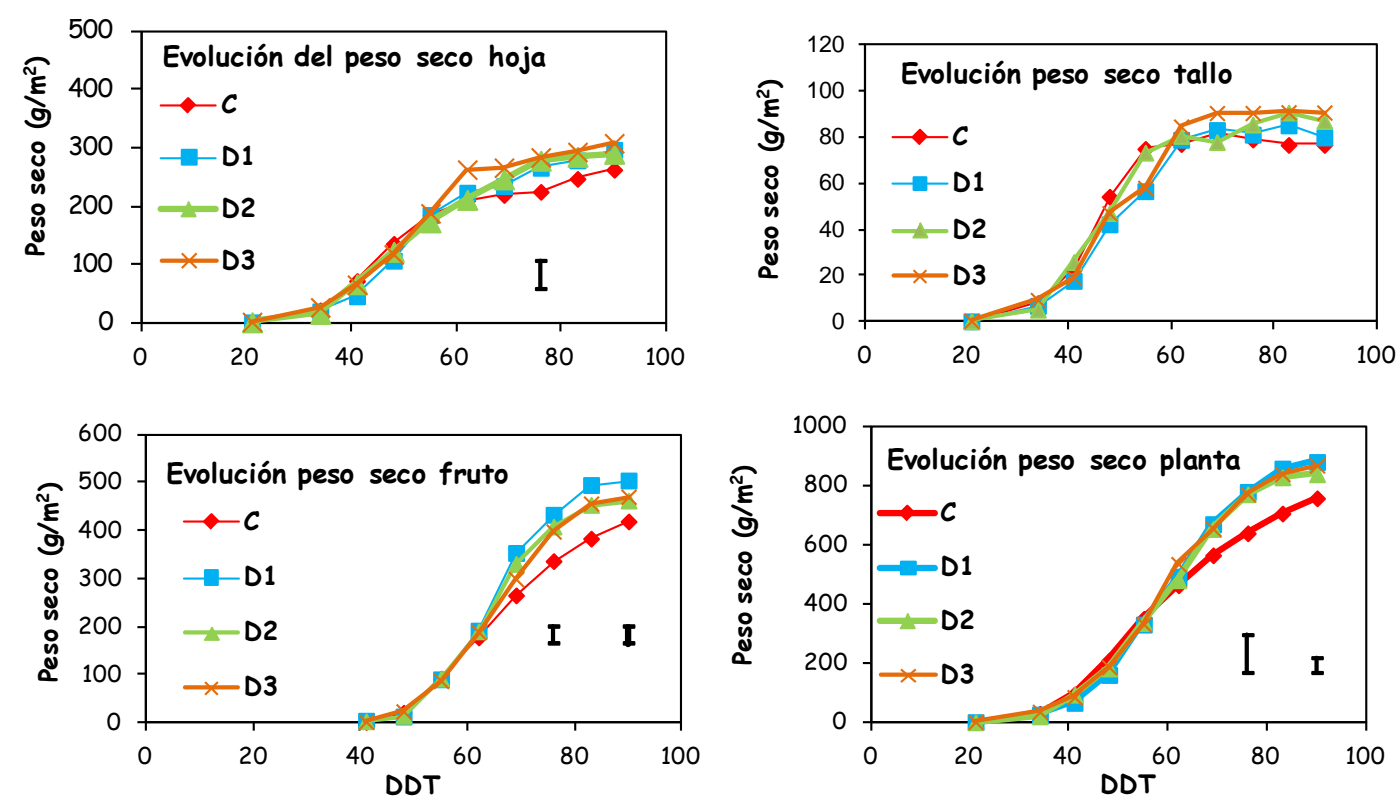

Figura.4.1.2 Producción de materia seca $\left(\mathrm{g} \mathrm{m}^{-2}\right)$ de la hoja, tallo, fruto y la planta total durante la temporada de crecimiento en 2012.

*Cada punto es la media de las cuatro réplicas. Las barras representan la menor diferencia significativa $(p \leq 0,05)$.

En 2013 (Figura 4.1.3), al igual que en el 2012 la aplicación de compost tuvo efecto positivo en general en la acumulación del peso seco de la planta, 
obteniéndose los valores más bajos de producción de materia seca en el caso del control. Las diferencias fueron significativas a los 95 DDT entre todos los tratamientos y el control en el caso de las hojas, en el caso del fruto con el tratamiento $D_{2}$ y con $D_{2}$ y $D_{3}$ en el caso del tallo.
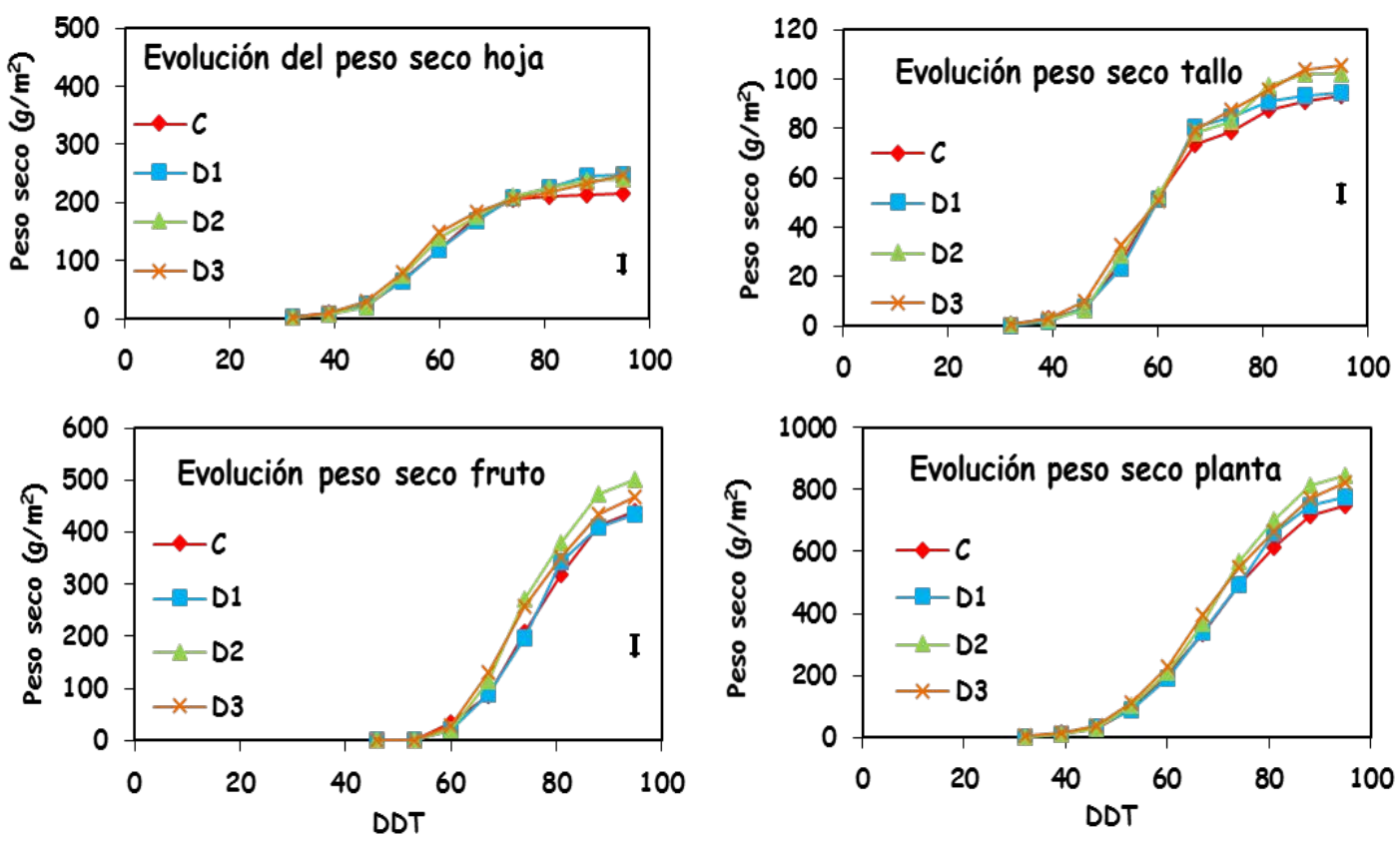

Figura 4.1.3 Producción de materia seca $\left(\mathrm{g} \mathrm{m}^{-2}\right)$ de la hoja, tallo, fruta y la planta aérea total durante la temporada de crecimiento en 2013.

* Cada punto de datos es la media de las cuatro réplicas. Las barras representan la menor diferencia significativa $(p \leq 0,05)$.

Las dosis óptimas de compost de orujo fueron, la $D_{1}$ en el 2012 , obteniendo $502,73 \mathrm{~g} \mathrm{~m}^{-2}$ de biomasa de fruto y la dosis $D_{2}$, en el año 2013 $\left(502,00 \mathrm{~g} \mathrm{~m}^{-2}\right)$ lo que supuso un incremento del $20 \%$ y $14 \%$ respectivamente respecto a lo obtenido en el suelo sin enmendar. La dosis de compost añadido al suelo, determinó el tipo de influencia, así, la dosis más alta de compost, favoreció fundamentalmente el desarrollo vegetativo de hoja y tallo, mientras que las dosis más bajas $D_{1}$ Y $D_{2}$, favorecieron la acumulación de biomasa en la parte reproductiva (fruto). 


\section{> DISTRIBUCIÓN DE MATERIA SECA}

La hoja fue el órgano que más contribuyó a la biomasa total al comienzo del ciclo de cultivo en los tres años, representando entre el 70 y el 85\%, (Figura 4.1.4).
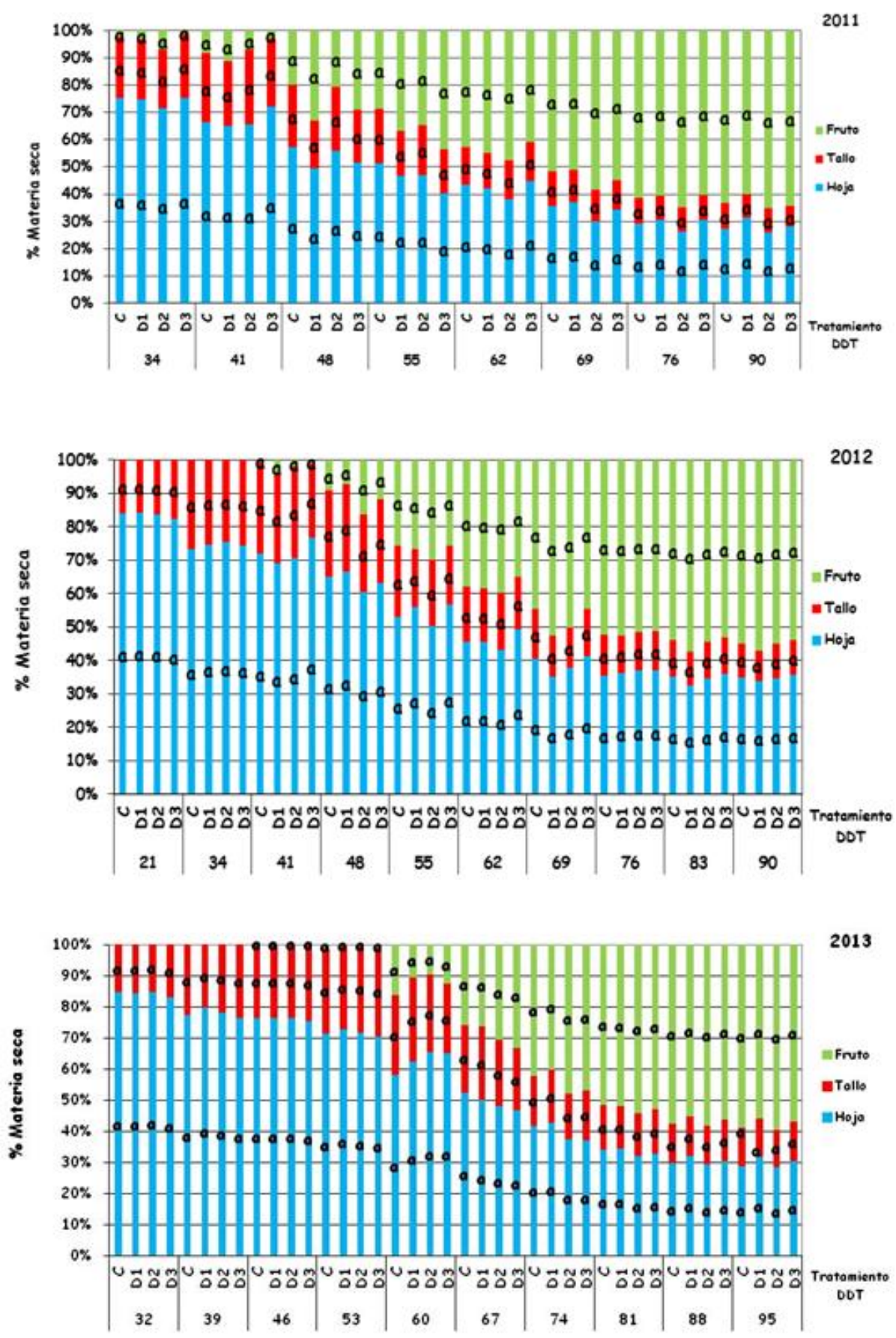

Figura.4.1.4 Distribución materia seca en hoja, tallo y fruto durante la temporada de crecimiento en 2011, 2012 y 2013. 
El tallo tuvo una contribución más estable respecto al total de la planta. El crecimiento del fruto fue rápido y también su contribución a la biomasa total: $65 \%$ en $2011,57 \%$ en 2012 y $60 \%$ en 2013. Según Fagan et al. (2006) hay un efecto inverso entre la biomasa de fruto y la hoja.

En general, la contribución del fruto a la materia seca total, es mayor con la aplicación de compost, destacando la dosis $D_{2}$ en los años 2011 y 2013 y la dosis $D_{1}$ en el 2012. Ello puede ser debido a que el mayor crecimiento de biomasa de hojas observado con la aplicación de la enmienda orgánica, produce gran cantidad de asimilados que se destinaran parcialmente a los frutos durante su crecimiento y desarrollo (Hubbard et al., 1990).

\section{LAI Y LAD}

En la figura 4.1.5 se puede apreciar la evolución del LAI a lo largo del ciclo del cultivo durante los años de ensayo. Las curvas en todos los casos tienen una tendencia creciente con el área foliar, alcanzando su valor máximo (momento en el que se produce el mayor aprovechamiento de la radiación) cuando se produce la formación y engorde de los frutos, lo que ocurrió los tres años con el tratamiento $D_{2}$ a los 69 DDT en $2011\left(2,17 \mathrm{~cm}^{2} \mathrm{~cm}^{-2}\right)$ y $2012\left(3,03 \mathrm{~cm}^{2} \mathrm{~cm}^{-2}\right)$ y a los 74 DDT el $2013\left(2,46 \mathrm{~cm}^{2} \mathrm{~cm}^{-2}\right)$. Estos resultados son comparables a los obtenidos por Ribas et al. (2000) y Paes (2011) para un cultivo de melón.

Sin embargo hay que destacar, que valores altos de este índice no están siempre relacionados con una mayor cantidad de fotosintesis, ya que se ve afectado por la disposición de las hojas en la planta, lo que varía con la morfología de la especie y las condiciones ambientales, (Barraza, 2000). Esto lo ratifica Hunt (1982) que dice que algunos valores altos de LAI pueden ocurrir cuando las hojas del cultivo no cubren toda la superficie del suelo.

La disminución observada en el valor del LAI al final del ciclo, debida posiblemente a la menor expansión celular y trasporte de fotoasimilados hacia los puntos de crecimiento (Carranza, 2009), es prácticamente igual en los tres años e independiente de la dosis de compost aplicada. En el 2011 y 2012 la senescencia de las hojas es más lenta cuando se aplica compost de orujo. 

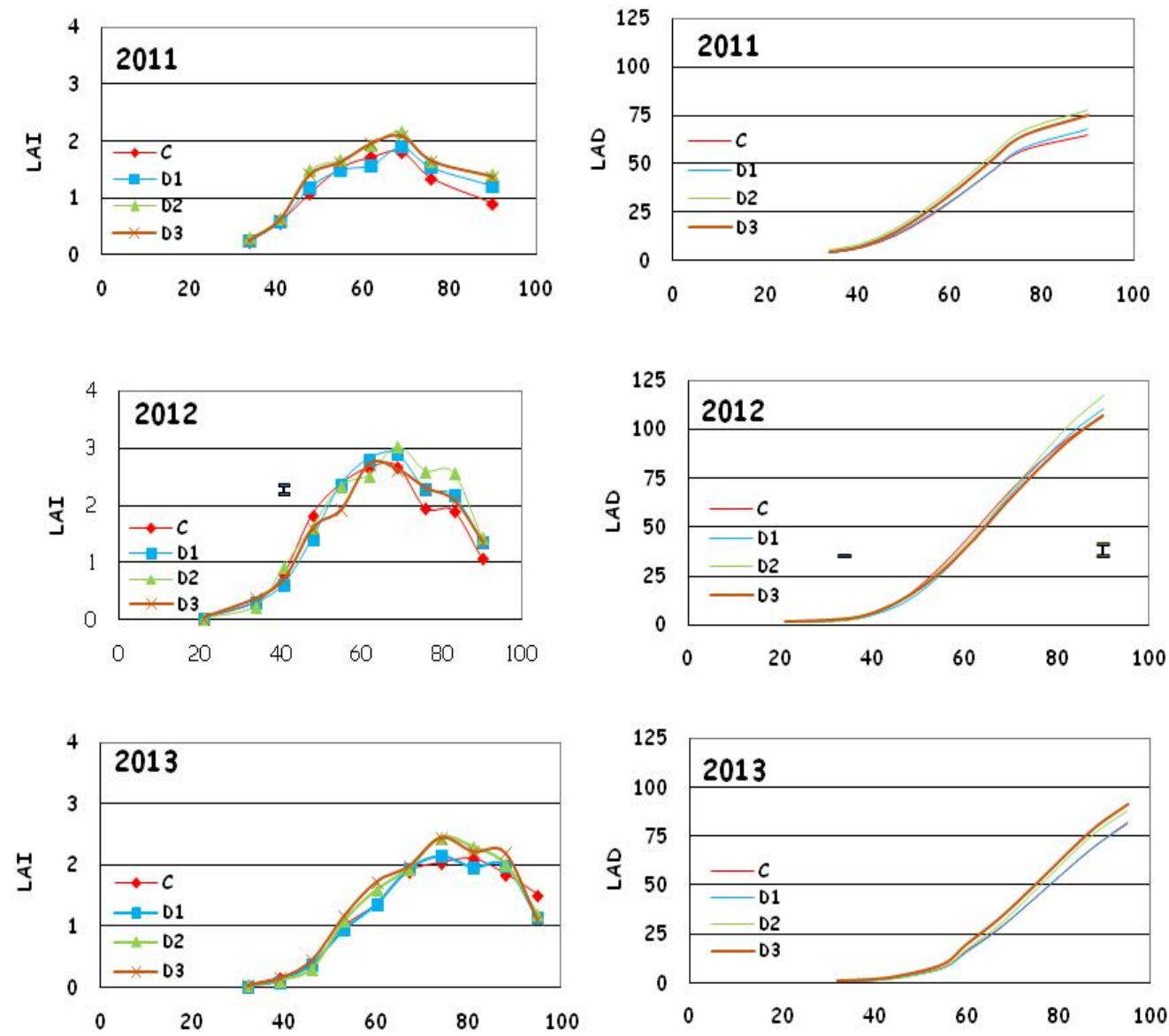

DDT

DDT

Figura 4.1.5 Índice de area foliar (LAI) y Duración del area foliar (LAD) durante la temporada de crecimiento en 2011, 2012 y 2013.

*Cada punto es la media de las cuatro réplicas. Las barras representan la menor diferencia significativa $(p \leq 0,05)$.

La duración de área foliar (LAD) en los 3 años de ensayo, se vio afectada de forma positiva por la aplicación de compost, alcanzando en todos los casos su valor máximo al final del ciclo del cultivo los años $2011(78,08)$ y $2012(117,45)$ con la $D_{2}$ y el $2013(91,64)$ con la $D_{3}$.

En general las curvas del LAD tienen un comportamiento creciente durante todo el periodo posterior al trasplante. Según Cayón (1992), la capacidad fotosintética de las hojas aumenta hasta la madurez, disminuyendo luego con la edad. En nuestro caso dado el periodo de toma de muestras no hemos observado el final de la senescencia. 
Según Hunt (1982) valores elevados de LAD, indican una mayor magnitud del área foliar y de su persistencia a través del tiempo, produciéndose un mayor aprovechamiento de la radiación solar, lo cual se manifiesta en un mayor crecimiento general de las plantas, mayor acumulación de materia seca y mayor rendimiento total.

\section{> ÍNDICES DE CRECIMIENTO DEL CULTIVO}

Con objeto de analizar los datos correspondientes a los tres años del experimento, los índices se han calculado siempre para tres periodos diferentes de 14 días cada uno (I, II y III), a excepción del FGR, que se ha calculado únicamente en el periodo IV:

I- desde comienzo de muestreo hasta cuajado de los frutos.

II- desde el cuajado de los frutos hasta que finaliza el crecimiento de la parte vegetativa de la planta.

III- desde final crecimiento vegetativo de la planta hasta crecimiento y maduración de los frutos.

IV- desde cuajado de frutos hasta su maduración.

Como se puede ver en la figura 4.1.7 las fechas en los intervalos elegidos fueron diferentes cada año. En el año 2013, se produjo un retraso fenológico general, debido a las bajas temperaturas (Figura 4.1.6) que se alcanzaron durante los meses de mayo y junio, lo que dio lugar a un retraso en la floración femenina y cuajado.
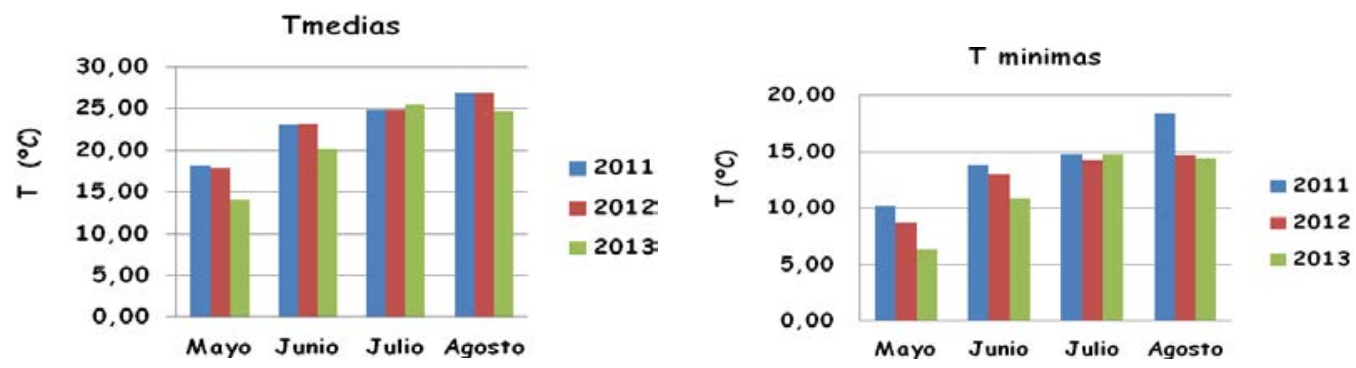

Figura 4.1.6 Temperaturas medias y mínimas durante la temporada de crecimiento del cultivo en 2011, 2012 y 2013. 

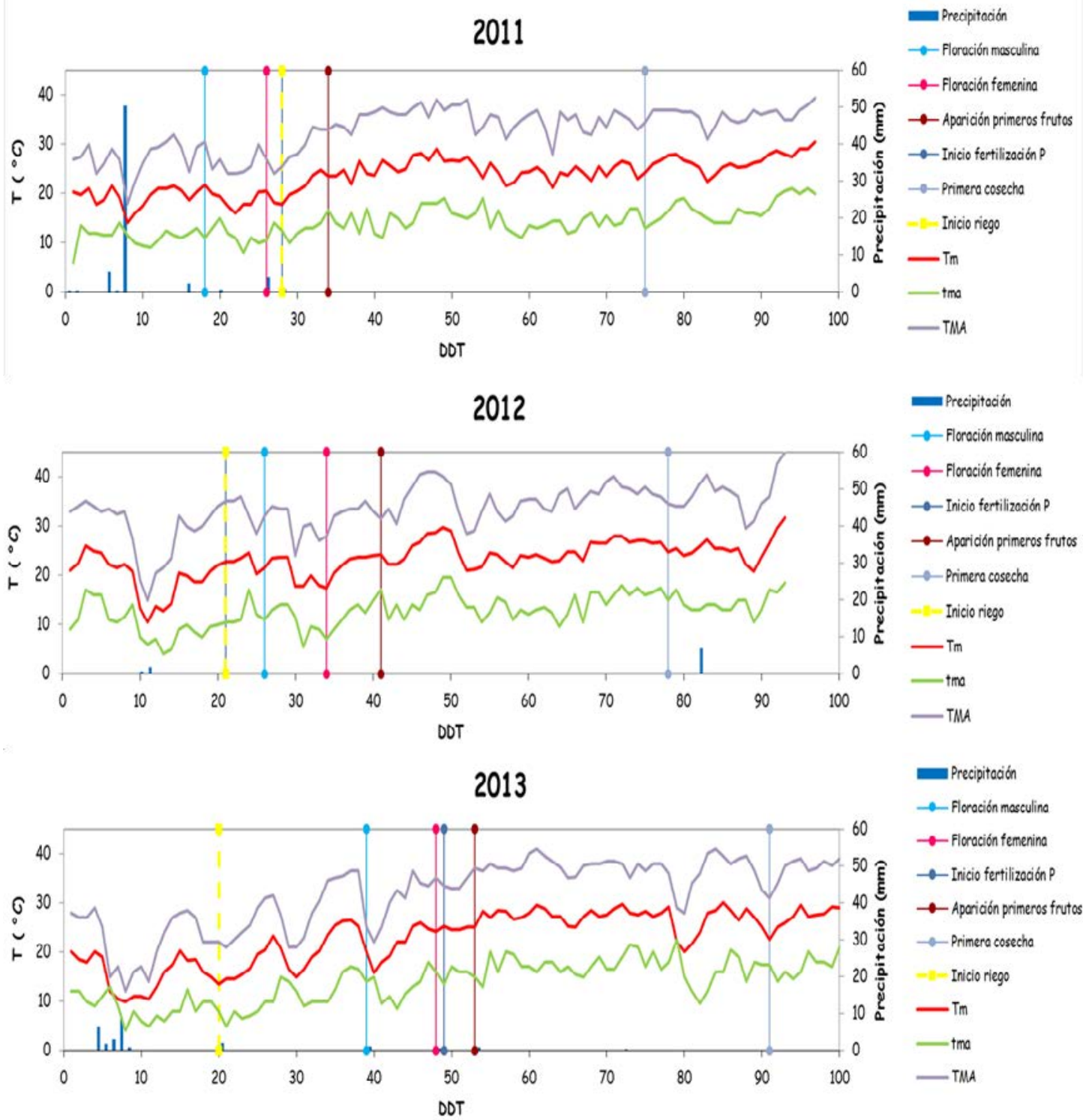

Figura 4.1.7 Precipitaciones, Temperaturas medias $(\mathrm{Tm})$, temperaturas mínimas (tma) y temperaturas máximas (TMA) durante la temporada de crecimiento del cultivo en 2011, 2012 y 2013.

* Las líneas verticales representan el comienzo de los diferentes estadios fenológicos de la planta.

En la tabla 4.1.1, se recogen los valores medios de los índices morfológicos a lo largo del ciclo de cultivo del melón: 
Tabla 4.1.1 Evolución de los índices morfológicos (SLA, LWR y LAR) durante los tres periodos definidos I, II y II del ciclo de cultivo del melón.

$$
S L A_{t}=\frac{L A}{W_{h}} \quad L W R_{t}=\frac{W_{k}}{W_{p t}} \quad L A R_{t}=\frac{L A}{W_{p t}}
$$

\begin{tabular}{|c|c|c|c|c|c|c|c|c|c|}
\hline & \multicolumn{3}{|c|}{$\begin{array}{c}\text { SLA } \\
\left(\mathrm{cm}^{2} \mathrm{~g}^{-1}\right)\end{array}$} & \multicolumn{3}{|c|}{ LWR } & \multicolumn{3}{|c|}{$\begin{array}{c}\text { LAR } \\
\left(\mathrm{cm}^{2} \mathrm{~g}^{-1}\right)\end{array}$} \\
\hline & I & II & III & I & II & III & I & II & III \\
\hline$c$ & $140,79 a$ & $120,81 a$ & $98,25 a$ & $0,66 a$ & $0,51 a$ & $0,36 a$ & $94,01 a$ & $61,95 a$ & $35,98 a$ \\
\hline D1 & $143,14 a$ & $120,95 a$ & $93,71 a$ & $0,63 a$ & $0,46 c$ & $0,37 a$ & $89,69 a$ & $56,44 a$ & $34,60 a$ \\
\hline D2 & $140,70 a$ & $128,48 a$ & 118,16 a & $0,64 a$ & $0,47 \mathrm{a}$ & $0,31 a$ & $90,87 a$ & $60,89 a$ & $37,60 a$ \\
\hline D3 & $144,12 a$ & $122,65 a$ & $104,47 a$ & $0,66 a$ & $0,45 \mathrm{c}$ & $0,32 a$ & $95,42 a$ & $55,70 a$ & $34,15 a$ \\
\hline$c$ & $130,31 a$ & $129,48 \mathrm{~b}$ & $111,59 \mathrm{~b}$ & $0,74 a$ & $0,54 \mathrm{c}$ & $0,40 a$ & $97,02 a$ & $70,73 a$ & $45,12 a$ \\
\hline D1 & $141,16 a$ & $128,51 b$ & $111,71 \mathrm{~b}$ & $0,74 a$ & $0,56 \mathrm{c}$ & $0,38 a$ & $104,32 a$ & $72,23 a$ & $43,29 a$ \\
\hline D2 & $140,75 a$ & $129,10 \mathrm{~b}$ & $111,93 \mathrm{~b}$ & $0,74 a$ & $0,54 \mathrm{c}$ & $0,39 a$ & $104,65 a$ & $70,31 a$ & $44,25 a$ \\
\hline D3 & $132,70 a$ & $113,55 a$ & $94,17 a$ & $0,74 a$ & $0,56 \mathrm{c}$ & $0,42 a$ & $98,35 a$ & $64,68 \mathrm{a}$ & $40,24 a$ \\
\hline \multirow{4}{*}{$\begin{array}{l}\text { D2 } \\
\text { D3 }\end{array}$} & $150,33 a$ & $107,17 a$ & $96,02 a$ & $0,74 a$ & $0,51 a$ & $0,35 a$ & $112,21 a$ & $54,76 a$ & $34,00 \mathrm{a}$ \\
\hline & $147,95 a$ & $111,49 a$ & $90,70 a$ & $0,75 a$ & 0,520 & $0,37 a$ & $112,23 a$ & $57,95 a$ & $33,53 \mathrm{a}$ \\
\hline & $146,96 a$ & $114,13 a$ & $101,40 a$ & $0,75 a$ & $0,50 \mathrm{c}$ & $0,33 a$ & $111,66 a$ & $57,36 a$ & $33,74 a$ \\
\hline & $149,82 \mathrm{a}$ & $114,68 a$ & $105,44 a$ & $0,74 a$ & $0,50 \mathrm{c}$ & $0,33 a$ & $111,94 a$ & $56,88 a$ & $35,48 \mathrm{a}$ \\
\hline
\end{tabular}

*En cada año los valores seguidos de la misma letra no tienen diferencias significativas $(p \leq 0,05)$.

El valor de los tres índices morfológicos, desciende a lo largo de todo el periodo de muestreo, independientemente del tratamiento al igual que lo descrito por Hunt (1982) y Evans (1972).

El valor máximo en todos los casos, se obtuvo siempre en la fecha correspondiente a la primera toma de muestra después del trasplante (34 DDT, 21 DDT y 32 DDT para los años 2011, 2012 y 2013) respectivamente, disminuyendo posteriormente a lo largo de todo el ciclo.

Como se puede apreciar del estudio de los datos de los tres años, la aplicación del compost no produjo variaciones significativas en los valores del LWR ni del LAR en ninguno de los periodos estudiados. En el caso del SLA, la aplicación de la dosis $D_{3}$ del compost en el 2012, produjo una disminución de este índice en los periodos II y III respecto al resto de los tratamientos. Ello se debe a que se produjo una mayor acumulación de biomasa en hoja con dicho tratamiento, acompañado de una disminución del área foliar respecto al resto de los tratamientos. 
Hay que tener en cuenta que el SLA es un rasgo morfológico, que tiene un significado adaptativo importante en las plantas herbáceas (Poorter, 1989) y que mide la superficie foliar de la planta en términos de densidad o grosor relativo de la hoja, por lo que es lógico que en nuestro caso no se hayan obtenido grandes diferencias.

La disminución del LWR a lo largo de los tres periodos (I, II y III), se debe a que al principio del ciclo del cultivo, hay una mayor localización de los asimilados en hoja, a continuación disminuye, lo que significa que otros órganos de la planta empiezan a ser dominantes sobre la distribución de asimilados a lo largo del ciclo del cultivo, lo que también fue observado por Santos et al. (2014).

Los valores altos iniciales del LAR, pueden ser debidos a que las plantas utilizan sus fotoasimilados en mayor cantidad para el desarrollo y crecimiento de las áreas fotosintéticamente activas generando gastos energéticos, lo que conlleva a menor peso. Su posterior disminución, es debida a que algunas hojas cesan su expansión mientras otras entran en senescencia, teniendo plantas que acumulan mayor materia seca y disminuyen su área fotosintéticamente activa (Archila et al., 1998).

Las relaciones entre índices ( $L A R=1,4475 S L A-109,34 R^{2}=0,88$ y $\left.L A R=180,82 L W R-28,376 R^{2}=0,97\right)$ muestran que el peso relativo del $L W R$ en el valor del LAR es mucho mayor que el correspondiente al SLA.

A continuación en la tabla 4.1.3, se recogen los valores medios de la tasa de asimilación neta (NAR) así como los índices relacionados con las velocidades de crecimiento, tanto de las partes vegetativas como reproductivas del cultivo a lo largo del ciclo del melón: velocidad de crecimiento de la hoja (LGR), velocidad de crecimiento del cultivo (CGR), velocidad de crecimiento relativo (RGR) y velocidad de crecimiento del fruto (FGR). 


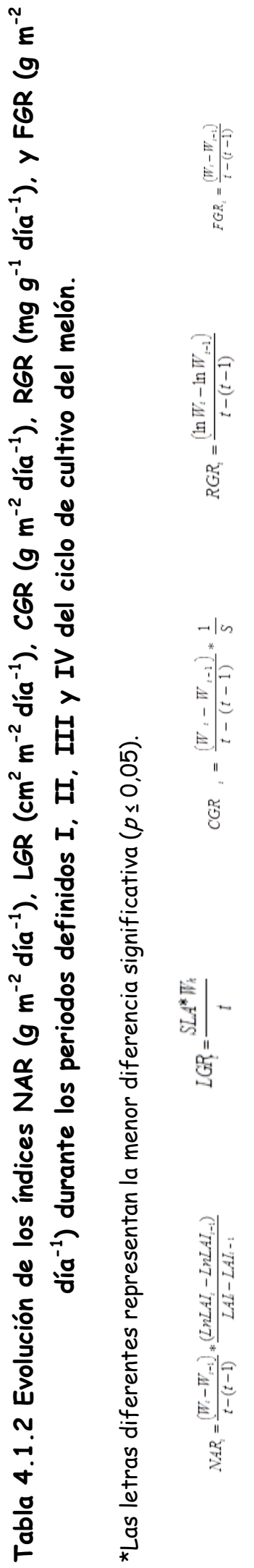

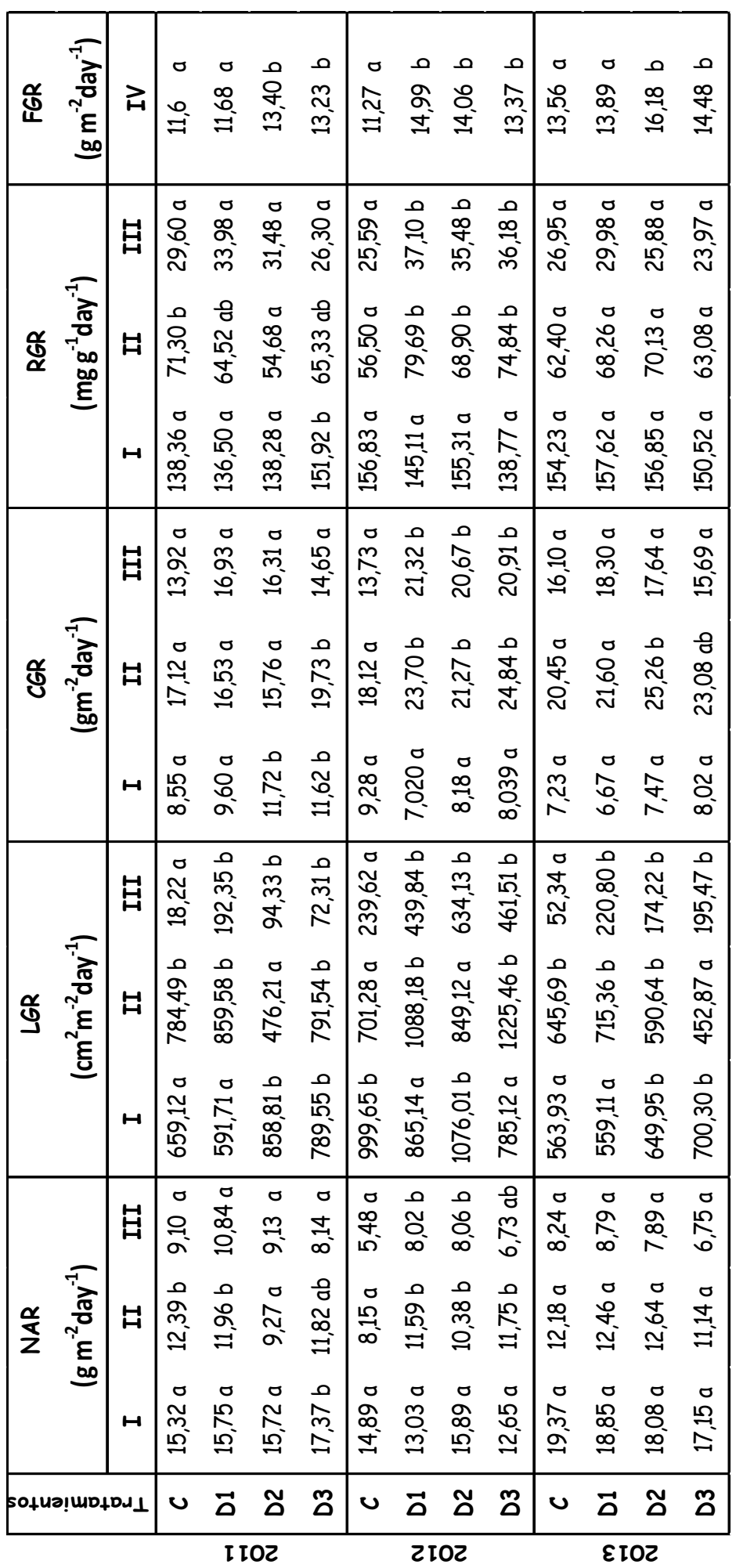


La aplicación de compost de orujo influyó los dos primeros años de ensayo en el valor de la tasa de asimilación neta (NAR) (Tabla 4.1.2). Este índice, es el resultado del balance neto entre las ganancias por la tasa de fotosíntesis y las perdidas por la tasa de respiración de hojas, tallos y raíces. Describe la capacidad de la planta para incrementar su masa seca en función del área de asimilación, en los distintos periodos del ciclo de crecimiento. Este índice es función del área foliar, de la edad de las hojas y de los procesos de regulación interna relacionados con la demanda de los asimilados (Hunt, 1982). Su valor no es constante ya que decrece con la edad de la planta. La disminución del valor del NAR a lo largo del tiempo ha sido descrito en melón por Paes (2011) y en otros cultivos hortícolas como el tomate por Lopes et al. (2011).

Los valores correspondientes a este índice, variaron entre $5,48 \mathrm{~g} \mathrm{~m}^{-2}$ día $^{-1}$ y $19,37 \mathrm{~g} \mathrm{~m}^{-2}$ día ${ }^{-1}$ según el año. El valor mínimo se alcanzó todos los años al final del ciclo. Esta respuesta está relacionada con el área foliar, ya que los primeros días de cultivo las hojas son más eficientes en la asimilación de $\mathrm{CO}_{2}$, porque están más expuestas a la radiación.

En el periodo I solo se encontraron diferencias significativas $(p \leq 0,05)$ con la aplicación del compost de orujo, el año 2011 entre el tratamiento $D_{3}$ y el resto de tratamientos. En el periodo II, el valor máximo del NAR $\left(12,64 \mathrm{~g} \mathrm{~m}^{-2}\right.$ día $^{-1}$ ) se obtuvo con la $D_{2}$ en 2013. En este periodo, la aplicación de compost tuvo un efecto opuesto en la variación de este índice dependiendo del año de estudio. El año 2011 descendió su valor en las parcelas enmendadas con compost, observándose diferencias significativas $(p \leq 0,05)$ entre el tratamiento $D_{2}$ y el resto de los tratamientos y el año 2012 el efecto fue el opuesto, produciéndose diferencias significativas $(p \leq 0,05)$, entre todos los tratamientos y el testigo. En el periodo III, durante la senescencia de los órganos vegetativos y la maduración de los frutos, el valor máximo del NAR $\left(10,84 \mathrm{~g} \mathrm{~m}^{-2}\right.$ día $\left.^{-1}\right)$ se obtuvo con la $D_{1}$ en 2011. En este periodo, solo se observó respuesta a la aplicación de compost en el año 2012, en el que se produjeron diferencias significativas $(p \leq 0,05)$ entre todos los tratamientos y el testigo.

En general, la aplicación de compost tuvo un efecto positivo en todos los índices de velocidad de crecimiento estudiados, como se observa en la tabla 4.1.3.

La velocidad de crecimiento de las hojas (LRG), aumentó hasta el cuajado de los frutos, descendiendo a continuación al aumentar la producción de estos, debido a la translocación de asimilados (Rincon Sánchez et al., 1998). 
En los tres periodos estudiados, se observó un efecto significativo $(p \leq 0,05)$ con la aplicación del compost en el valor del LGR los tres años de ensayo. La aplicación de compost en general, aumentó la velocidad de crecimiento de las hojas, siendo este efecto más marcado en el periodo I con el tratamiento $D_{2}$ los dos primeros años y con el $D_{3}$ en el 2013. La influencia de la dosis de compost en los periodos II y III varía según el año en el que se realiza el ensayo (Tabla 4.1.3). Las diferencias encontradas en el periodo II, pueden ser debidas a que en dicho periodo, el engrose de los frutos y la consiguiente tras locación de nutrientes a los órganos en formación, va en detrimento de la producción de hojas. En el periodo III, las diferencias significativas $(p \leq 0,05)$, se produjeron los tres años entre los tres tratamientos y el testigo.

El máximo valor de LGR $\left(1225,46 \mathrm{~cm}^{2} \mathrm{~m}^{-2}\right.$ día $\left.{ }^{-1}\right)$ se alcanzó con el tratamiento $D_{3}$ en el periodo II el año 2012.

En el caso de la velocidad de crecimiento del cultivo, CGR, que representa el aumento de materia seca de la planta en el área de superficie ocupada por la misma (Hunt, 1982), se observaron varios patrones distintos de comportamiento como consecuencia de la aparición y engrosamiento de los frutos los distintos años. El valor máximo del CGR, suele coincidir con el mayor valor de LAI, es decir, cuando las plantas son suficientemente grandes o densas para explotar todos los factores ambientales en mayor grado (Brown, 1984).

El efecto positivo del compost en la velocidad de crecimiento del cultivo se puso de manifiesto sobre todo el año 2012 en los periodos II y III que se obtuvieron diferencias significativas $(p \leq 0,05)$ entre todos los tratamientos y el testigo.

La velocidad de crecimiento relativo del cultivo, $R G R$, representa el aumento de masa seca en relación a la biomasa existente por unidad de tiempo. Al igual que el NAR, sus valores máximos se produjeron siempre en las primeras fases del cultivo. Este comportamiento del RGR es común para la mayoría de las especies, incluido el melón (Paes, 2011).

En este ensayo, el comportamiento observado en el $R G R$ se encuentra asociado a un aumento del NAR ( $\left.R G R=12,49 \mathrm{NAR}-66,36 ; R^{2}=0,85\right)$ caracterizado por una mayor eficiencia fotosintética, más que con el LAR ( $R G R=1,7872$ LAR 38,123; $R^{2}=0,96$ ) (Figura 4.1.8). 

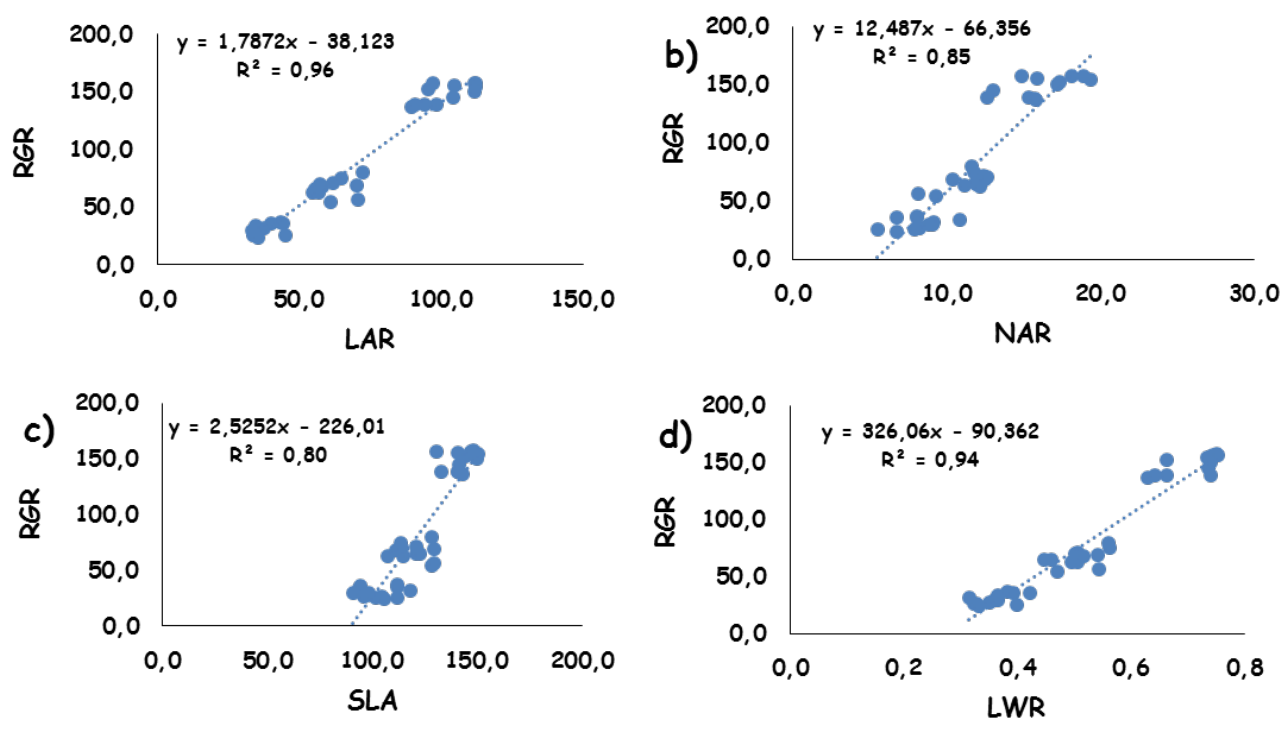

Figura 4.1.8 Relación entre la tasa de crecimiento relativo (RGR) y sus componentes: a) Razón de área foliar (LAR), b) Tasa de Asimilación neta (NAR), c) Área especifica foliar (SLA) y d) Relación de peso foliar (LWR) durante la temporada de crecimiento en 2011, 2012 y 2013.

*Cada punto de datos es la media de las cuatro réplicas.

Según diversos autores (Poorter, 1989; Poorter and Remkes, 1990; Garnier, 1992; Lambers and Pooter, 1992; Marañon y Grubb, 1993; Garmier and Laurent, 1994) el SLA puede explicar el $80 \%$ de la variación de los valores de $R G R$ si se compara su valor en plantas de distintas especies. En nuestro caso las relaciones encontradas han sido: ( $\left.R G R=326,06 L W R-90,362 ; R^{2}=0,95\right)$ y $(R G R=$ 2,5252 SLA - 226,01; $\left.R^{2}=0,80\right)$.

En el periodo I solo se produjeron diferencias significativas $(p \leq 0,05)$ con la aplicación del compost de orujo, en el año 2011 entre el tratamiento $D_{3} y$ el resto de tratamientos. En el periodo II el valor máximo del RGR $\left(79,69 \mathrm{mg} \mathrm{g}^{-1}\right.$ día $^{-1}$ ) se obtuvo con la $D_{1}$ en 2012 , en este periodo la aplicación de compost tiene un efecto opuesto en la variación de este índice dependiendo del año de estudio. El año 2011 desciende su valor en las parcelas enmendadas con compost, observándose diferencias significativas $(p \leq 0,05)$ entre el tratamiento $D_{2}$ y el resto de los tratamientos. En el año 2012, se produjo el efecto opuesto, produciéndose diferencias significativas $(p \leq 0,05)$, entre todos los tratamientos y el testigo. En el periodo III, durante la senescencia de los órganos vegetativos y la maduración de los frutos, el valor máximo del RGR $\left(37,10 \mathrm{mg} \mathrm{g}^{-1}\right.$ día $^{-1}$ ) se obtuvo con la $D_{1}$ en 2012 , en este periodo, solo se observó respuesta a la aplicación de compost en el RGR en el año 2012, en el que se produjeron diferencias significativas $(p \leq 0,05)$ entre todos los tratamientos y el testigo. 
La velocidad de crecimiento del fruto, FGR, que representa el aumento diario de materia seca del fruto, se incrementó respecto al testigo, un $15 \%$ en el primer año (2011) un 25\% en el segundo (2012) y un 19\% en el 2013, obteniéndose diferencias significativas $(p \leq 0,05)$ con la aplicación del compost de orujo, sobre todo con las dosis más altas $\left(D_{2}\right.$ y $\left.D_{3}\right)$ respecto al testigo los tres años de ensayo (Tabla 4.1.3).

La matriz de correlación entre los diferentes índices de crecimiento obtenidos cada año de ensayo se representa en la figura 4.1.9.

\begin{tabular}{|c|c|c|c|c|c|c|c|c|c|c|c|c|c|c|c|c|}
\hline 2011 & LAI & & LAD & & SLA & & LWR & & LAR & & LGR & NAR & RGR & CGR & & FGR \\
\hline LAI & 1 & & & & & & & & & & & & & & & \\
\hline LAD & 0,779 & * & 1 & & & & & & & & & & & & & \\
\hline SLA & $-0,601$ & & $-0,813$ & $\star$ & 1 & & & & & & & & & & & \\
\hline LWR & $-0,904$ & $\star \star$ & $-0,948$ & $\star \star$ & 0,781 & $\star$ & 1 & & & & & & & & & \\
\hline LAR & $-0,881$ & * & $-0,930$ & $\star \star$ & 0,880 & * & 0,978 & $\star \star$ & 1 & & & & & & & \\
\hline LGR & $-0,629$ & & $-0,823$ & $\star$ & 0,745 & * & 0,730 & * & 0,977 & $\star \star$ & 1 & & & & & \\
\hline NAR & $-0,875$ & $\star$ & $-0,831$ & $\star$ & 0,678 & & 0,869 & * & 0,866 & & 0,737 & 1 & & & & \\
\hline RGR & $-0,906$ & $\star \star$ & $-0,901$ & $\star \star$ & 0,818 & $\star$ & 0,972 & $\star \star$ & 0,977 & $\star \star$ & 0,336 & 0,938 & $\begin{array}{ll}\star \star & 1\end{array}$ & & & \\
\hline CGR & 0,311 & & $-0,271$ & & 0,242 & & 0,031 & & 0,023 & & 0,336 & $-0,246$ & 0,023 & 1 & & \\
\hline FGR & 0,700 & & 0,200 & & $-0,132$ & & $-0,391$ & & $-0,393$ & & $-0,238$ & $-0,663$ & 0,023 & 0,825 & * & 1 \\
\hline 2012 & LAI & & LAD & & SLA & & LWR & & LAR & & LGR & NAR & $R G R$ & CGR & & FGR \\
\hline LAI & 1 & & & & & & & & & & & & & & & \\
\hline LAD & 0,559 & & 1 & & & & & & & & & & & & & \\
\hline SLA & $-0,311$ & & $-0,898$ & $\star$ & 1 & & & & & & & & & & & \\
\hline LWR & $-0,791$ & * & $-0,934$ & $\star \star$ & 0,761 & & 1 & & & & & & & & & \\
\hline LAR & $-0,696$ & & $-0,955$ & $\star \star$ & 0,885 & * & 0,969 & $\star \star$ & 1 & & & & & & & \\
\hline LGR & 0,549 & & $-0,615$ & & 0,462 & & 0,484 & & 0,459 & & 1 & & & & & \\
\hline NAR & $-0,845$ & * & $-0,901$ & $\star \star$ & 0,751 & $\star$ & 0,916 & 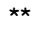 & 0,906 & $\star \star$ & 0,530 & 1 & & & & \\
\hline RGR & $-0,921$ & $\star \star$ & $-0,876$ & $\star$ & 0,756 & * & 0,951 & $\star \star$ & 0,948 & $\star \star$ & 0,409 & 0,963 & $\star \star$ & & & \\
\hline CGR & 0,812 & $\star$ & $-0,153$ & & 0,099 & & $-0,116$ & & $-0,124$ & & 0,532 & $-0,007$ & $-0,22$ & 1 & & \\
\hline FGR & 0,567 & & $-0,174$ & & 0,354 & & $-0,096$ & & 0,029 & & $-0,059$ & 0,152 & $-0,09$ & 0,747 & * & 1 \\
\hline 2013 & LAI & & LAD & & SLA & & LWR & & LAR & & LGR & NAR & RGR & $C G R$ & & FGR \\
\hline LAI & 1 & & & & & & & & & & & & & & & \\
\hline LAD & 0,677 & & 1 & & & & & & & & & & & & & \\
\hline$S L A$ & $-0,681$ & & $-0,936$ & $\star \star$ & 1 & & & & & & & & & & & \\
\hline LWR & $-0,838$ & * & $-0,956$ & $\star \star$ & 0,921 & $\star \star$ & 1 & & & & & & & & & \\
\hline LAR & $-0,849$ & $\star$ & $-0,935$ & $\star \star$ & 0,956 & $\star \star$ & 0,986 & $\star \star$ & 1 & & & & & & & \\
\hline LGR & $-0,317$ & & $-0,583$ & & 0,427 & & 0,497 & & 0,423 & & 1 & & & & & \\
\hline NAR & $-0,734$ & * & $-0,909$ & $\star \star$ & 0,817 & $\star$ & 0,877 & * & 0,838 & $\star$ & 0,533 & 1 & & & & \\
\hline RGR & $-0,949$ & $\star \star$ & $-0,889$ & $\star$ & 0,944 & $\star \star$ & 0,949 & $\star \star$ & 0,971 & $\star \star$ & 0,359 & 0,878 & * & & & \\
\hline CGR & 0,648 & & 0,177 & & $-0,456$ & & $-0,369$ & & $-0,484$ & & 0,308 & $-0,032$ & $-0,5$ & 1 & & \\
\hline FGR & 0,714 & * & 0,247 & & $-0,494$ & & $-0,438$ & & $-0,539$ & & $-0,460$ & $-0,055$ & $-0,5$ & 0,804 & * & 1 \\
\hline
\end{tabular}

Figura 4.1.9 Matriz de correlación de los indices de crecimiento: LAI, LAD, SLA, LWR , LAR, LGR, NAR, RGR, CGR Y FGR (2011, 2012 y 2013).

* Diferencias significativas del $95 \%(p \leq 0,05)$, ** diferencias significativas del $99 \%(p \leq 0,01)$. 


\subsection{Dinámica de la absorción de los nutrientes ( $N$ y $P$ ) y su} distribución en el cultivo de melón

El conocimiento de la dinámica de absorción y distribución de nutrientes, en los diferentes órganos de la planta de melón cuando se aplica compost de orujo en diferentes dosis, proporciona información sobre las posibles diferencias existentes entre la fertirrigación tradicional y la fertilización orgánica a la hora del aprovechamiento del $N$ y $P$ contenidos en el residuo orgánico. Dada la riqueza del suelo del experimento en potasio, no se estudió este elemento como variable.

Aunque muchos autores han estudiado la absorción de nutrientes, fundamentalmente nitrógeno, en fertirrigación, Reticulatus (Purqueiro et al., 2003; Kirnak et al., 2005), Cantalupensis (Pérez - Zamora and Cigales-Rivero, 2001; Fagan et al., 2006), Piel de sapo (Castellanos et al., 2006), no existen antecedentes con la aplicación de compost de orujo. Además la mayoría de los ensayos fueron realizaros en invernadero o hidroponía.

- CONCENTRACIÓN, ABSORCIÓN Y DISTRIBUCIÓN DE NITRÓGENO EN LAS PARTES AÉREAS DE LA PLANTA (HOJA, TALLO Y FRUTO)

La dosis de compost no tuvo un efecto claro en la concentración de $\mathrm{N}$ en hoja, tallo y fruto a lo largo del ciclo de cultivo (Figura 4.2.1).

En todos los casos se obtuvieron concentraciones más altas en la etapa temprana del ciclo vegetativo, bajando paulatinamente hasta llegar a estabilizarse. Este comportamiento también ha sido encontrado por otros autores en el cultivo de melón, como Panagiotopoulos (2001) y Kirnak et al. (2005). 

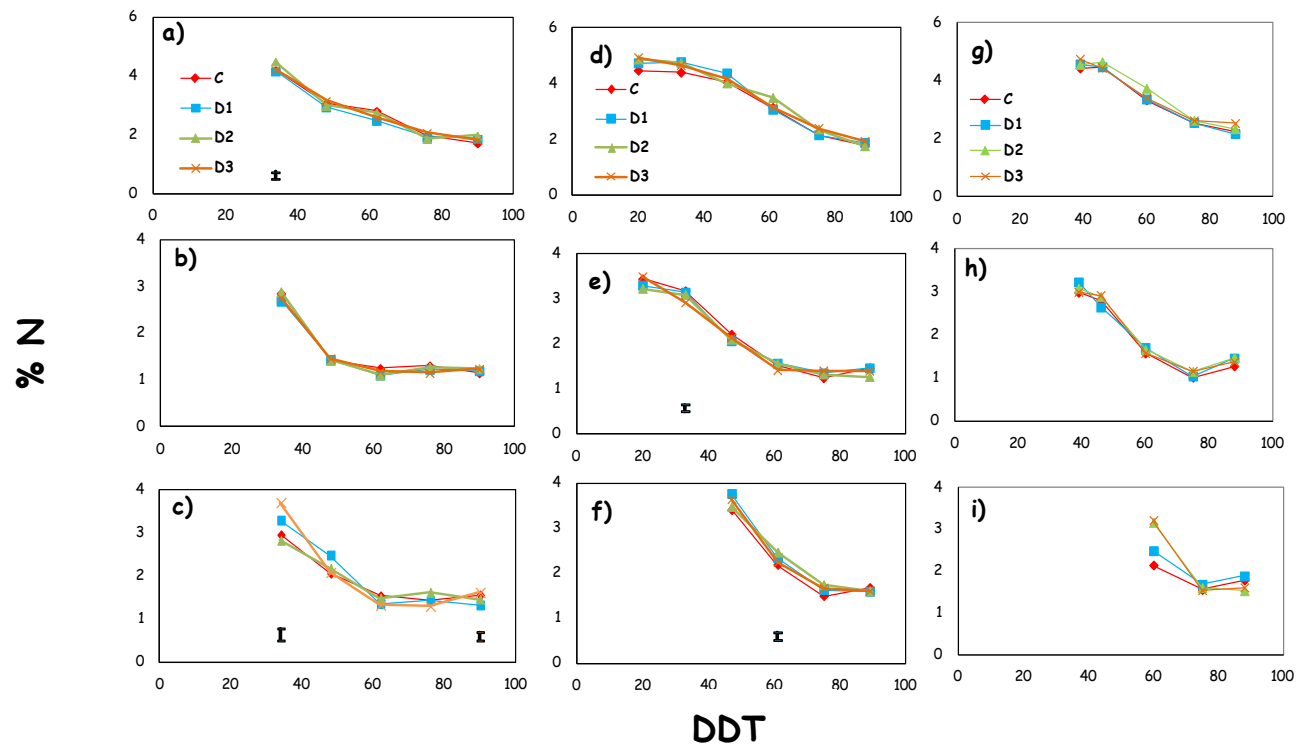

Figura 4.2.1 Efecto de la dosis de compost aplicado en la acumulación de $\mathrm{N}$ en las diferentes partes de la planta de melón: hoja ( $a, d$ y $g)$, tallo $(b$, e y $h$ ) y fruta (c, f y i) en el año 2011 ( $a, b$ y c), 2012 (d, e y f) y 2013 ( $g, h$ y i).

La hoja fue el órgano con la mayor concentración de $N$ (Figuras 4.2. 1 a,d y g) obteniéndose el valor máximo aproximadamente $5 \% \mathrm{~N}$ con la $D_{3}$ el año 2012. A partir aproximadamente de 35 y 45 DDT, en 2012 y 2013, respectivamente, en función del tratamiento y año, se observó una disminución de entre el $41 \%$ $\left(D_{2}\right.$ en 2012$)$ y el $76 \%\left(D_{3}\right.$ en 2013$)$ de la concentración de $N$ en la hoja.

Los contenidos de $\mathrm{N}$ foliar en el cuajado suelen estar dentro del intervalo 2-4\% señalado por Marr y Lamont (1992), Sin embargo, en la zona de Ciudad Real, es frecuente obtener un contenido de $N$ foliar próximo al $5 \%$ ya que se riega con agua de sondeo con alta concentración de nitratos y normalmente además, se aplica fertilización nitrogenada. Algunos autores como Kirnak et al. (2005) obtuvieron al final del periodo de cultivo concentraciones en hoja mucho más elevadas ( $8 \%$ ) en cv. Polidor. Castellanos et al. (2006) obtuvieron concentraciones similares a las nuestras con melón Piel de sapo.

La concentración de $\mathrm{N}$ en el tallo disminuye a lo largo del ciclo de cultivo, encontrando diferencias comprendidas entre un $10 \%\left(D_{2}\right.$ en 2012$)$ y un $46 \%\left(D_{3}\right.$ en 2013) entre los 20-39 DDT y los 60 DDT. No se han encontrado diferencias significativas entre tratamientos, a excepción del 2012 a los 39 DDT (Figura 4.2.1 e). 
La aplicación de una dosis de compost elevada $D_{3}$, incremento el $\% \mathrm{~N}$ en el fruto en las primeras etapas de crecimiento del melón, existiendo diferencias significativas entre tratamientos (34 DDT en 2011 y 61 DDT 2012). La tardía aparición de los frutos el 2013 hace que los resultados no sean comparables con los años anteriores.

En la figura 4.2 .2 se representa la absorción de $N\left(\mathrm{~g} \mathrm{~m}^{-2}\right)$ por las diferentes partes de la planta de melón en función de las diferentes dosis de compost de orujo aplicadas.
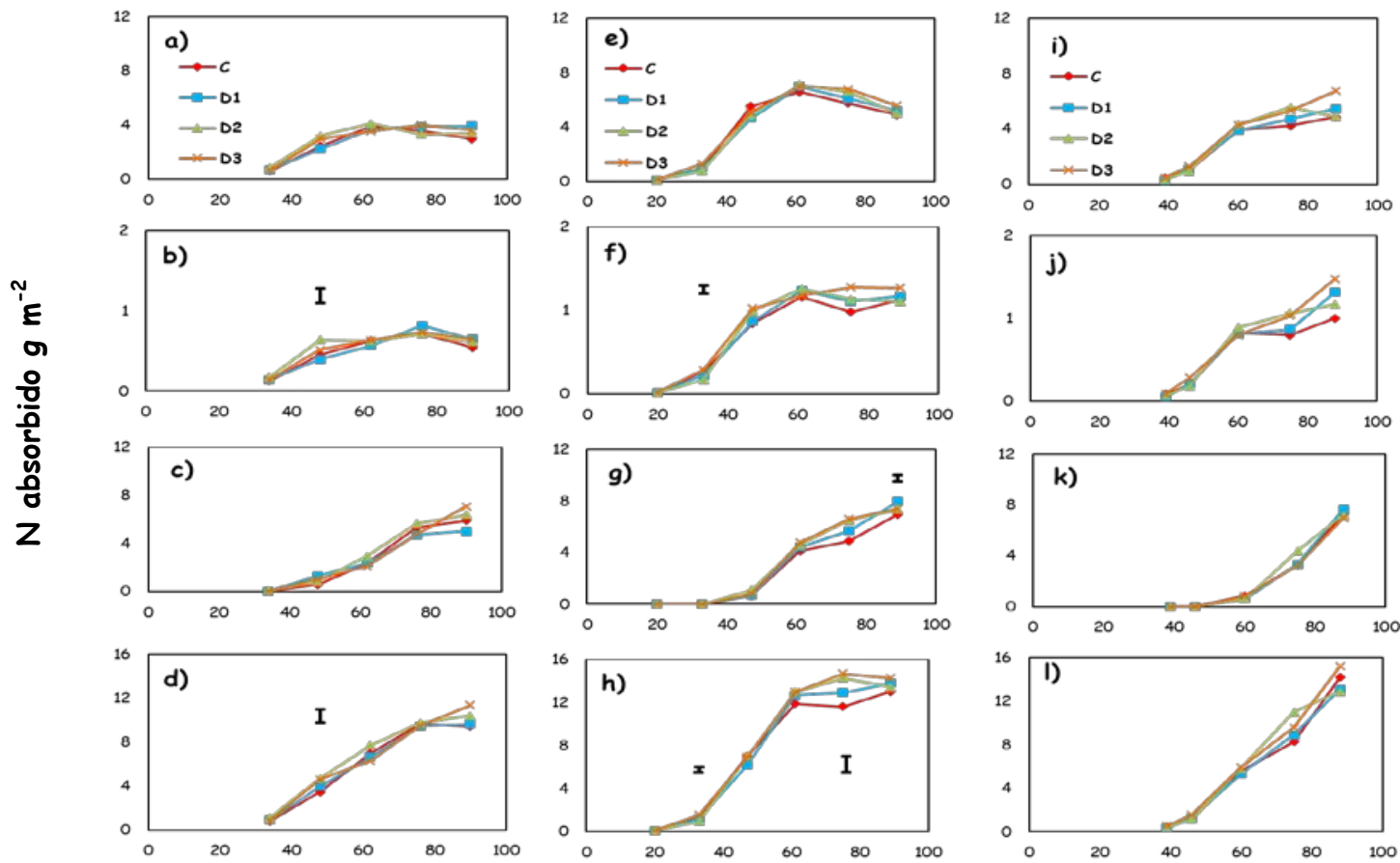

DDT

Figura 4.2.2 Efecto del compost aplicado en la absorción de $\mathrm{N}\left(\mathrm{g} \mathrm{m}^{-2}\right)$ de las diferentes partes de la planta de melón: hoja ( $a$, e $y$ i), tallo $(b, f y j)$, fruto (c, $g$ y $k$ ) y en la planta de melón completa (,$h$ y $l$ ) en 2011 ( $a, b, c$ y d), 2012 (e, $f, g$ y h) y 2013 (i, j, k y l).

En ninguno de los tres años de experimentación se han encontrado diferencias significativas en la cantidad de $\mathrm{N}$ absorbido por la Hoja. Por el contrario sí se encontraron dichas diferencias en el tallo, fruto y planta completa tanto el 2011 como el 2012 aunque en diferentes fechas. 
En 2011, la absorción total de $\mathrm{N}$ por las plantas de melón fue significativamente afectado por la aplicación de compost a 48 DDT. En esta etapa, la acumulación de $\mathrm{N}$ en la hoja tendió a aumentar en las parcelas enmendadas con respecto al control $(p \leq 0,09)$ (incremento máximo del $29 \%$ con $D_{2}$ ), siendo este incremento estadísticamente significativo en el tallo ( $42 \%$ de aumento con $D_{2}$ ) y, en consecuencia, en toda la planta. Sin embargo, al final del ciclo de crecimiento, este efecto fue menos pronunciado y no se observaron diferencias significativas con la adición de compost.

La evolución de la distribución del $N$ en las distintas partes de la planta a lo largo del tiempo se representa en la figura 4.2.3.

No se observaron diferencias significativas $(p \leq 0,01)$ en el efecto de la aplicación del compost ni de la dosis, en la distribución de $N$ en hoja, tallo y fruto en relación con el total de la planta en ninguna de las fechas de muestreo en los tres años de ensayo (Figura 4.2.3). La mayor acumulación de $N$ en el fruto se obtuvo en el 2011 con la $D_{3}$ a los 90 DDT (63\%).

En general en todas las partes de la planta, excepto en el fruto, se observa una disminución en el contenido de $\mathrm{N}$, a medida que estos van creciendo, como consecuencia de la competencia por este nutriente, ya que el fruto tiene un crecimiento muy rápido y toma gran cantidad de éste en detrimento del resto de órganos que funcionan como elementos suministradores de $N$ (Fukutoku et al., 2000). 
Distribución de $\mathrm{N}$ en la planta 2011

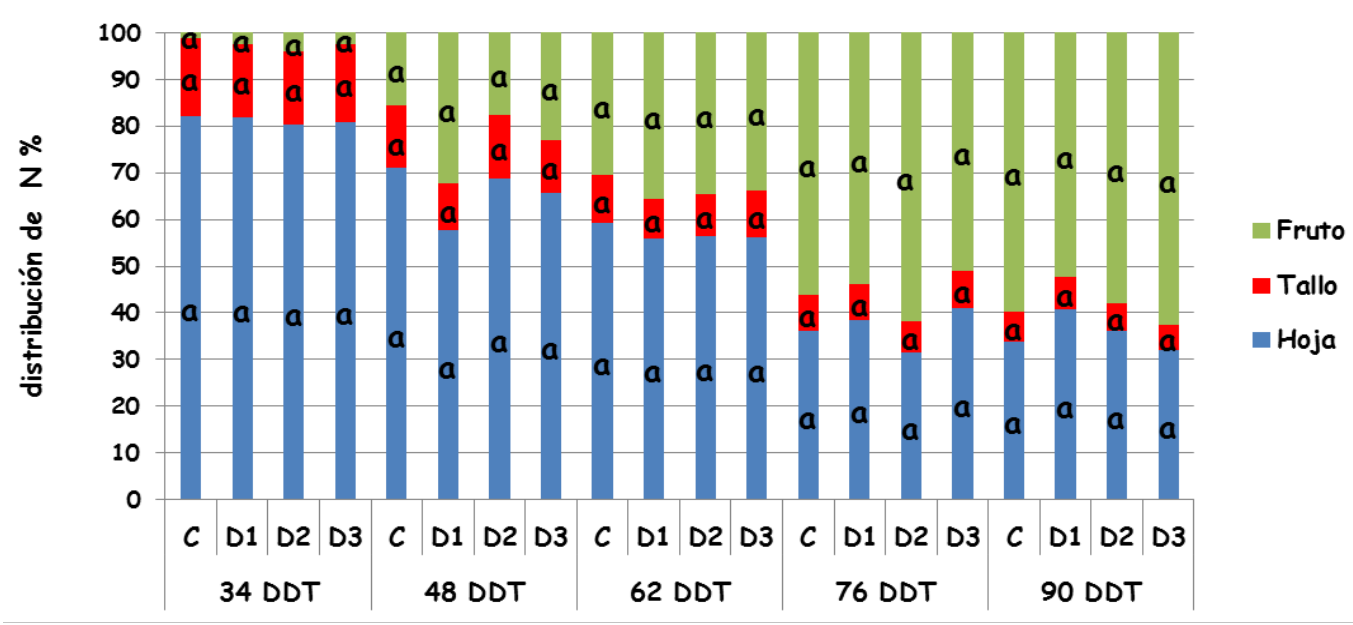

Distribución de $\mathrm{N}$ en la planta 2012

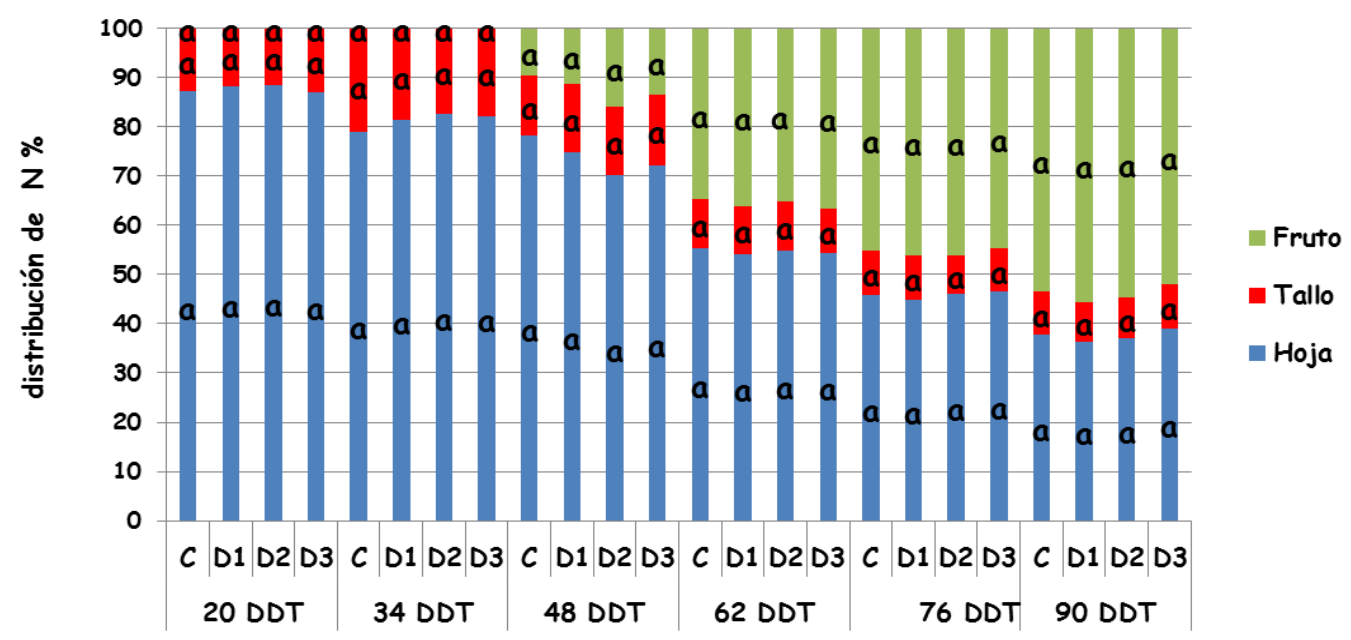

Distribución de $N$ en la planta 2013

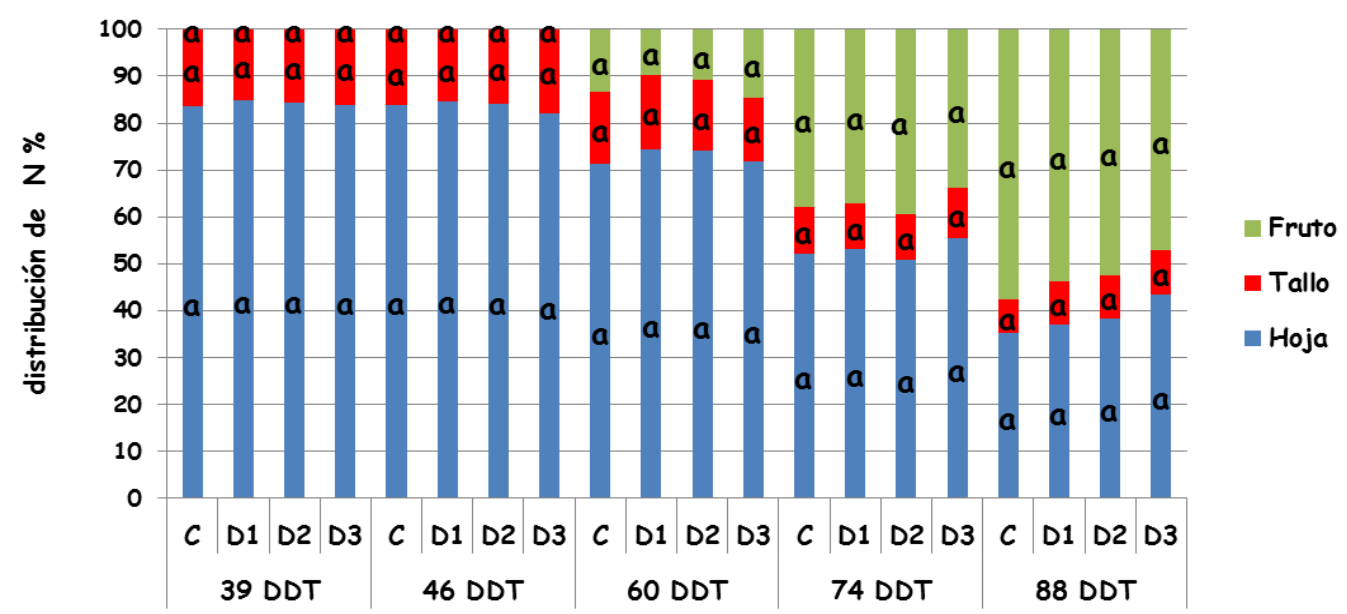

Figura 4.2.3 Distribución de nitrógeno en las hojas, tallos y frutos durante la temporada de crecimiento en 2011, 2012 y 2013. 


\section{> CONCENTRACIÓN, ABSORCIÓN Y DISTRIBUCIÓN DE FÓSFORO EN LAS PARTES AÉREAS DE LA PLANTA (HOJA, TALLO Y FRUTO)}

La absorción de fósforo siguió una tendencia similar a la de $\mathrm{N}$ por lo que solamente se realizó el seguimiento del P a lo largo de todo el ciclo de cultivo, las dos primeros años (2011 y 2012).

La cantidad de $P$ aplicado con el compost no tuvo un efecto claro en la concentración de $P$ en hoja, tallo y fruto en ninguno de los dos años (2011 y 2012) (Figura 4.2.4). Independientemente del tratamiento, los valores más altos de concentración de $P$ se obtuvieron al principio del ciclo vegetativo y fueron bajando paulatinamente hasta el final del ciclo del cultivo.
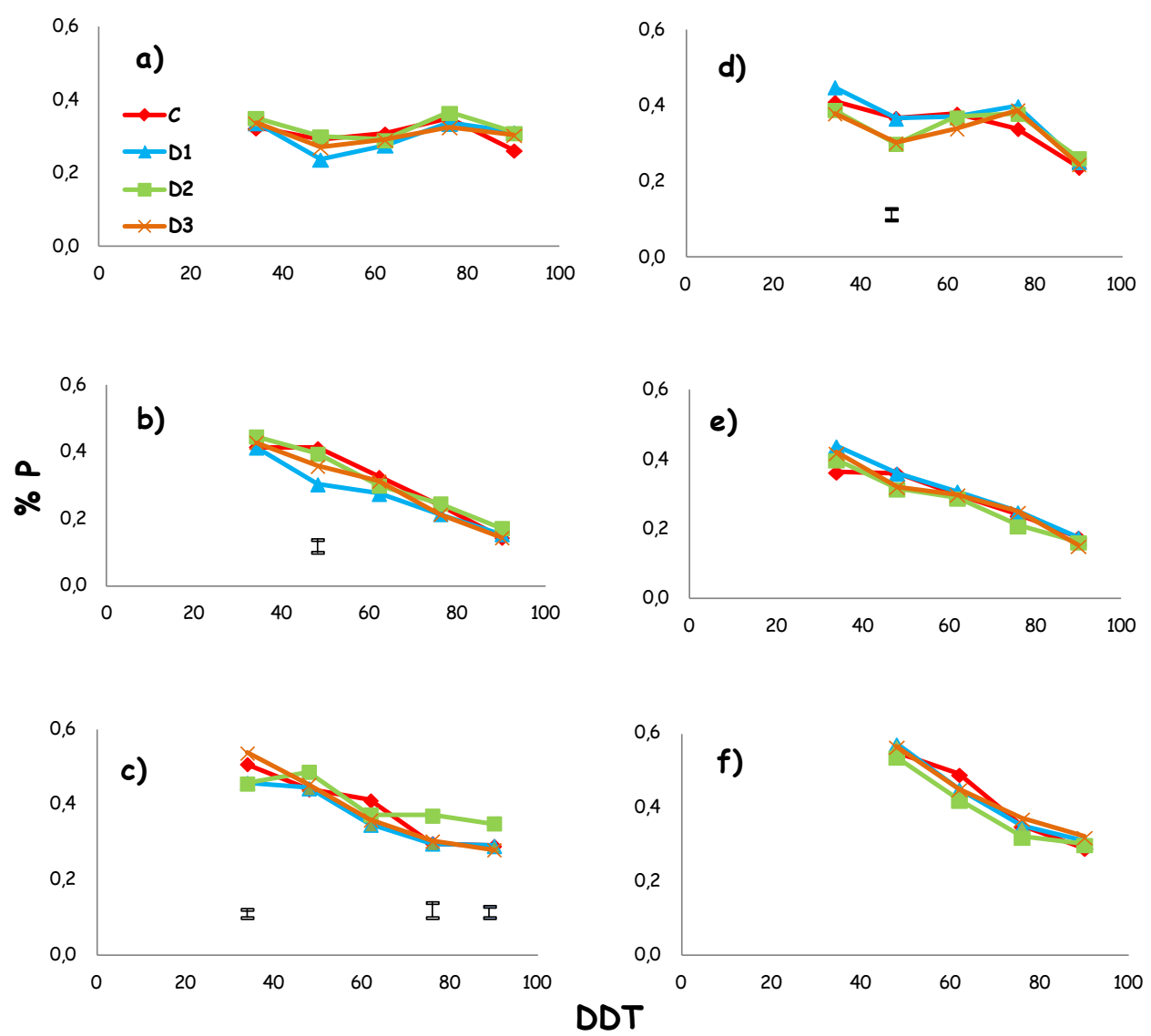

Figura 4.2.4 Efecto de la dosis de compost aplicado en la acumulación de $P$ en las diferentes partes de la planta de melón: hoja ( $a$ y d), tallo (b y e), fruto ( $c$ y $f$ ) en 2011 ( $a, b$ y $c$ ) y 2012 (d, e y f). 
El mayor \% de $P$ se obtuvo en el fruto, obteniéndose el valor máximo aproximadamente $0,5 \% P$ con la $D_{3}$ el año 2011 y $0,6 \%$ con la $D_{1}$ en el año 2012 , observándose únicamente diferencias significativas el año $2011(p \leq 0,01)$ a los 34 DDT, 76 DDT y 89 DDT con la $D_{2}$. En la hoja solamente se encontraron diferencias significativas en el 2012 a los 48 DDT.

En la figura 4.2 .5 se representa la absorción de $P\left(\mathrm{~g} \mathrm{~m}^{-2}\right)$ por las diferentes partes de la planta de melón en función de las diferentes dosis de compost.
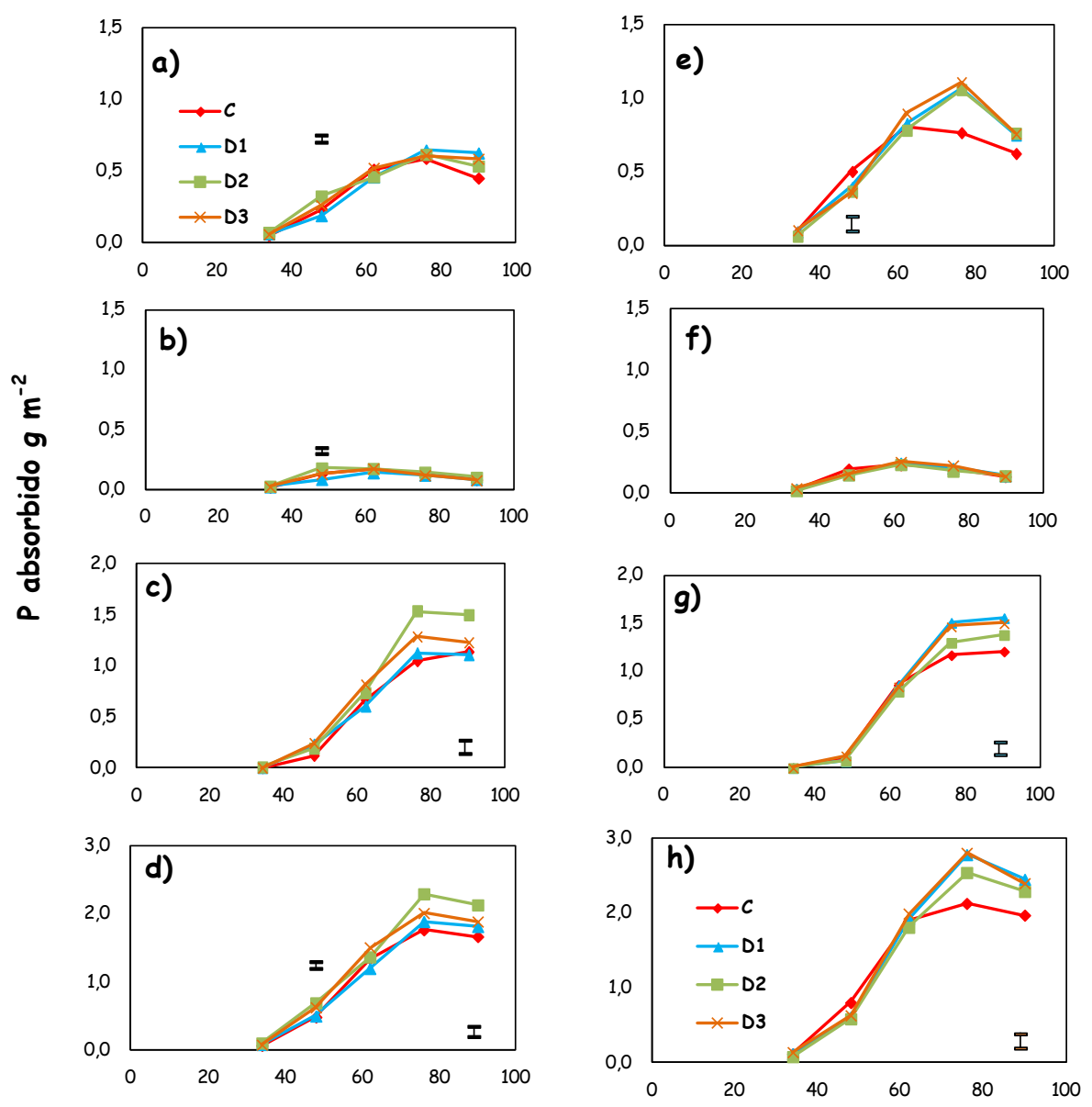

DDT

Figura 4.2.5 Efecto del compost aplicado en la absorción de $P\left(\mathrm{~g} \mathrm{~m}^{-2}\right)$ de las diferentes partes de la planta de melón: hoja ( $a$ y e ), tallo ( $b$ y $f$ ), fruto ( $c$ y g) y en la planta de melón completa (d y h) en 2011 ( $a, b, c$ y d) y 2012 (e, f, g y h). 
La adición de compost afectó significativamente $(p \leq 0,01)$ a la acumulación de $P$ en las diferentes partes de la planta y en toda la planta (Figura 4.2.5), aunque el efecto de la dosis de compost es diferente en los dos años estudiados. Así en el 2011, destaca el efecto de la dosis $D_{2}$ al final del ciclo de cultivo ( $47 \%$ de aumento respecto al testigo en el caso del fruto), mientras que en el 2012, aunque la aplicación del compost aumenta en todos los casos la absorción de $P$, el efecto de la dosis no es claro.

No se observó diferencias significativas en el efecto de la aplicación del compost $n i$ de la dosis, en la distribución de $P$ en hoja, tallo y fruto en relación con el total de la planta en ninguna de las fechas de muestreo en los dos años (2011 y 2012) (Figura 4.2.6),
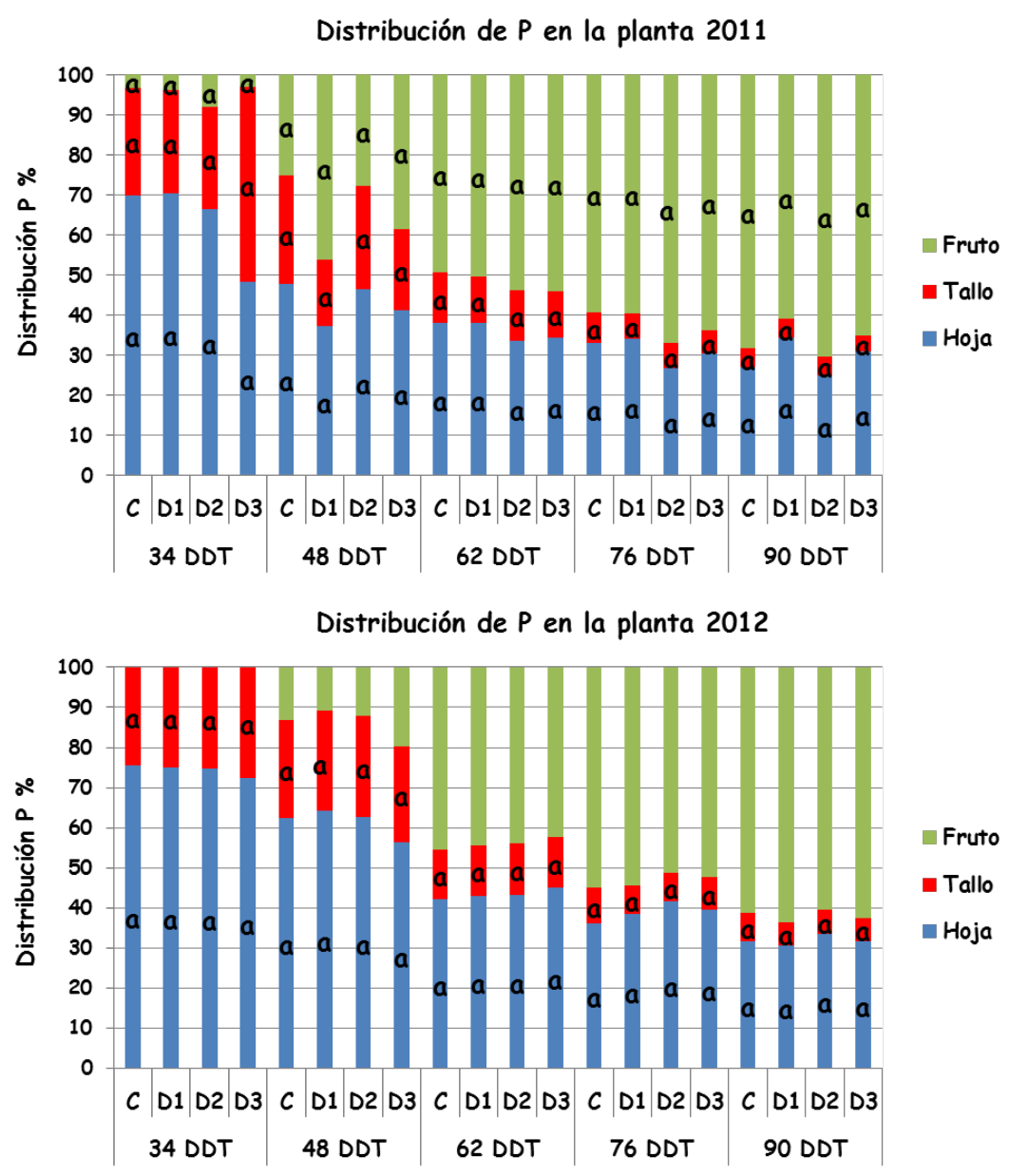

Figura 4.2.6 Distribución de fósforo en las hojas, tallos y frutos durante la temporada de crecimiento en 2011 y 2012. 
Al igual que en el caso del $N$, en todas las partes de la planta, excepto en el fruto, se observa una disminución en el contenido de $P$, a medida que estas van creciendo. En general al final del ciclo, el fruto fue el que contribuyó con mayor $\%$ de $P$ al total de la planta.

La relación entre el $\mathrm{N}$ y $\mathrm{P}$ absorbido por el cultivo de melón en los tres años de estudio se muestra en la figura 4.2.7.

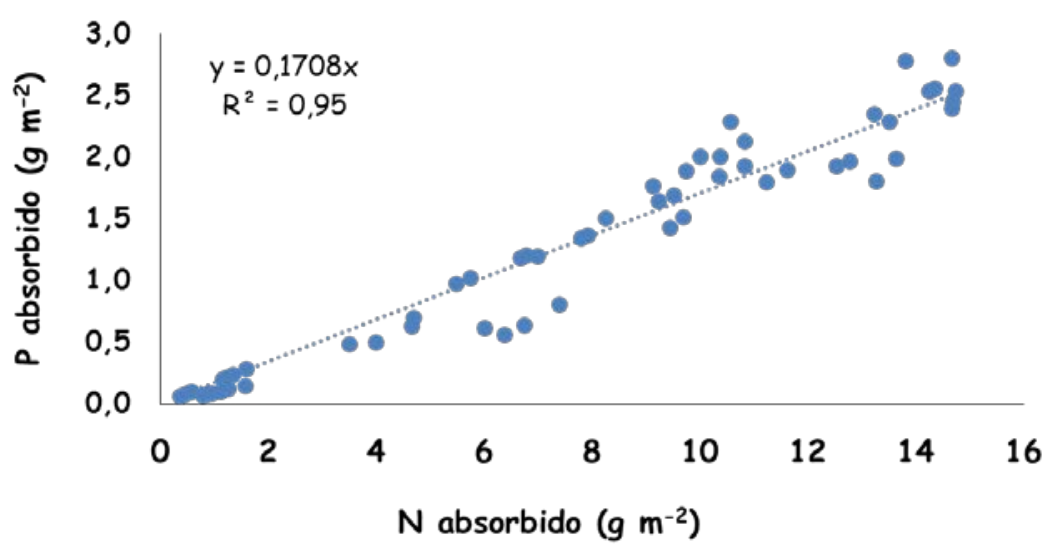

Figura 4.2.7 Relación entre el $N$ y el $P$ absorbido por la planta $\left(\mathrm{g} \mathrm{m}^{-2}\right)(2011,2012$ y 2013).

\section{ABSORCIÓN DE NUTRIENTES ( $N$ Y P) EN FUNCIÓN DE SU DISPONIBILIDAD}

Es sabido que el incremento de nitrógeno produce un incremento de la producción hasta un valor máximo optimo por encima del cual la producción se estabiliza o incluso disminuye (Pinto et al., 1997; Purqueiro et al., 2003; PérezZamora et al., 2001 y Kirnak et al., 2005). De forma semejante a la producción, la acumulación de nutriente por la planta aumenta cuando se incrementa la cantidad de nutriente disponible, tendiendo gradualmente a estabilizarse (Figura 4.2 .8 a). Este efecto no se observa claramente en el caso del fósforo, ya que la cantidad de $P$ no es determinante en la producción, siempre que las necesidades de este nutriente estén cubiertas. 

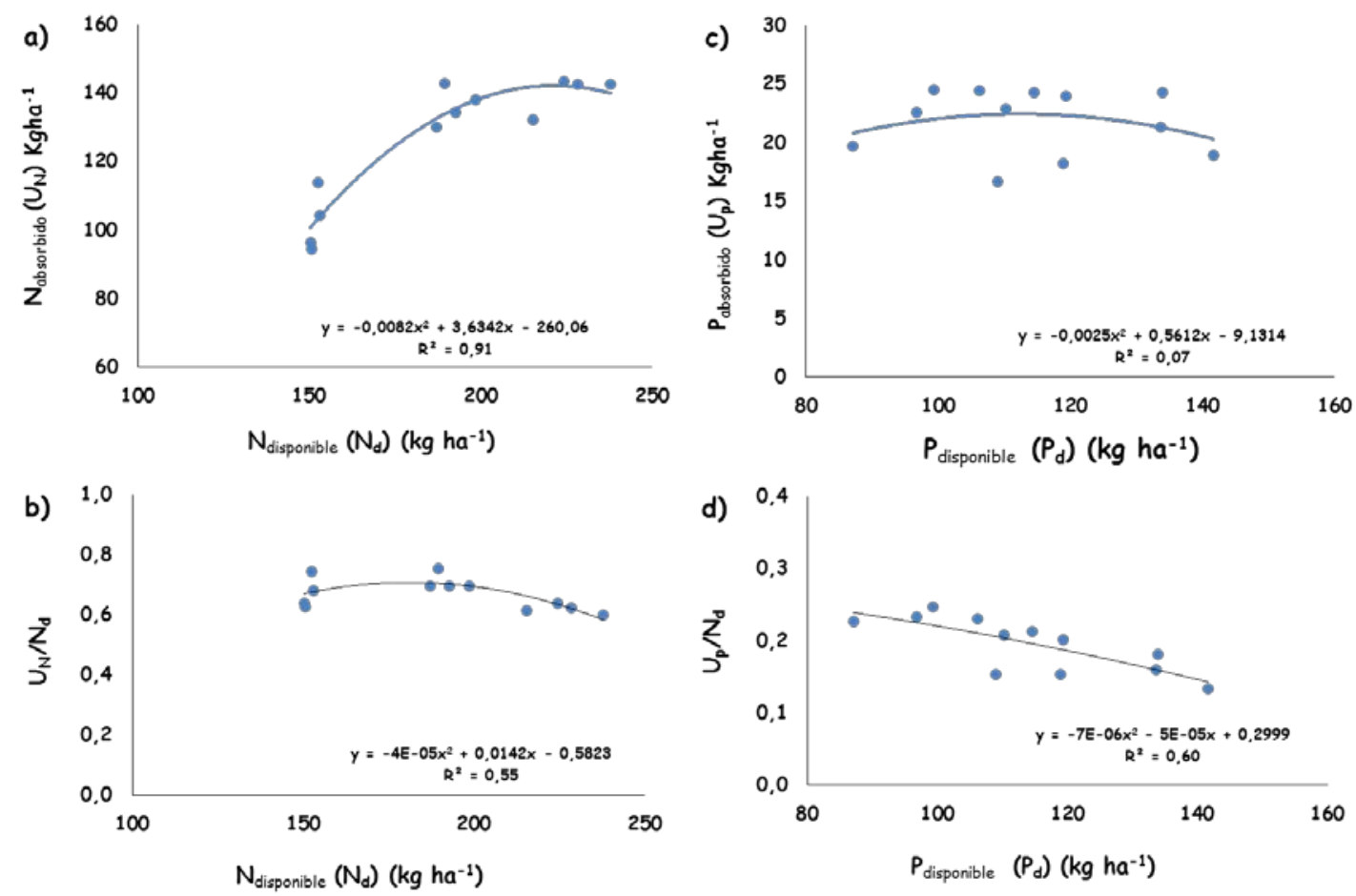

Figura 4.2.8 Absorción de nutrientes $(N$ y $P$ ) en función de la cantidad disponible: a) $\mathrm{N}$ absorbido frente a $\mathrm{N}$ disponible; b) Relación $\mathrm{N}$ absorbido/ $\mathrm{N}$ disponible frente a $N$ disponible; $c) P$ absorbido frente a $P$ disponible; $d)$ Relación $\mathrm{P}$ absorbido/P disponible frente a $\mathrm{P}$ disponible.

A lo largo de los tres años de experimentación, se produjo un aumento tanto del nitrógeno aplicado (desde 89,4 a 146,32 $\mathrm{kg} \mathrm{ha}^{-1}$ ), fundamentalmente debido al aportado por el agua de riego, como del nitrógeno disponible (desde 150,4 a $237,90 \mathrm{~kg} \mathrm{ha}^{-1}$ ) consecuencia en este caso del nitrógeno mineral existente en el suelo. La relación entre el $\mathrm{N}$ absorbido y el disponible frente al $\mathrm{N}$ disponible se representa en la figura $4.2 .8 \mathrm{~b}$.

4.3. Producción y calidad del cultivo de melón. Influencia de la dosis de compost de orujo

La producción de melón depende fuertemente de la cantidad de nitrógeno suministrado en cada etapa crucial en todo el ciclo de vida de la planta (Zhang et al., 2007). 


\section{INFLUENCIA DE LA DOSIS DE COMPOST EN LA PRODUCCIÓN DE MELÓN}

En la figura 4.3.1 se representa la producción total y comercial de melón en las diferentes cortas, en función del tratamiento durante los tres años de ensayo. En todos los casos, la mayor producción se obtuvo siempre en la segunda corta, resultado similar al obtenido por Cabello et al. (2009). Sin embargo el efecto de la dosis en la producción total en dicha corta, varío cada año de ensayo: en $2011 D_{3}\left(16,82+h a^{-1}\right)$, en $2012 D_{1}\left(22,10+h a^{-1}\right)$ y en $2013 D_{2}\left(16,93+h a^{-1}\right)$.
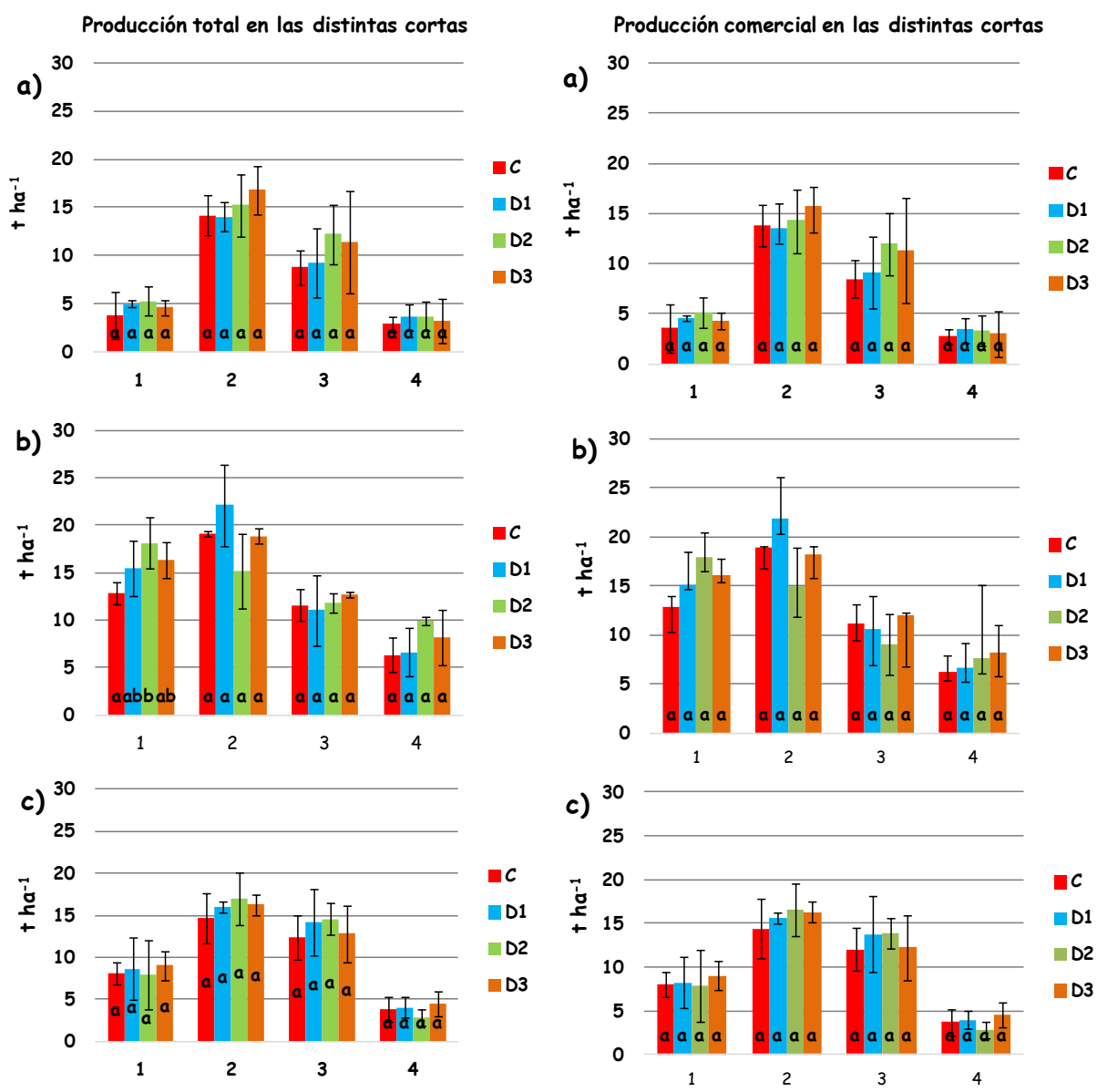

Figura 4.3.1 Producción total y comercial en las distintas cortas los tres años de ensayo 2011 (a), 2012 (b) y 2013 (c).

*Las barras negras verticales representan la desviación típica.Para un mismo parámetro y año, resultados seguidos de la misma letra, no son diferentes con una significación $p \leq 0,05$. 
La mayor producción total de melón se obtuvo el año $2012\left(56,1\right.$ t ha $\left.{ }^{-1}\right)$ (Tabla 4.3.1) para la dosis más alta de compost $\left(D_{3}\right)$ existiendo ese año diferencias significativas con respecto al control pero no asi, entre los distintos tratamientos de compost de orujo aplicados. La menor producción se obtuvo en 2011, debido a que las temperaturas durante la época de polinización fueron altas lo que dio lugar a frutos pequeños y redondos fundamentalmente en la primera corta.

Hay que destacar que existe una clara relación lineal entre la producción total y la comercial (Figura 4.3.2).

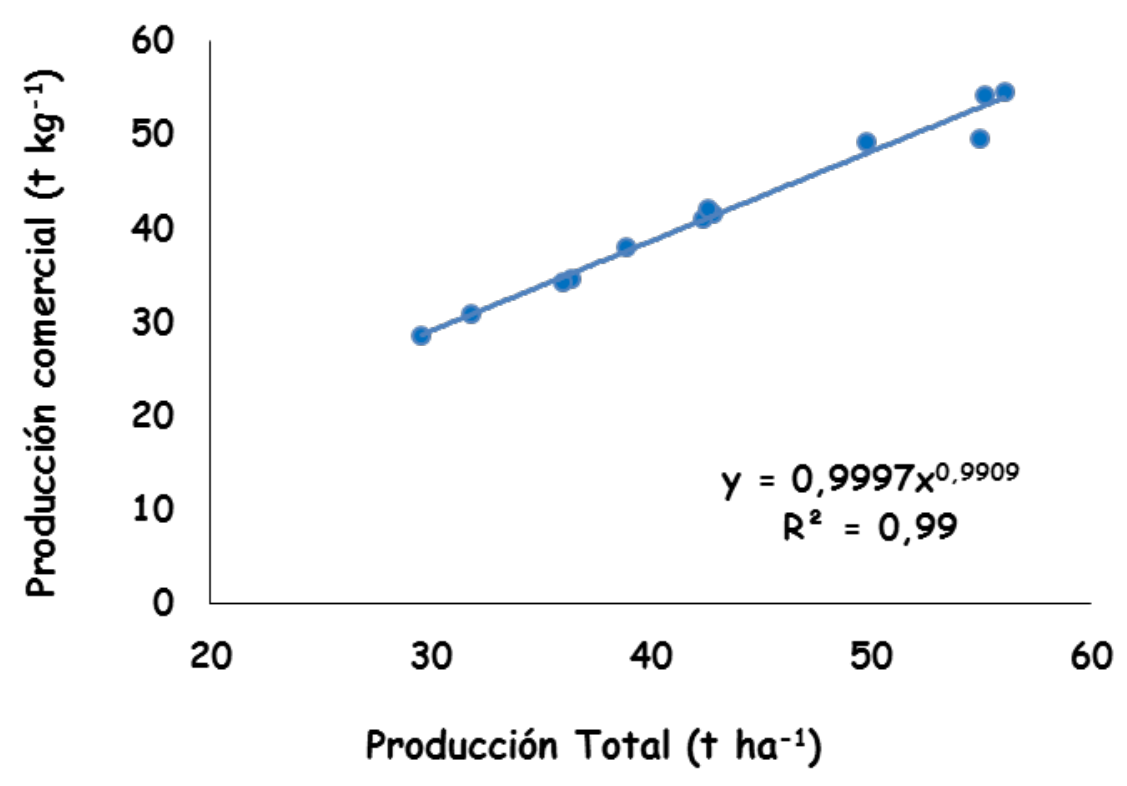

Figura 4.3.2 Relación entre la producción total y comercial del fruto del melón de los tres años de ensayo 2011, 2012 y 2013.

En los dos primeros años de estudio la incorporación de compost aumento significativamente el rendimiento del melón (Tabla 4.3.1). En 2011 solo la aplicación de las dosis más altas $\left(D_{2}\right.$ y $\left.D_{3}\right)$ dio como resultado un mayor rendimiento con respecto al control (23\% y $22 \%$, respectivamente). Sin embargo, en 2012, la mejora del rendimiento de los cultivos con compost se observó independiente de la dosis aplicada (aumentando el 11\% como promedio). 
Como se aprecia en la tabla 4.3.1 el incremento de cosecha el 2012, se debió a un aumento significativo en el número y peso de frutos.

La eficiencia de manejo (ME), calculada como la relación entre el rendimiento $\left(t \mathrm{ha}^{-1}\right.$ ) y la cantidad de nitrógeno lixiviado $\left(\mathrm{kg} \mathrm{ha}^{-1}\right)$ (Castellanos et al., 2013), dato importante en zonas vulnerables, se muestra en la tabla 4.3.1.

Tabla 4.3.1 Producciones, pesos medios, $n^{\circ}$ de frutos y eficiencia de manejo (ME) en función de la dosis de compost.

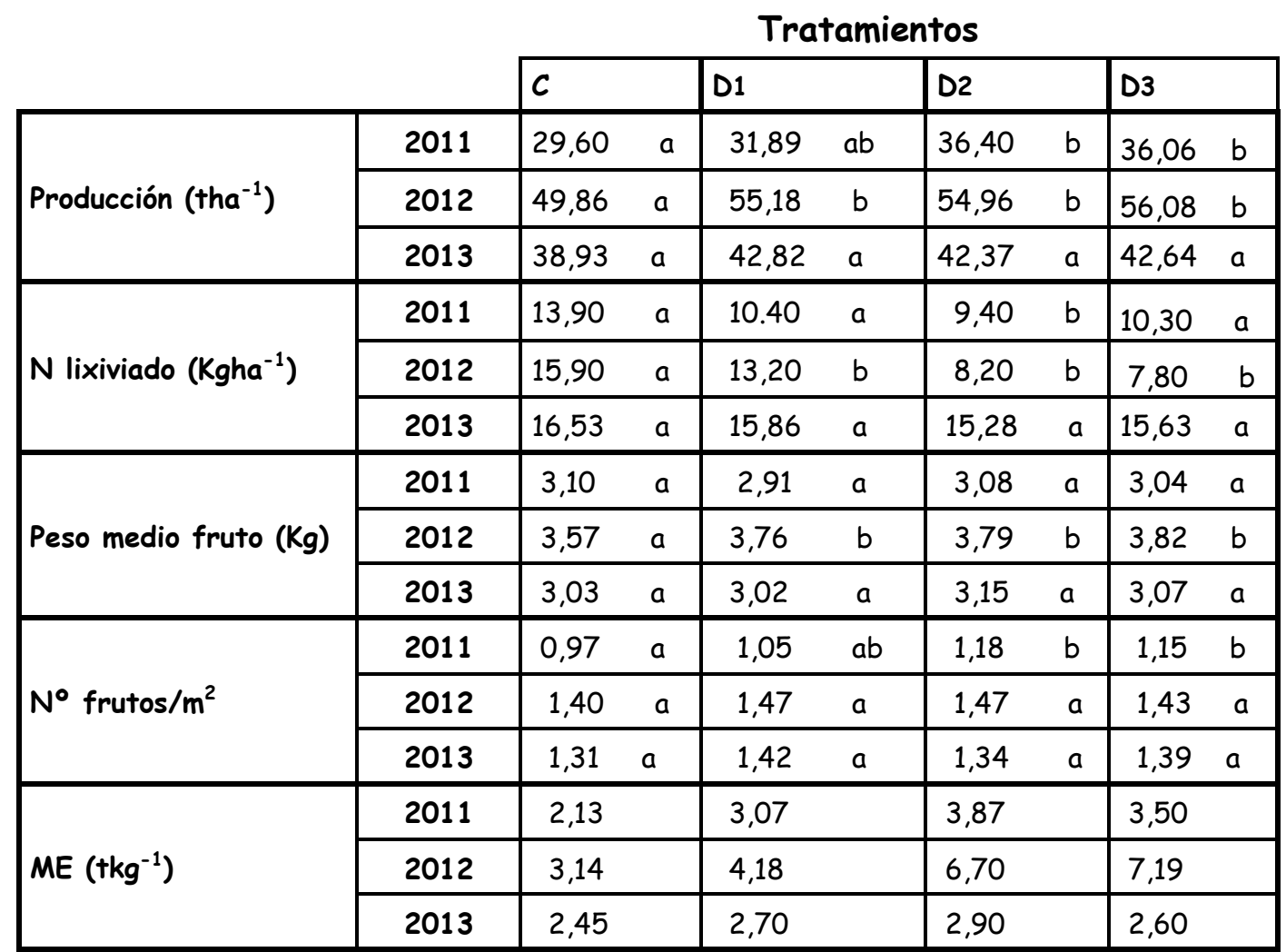

*Para un mismo parámetro y año resultados seguidos de la misma letra, no son diferentes con una significación $(p \leq 0,05)$.

La eficiencia de manejo aumentó con la aplicación de compost de orujo y con la dosis los dos primeros años, ya que no sólo se produjo un incremento de cosecha, sino que además, disminuyó la cantidad de nitrógeno lixiviado. En el 2013, se obtuvieron valores inferiores del ME respecto al 2011 y 2012, al producirse simultáneamente, una disminución de la cosecha y una mayor cantidad de nitrógeno lixiviado. 
En la figura 4.3.3 se representan las relaciones entre el rendimiento relativo de melón con el total de los nutrientes ( $N$ y $P$ ) aplicados (agua de riego + compost según la dosis del mismo) y los absorbidos por la planta.
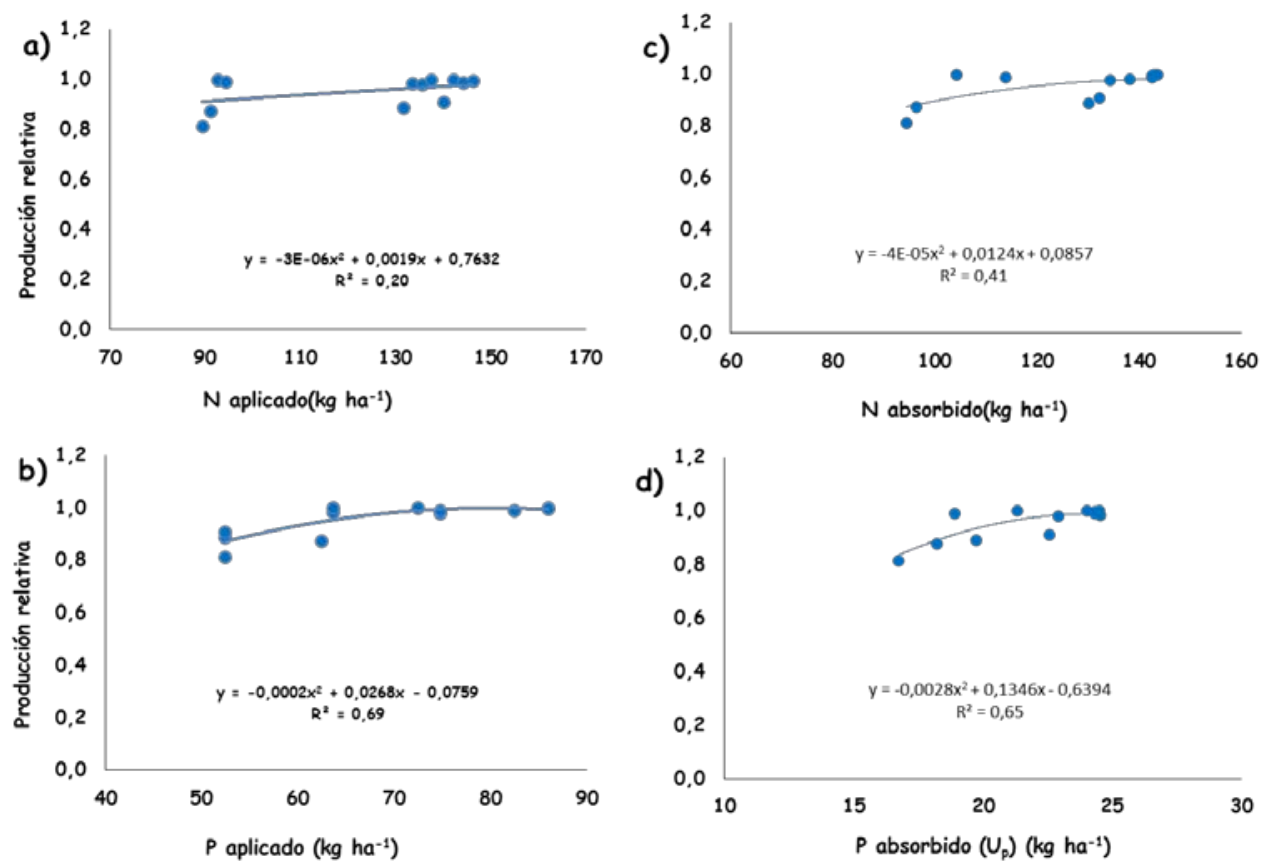

Figura 4.3.3 Producción relativa de fruto de melón frente a) al $N$ aplicado $\left(N_{A}\right)$ y b) al $P$ aplicado $\left(P_{A}\right)$ c) al $N$ absorbido $\left(U_{N}\right)$ y d) al $P$ absorbido $\left(U_{P}\right)$.

*El rendimiento relativo se calculó mediante la relación entre el rendimiento en fruto obtenido con cada uno de los tratamientos y el rendimiento máximo. El nutriente aplicado ( $N$ o $P)$, incluye el aportado con el agua de riego y el procedente del compost.

En el caso del N, la máxima producción relativa se obtendría con la aplicación de $158 \mathrm{~kg} \mathrm{~N} \mathrm{ha}^{-1}$ (Figura 4.3 .3 a) y la máxima absorción seria $155 \mathrm{~kg} \mathrm{~N}$ $\mathrm{ha}^{-1}$ para la producción relativa máxima (Figura $4.3 .3 \mathrm{c}$ ), dato que coincide con lo obtenido por Castellanos et al. (2010) en un cultivo de melón con fertirrigación. Este valor máximo de $\mathrm{N}$ absorbido, puede ser interpretado como la cantidad mínima de $\mathrm{N}$ a la que debe tener acceso el cultivo para obtener la producción máxima. En el caso del $P$, la máxima producción relativa se obtendría con la aplicación de $67 \mathrm{~kg} \mathrm{P} \mathrm{ha}^{-1}$ (Figura 4.3 .3 b) y la máxima absorción seria $24 \mathrm{~kg} P$ $\mathrm{ha}^{-1}$ para la producción relativa máxima (Figura 4.3.3 d). En nuestro ensayo el efecto del compost en la eficacia de la absorción de $P$ por la planta es muy ligero debido a que en todos los tratamientos se aplicó una importante fuente de 
fósforo inorgánico (ácido fosfórico) que cubría con creces las necesidades del cultivo.

\section{INFLUENCIA DE LA DOSIS DE COMPOST EN LA CALIDAD}

\section{DEL MELÓN}

En la tabla 4.3.2 se recogen diferentes parámetros de calidad del melón

Tabla 4.3.2 Parámetros de calidad del melón en función de la dosis de compost aplicada.

\begin{tabular}{|c|c|c|c|c|c|c|c|c|c|c|c|c|c|}
\hline Tratamiento & Años & & $c$ & & & $D_{1}$ & & & $D_{2}$ & & & $D_{3}$ & \\
\hline \multirow{3}{*}{ Longitud (cm) } & 2011 & 21,4 & $\pm 1,4$ & & 24,3 & $\pm 1,4$ & $b$ & 24,8 & $\pm 0,83$ & & 24,3 & $\pm 1,7$ & $b$ \\
\hline & 2012 & 25,9 & $\pm 0,2$ & & 26,9 & $\pm 1,4$ & $b$ & 27,0 & $\pm 0,31$ & & 27,1 & $\pm 0,13$ & $b$ \\
\hline & 2013 & 24,8 & $\pm 0,3$ & & 24,3 & $\pm 0,7$ & $a$ & 24,6 & $\pm 0,19$ & & 24,4 & $\pm 0,71$ & $a$ \\
\hline \multirow{3}{*}{ Anchura $(\mathrm{cm})$} & 2011 & 15,0 & $\pm 1,0$ & $a$ & 15,9 & $\pm 0,7$ & $a b$ & 16,5 & $\pm 0,44$ & & 16,5 & $\pm 0,56$ & $b$ \\
\hline & 2012 & 16,9 & $\pm 0,1$ & $a$ & 17,6 & $\pm 0,3$ & $b$ & 17,3 & $\pm 0,36$ & & 17,4 & $\pm 0,18$ & $b$ \\
\hline & 2013 & 16,0 & $\pm 0,1$ & $a$ & 16,0 & $\pm 0,7$ & $a$ & 16,1 & $\pm 0,36$ & & 15,6 & $\pm 0,46$ & $a$ \\
\hline \multirow{3}{*}{ Grosor pulpa $(\mathrm{cm})$} & 2011 & 4,0 & $\pm 0,2$ & & 4,2 & $\pm 0,3$ & $a$ & 4,4 & $\pm 0,19$ & & 4,5 & $\pm 0,15$ & $a$ \\
\hline & 2012 & 4,4 & $\pm 0,2$ & & 4,6 & $\pm 0,1$ & $a b$ & 4,5 & $\pm 0,29$ & & 4,7 & $\pm 0,16$ & $b$ \\
\hline & 2013 & 4,6 & $\pm 0,1$ & & 4,5 & $\pm 0,1$ & $a$ & 4,6 & $\pm 0,13$ & & 4,4 & $\pm 0,2$ & $a$ \\
\hline \multirow{3}{*}{ Grosor cort. (mm) } & 2011 & 5,9 & $\pm 0,5$ & & 6,2 & $\pm 0,5$ & $a$ & 6,7 & $\pm 0,07$ & & 6,3 & $\pm 0,26$ & $a$ \\
\hline & 2012 & 7,5 & $\pm 0,1$ & & 7,8 & $\pm 0,3$ & $a$ & 7,5 & $\pm 0,44$ & & 7,5 & $\pm 0,42$ & $a$ \\
\hline & 2013 & 6,8 & $\pm 0,1$ & & 6,7 & $\pm 0,3$ & $a$ & 7,2 & $\pm 0,28$ & & 6,7 & $\pm 0,04$ & $a$ \\
\hline \multirow{3}{*}{ Firmeza pulpa (kg) } & 2011 & 2,6 & $\pm 0,1$ & & 2,8 & $\pm 0,1$ & $a$ & 2,9 & $\pm 0,16$ & & 2,9 & $\pm 0,01$ & $a$ \\
\hline & 2012 & 2,9 & $\pm 0,1$ & & 2,9 & $\pm 0,1$ & $a$ & 2,9 & $\pm 0,21$ & & 2,7 & $\pm 0,01$ & $a$ \\
\hline & 2013 & 3,0 & $\pm 0,03$ & & 2,9 & $\pm 0,1$ & $a$ & 3,0 & $\pm 0,11$ & & 3,0 & $\pm 0,08$ & $a$ \\
\hline \multirow{3}{*}{ Indice pulpa } & 2011 & 0,53 & $\pm 0,02$ & & 0,53 & \pm 0 & $a$ & 0,54 & $\pm 0,03$ & & 0,54 & $\pm 0,01$ & $a$ \\
\hline & 2012 & 0,52 & $\pm 0,02$ & & 0,52 & \pm 0 & $a$ & 0,52 & $\pm 0,03$ & & 0,54 & $\pm 0,02$ & $a$ \\
\hline & 2013 & 0,58 & $\pm 0,02$ & & 0,57 & \pm 0 & $a$ & 0,57 & $\pm 0,03$ & $a$ & 0,56 & $\pm 0,03$ & $a$ \\
\hline \multirow{3}{*}{ Azúcar $\left({ }^{\circ}\right.$ Brix $)$ ) } & 2011 & 11,6 a & $\pm 0,9$ & & 12,5 & $\pm 0,6$ & $a$ & 12,3 & $\pm 0,83$ & & 12,5 & $\pm 0,28$ & $a$ \\
\hline & 2012 & 13,3 a & $\pm 0,5$ & $a$ & 13,9 & $\pm 0,6$ & $a b$ & 13,8 & $\pm 0,27$ & $a b$ & 14,2 & $\pm 0,07$ & $b$ \\
\hline & 2013 & 13,5 a & $\pm 0,5$ & $a$ & 13,1 & $\pm 0,5$ & $a$ & 13,7 & $\pm 0,84$ & & 13,7 & $\pm 0,9$ & a \\
\hline
\end{tabular}

*Para un mismo parámetro y año, los valores seguidos de la misma letra no tienen diferencias significativas $(p \leq 0,05)$.

Los dos primeros años (2011 y 2012), la aplicación de compost produjo frutos de mayor calibre, tanto en longitud como en anchura. Sin embargo, en el año 2013 no se encontraron diferencias significativas entre tratamientos. Únicamente en el año 2012 hubo diferencias significativas en el grosor de la pulpa respecto al control, aunque en 2011 se observó la misma tendencia. 
Idéntico comportamiento se obtuvo en el contenido de azúcar de los frutos ('Brix). En el resto de los parámetros analizados, no se observaron diferencias significativas con la aplicación de compost de orujo en ningún año.

En un trabajo paralelo con paneles de cata, realizado por Gonzalez, M.A. (no publicado), se obtuvo, que los melones obtenidos mediante el tratamiento $D_{2}$ fueron los que presentaron mayores intensidades de sabor y olor, menores intensidades de olor a verde y a pepino y notas más dulces y afrutadas, produciéndose sin embargo, una disminución de la calidad sensorial de los melones, apareciendo o intensificándose algunos atributos como el olor a pepino y a verde, cuando el cultivo se fertilizaba con una dosis más elevada de compost de orujo de uva.

4.4. Impacto ambiental del uso del compost de orujo en zonas vulnerables. Balances de nitrógeno y de fósforo

\section{$>$ BALANCE DE N EN EL SISTEMA SUELO-PLANTA}

En la tabla 4.4 .1 se muestran el balance de $N$ para los tres años de ensayo. La cantidad total de $\mathrm{N}$ disponible aplicada en cada tratamiento, es la suma del $\mathrm{N}$ mineral aportado con el compost y el $\mathrm{N}$ contenido en el agua de riego, que fue distinto cada campaña $\left(89,40,131,60\right.$ y $140,00 \mathrm{~kg} \mathrm{ha}^{-1}$ los años 2011, 2012 y 2013 respectivamente). El $\mathrm{N}$ disponible total se consideró como la suma del $\mathrm{N}$ disponible aplicado más el $\mathrm{N}$ mineral del suelo antes de trasplantar las plantas de melón. El $\mathrm{N}$ total absorbido se determinó como la suma del $\mathrm{N}$ absorbido por cada órgano de la planta incluido los frutos.

Como se puede apreciar, la principal entrada de $N$ en los tres años de experimentación, se debe al agua de riego. Esta importante entrada de $\mathrm{N}$ se debe a la alta concentración en nitratos en las aguas subterráneas, que son la fuente del agua de riego en este zona (Castellanos et al., 2013). Dichas concentraciones fueron 116, 125 y 135 ppm los años 2011, 2012 y 2013 respectivamente. Esta es la razón por la cuál, la contribución de nitrógeno mineral aportada con el compost del total del $\mathrm{N}$ aplicado fuera insignificante (entre 1,63 y $6,22 \mathrm{~kg} \mathrm{ha}^{-1}$ ) y como consecuencia, que dentro del mismos año las diferencias entre tratamientos fueran pequeñas. 
Tabla 4.4.1 Balance de $N$ en el sistema suelo-planta en los años 2011,2012 y 2013 en $\mathrm{kg} \mathrm{ha}^{-1}$.

\begin{tabular}{|c|c|c|c|c|c|c|c|c|c|c|c|c|c|}
\hline \multirow[t]{2}{*}{ BALANCE } & \multicolumn{2}{|l|}{ (kg N/ha) } & \multicolumn{3}{|c|}{ ENTRADAS } & \multicolumn{7}{|c|}{ SALIDAS } & BALANCE \\
\hline & Tratamiento & $\begin{array}{l}\mathrm{N} \text { min } \\
\text { compost }\end{array}$ & $N$ agua riego & $\begin{array}{c}N \text { suelo } \\
\text { inicial }\end{array}$ & TOTAL & $\begin{array}{c}\text { Extracción } \\
\text { cultivo }\end{array}$ & & N lixiviado & & N suelo finc & & TOTAL & Ent-Salidas \\
\hline \multirow{4}{*}{2011} & c & 0 & 89,40 & 61,33 & 150,73 & 94,40 & a & 13,90 & $a$ & 73,29 & $\mathrm{a}$ & 181,59 & $-30,86$ a \\
\hline & $D_{1}$ & 1,63 & 89,40 & 59,32 & 150,35 & 96,20 & a & 10,40 & a & 89,00 & b & 195,60 & $-45,25$ b \\
\hline & $D_{2}$ & 3,27 & 89,40 & 60,38 & 153,05 & 104,20 & a & 9,40 & a & 138,18 & c & 251,78 & $-98,73$ \\
\hline & $D_{3}$ & 4,90 & 89,40 & 58,26 & 152,56 & 113,80 & a & 10,30 & a & 141,25 & c & 265,35 & $-112,79 d$ \\
\hline & c & 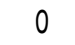 & 131,60 & 55,44 & 187,04 & 130,10 & a & 15,90 & b & 65,00 & c & 211,00 & $-23,96 \quad a$ \\
\hline & $D_{1}$ & 1,97 & 131,60 & 64,98 & 198,55 & 138,00 & a & 13,20 & $a b$ & 83,88 & b & 235,08 & $-36,53 \mathrm{~b}$ \\
\hline & $D_{2}$ & 3,95 & 131,60 & 57,21 & 192,76 & 134,20 & a & 8,20 & $a$ & 115,15 & c & 257,55 & $-64,79 \mathrm{c}$ \\
\hline & $D_{3}$ & 5,92 & 131,60 & 51,94 & 189,46 & 142,80 & a & 7,80 & $a$ & 137,03 & d & 287,63 & $-98,17 d$ \\
\hline & $c$ & 0 & 140,10 & 75,20 & 215,30 & 132,21 & a & 16,50 & a & 85,80 & c & 236,26 & $-18,86$ a \\
\hline & $D_{1}$ & 2,07 & 140,10 & 82,24 & 224,41 & 143,50 & a & 15,86 & a & 89,48 & 0 & 248,84 & $-24,43 a$ \\
\hline & $D_{2}$ & 4,15 & 140,10 & 84,16 & 228,41 & 142,46 & $a$ & 15,28 & a & 114,31 & 6 & 272,05 & $-43,64 \quad b$ \\
\hline & $D_{3}$ & 6,22 & 140,10 & 91,58 & 237,90 & 142,53 & a & 15,63 & $a$ & 150,19 & $c$ & 308,35 & $-70,45$ \\
\hline
\end{tabular}

*En cada año los valores seguidos de la misma letra no tienen diferencias significativas $(p \leq 0,05)$.

En los años en que tuvo lugar el experimento de campo, no hubo diferencias significativas en la extracción de $N$ por el cultivo entre tratamientos. Castellanos et al. (2012) recomendó en las mismas condiciones para el cultivo de melón, aplicaciones de $\mathrm{N}$ de $90-100 \mathrm{~kg} \mathrm{ha}^{-1}$, dichas cantidades en todos los casos fueron cubiertas con lo aportado por el agua de riego, lo que podría explicar la ausencia de respuesta de la absorción de $\mathrm{N}$ a la aplicación de compost.

Como se puede observar en la tabla 4.4.1, al final del ciclo del cultivo se produjo un incremento en el contenido en nitrógeno mineral del suelo que dependió de la dosis de compost aplicada, como consecuencia de la mineralización del nitrógeno orgánico.

Las pérdidas de $\mathrm{N}$ por lixiviación, se producen cuando hay una alta cantidad de $\mathrm{NO}_{3}{ }^{-}$en el suelo junto con un alto volumen de drenaje ( $\mathrm{Di}$ y Cameron, 2002). Las pérdidas por drenaje fueron bajas durante la temporada de crecimiento del cultivo, produciéndose un incremento tras la senescencia del melón con el consiguiente aumento del $\mathrm{N}$ lixiviado (Figura 4.4.1). 

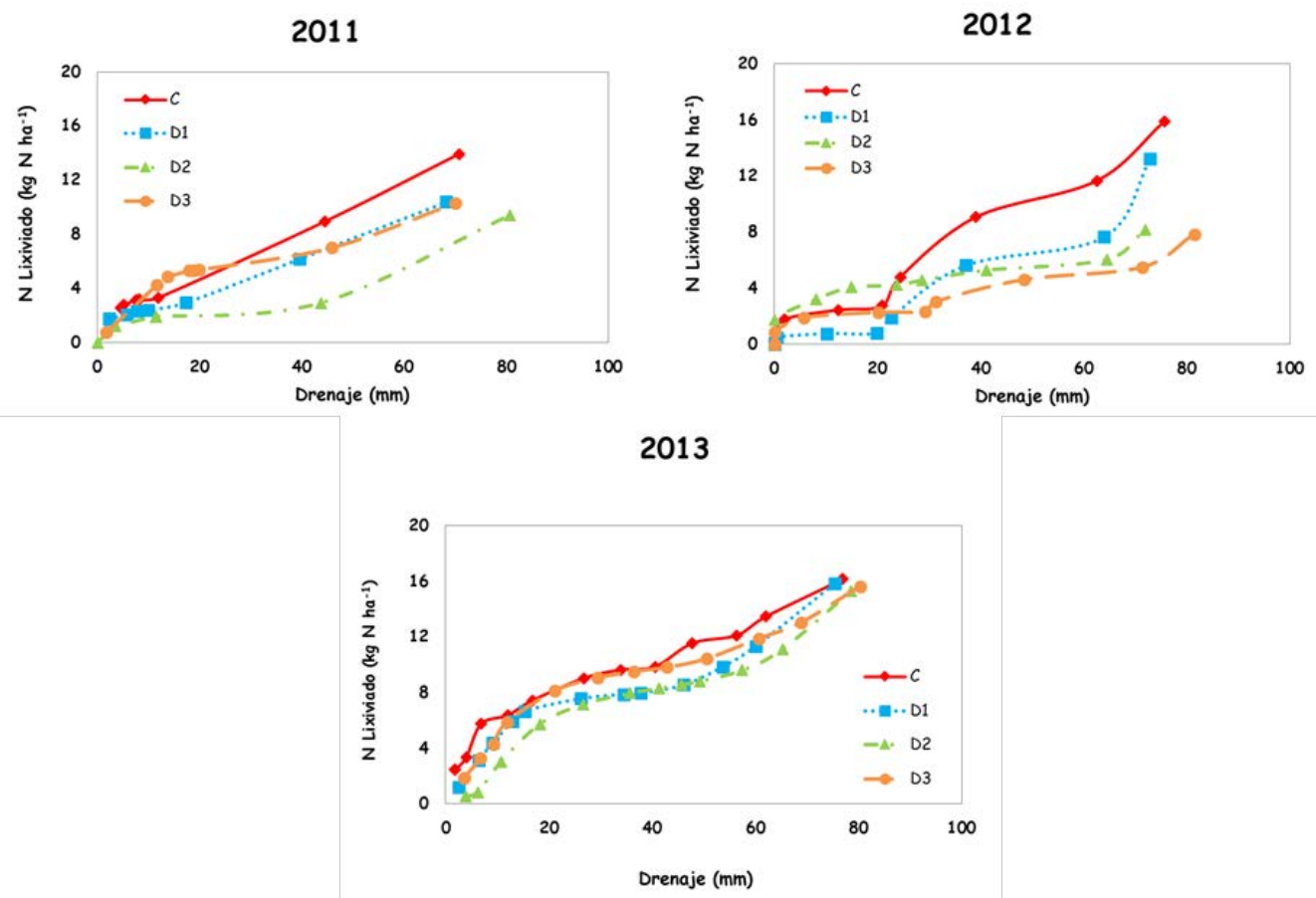

Figura 4.4.1 Cantidad de $\mathrm{N}$ lixiviado $\left(\mathrm{kg} \mathrm{N} \mathrm{ha}^{-1}\right)$ en función del drenaje $(\mathrm{mm})$ en los distintos años de ensayo (2011, 2012 y 2013) según los distintos tratamientos (C. $D_{1}, D_{2}$ y $\left.D_{3}\right)$.

En la tabla 4.4 .2 se recogen los datos del drenaje $(\mathrm{mm})$ y nitrógeno perdido por lixiviación ( $\mathrm{kg} \mathrm{N} \mathrm{ha}^{-1}$ ) acumulados con los diferentes tratamientos en los tres años estudiados.

Tabla 4.4.2 Datos de drenaje y $N$ lixiviado acumulado en los años 2011, 2012 y 2013 en kg ha ${ }^{-1}$.

\begin{tabular}{|c|c|c|c|}
\cline { 2 - 4 } \multicolumn{1}{c|}{2011} & Tratamiento & $\begin{array}{c}\text { Drenaje } \\
(\mathrm{mm})\end{array}$ & $\begin{array}{c}\text { N lixiviado } \\
\left(\mathrm{kg} \mathrm{N} \mathrm{ha}^{-1}\right)\end{array}$ \\
\hline \multirow{6}{*}{2012} & C & $70,8 \mathrm{a}$ & $13,9 \mathrm{a}$ \\
& D1 & $68,3 \mathrm{a}$ & $10,4 \mathrm{a}$ \\
& D2 & $80,7 \mathrm{a}$ & $9,4 \mathrm{a}$ \\
& D3 & $70,0 \mathrm{a}$ & $10,3 \mathrm{a}$ \\
\hline \multirow{6}{*}{2013} & C & $92,0 \mathrm{a}$ & $15,9 \mathrm{~b}$ \\
& D1 & $92,9 \mathrm{a}$ & $13,2 \mathrm{ab}$ \\
& D2 & $88,3 \mathrm{a}$ & $8,2 \mathrm{a}$ \\
& D3 & $96,5 \mathrm{a}$ & $7,8 \mathrm{a}$ \\
\hline & C & $77,0 \mathrm{a}$ & $16,5 \mathrm{a}$ \\
& D1 & $75,5 \mathrm{a}$ & $15,9 \mathrm{a}$ \\
& D2 & $78,5 \mathrm{a}$ & $15,3 \mathrm{a}$ \\
& D3 & $80,3 \mathrm{a}$ & $15,6 \mathrm{a}$ \\
\hline
\end{tabular}

*En cada año los valores seguidos de la misma letra no tienen diferencias significativas $(p \leq 0,05)$. 
No se apreciaron diferencias significativas en el drenaje entre los distintos tratamientos los distintos años de ensayo, a pesar de presentar una clara tendencia a disminuir con la aplicación de las diferentes dosis de compost.

Durante todo el ciclo del cultivo en los tres años de ensayo, las mayores pérdidas de nitrógeno por lixiviación se produjeron en las parcelas del tratamiento control: 13,90 (2011), 15,90 (2012) y 16,50 (2013) $\mathrm{Kg} \mathrm{ha}^{-1}$, disminuyendo considerablemente con la aplicación del compost entre un 20\%$50 \%$ dependiendo de la dosis del compost y del año (Tabla 4.4.1). Únicamente en el año 2012, se obtuvieron diferencias significativas entre los tratamientos con dosis más altas de compost, $D_{2}$ y $D_{3}$ y el resto. Este efecto es contrario al observado por Castellanos et al. (2007) usando fertirrigacion en melón, en el que las pérdidas por lixiviación aumentaban exponencialmente con la cantidad de nitrógeno disponible aplicado.

La cantidad de nitrógeno mineralizado (NM) durante el ciclo del cultivo, obtenido por diferencias entre entradas y salidas, fue siempre mayor en las parcelas enmendadas con compost, siendo el efecto directamente proporcional a la dosis aplicada. En 2011 el rango de NM vario entre 30,86 y $112,79 \mathrm{~kg} \mathrm{ha}^{-1}$, en 2012 entre 23,96 y $98,17 \mathrm{~kg} \mathrm{ha}^{-1}$ y en 2013 entre 18,86 y $70,45 \mathrm{~kg} \mathrm{ha}^{-1}$.

Los valores correspondientes al índice de mineralización del nitrógeno (NMI) en los tres años de experimentación se recogen en la tabla 4.4.3.

Tabla 4.4.3 Valores del índice de mineralización los años 2011, 2012 y 2013.

\begin{tabular}{|c|c|c|c|c|c|}
\cline { 3 - 6 } \multicolumn{2}{c|}{$N M I=\frac{N M}{N d}$} & $C$ & $D_{1}$ & $D_{2}$ & $D_{3}$ \\
\hline \multirow{3}{*}{ NMI } & 2011 & 0,20 & 0,30 & 0,65 & 0,74 \\
\cline { 2 - 6 } & 2012 & 0,13 & 0,18 & 0,34 & 0,52 \\
\cline { 2 - 6 } & 2013 & 0,09 & 0,10 & 0,19 & 0,30 \\
\hline
\end{tabular}

Como se observa, dentro de un mismo año, este índice aumenta al aplicar compost respecto al testigo y con la dosis aplicada. Dicho aumento está comprendido entre $230 \%$ (2013) y $300 \%$ (2012) con la $D_{3}$ frente al control.

En la figura 4.4 .2 se representan los valores obtenidos para este índice los tres años del experimento junto con los obtenidos mediante fertirrigación por Castellanos et al. (2013). 


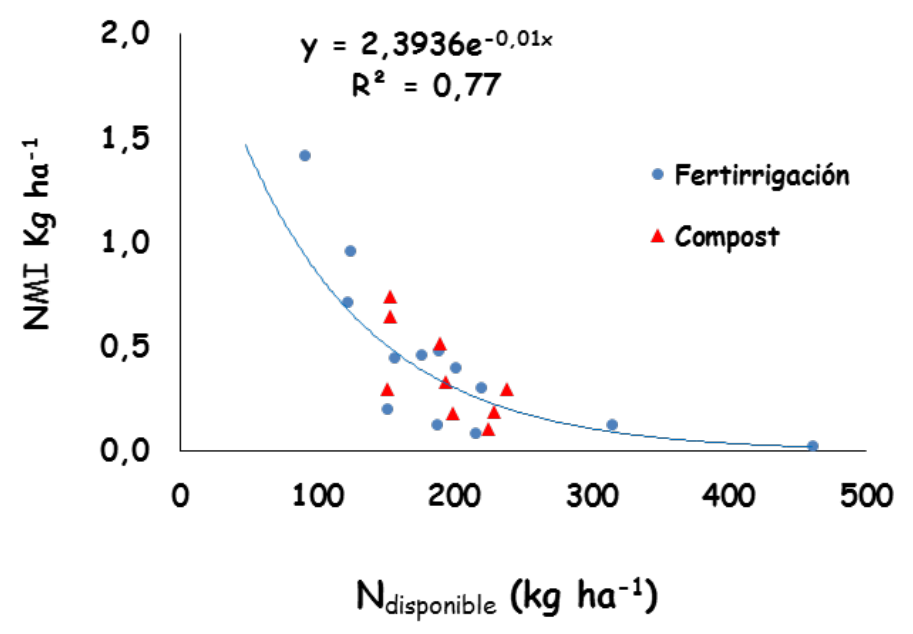

Figura 4.4.2 Índice de mineralización de nitrógeno (NMI) (fertirrigación y compost) versus $\mathrm{N}$ disponible.

La relación entre el índice de mineralización y el nitrógeno disponible es muy significativa, y está representada por una relación exponencial $\left(R^{2}=0,77\right)$, que indica, que un aumento en el nitrógeno disponible produce una disminución exponencial del NMI.

\section{BALANCE DE P EN EL SISTEMA SUELO-PLANTA}

El balance de $P$ en los tres años de experimento (entradas-salidas) se recoge en la tabla 4.4.4. Hay que destacar, que el $P$ aportado por el compost corresponde únicamente a la fracción de P lábil (apartado 3.3.3).

El contenido total de fosforo del compost de orujo fue de (6800-7600 $\mathrm{mg} \mathrm{kg} \mathrm{k}^{-1}$ ), del cual el $71 \%$ corresponde a $P$ inorgánico y el $29 \%$ a orgánico. EI $P$ soluble en agua representa aproximadamente un $11 \%$, el extraído con membrana un $7 \%$ y el extraído con bicarbonato sódico un $5 \%$, por lo que el $P$ lábil representa un $22 \%$ del total. Esta fracción está compuesta por $P$ ortofosfato y $P$ orgánico fácilmente degradable, como mono esteres lábiles, fosfolípidos, etc... (Turner and Leytem, 2004), que es de fácil disponibilidad para los cultivos (Grigatti et al., 2015, 2017; Tampio et al., 2016). 
La cantidad de $P$ disponible para el cultivo con cada tratamiento, corresponde a la suma del $P$ lábil aportado por el compost, el $P$ aportado con el agua de riego y el $P$ Olsen inicial del suelo antes de trasplantar las plantas de melón. EI P absorbido por el cultivo de melón, se determinó como la suma del P absorbido por cada órgano de la planta incluido los frutos.

Como se puede observar en la tabla 4.4 .4 al final del ciclo de cultivo, con la aplicación del compost, se produce un incremento del $P$ disponible en el suelo directamente proporcional a la dosis aplicada, existiendo los años 2012 y 2013 diferencias significativas ( $p \leq 0,05$ ) entre el control y todos los tratamientos, aunque no entre tratamientos.

Tabla 4.4.4 Balance de $P$ en el suelo al final del ensayo en los años 2011, 2012 y 2013.

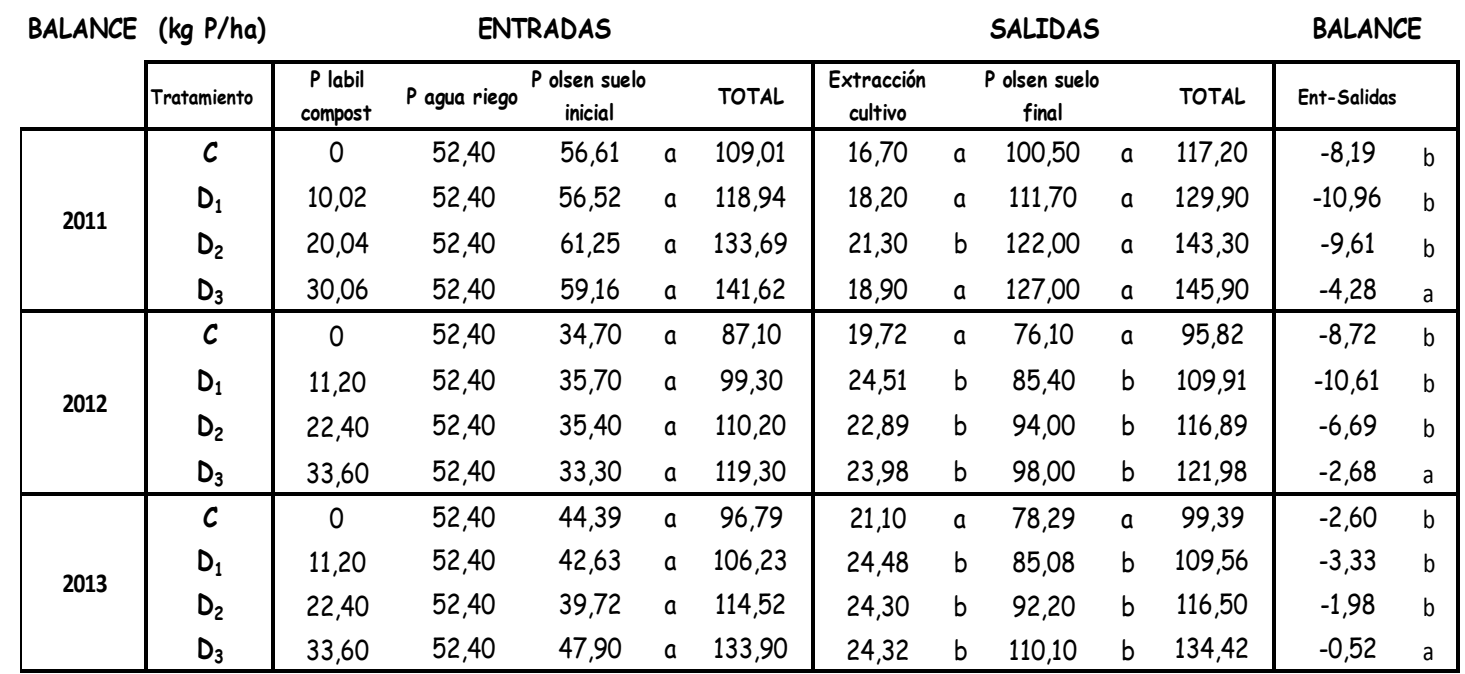

*En cada año los valores seguidos de la misma letra no tienen diferencias significativas $(p \leq 0,05)$.

Las mayores extracciones de $P$ por el cultivo, se obtuvieron en el año 2012 y 2013 con el tratamiento $D_{1}(24 \%$ y $16 \%$ respectivamente respecto a los controles), existiendo diferencias significativas $(p \leq 0,05)$ entre las diferentes dosis utilizadas y el control. En el año 2011, solo se produjeron diferencias significativas $(p \leq 0,05)$ con el tratamiento $D_{2}$ respecto al resto. La cantidad de $P$ lixiviado obtenido, fue despreciable razón por la cual no se ha incluido en el balance (Gros, 1992). 
La acumulación de $P$ en la capa superficial del suelo al final del año de aplicación del compost, se debe por una parte a la mineralización del $\mathrm{P}$ orgánico, y por otra, al incremento de la movilidad de este elemento debido al efecto de la materia orgánica (Eghball et al., 1996; Whalen and Chang, 2001; Bar-Tal et al., 2004).

A diferencia del $N$, cuando se añade $P$ al suelo procedente de fertilizantes o de residuos orgánicos, se producen una serie de complejas reacciones tanto químicas como biológicas que pueden retirar el fósforo de la disolución del suelo, aunque se encuentre en forma de iones dihidrogenofosfato. Sin embargo, esto no implica que el $P$ no se encuentre disponible para el cultivo. En la tabla 4.4.4, se observa como se ha producido un balance negativo (entradas-salidas) lo que implica que se ha producido una movilización del $P$ procedente del residuo o del suelo.

Los valores correspondientes al índice de recuperación de fosforo, calculado como la relación entre el fosforo recuperado y el fosforo inicial disponible en el suelo, son muy bajos en todos los casos como consecuencia de las características del suelo, razón por la cual, no se muestran.

\subsection{Indices de eficiencia del uso de nitrógeno y del fósforo para optimizar el uso del compost de orujo en un cultivo de melón}

\section{EFICIENCIA DEL USO DEL N}

En la tabla 4.5 .1 se recogen los valores de los diferentes índices de eficacia del uso del $\mathrm{N}$ obtenidos en el sistema suelo planta (2011, 2012 y 2013).

Los cuatro primeros índices, están relacionados con la producción total de melón/biomasa y el nitrógeno, aplicado/absorbido, $\left(P F P_{N}, A E_{N}, I E_{N} y\right.$ TBNUEN), mientras que los tres últimos $\left(N U_{p} E_{N}, R E_{N}\right.$ y $\left.N H I_{N}\right)$, están relacionados con la extracción del nutriente, en este caso el nitrógeno. 
Tabla 4.5.1 Índices de eficiencia del uso del $\mathrm{N}$ en el sistema suelo planta en los años 2011, 2012 y 2013.

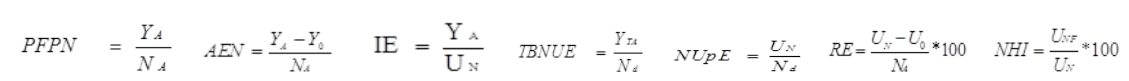

\begin{tabular}{|c|c|c|c|c|c|c|c|c|}
\hline & \multirow{2}{*}{ Tratamiento } & $\operatorname{PFP}_{N}$ & $A E_{N}$ & $\mathrm{IE}_{\mathrm{N}}$ & TBNUE $_{\mathrm{N}}$ & $\mathrm{NUpE}_{\mathrm{N}}$ & $\mathrm{RE}_{\mathrm{N}}$ & $N H I_{N}$ \\
\hline & & \multicolumn{5}{|c|}{$\left(\mathrm{Kgkg}^{-1}\right)$} & \multicolumn{2}{|c|}{$\%$} \\
\hline \multirow{4}{*}{2011} & $c$ & 331,10 & - & 313,56 & 41,08 & 0,63 & - & 53,71 \\
\hline & $D_{1}$ & 350,32 & 25,16 & 331,50 & 42,25 & 0,64 & 1,98 & 63,62 \\
\hline & $D_{2}$ & 392,79 & 73,38 & 349,33 & 42,97 & 0,68 & 10,58 & 60,08 \\
\hline & $D_{3}$ & 382,40 & 68,50 & 316,87 & 44,76 & 0,75 & 20,57 & 62,39 \\
\hline \multirow{4}{*}{2012} & $c$ & 378,88 & - & 383,24 & 40,50 & 0,70 & - & 53,50 \\
\hline & $D_{1}$ & 413,12 & 39,83 & 399,86 & 44,32 & 0,70 & 5,91 & 57,68 \\
\hline & $D_{2}$ & 405,46 & 37,62 & 409,54 & 43,51 & 0,70 & 3,02 & 54,62 \\
\hline & $D_{3}$ & 407,80 & 45,23 & 392,72 & 45,83 & 0,75 & 9,24 & 52,38 \\
\hline \multirow{4}{*}{2013} & $c$ & 277,89 & - & 294,49 & 34,78 & 0,61 & - & 48,71 \\
\hline & $D_{1}$ & 301,19 & 27,34 & 298,48 & 34,63 & 0,64 & 7,92 & 53,39 \\
\hline & $D_{2}$ & 293,73 & 23,83 & 297,41 & 36,96 & 0,62 & 7,11 & 50,54 \\
\hline & $D_{3}$ & 291,42 & 25,34 & 299,18 & 34,55 & 0,60 & 7,05 & 48,83 \\
\hline
\end{tabular}

Dentro de los índices relacionados con la producción y por lo tanto con el valor económico del cultivo, en todos los casos, la aplicación de compost de orujo produce un incremento de los mismos respecto al testigo. Sin embargo no existe una clara influencia de la dosis de compost, Así, en el año 2011, la dosis $D_{2}$ es la más eficaz en aquellos índices relacionados con la producción de fruto, no así en el caso del TBNUE $E_{N}$, que depende de la biomasa total. En 2012 y 2013 los resultados son variables no existiendo diferencias significativas entre dosis.

En el caso de los índices relacionados con la absorción de nitrógeno, únicamente se aprecia el efecto de la dosis de compost los dos primeros años en el $R E_{N}$, destacando la dosis $D_{3}$. En el caso del índice de cosecha, la dosis $D_{1}$ produce el valor más alto.

Hay que destacar los bajos índices de eficacia obtenidos en el año 2013. Ello puede ser debido a las diferentes características del compost utilizado ese año mucho más estable que en los años anteriores. 


\section{> EFICIENCIA DEL USO DE FÓSFORO}

Hay que tener en cuenta, que tanto el rendimiento de un cultivo como el $P$ absorbido por el mismo, no dependen únicamente de la disponibilidad del $P$ que se encuentra en el suelo, sino también de otros factores que varían cada año: clima, la disponibilidad de otros nutrientes, N y K fundamentalmente, el estrés fisiológico y otros factores que dependen del tipo de suelo, como su estructura.

Dado que en los experimentos de campo (ver balance de $N$ ) las cantidades de $\mathrm{N}$ disponible en el suelo han variado cada año, fundamentalmente por la cantidad de $\mathrm{N}$ aportado por el agua de riego, los datos de eficiencia de fósforo interanuales no son comparables. Sin embargo, si lo son los obtenidos con los diferentes tratamientos cada año, ya que las diferencias en el contenido de $\mathrm{N}$ disponible procedente del suelo son poco significativas. Por otra parte, la cantidad de $P$ aportado en el agua de riego es prácticamente constante a lo largo de los años, a diferencia del contenido en $P$ Olsen del suelo. Las diferencias interanuales en el contenido de $P$ lábil del compost de orujo son poco significativas. Esta es la razón por la que las variaciones en un mismo año de los índices de eficiencia pueden ser atribuidas a la dosis de compost.

Hay que destacar que al igual que se hizo en el balance de fósforo, para el cálculo de los índices de eficiencia, únicamente se han tenido en cuenta las formas de $P$ disponible tanto en el caso del suelo como en el del compost.

En la tabla 4.5.2 se recogen los valores de los diferentes índices obtenidos de la eficiencia del uso del P en el sistema suelo planta (2011, 2012 y 2013).

Al igual que en el caso del $N$ los cuatro primeros índices, están relacionados con la producción total de melón y el fosforo, aplicado o absorbido, $\left(P F P_{p}, A E_{p}, I E_{p}\right.$ y $T B N U E_{p}$ ), mientras que los tres últimos ( $N U_{p} E_{p}, R E_{p}$ y $\left.N H I_{p}\right)$, están relacionados con la extracción del nutriente, en este caso el fosforo. 
Tabla 4.5.2 Índices de eficiencia del uso del $P$ en el sistema suelo planta en los años 2011,2012 y 2013.

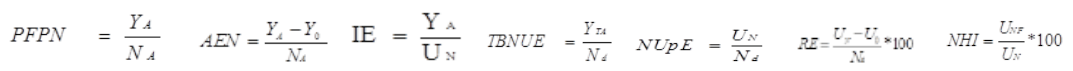

\begin{tabular}{|c|c|c|c|c|c|c|c|c|}
\hline & \multirow{2}{*}{ Tratamiento } & PFP $_{p}$ & $A E_{p}$ & IEp & TBNUE $_{p}$ & NUpEp & $R E_{p}$ & $N H I_{p}$ \\
\hline & & \multicolumn{5}{|c|}{$\left(\mathrm{Kgkg}^{-1}\right)$} & \multicolumn{2}{|c|}{$\%$} \\
\hline \multirow{4}{*}{2011} & $c$ & 564,89 & - & 1772,46 & 56,80 & 0,15 & - & 53,89 \\
\hline & $D_{1}$ & 510,89 & 36,69 & 1752,20 & 53,41 & 0,15 & 2,40 & 44,51 \\
\hline & $D_{2}$ & 502,48 & 93,87 & 1708,92 & 49,20 & 0,16 & 6,35 & 64,79 \\
\hline & $D_{3}$ & 437,30 & 78,34 & 1907,94 & 48,22 & 0,13 & 2,67 & 60,32 \\
\hline \multirow{4}{*}{2012} & $c$ & 951,53 & - & 2527,83 & 86,98 & 0,23 & - & 45,63 \\
\hline & $D_{1}$ & 867,60 & 83,65 & 2251,54 & 88,63 & 0,25 & 7,52 & 49,78 \\
\hline & $D_{2}$ & 734,75 & 68,18 & 2401,18 & 76,10 & 0,21 & 4,23 & 41,07 \\
\hline & $D_{3}$ & 652,09 & 72,33 & 2338,37 & 72,79 & 0,20 & 4,95 & 38,78 \\
\hline \multirow{4}{*}{2013} & $c$ & 743,00 & - & 1726,18 & 77,37 & 0,23 & - & 39,90 \\
\hline & $D_{1}$ & 673,26 & 61,12 & 1749,58 & 73,15 & 0,23 & 3,02 & 49,85 \\
\hline & $D_{2}$ & 566,44 & 45,95 & 1743,32 & 73,71 & 0,21 & 2,34 & 38,68 \\
\hline & $D_{3}$ & 495,83 & 43,12 & 1753,67 & 61,39 & 0,18 & 2,05 & 38,25 \\
\hline
\end{tabular}

En el caso de índices de $P$ relacionados con la producción de fruto, únicamente la aplicación de compost e independientemente del año de estudio, disminuye el factor parcial de productividad (PFP $)$ respecto al control, siendo el efecto directamente proporcional a la dosis de compost aplicada. No existe un efecto marcado en el caso de los otros dos índices ( $A E_{p}$ y $I E_{p}$ ). En el caso del TBNUE $_{p}$, el comportamiento es semejante al PFP. En el caso de los índices relacionados con la absorción de fósforo, los resultados no son concluyentes.

En general, en todos los casos se ha observado una clara influencia positiva de la aplicación del compost en los índices de eficiencia tanto en el caso del nitrógeno como en el del fósforo, sin embargo no se ha obtenido un efecto claro de la dosis de aplicación.

\subsection{La aplicación del compost de orujo frente a la fertirrigación: Evaluación agronómica y ambiental \\ Con el fin de poder comparar los resultados obtenidos mediante la aplicación de compost de orujo de vid con los del método tradicional de producción de la zona (fertirrigación), se han representado en la misma grafica}


(Figura 4.6.1) los datos de las producciones relativas del cultivo de melón frente al $\mathrm{N}$ disponible independientemente de la fuente de procedencia. Los datos correspondientes a fertirrigación han sido obtenidos de Castellanos et al., 2010, 2013 en un ensayo de tres años, con diferentes dosis de nitrógeno aplicado como nitrato amónico, realizado con el mismo cultivo y misma zona.

Se han utilizado en todos los casos, la producción relativa de melón, para poder comparar datos correspondientes a diferentes campañas, representando en el eje de abscisas el $\mathrm{N}$ total disponible, que incluye en este caso, tanto el $\mathrm{N}$ aplicado con el agua de riego y en su caso del compost de orujo, como el $\mathrm{N}$ mineralizado a lo largo del ciclo de cultivo.

En los dos casos, aplicación de compost de orujo y fertirrigación, los datos se ajustan a una curva polinómica de segundo orden (Figura 4.6.1). En el caso de la fertirrigación, se obtiene un rendimiento relativo máximo con $315 \mathrm{~kg}$ de $\mathrm{N}$ total disponible $\mathrm{ha}^{-1}$. Con los tratamientos de compost de orujo, el rendimiento máximo se logra con cantidades de $\mathrm{N}$ disponibles más bajas, lo que implica un efecto positivo sobre la producción, de la incorporación al suelo de este residuo, hecho importante en una zona vulnerable, con altas concentraciones de nitratos en la propia agua de riego.

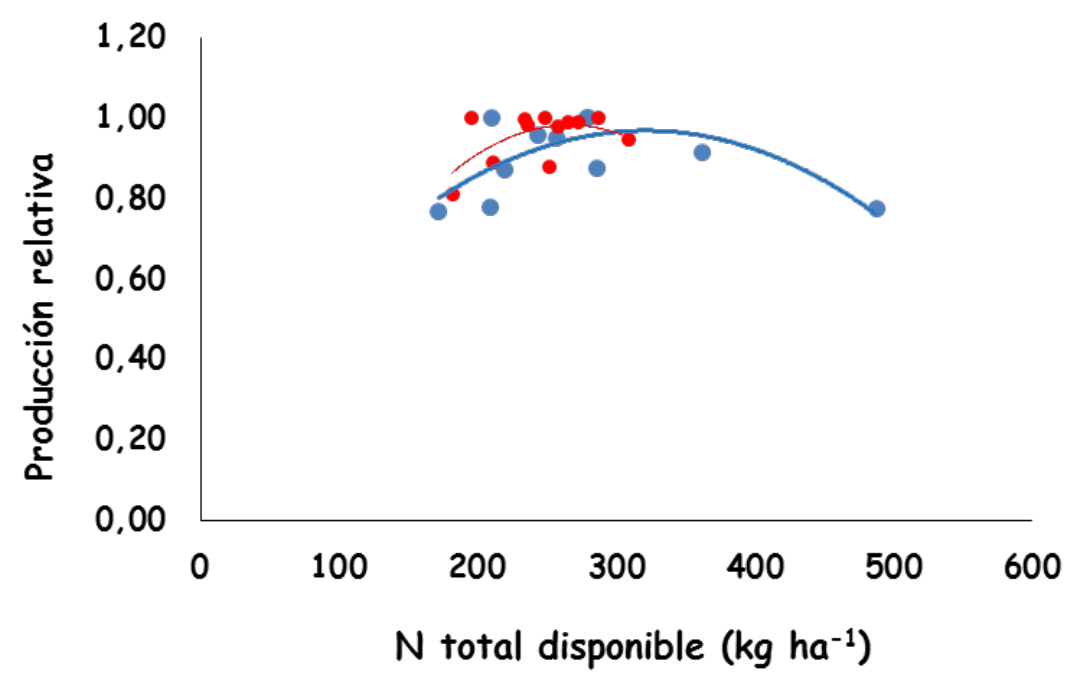

Figura 4.6.1 Relaciones entre el rendimiento relativo (rendimiento de fruta/máxima rendimiento de fruta) y $\mathrm{N}$ total disponible con fertilización orgánica y fertirrigación, incluido el $\mathrm{N}$ mineralizado del suelo a lo largo del ciclo del cultivo. *Cada punto es la media de cuatro repeticiones. 
El uso de funciones simétricas, como polinomios de segundo grado, por lo general muestran ajustes más bajos que cuando se utilizan dos funciones diferentes. Dado que el rendimiento relativo en función del $\mathrm{N}$ total disponible, muestra un comportamiento diferente cuando no se ha alcanzado la cantidad óptima de $\mathrm{N}$ y cuando se ha superado dicha cantidad, se ha dividido la respuesta del cultivo, rendimiento, en dos intervalos, (0-287 y 209-487,3 $\mathrm{kg} \mathrm{N} \mathrm{ha}^{-1}$ ), obteniendo dos ecuaciones de primer grado (Figura 4.6.2).

La primera línea recta (2), tiene una pendiente positiva mayor que la de la segunda (3), y muestra un aumento en el rendimiento relativo con el aumento del $\mathrm{N}$ disponible en el intervalo de 172 a $287 \mathrm{~kg} \mathrm{ha}^{-1}$. La segunda línea recta (3), tiene una pendiente negativa, y muestra la disminución del rendimiento con el aumento del $\mathrm{N}$ disponible. El valor del rendimiento máximo se obtiene con 267 $\mathrm{kg}$ de $\mathrm{N}$ total disponible $\mathrm{ha}^{-1}$.

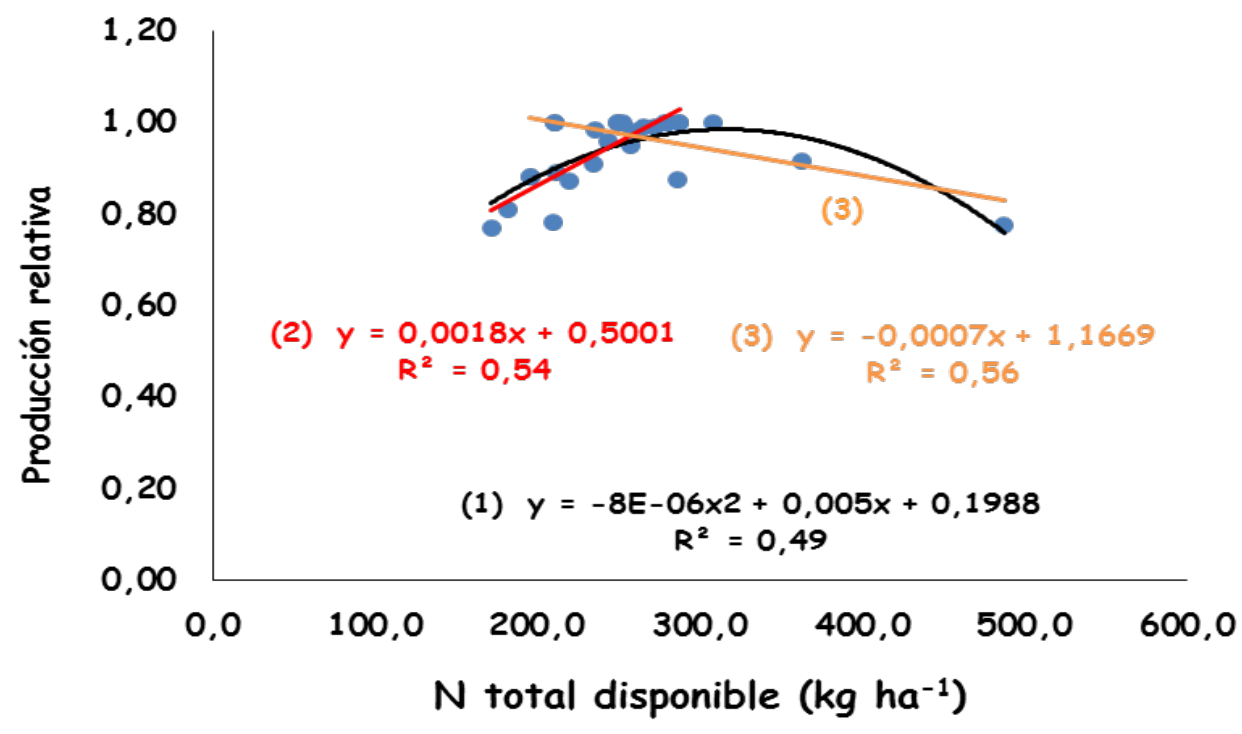

Figura 4.6.2 Relaciones entre el rendimiento relativo (rendimiento de fruta/máximo rendimiento de fruta) y $\mathrm{N}$ total disponible con fertilización orgánica y

fertirrigación.

*Cada punto de datos es la media de cuatro repeticiones. 
Se han elegido una serie de índices representativos del comportamiento agronómico, económico y ambiental, para valorar conjuntamente las diferencias de comportamiento entre la fertirrigación tradicional y la utilización de un residuo orgánico compostado. Los índices elegidos se muestran en la figura 4.6.3.

Dado que la problemática fundamental en zonas vulnerables se debe al uso del nitrógeno, los índices elegidos, se refieren únicamente a este elemento.

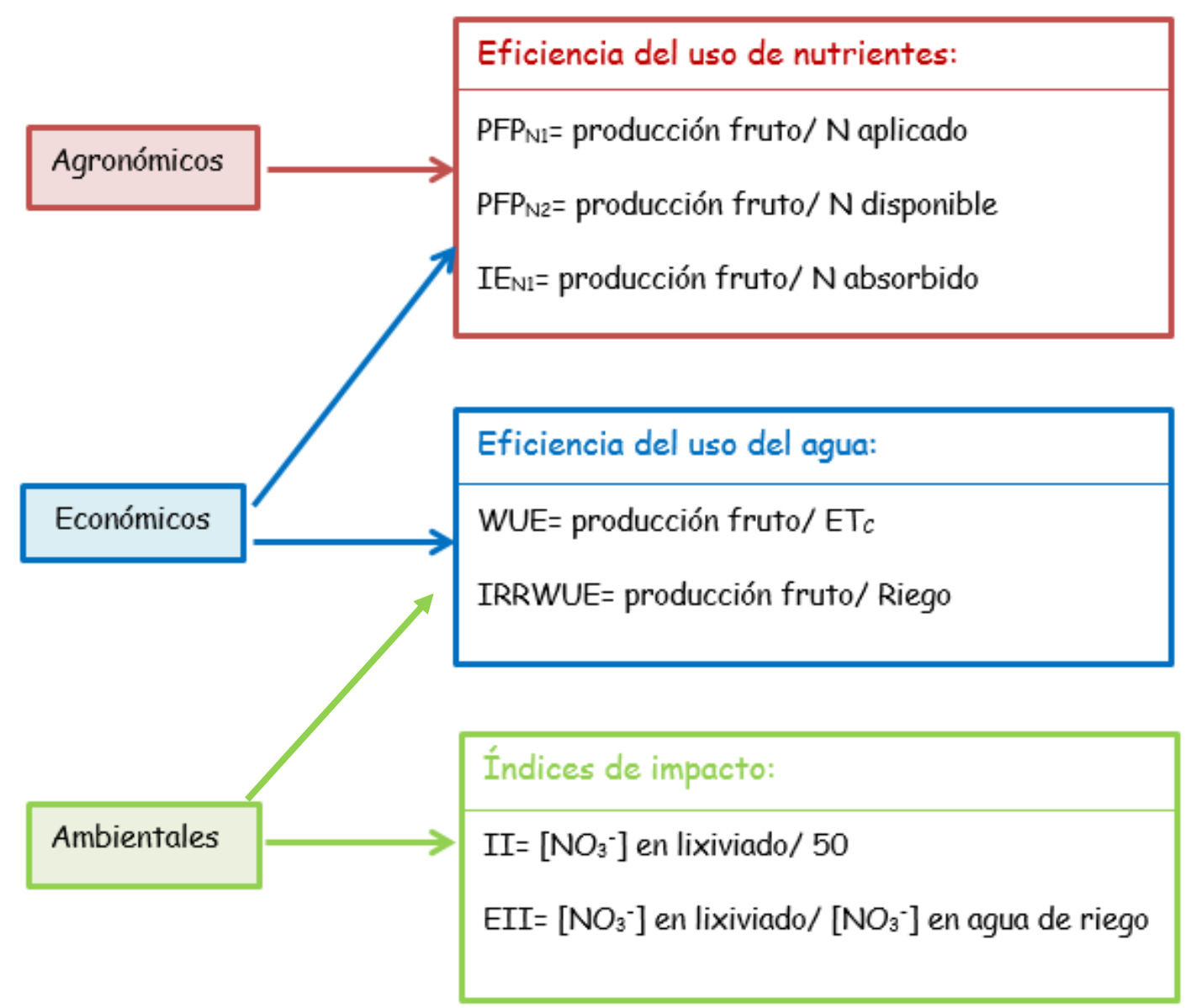

Figura 4.6.3 Índices agronómicos, económicos y ambientales utilizados para comparar la fertirrigación y la fertilización orgánica (Castellanos et al., 2013). 
$>$ Eficiencia del uso de nutrientes

En la figura 4.6.4, se muestran conjuntamente los resultados de los índices de eficiencia relacionados con la producción de fruto obtenida mediante ambos sistemas. Como se puede observar, en ambos casos el comportamiento es similar, lo que indica que los índices que dependen de la producción de fruto con respecto al $\mathrm{N}$ aplicado, disponible 0 absorbido, están relacionados fundamentalmente con el $\mathrm{N}$ del que dispone el cultivo para su desarrollo, y no de la forma: mineral u orgánico, en la que se aplican al suelo.
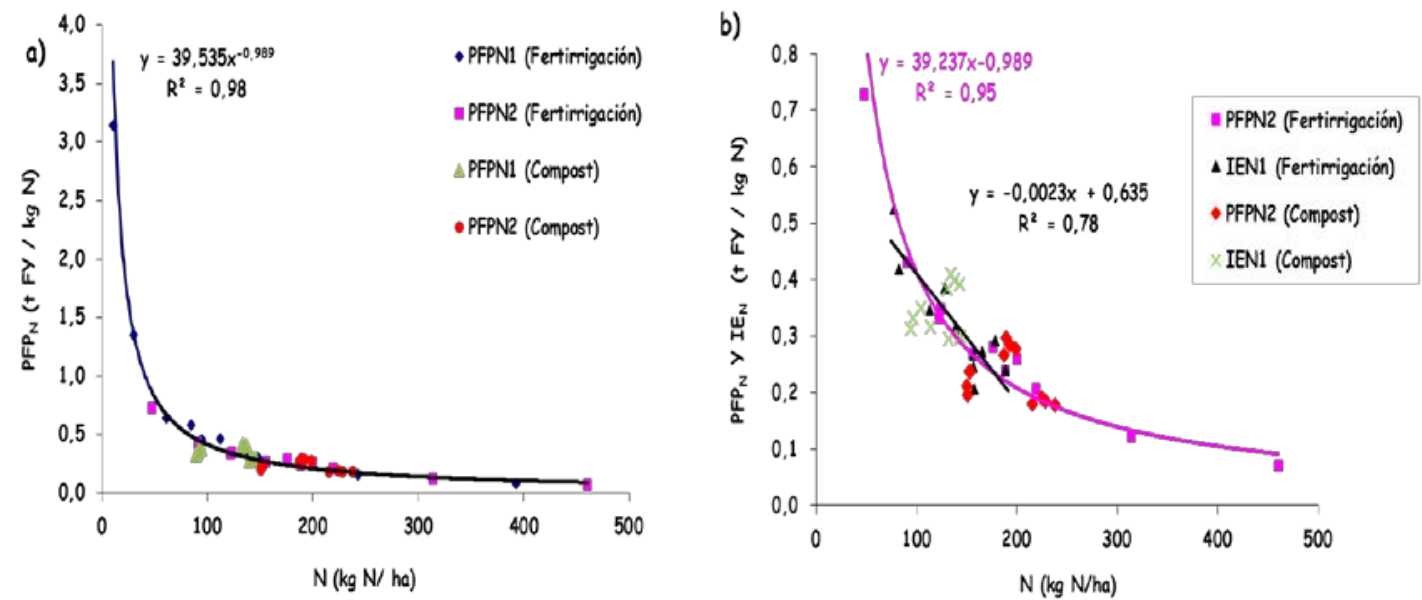

Figura 4.6.4 Comparación de los índices de eficiencia relacionados con la producción de fruto en función de a) $\mathrm{N}$ aplicado $\left(\mathrm{PFPN}_{1}\right.$ ) y $\mathrm{N}$ disponible $\left(\mathrm{PFPN}_{2}\right.$ ); b) $\mathrm{N}$ disponible $\left(P F P N_{2}\right)$ y $N$ absorbido $\left(\right.$ IEN $_{1}$ ) obtenidos en fertirrigación y mediante la aplicación de compost.

\section{Eficiencia del uso del agua}

La cantidad de agua de riego sin considerar el riego de implantación fue: $341,30,461,00$ y $487,00 \mathrm{~mm}$ en 2011, 2012 y 2013 respectivamente, siendo los valores de ETC de $282,10,386,60$ y $410,35 \mathrm{~mm}$ respectivamente.

En algunos casos para calcular el IRRWUE, se tiene en cuenta además del agua aportada por el riego, la aportada por la precipitación, pero en nuestro caso esta última se ha considerado despreciable al igual que Castellanos et al. (2013). 
En la tabla 4.6 .1 se recogen los valores obtenidos para los índices de uso de eficiencia del agua, en el caso de la aplicación de compost de orujo, los tres años de ensayo.

Tabla 4.6.1 Valores de los índices de la eficiencia del uso del agua en el sistema suelo planta en los años 2011, 2012 y 2013.

\begin{tabular}{|c|c|c|c|c|c|}
\multicolumn{1}{c}{} & \multicolumn{5}{c|}{ Tratamientos } \\
\cline { 2 - 6 } \multicolumn{1}{c|}{} & Año & $C$ & $D_{1}$ & $D_{2}$ & $D_{3}$ \\
\hline \multirow{3}{*}{ WUE } & 2011 & 10,5 & 11,3 & 12,9 & 12,8 \\
& 2012 & 12,9 & 14,3 & 14,2 & 14,5 \\
& 2013 & 9,5 & 10,4 & 10,3 & 10,4 \\
\hline \multirow{3}{*}{ IRRWUE } & 2011 & 8,7 & 9,3 & 10,7 & 10,6 \\
& 2012 & 10,8 & 12,0 & 11,9 & 12,2 \\
& 2013 & 8,0 & 8,8 & 8,7 & 8,7 \\
\hline
\end{tabular}

Para un mismo año de experimentación, la eficiencia del uso del agua es proporcional a la producción de fruto, que es siempre mayor cuando se aplica compost de orujo. Los valores más altos de los índices relacionados con el uso del agua, se obtuvieron en el año 2012, con un incremento del WUE del $12 \%$ y del IRRWUE del $13 \%$ con la $D_{3}$ frente al control. En ambos casos, la influencia de la dosis de aplicación del compost es poco marcada.

En la figura 4.6.5, se representan los datos de ambos índices frente a la cantidad de nitrógeno disponible ( $\left.\mathrm{kg} \mathrm{ha}^{-1}\right)$, en dos escenarios diferentes: fertirrigación y fertilización orgánica con compost de orujo. Se observa, que para la misma cantidad de nitrógeno disponible en el suelo, con la aplicación de compost en 2011 y 2012, se obtienen siempre valores más altos de WUE y IRRWUE, que con la fertirrigación tradicional de la zona (Castellanos et al., 2013). El nitrógeno disponible en el suelo correspondiente a los valores máximos de los índices, fue en ambos casos de $189 \mathrm{~kg} \mathrm{~N} \mathrm{ha}^{-1}$, valor para el cual se obtiene el mayor rendimiento en fruto. En el caso de la fertirrigación, ese valor de nitrógeno disponible corresponde a una cantidad de nitrógeno aplicado de $148 \mathrm{~kg}$ $\mathrm{N} \mathrm{ha}^{-1}$, mientras que en el caso de la fertilización orgánica fue $138 \mathrm{~kg} \mathrm{~N} \mathrm{ha}^{-1}$. 

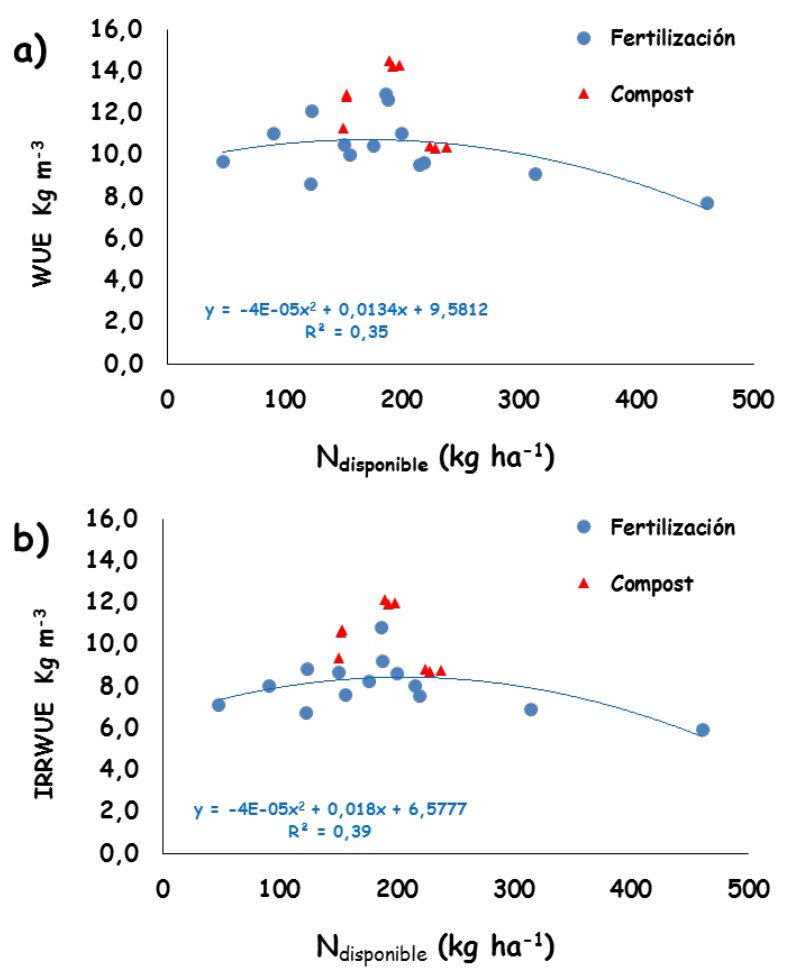

Figura 4.6.5 Índices de eficiencia del agua, (fertirrigación y aplicación de compost) en función del nitrógeno disponible $\left(\mathrm{kg} \mathrm{ha}^{-1}\right)$ : a) WUE y b) IRRWUE $\left(\mathrm{kg} \mathrm{m}^{-3}\right)$.

\section{Indices de impacto ambiental}

La fertilización orgánica con compost de orujo disminuye los índices de impacto, siendo el efecto proporcional a la dosis (Figura 4.6.6). Los tratamientos en los que la concentración de nitrato en el lixiviado es superior a $50 \mathrm{mg} \mathrm{L}^{-1}$ (índice II $\geq 1$ ), localizados en la parte superior de la línea horizontal, no cumplirían la Directiva Europea para aguas de consumo humano.

En la mayoría de los casos (Figura 4.6 .6 a), los valores del índice de impacto (II) se encuentran por encima del valor 1 , debido a que la concentración de nitratos en el agua subterránea utilizada para el riego, como ya se ha indicado, es altísima en la zona. La aplicación de compost, disminuye el riesgo ambiental del uso del agua para consumo humano, aunque solamente, con las dosis $D_{2}$ y $D_{3}$ en el 2012, la concentración de nitratos en el lixiviado, no supero el límite establecido por la Directiva Europea. 
El índice de impacto ambiental (EII) es una práctica herramienta para cuantificar el riesgo de contaminación de los acuíferos al adicionar nitrógeno. Los tratamientos para los cuales EII $\leq 1$, no aumentarían la concentración de nitratos de las aguas subterráneas respecto a su valor inicial. En nuestro caso, con ningún tratamiento, estaríamos aumentando la contaminación de los acuíferos (Figura 4.6 .6 b), habiendo una clara tendencia a disminuir dicha amenaza con el aumento de la dosis de compost todos los años de experimentación.
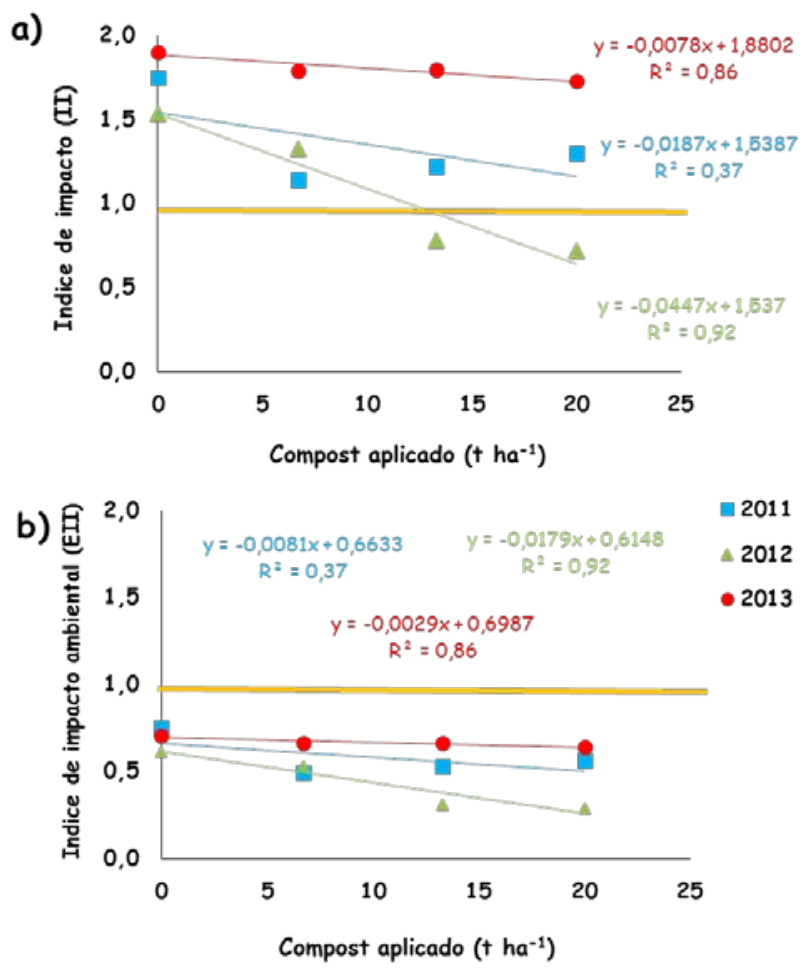

Figura 4.6.6 Índices ambientales en función de la dosis de compost aplicada los años 2011, 2012 y $2013\left(t \mathrm{ha}^{-1}\right)$ : a) Índice de impacto (II) y b) Índice de impacto ambiental (EII).

Si representamos los resultados obtenidos para estos índices, en función del $\mathrm{N}$ disponible para el cultivo con la aplicación de compost y con la fertirrigación (Castellanos et al., 2013) (Figura 4.6.7), se observa que para el conjunto de datos, en el caso del índice de impacto (II), solamente para cantidades inferiores a $228 \mathrm{~kg} \mathrm{~N} \mathrm{ha}^{-1}$ de $\mathrm{N}$ disponible, en el que se ha incluido el $\mathrm{N}$ mineralizado en el periodo de cultivo, se cumple la Directiva Europea. 
Únicamente con la aplicación de compost de orujo se ha obtenido un valor de II 1 en el año 2012 con las dos dosis mayores $\left(D_{2}\right.$ y $D_{3}$ ) (Figura 4.6.7 a).

En cuanto al índice de impacto ambiental (EII) (Figura 4.6.6 b), con la aplicación de compost, en ningún caso se aumenta la concentración de $\mathrm{N}$ de las aguas subterráneas respecto al valor original del agua de riego, mientras que con la fertirrigación, solo se obtendría ese resultado con cantidades de $N$ total disponible inferiores a $232 \mathrm{~kg} \mathrm{~N} \mathrm{ha}^{-1}$.
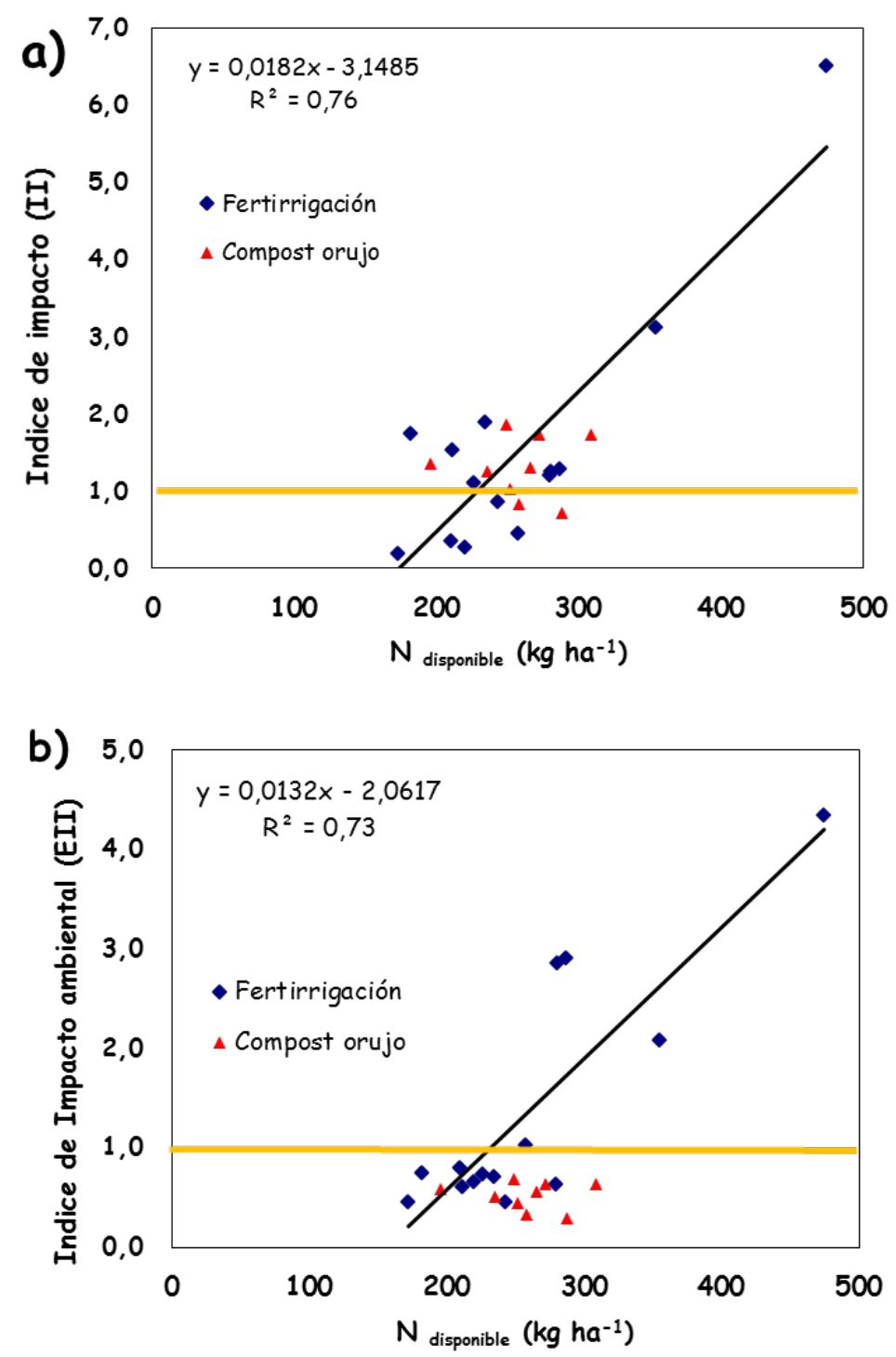

Figura 4.6.7 Índices ambientales en función del nitrógeno disponible $\left(\mathrm{kg} \mathrm{ha}^{-1}\right)$ (fertirrigación y aplicación del compost): a) Índice de impacto (II), b) Índice de impacto ambiental (EII). 


\subsection{Efecto residual de la aplicación del compost de orujo sobre un} cultivo de trigo

En la figura 4.7.1, se representa la concentración de distintos nutrientes en el suelo ( $\mathrm{mg} \mathrm{kg}^{-1}$ ) al inicio del experimento y una vez recogido el cultivo de melón, en los distintos años de ensayo (2011, 2012 y 2013) según los distintos tratamientos $\left(C, D_{1}, D_{2}\right.$ y $\left.D_{3}\right)$.
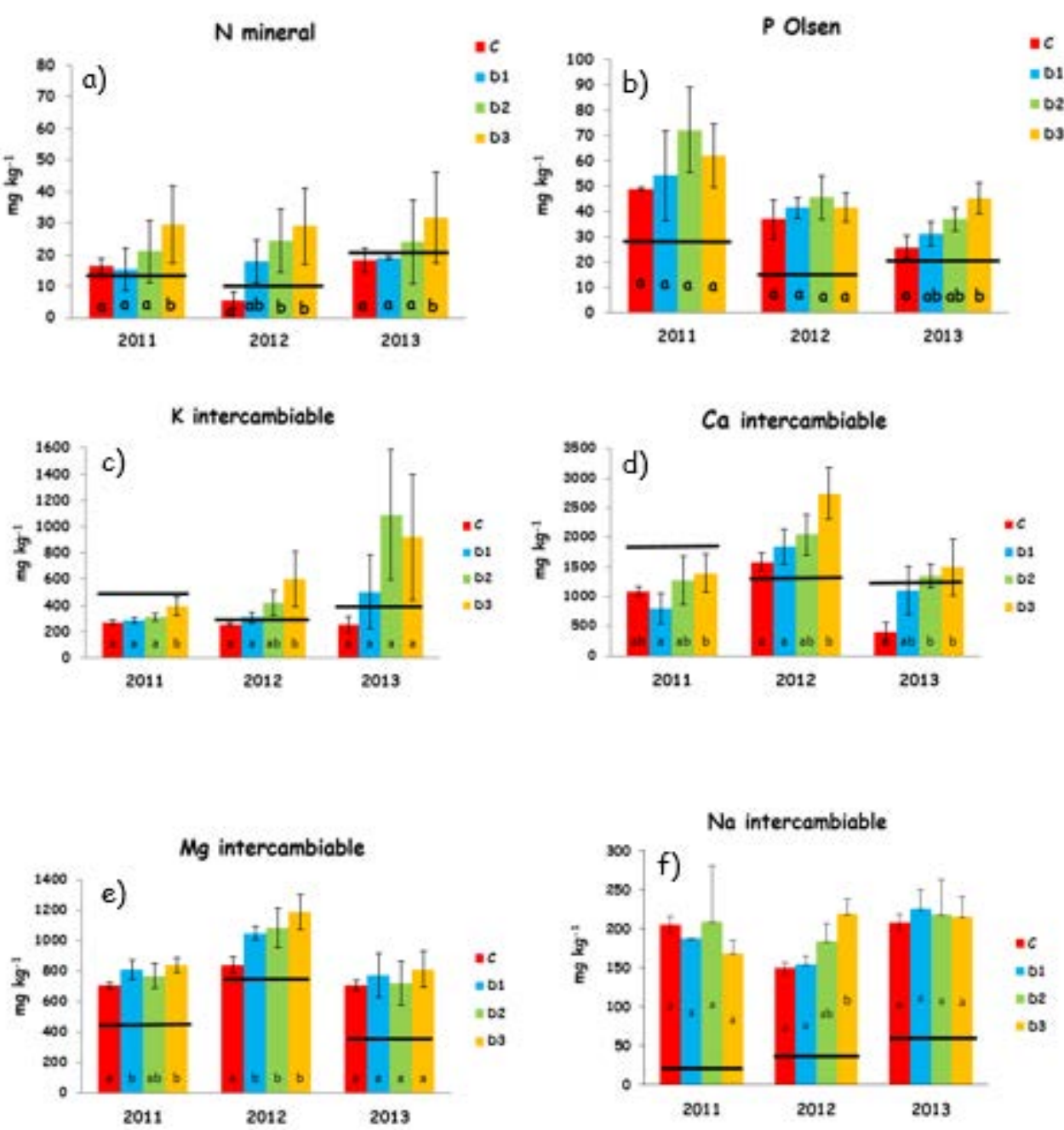

Figura 4.7.1 Nutrientes disponibles en el suelo después del periodo de cultivo de melón (mg kg-1) en los distintos años de ensayo (2011, 2012 y 2013).

* La concentración inicial de los nutrientes en el suelo se representa por $($ ) Para un mismo parámetro y año, resultados seguidos de la misma letra, no son diferentes con una significación $(p \leq 0,05)$. 
En general, la aplicación de compost de orujo, dio lugar a un aumento de la concentración de nutrientes en el suelo, siendo más marcado dicho aumento en el caso del fosforo Olsen, magnesio y sodio intercambiables, en los tres años de ensayo (Figura 4.7.1. b, e y f). En el caso del $\mathrm{N}$ mineral, con la dosis más alta de compost $\left(D_{3}\right)$, se obtuvieron siempre diferencias significativas $(p \leq 0,05)$ respecto a los demás tratamientos, los tres años de ensayo compost. En el año 2012, se produjeron diferencias significativas $p \leq 0,05$ de todas las dosis de compost frente al control, aunque no se observó diferencias entre dosis.

Diversos autores han demostrado, que la aplicación de compuestos orgánicos a los suelos, mejora el comportamiento de los elementos del suelo a través de los grupos activos (ácidos fúlvicos y húmicos), que tienen la capacidad de retener elementos en forma de complejos o quelatos. (Shafeek et al., 2015) Estos materiales por acción de los microorganismos, aportan lentamente los elementos al suelo. La disponibilidad de los nutrientes, depende del tipo de material orgánico aplicado y del tipo de microorganismos (Saha et al., 1998). Marculescu et al. (2002) afirmaron, que el contenido en el suelo de macro y micronutrientes aumenta por el uso de fertilizantes orgánicos, los cuales juegan un papel esencial en el crecimiento y desarrollo de las plantas. Ozores-Hampton et al. (2011) obtuvieron que las enmiendas orgánicas, además de aumentar la materia orgánica, aumentan tres veces el contenido en el suelo de la mayoría de los nutrientes incluidos el P, K, Ca y el Mg.

Al tratarse de una zona vulnerable con un contenido en nitratos en el agua de riego muy elevado, es necesario estudiar después del cultivo de melón, el efecto del $\mathrm{N}$ residual disponible en el suelo y su distribución espacial, como consecuencia de cada tratamiento con compost de orujo. Para valorar dicho efecto residual durante tres años se plantó trigo de invierno (Triticum aestivum L., cv Garcia) de ciclo largo, muy ávido de N, como cultivo captura. (El ensayo de campo esta descrito en el capítulo 3).

En la figura 4.7.2, se muestran los datos originales de producción de grano ( $a, b$ y $c$ ) y $N$ absorbido por el mismo ( $d$, e y $f$ ), en las 128 muestras de trigo cosechadas a lo largo de la línea del transecto en las campañas 2011-2012, 2012-2013 y 2013-2014. Se incluye también el $N$ disponible en el suelo, procedente del cultivo del melón en cada tratamiento. 
a)

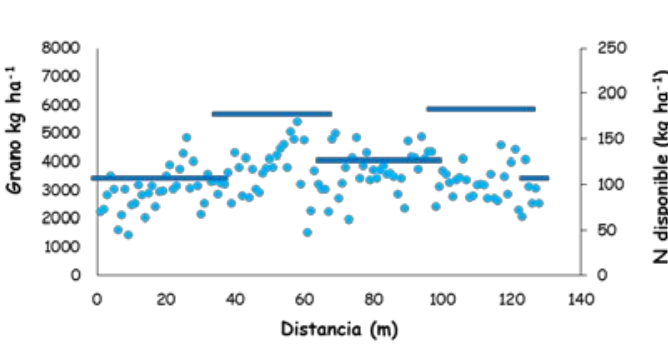

b)

- Producción grano 2012-2013 -N disponible 2012-2013

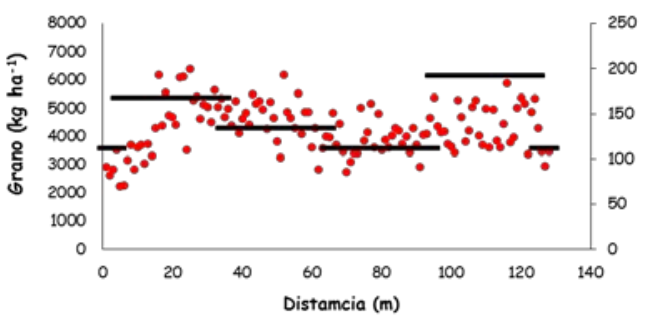

c)

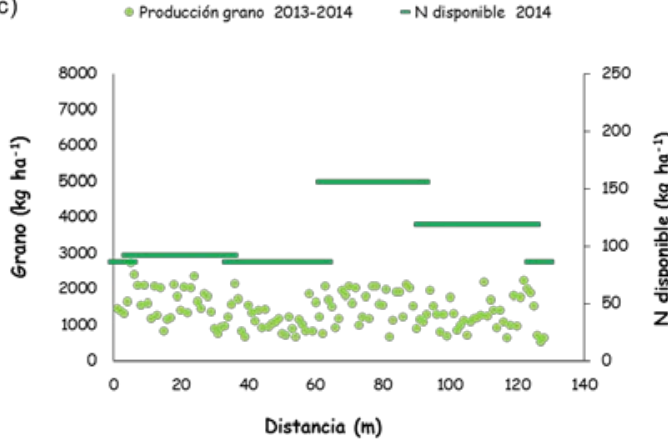
- N extraido 2011-2012 - $\mathrm{N}$ disponible 2011-2012

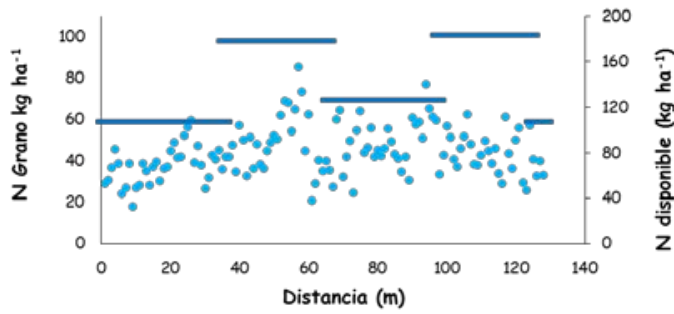

e) - N extraido 2012-2013 - N disponible 2012-2013

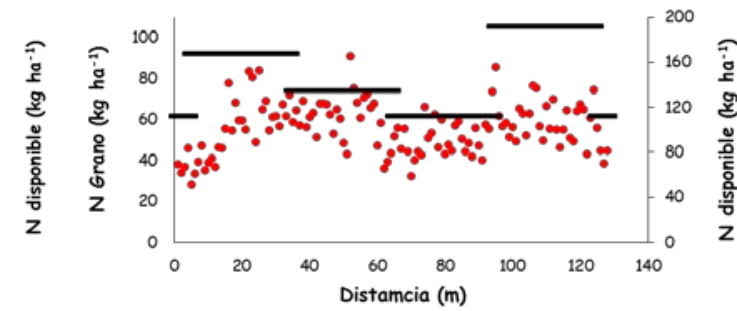

f) N extraido 2013-2014 -N disponible 2014

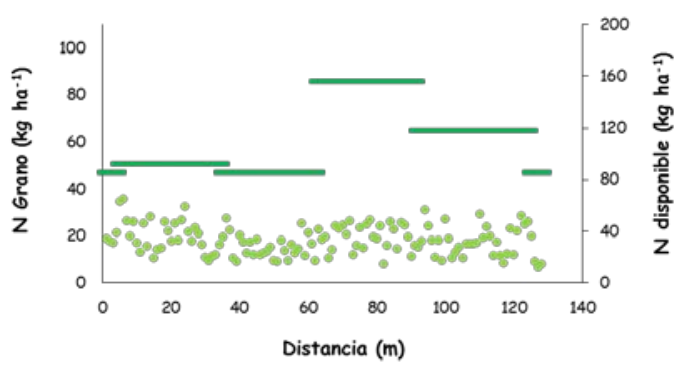

Figura 4.7.2 Datos originales de las dos variables estudiadas a) Producción de grano y b) $\mathrm{N}$ absorbido por el mismo en $\mathrm{Kg} \mathrm{ha}^{-1}$ a lo largo del transecto, incluyendo el $\mathrm{N}$ disponible en el suelo procedente del cultivo del melón en cada tratamiento en las tres campañas: 2011-2012, 2012-2013 y 2013-2014.

A partir de los datos originales de la figura 4.7.2, se han obtenido los datos medios de la produccion, $\mathrm{N}$ extraido y $\mathrm{N}$ disponible correspondiente a cada uno de los tratamientos en los diferentes escenarios estudiados. (Tabla 4.7.1.). 
Tabla 4.7.1 Valores medios de producción de grano, $\mathrm{N}$ extraído por el grano de trigo y $\mathrm{N}$ inicial disponible en el suelo.

\begin{tabular}{|c|c|cc|cc|c|}
\cline { 2 - 6 } \multicolumn{2}{|c|}{} & $\begin{array}{c}\text { Producción } \\
\text { Grano }\end{array}$ & $N_{\text {extraido grano }}$ & $N_{\text {disponible }}$ \\
\cline { 2 - 7 } 2011-2012 & \multicolumn{5}{|c|}{ kg ha $^{-1}$} \\
& $C$ & 3016 & $a$ & 38,1 & $a$ & 107,3 \\
& $D_{1}$ & 3733 & $b$ & 49,0 & $b$ & 126,6 \\
& $D_{2}$ & 3657 & $b$ & 48,9 & $b$ & 178,1 \\
& $D_{3}$ & 3255 & $a$ & 44,3 & $b$ & 183,3 \\
\hline \multirow{3}{*}{$2012-2013$} & $C$ & 3931 & $a$ & 50,7 & $a$ & 112,0 \\
& $D_{1}$ & 4563 & $b$ & 60,6 & $b$ & 134,4 \\
& $D_{2}$ & 4466 & $b$ & 56,4 & $b$ & 168,0 \\
& $D_{3}$ & 4434 & $b$ & 60,4 & $b$ & 192,0 \\
\hline & $C$ & 1160 & $a$ & 15,4 & $a$ & 85,8 \\
& $D_{1}$ & 1609 & $b$ & 20,5 & $b$ & 91,9 \\
& $D_{2}$ & 1326 & $a$ & 17,2 & $b$ & 118,4 \\
& $D_{3}$ & 1581 & $b$ & 19,8 & $b$ & 155,8 \\
\hline
\end{tabular}

*En cada año los valores seguidos de la misma letra no tienen diferencias significativas $(p \leq 0,05)$.

La mayor producción de trigo se alcanzó en las tres campañas del ensayo, 2011-2012, 2012-2013 y 2013-2014, con el efecto residual procedente de la dosis de compost de orujo aplicada al melón $D_{1}$, aunque en general, las diferencias no fueron significativas con el resto de las dosis (Tabla 4.7.1). Las producciones en la campaña 2013-2014 fueron mucho más bajas que en la campaña 2011-2012 y 2012-2013, debido a las bajas precipitaciones en el periodo de espigado y llenado de grano y a las elevadas temperaturas durante ese periodo (Figura 4.7.3).

Tanto la producción de grano como el nitrógeno extraído por el mismo, es directamente proporcional al nitrógeno disponible en el suelo al inicio del cultivo, en cada uno de los años del experimento. Sin embargo, ambos valores, fueron superiores en la campaña 2012-2013 seguida de la 2011-2012 y por último de la 2013-2014, para un mismo valor de nitrógeno disponible en el suelo. En todos los casos a partir de un valor de nitrógeno disponible (150-162 $\mathrm{kg} \mathrm{ha}^{-1}$ ), se produce un descenso de producción y de nitrógeno extraído. 

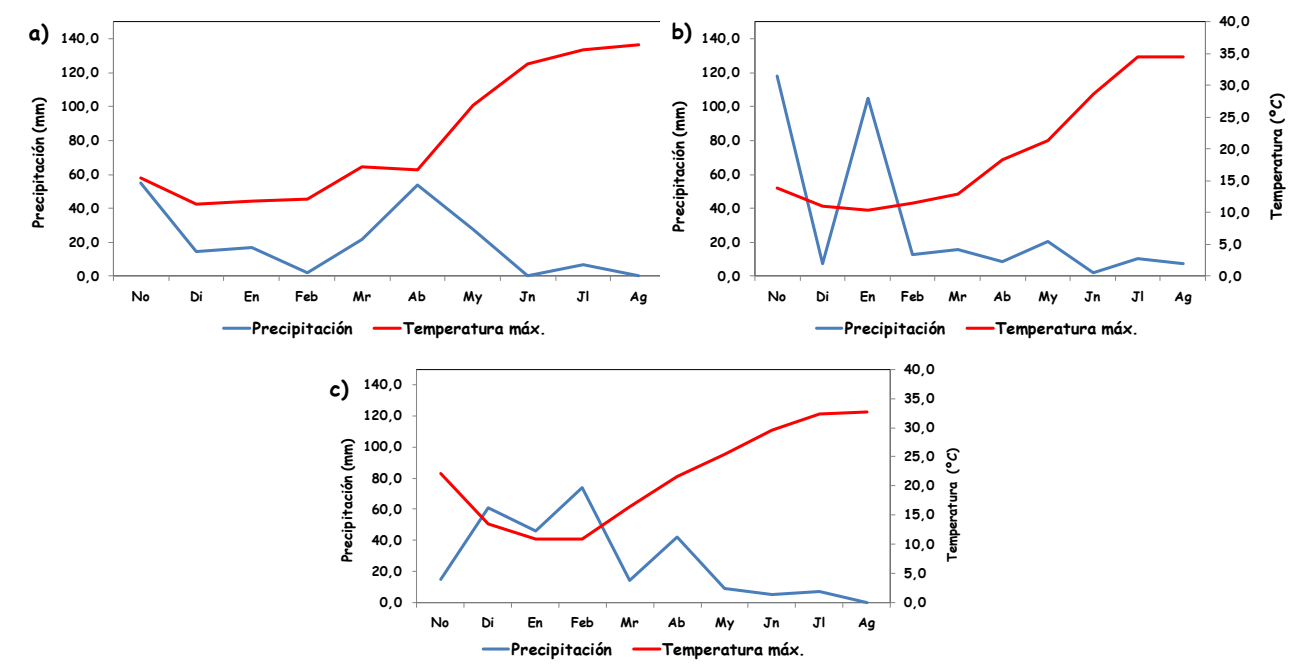

Figura 4.7.3 Evolución de los datos de precipitación y temperaturas máximas durante el periodo del cultivo del trigo: a) 2011-2012 b) 2012-2013 y c) 20132014.

Por otra parte, se ha calculado la eficacia o producción relativa, dividiendo todos los datos por la producción máxima obtenida durante todo el periodo experimental (6399 $\mathrm{kg} \mathrm{ha}^{-1}$ ) en la campaña 2012-2013. Además, se ha calculado la eficacia del uso del $\mathrm{N}$, como la relacción entre el $\mathrm{N}$ extraído por el grano de trigo y el $\mathrm{N}$ disponible en cada punto del transecto. En la figura 4.7.4, se representan los valores correspondientes a la producción relativa frente a la eficacia del uso del $\mathrm{N}$.

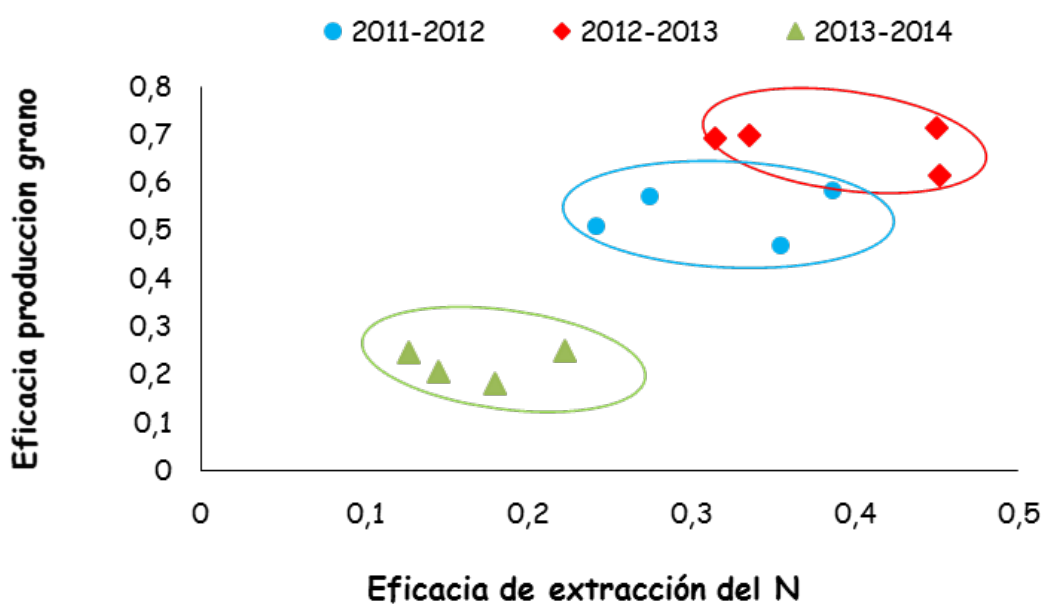

Figura 4.7.4 Valores medios de eficacia de producción de grano y eficacia de extracción de $\mathrm{N}$ por el grano. 
Las mayores eficacias tanto de producción como de $\mathrm{N}$ extraído se obtuvieron en la campaña 2012-2013, campaña en la que se incorporó $47 \mathrm{~kg} \mathrm{ha}^{-1}$ de nitrógeno procedente de urea como fuente adicional. El riego de apoyo en la campaña 2011-2012, con la consiguiente incorporación de $34 \mathrm{~kg} \mathrm{ha}^{-1}$ de N nítrico procedente del agua de riego, provoco una situación intermedia entre 2012-2013 y 2013-2014, respecto a dichas eficacias. Por ultimo en la campaña 2013-2014, en el que no se incorporó de forma adicional ninguna fuente de $N$, se obtuvieron los valores más bajos de ambos índices. Sin embargo en este caso, se encontraron diferencias significativas $(p \leq 0,05)$ entre los tratamientos $C$ y $D_{3}$ frente al $D_{1}$ y $D_{2}$.

En la figura 4.7 .5 se representa de forma conjunta la producción relativa de grano, considerando como valor de referencia, el máximo obtenido durante los tres años de experimentación, respecto al $\mathrm{N}$ extraído ( $\left.\mathrm{kg} \mathrm{ha}^{-1}\right)$ por el grano de trigo, en las campañas 2011-2012, 2012-2013 y 2013-2014. El conjunto de los datos presenta una elevada correlación $\left(R^{2}=0,97\right)$.

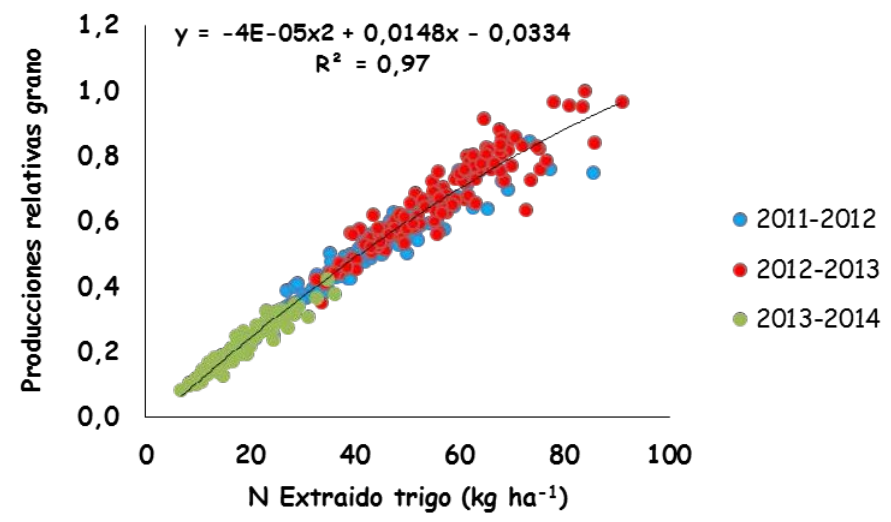

Figura 4.7.5 Producción relativa de grano en relación al $\mathrm{N}$ extraído $\left(\mathrm{kg} \mathrm{ha}^{-1}\right)$ por el cultivo de trigo: 2011-2012, 2012-2013 y 2013-2014.

Aunque la respuesta del trigo está determinada por el nitrógeno existente en el suelo dentro de una misma parcela de tratamiento, hay una elevada variabilidad en la concentración de nitrógeno mineral en la misma, y existe una dificultad intrínseca utilizando la estadística clásica, en dilucidar, si los resultados dependen de la dosis de aplicación del compost o de la distribución espacial del nitrógeno, como consecuencia del tipo de aplicación del residuo o de la variabilidad del suelo. El trigo utiliza de forma efectiva el nitrógeno residual procedente del cultivo anterior. Entre ambos cultivos, se producen una serie de procesos que influyen en el ciclo del nitrógeno: absorción 
del $\mathrm{N}$ por el melón, mineralización del $\mathrm{N}$ orgánico del suelo, mineralización del $\mathrm{N}$ orgánico del compost de orujo, lixiviación de N-nitratos, difusión horizontal de las formas soluble de nitrógeno y absorción del $\mathrm{N}$ por el cultivo de trigo.

En nuestro caso, la aplicación en el suelo del compost de orujo en el cultivo previo del melón, se realizó como ya se ha comentado en el capítulo 3 , en la línea de cultivo mediante abonadora específica en línea, dejando un pasillo de 1,5 metros entre las líneas de aplicación sin compost. La toma de muestras de trigo en el transecto, se realizó de forma perpendicular a las líneas de aplicación del compost, por lo que los resultados obtenidos presentan una gran variabilidad espacial. Dicha variabilidad, es el resultado de dos factores; por una parte, de la posición del cultivo de melón y por otra, de la aplicación localizada del compost en las líneas del cultivo a diferentes dosis, produciendo una distribución no uniforme a lo largo de la línea del transecto.

Estudiando la variación y correlación de estas variables a diferentes frecuencias, se puede conocer el factor dominante que influye en la propiedad que interesa, si esta cambia con la frecuencia y cuantificar su importancia relativa.

Los datos de la entropía relativa $E(\delta)$ y de la variación de la entropía $\Delta E$ (ठ) de la producción de grano, en las campañas 2011-2012, 2012-2013 y 20132014 , en función de los diferentes intervalos del transecto, se representan en la figura 4.7.6.

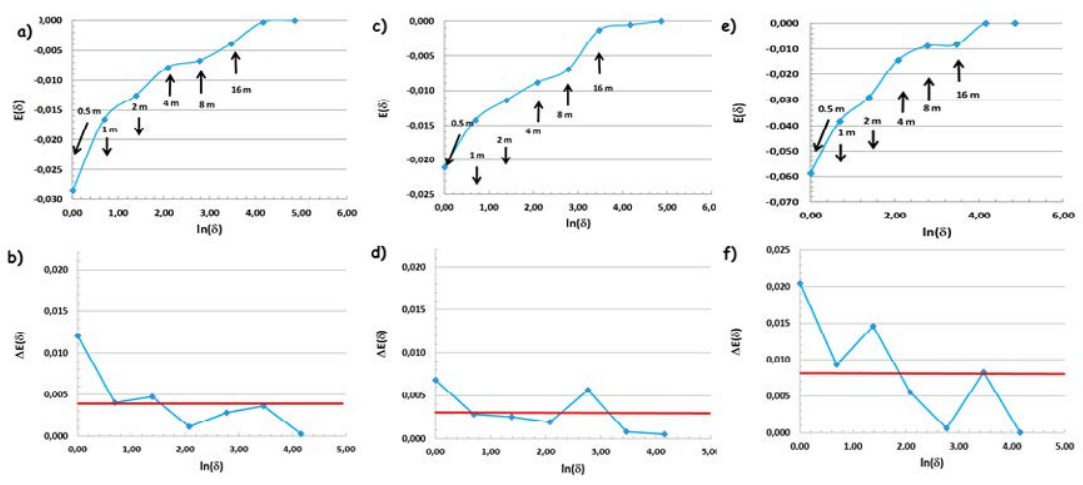

Figura 4.7.6 Estudio de la entropía: ( $a, c$ y e) Entropía relativa $E(\delta)$ de la producción de trigo; (b, d y f) Variación de la entropía relativa $\Delta E(\delta)$. (a y b): 2011-2012; ( c y d): 2012-2013; ( e y f): 2013-2014.

* La línea roja representa una variación constante de la entropía. La distancia equivalente de los datos de $\delta$, se han marcado en $E(\delta)$. 
Como se puede observar, en general el comportamiento de las variaciones de entropía relativa de la producción de grano, son similares las campañas 20112012 y 2013-2014, aunque en esta última campaña, las variaciones son más acusadas en todos los intervalos del transecto, probablemente porque no se aplicó ningún tratamiento adicional.

Como se puede observar en la figura $4.7 .6(b, d$ y $f$ ), los resultados a gran escala ( $q=64 \mathrm{~m}$ y $\delta=128$ muestras recogidas del transecto), no presentan en ningún caso variación apreciable de la entropía relativa, lo cual significa que en el conjunto global no existen diferencias significativas entre los $32 \mathrm{~m}$ finales $e$ iniciales del transecto. Sin embargo, a una escala más pequeña, de 32 a $16 \mathrm{~m}$, en las campañas 2011-2012 y 2013-2014 los valores de entropía relativa son diferentes, siendo el incremento de la entropía significativo, lo que implica que existe una variación en la producción de grano en función de los tratamientos. Este efecto no se apreció en la campaña 2012-2013, probablemente debido a la incorporación durante el periodo de cultivo de trigo de $100 \mathrm{~kg} \mathrm{ha}^{-1}$ de urea, que enmascaró el nitrógeno disponible del suelo procedente de los tratamientos de compost. Dentro de un mismo tratamiento, escalas 16-8 y 8-4 $\mathrm{m}$, en las campañas 2011-2012 y 2013-2014, la variación de entropía es pequeña. Sin embargo, en el cambio de escala, de 4 a $2 \mathrm{~m}$, se produce un importante incremento de entropía, debido al efecto del marco de plantación utilizado en el cultivo precedente, melón, que determinó la línea de aplicación del compost de orujo. Este efecto pero mucho más marcado, se observa en la escala de 0 a 1 metros.

Si comparamos estos resultados con los obtenidos por Tarquis et al, 2017, observamos un comportamiento semejante, que sugiere que a estas escalas, la variación es debida fundamentalmente a la posición de las líneas de cultivo de melón debido a la absorción del nitrógeno aplicado. Hay que destacar, que en nuestro caso, la aplicación de compost de orujo, disminuye la magnitud de las diferencias encontradas.

En la figura 4.7.7, se representa la entropía relativa $E(\delta)$ y la variación de la entropía $\Delta E(\delta)$ correspondiente al $N$ extraído por el grano, en las campañas 2011-2012, 2012-2013 y 2013-2014, en función de los diferentes intervalos del transecto. Dentro de un mismo año, en la mayoría de las escalas, el $\mathrm{N}$ absorbido sigue el mismo comportamiento que el peso de grano, apareciendo los máximos a las mismas escalas. 

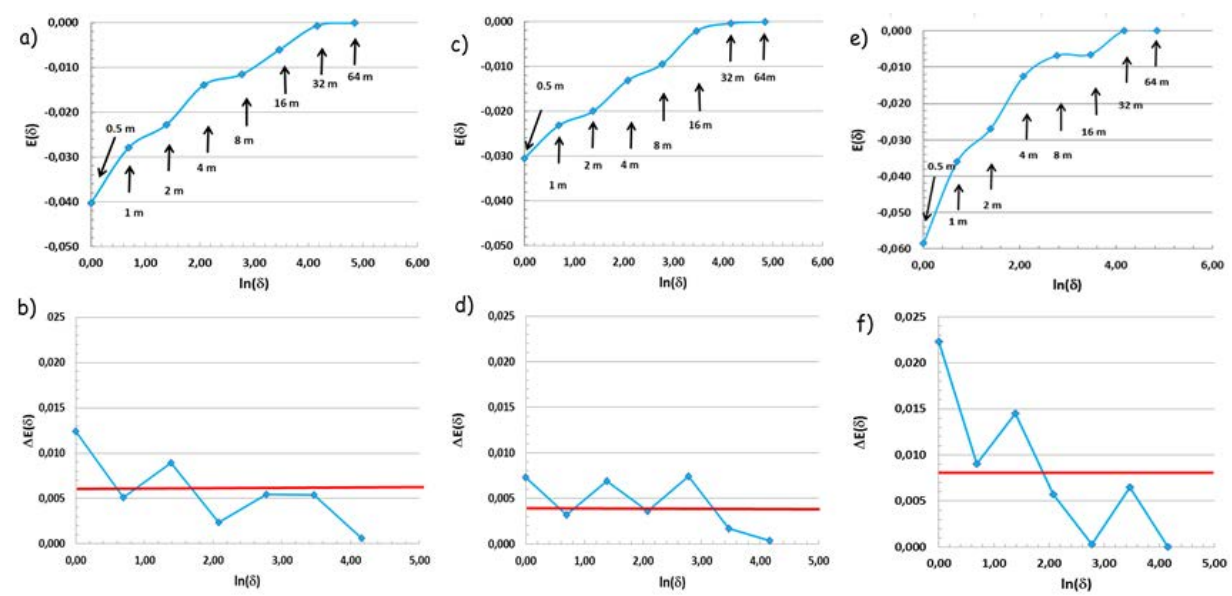

Figura 4.7.7 Estudio de la entropía: (a, c y e) Entropía relativa $E(\delta)$ del $N$ extraído por el trigo; (b, $d$ y f) Variación de la entropía relativa $\Delta E(\delta)$. ( $a$ y b): 2011-2012: (c y d): 2012-2013:.(e y f): 2013-2014.

* La línea roja representa una variación constante de la entropía. La distancia equivalente de los datos de $\delta$, se han marcado en $E(\delta)$.

En el caso del $\mathrm{N}$ mineral disponible en el suelo, la variación de la entropía relativa (Figura 4.7.8) muestra que el factor más relevante de los que influyen en la variabilidad, no es ni la posición de la línea de cultivo de melón, ni la colocación del compost en dicha línea. La mineralización del compost de orujo a lo largo del periodo estudiado, y la influencia en dicha mineralización de la adición de fuentes nitrogenadas complementarias en las campañas 2011-2012 y 2012-2013, parecen ser factores de influencia más significativos.
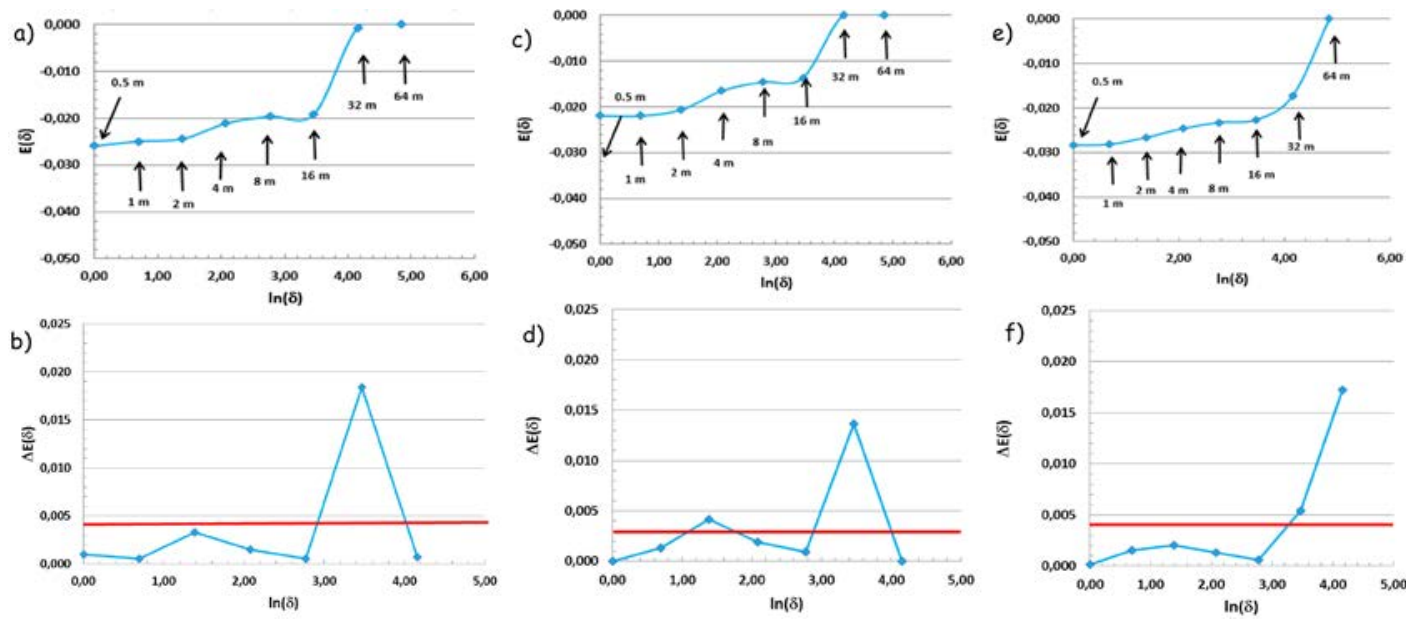

Figura 4.7.8 Estudio de la entropía: ( $a, c$ y e) Entropía relativa $E(\delta)$ del $N$ disponible en el suelo para el trigo; $(b, d$ y $f$ ) Variación de la entropía relativa $\Delta E(\delta)$. ( y b): 2011-2012; (c y d): 2012-2013; ( e y f): 2013-2014.

* La línea roja representa una variación constante de la entropía. La distancia equivalente de los datos de $\delta$, se han marcado en $E(\delta)$. 

Capítulo 5

DISCUSIÓN GENERAL 

A continuación se discuten los resultados más relevantes en función de los objetivos planteados en este estudio.

\subsection{Dinámica de crecimiento del cultivo de melón}

En el apartado 4.1 del capítulo 4 se pone de manifiesto que la aplicación de compost de orujo desalcoholizado proveniente de la industria vitivinícola favoreció la acumulación de materia seca total (incremento entre 10-16\%) y de las diferentes partes de la planta, aunque se observó un comportamiento diferente en la acumulación de materia seca de la parte vegetativa (hoja y tallo), que se vio más favorecida con la dosis mayor $\left(D_{3}\right)$ frente a la acumulación de materia seca del fruto que fue superior con los tratamientos $D_{1} y_{2} D_{2}$. Esta diferencia de comportamiento de la parte vegetativa frente a la productiva, fue observada también por otros autores (Castellanos et al., 2012 y Kirnak et al., 2005) en melón con tratamientos de diferentes dosis de $\mathrm{N}$ con fertirrigación. Los valores máximos de biomasa obtenidos en el experimento, fueron superiores a los obtenidos por Kirnak et al. (2005) seguramente debido a que se utiliza una variedad distinta de melón ( $c v$ Polidor) y a las diferentes condiciones climatológicas de ambos experimentos. Sin embargo, dichos resultados, son parecidos a los obtenidos por Castellanos et al. (2012) para la misma variedad de melón y cantidad de $\mathrm{N}$ disponible.

Otros autores, también encontraron efectos positivos en el crecimiento de las plantas con la combinación de fertilización inorgánica y materia orgánica. Tzortzakis et al. (2012) comentaron aumentos en el crecimiento del pimiento combinando fertirrigación con la aplicación de compost de residuos sólidos municipales y Ahmed and Shalaby (2012) encontraron que la aplicación de compost de estiércol o algas marinas mejora el crecimiento vegetativo del pepino. Jimenez et al. (1997) encontraron que la aplicación de compost de estiércol producía un incremento significante en los parámetros de crecimiento (Numero de hojas por planta, longitud del tallo peso de materia seca y producción de frutos) de la planta del melón comparándolo con el control.

Todos los años, el fruto fue el que más contribuyó al peso seco del total de la planta. Valantin et al, (1998) demostraron que el número de frutos, es el factor que determina la asignación de los recursos entre los órganos vegetativos y reproductivos constituyendo los frutos grandes sumideros, que crecen a expensas de la formación de la hoja. Otros autores (Prata et al., 1999; Lima et 
al., 2001 y Duarte et al., 2002) también observaron una mayor contribución del fruto a la biomasa total.

La distribución de materia seca en las distintas partes de la planta, no se vio afectada con los diferentes tratamientos, al igual que lo observado por Rincòn et al., 1996 en un ensayo de fertirrigación en invernadero utilizando melón cv Toledo. Sin embargo, se observó un ligero aumento con los tratamientos de compost, en la actividad fotosintética de la planta (índice de área foliar (LAI) (del 15 a 23\% dependiendo del año) y la duración de área foliar (LAD) al principio del periodo de cuajado de los frutos en el año 2012. La determinación del índice de área foliar es importante para el análisis de crecimiento de las plantas (Kvet and Marshall, 1971), Ya que en las plantas de melón, la hoja constituye la principal fuente de fotoasimilados para los frutos (Castellanos et al., 2011) y se ve afectado por muchos factores entre ellos: las técnicas de manejo, el N disponible etc. (Hegde, 1988; Pospisil et al., 2000).

Teniendo en cuenta los resultados obtenidos para los índices de crecimiento estudiados (apartado 4.1 del capítulo 4), la aplicación de compost de orujo puso de manifiesto, un efecto positivo en todos aquellos relacionados con la velocidad de crecimiento de las distintas partes del cultivo (la velocidad de crecimiento de las hojas ( $L G R$ ), la velocidad de crecimiento Relativo (RGR), la velocidad de crecimiento del cultivo (CGR ) y la velocidad de crecimiento de los frutos (FGR)), así como con la tasa de asimilación neta (NAR), no observándose una respuesta clara en los índices morfológicos (el área foliar especifica (SLA), la relación de peso foliar (LW) y la razón de área foliar (LAR)), ya que estos últimos varían más cuando se habla de diferentes especies (Lambers and Pooter, 1992; Marañon and Grubb, 1993; Garmier and Laurent, 1994). Sin embargo, si se han observado en estos últimos índices, variaciones en algunos puntos del ciclo vegetativo del cultivo, que no han sido significativos en general y han tenido que ver con el estado fenológico del cultivo, produciéndose las mayores variaciones, en el momento de la aparición y engrosamiento de los frutos.

Para obtener un alto rendimiento y una calidad, es esencial que la biomasa de hojas tenga un crecimiento rápido y produzca una gran cantidad de asimilados, que se destinarán principalmente a los frutos durante su crecimiento y desarrollo (Hubbard et al., 1990; Bartolo and Schweissing, 1998).

La velocidad de crecimiento relativo y sus componentes, pueden utilizarse como indicadores para la evaluación de diferentes condiciones de crecimiento en el desarrollo de las plantas. Valores altos de RGR implican que se 
alcanza mayor tamaño de la planta en menos tiempo, lo que es una ventaja en condiciones ambientales favorables. Otros autores, han comentado efectos positivos en el valor de RGR con el uso de compost en fabes (Abdelhamid et al., 2004) o vermicompost en pepino (Sallaku et al., 2009). En nuestro estudio, los cambios en RGR con la aplicación de compost se asociaron a diferencias fisiológicas (NAR). Hay diferentes opiniones en la bibliografía con respecto a la importancia del NAR o LAR en el valor del índice de crecimiento de las plantas (Poorter and Van der Werf, 1998). De Groot et al. (2001) afirmaron que el NAR desempeñó un papel más importante que LAR en un cultivo de tomate cuando no hay limitación de nutrientes. Según Fontes et al. (2005) y Lopes et al. (2011), disminuciones en los valores de RGR se relacionan con la disminución de la tasa de asimilación neta (NAR) y la relación de área foliar (LAR). Barraza (2000b) explica este hecho debido a la correlación entre el proceso de crecimiento y el desarrollo de diversas partes de la planta, que tiene que ver con la forma en que las sustancias son traslocadas para el crecimiento y mantenimiento de órganos ya formados (hojas, ramas, flores y frutos). Esto lo explico también Fogg (1967) diciendo que el crecimiento de una parte de la planta, consume sustancias nutritivas y como resultado disminuye su concentración en los canales de suministro adyacentes, por lo tanto cuanto más activo sea el crecimiento de una parte, tanto más irán a parar a ella los materiales disponibles y tanto más se restringirá el crecimiento en otras partes.

Con el fin de demostrar en nuestro caso, el valor relativo de cada índice respecto al resto, se utilizó una matriz de correlación de Pearson, observándose que los valores del RGR los tres años, como era de esperar, mantenían una buena correlación positiva con sus componentes (NAR, LAR, SLA y LWR), siendo la correlación más elevada con el $L A R\left(R^{2}=0,98\right.$ y $\left.R^{2}=0,97\right)$ respectivamente los años 2011 y 2013 y con el NAR $\left(R^{2}=0,96\right)$ el año 2012.

Gratani et al. (2008), Heuvelink (1989) y De Groot (2001) demostraron, que los cambios en RGR dependían fundamentalmente de los cambios de NAR y no del valor del LAR. Sin embargo, otros autores, como Tittonell et al. (2002), explican las variaciones del RGR por la variación del LAR debido al crecimiento del área foliar y no por una mayor tasa de asimilación neta.

EI RGR mantiene una buena relación, pero negativa, con el $L A D\left(R^{2}=-0,90\right.$; $R^{2}=-0,88 ; R^{2}=-0,89$ respectivamente) los años 2011, 2012 y 2013 y también con el LAI $\left(R^{2}=-0,91 ; R^{2}=-0,92 ; R^{2}=-0,95\right.$ respectivamente) los años 2011,2012 y 2013. 
Así mismo, se ha encontrado una relación positiva directa $\left(R^{2}=0,70\right.$; $R^{2}=0,57$; y $R^{2}=0,71$ respectivamente) para los tres años de ensayo, entre la velocidad de crecimiento del fruto (FGR) y el LAI. Tanto el LAR como el LWR están correlacionados positivamente entre ellos $\left(R^{2}=0,98 ; R^{2}=0,97 ;\right.$ y $R^{2}=0,99$ respectivamente) y ambos con el SLA también positivamente y negativamente con el LAI y el LAD. Por último ningún índice de crecimiento muestra una correlación clara con la velocidad de crecimiento de las hojas (LGR), siendo el NAR el único que mostró correlación positiva con él los tres años de ensayo $\left(R^{2}=\right.$ 0,$74 ; R^{2}=0,53 ; R^{2}=0,53$ respectivamente) el 2011, 2012 y 2013.

La ligera mejora de RGR y NAR en las parcelas enmendadas con compost al final del ciclo de cultivo podría ser debido a un retraso en la senescencia de los órganos vegetativos $y$, en consecuencia, una mayor área fotosintética (Tekalign and Hammes, 2005), mayor eficacia de la planta como productora de nuevo material (Sivakumar and Shaw, 1978), con mayor ganancia de materia seca por unidad de tejido asimilatorio y por unidad de tiempo (Xiong et al., 2011 y Rincon Sanchez et al., 1998). Según Santos et al. (2014) el efecto positivo sobre la producción, consecuencia de la aplicación de fuentes orgánicas al suelo esta relacionada con el efecto nutricional y en consecuencia con los índices fisiológicos.

La evolución del LGR a lo largo del ciclo del cultivo del melón, puso de manifiesto, el efecto positivo de la aplicación de compost de orujo de vid, en la evolución de la senescencia de las hojas, ya que todos los años, la velocidad de crecimiento de las hojas fue mayor al final del ciclo del cultivo, independientemente de la dosis compost utilizada. De igual modo, los valores de la duración de área foliar (LAD) aumentaron siempre con la aplicación del compost respecto al testigo. Este hecho es positivo, ya que según Castellanos et al. 2011 en las plantas de melón la hoja constituye la principal fuente de fotoasimilados para los frutos y es lógico que los valores más altos de LAI coincidieran con los mayores valores de CGR. La aplicación del compost de orujo dependiendo del año de estudio supuso un incrementó entre un $15 \%$ y un $25 \%$ del FGR respecto al testigo. Según Santos et al. (2014) la utilización de biofertilizantes de estiércol de bovino digeridos vía aerobia y anaerobia, junto con fertilizantes minerales en melón Mirage (Harper), produce un mayor aporte nutricional y hace posible mayores tasas fotosintéticas y consecuentemente mayores cantidades de carbohidratos que se asignan a los órganos de reserva de las plantas, los frutos. 


\subsection{Producción y calidad de melón}

Algunos estudios defienden que la producción de melón con incorporación de fertilización orgánica al suelo, es similar o incluso superior que con el sistema convencional de fertilización mineral (Bulluck et al., 2002; Fernandes et al., 2003; Morra et al., 2003; Cürúk et al., 2004; Melero et al., 2006) además de contener en el fruto, igual o mayor cantidad de solidos solubles. (Cürük et al., 2004; Fernandes et al., 2003). La planta es capaz de absorber $N$ en algunas formas orgánicas, tales como aminoácidos (Näsholm et al., 2000), proteínas (Yamagata and Ae, 1999; Matsumoto et al., 2000) y mezcla de otros compuestos orgánicos solubles (Okamoto et al., 2003), lo que implica que la aplicación de compost de orujo puede proporcionar al cultivo de melón, varias de estas formas nitrogenadas, favoreciendo su crecimiento y desarrollo.

Con la aplicación de este residuo se puso de manifiesto una mejora del rendimiento de la fruta en las parcelas enmendadas de entre un $12 \%$ y $23 \%$ dependiendo de los años, debido tanto al mayor número de frutos como a su peso medio (apartado 4.3). Mkhabela and Warman (2005) también encontraron que había un efecto positivo en la utilización conjunta de compost y fertilización mineral en el rendimiento de patatas y maíz. Shafeek et al. (2015), en un estudio en el que comparaban la influencia de la fertilización orgánica y mineral en el crecimiento, rendimiento y calidad del fruto en un cultivo de melón Cantalupe, obtuvieron que la utilización de altas dosis de compost de estiércol simultáneamente a fertilizantes NPK, producen un incremento, aunque no significativo tanto del rendimiento en fruto, como de su calidad. En el mismo sentido El-Desuki et al. (2000) obtuvieron que la adición de materia orgánica en forma de estiércol, mejoró el crecimiento del melón Cantalupe, el contenido en NPK, la producción total y la calidad. Teixeira Lobo et al. (2019) en un ensayo en campo con dos tipos de melón distintos (Canary y Hale's best Jumbo), encontraron que la aplicación conjunta de nutrientes en forma mineral al suelo (40 kg de $\mathrm{N} \mathrm{ha}^{-1}, 120 \mathrm{~kg}$ de $\mathrm{P}_{2} \mathrm{O}_{5} \mathrm{ha}^{-1}$ y $40 \mathrm{~kg}$ de $\mathrm{K}_{2} \mathrm{O} \mathrm{ha}{ }^{-1}$ ), con materia orgánica, estiércol de vaca, produjo un incremento en la masa de fruto y en el rendimiento del $26 \%$ respecto a la fertilización únicamente mineral, así como el tamaño.

La diversidad de nutrientes esenciales presentes en el compost de orujo, contribuyó al aumento de la productividad del cultivo de melón, lo que también fue observado por otros autores (Freire et al., 2009; Rodrigues et al., 2008 y Santos et al., 2014). El aumento en el rendimiento de los cultivos y la calidad se han atribuido a veces a una mejor absorción de $N, P \circ K$ desde el compost 
(Mkhabela and Warman, 2005; Montemurro et al., 2005). El mayor número de frutos observado podría ser atribuido a una mayor absorción de $P$ en los tratamientos con compost (Figura 4.2.5), ya que según Rickard (2000), el número de frutos producidos por la planta dependen del número de flores producidas y del cuajado de frutos y Mendoza-Cortez et al. (2014) obtuvieron el mayor número de frutos por planta en un cultivo de melón con el aumento de las aplicaciones de P. Para conseguir la mejora referida, fue suficiente la aplicación de la dosis $D_{2}\left(13+h^{-1}\right)$ y ello puede ser debido a que la aplicación de cantidades mayores de compost, pueden disminuir la actividad microbiana, efecto que fue observado por Xue and Huang (2013) utilizando compost de lodos de depuradora, afectando por tanto a la disponibilidad de nitrógeno por la planta y a su rendimiento ya que, hemos visto, que ambos parámetros están directamente relacionados. Costa et al. (2011) aplicando abonos orgánicos de caprino y ovino en melón Cantaloupe, obtuvieron rendimientos comprendidas entre 40 y $45+\mathrm{ha}^{-1}$ y Freire et al. (2009) aplicando compuestos orgánicos líquidos vía fertirrigación, obtuvieron 52 tha $^{-1}$, rangos próximos a los encontrados en nuestro caso con la aplicación del compost de orujo desalcoholizado procedente de la industria vitivinícola.

La mayoría de los parámetros de calidad de la fruta, mejoraron con la aplicación del compost de orujo frente a los obtenidos en las parcelas no enmendadas, aunque no en todos se apreciaron diferencias entre los distintos tratamientos aplicados. Este hecho puede ser debido, a la mayor oferta de nutrientes en los suelos enmendados con compost de orujo, que contribuyen al mejor desarrollo y fructificación de los frutos (Teixeira Lobo et al., 2019). Otros autores (Roe et al., 1997; Bustamante et al., 2008 c) han confirmado, que los compost tienen la capacidad de suministrar macronutrientes y micronutrientes en el suelo para un óptimo crecimiento de las plantas. Marculescu et al. (2002), hicieron referencia a que la aplicación de fertilizantes orgánicos mejora el crecimiento vegetativo, la producción y la calidad de los frutos. Jiménez et al. (1997), obtuvieron que la aplicación de compost de estiércol en un cultivo de melón, produjo un incremento de los parámetros relacionados con el crecimiento vegetativo, así como en la producción y calidad de los frutos.

En el año 2013, no se apreció dicha mejora frente al control, debido probablemente a que a consecuencia de la mayor estabilidad del compost utilizado, el aporte de nutrientes procedentes de la mineralización del residuo orgánico fue baja, considerando que el ciclo de este cultivo es corto (80-90 días). Además, las condiciones climáticas en el año 2013, bajas temperaturas que 
incluso produjeron un retraso del desarrollo del cultivo, también pudieron afectar a dicha mineralización (Figuras 4.1.6 y 4.1.7).

La firmeza de la pulpa no se vio afectada por la aplicación de compost. Este resultado, coincide con los obtenidos por otros autores como Naidu et al. (2013) y Liguori et al. (2015), para melón y sandía respectivamente, con la aplicación de fertilizantes orgánicos, al contrario a lo encontrado por Santos et al. (2014). Al igual que Fernandes et al. (2003), se han obtenido mayores contenidos de sólidos solubles en el melón bajo fertilización orgánica. La anchura de los fruto aumento con la aplicación de compost, resultados similares fueron encontrados por Santos et al. (2014) aunque Costa (2011), no encontró diferencias en esta variable al evaluar la fertilización suplementada con diferentes compuestos orgánicos en un cultivo de melocotón. Un panel de catadores expertos, encontró que los melones obtenidos en las parcelas tratadas con la dosis $D_{2}$ presentaban las mejores cualidades organolépticas (datos no publicados).

\subsection{Comportamiento del nitrógeno y del fósforo aplicado}

La aplicación de compost de orujo desalcoholizado proveniente de la industria vitivinícola, no tuvo un efecto claro en la concentración de nitrógeno ni de fósforo en las distintas partes de la planta a lo largo del ciclo del cultivo de melón, ni tampoco produjo efecto apreciable en la distribución de ambos nutrientes en hoja, tallo y fruto, en ninguna de las fechas de muestreo en los años de ensayo (apartado 4.2). Los resultados obtenidos en la distribución de $N$ por la planta, fueron similares a lo que observaron Rincón et al. (1996) en un cultivo de melón cv Toledo en invernadero con fertirrigación.

En el caso del $N$, en todos los casos se obtuvieron concentraciones más altas en la etapa temprana del ciclo vegetativo, bajando paulatinamente hasta llegar a estabilizarse. Este comportamiento también ha sido encontrado por otros autores en el cultivo de melón, como Panagiotopoulos (2001) y Kirnak et al. (2005). Diferentes autores (Greenwood et al., 1990; Lemaire and Gastal, 1997) han señalado que la concentración de $N$ en las diferentes partes de la planta, disminuye cuando aumenta la biomasa vegetal (ley de la disminución progresiva, Le Bot et al. (1998)), y es debido a la translocación de $\mathrm{N}$ a los frutos.

Los fertilizantes químicos suministran los nutrientes de forma rápida. Sin embargo, un compost maduro aunque contiene generalmente bajos porcentajes 
de $N, P$ y otros nutrientes, presenta la ventaja de liberarlos lentamente en el suelo, lo que implica un mejor aprovechamiento por la planta (Martin and Gershuny, 1992). La aplicación conjunta de ambos tipos de fertilizantes, como es nuestro caso, implica grandes ventajas.

La aplicación del compost de orujo tuvo un efecto positivo en la absorción de $N$, únicamente en el tallo, fruto y planta completa frente al control, aunque no fue significativo. La máxima extracción de $\mathrm{N}$ coincidió con el desarrollo de la mayoría de los frutos, debido a que el $\mathrm{N}$ es un nutriente dominante en el crecimiento, la productividad y la longevidad (Huett, 1996). En el caso del $P$, hubo un efecto significativo $(p \leq 0,01)$ en la absorción de $P$ por la hoja, fruto $y$ planta completa los tres años de ensayo frente al control, aunque el efecto de la dosis no es claro. La máxima extracción de $P\left(24,5 \mathrm{~kg} \mathrm{ha}^{-1}\right)$ se obtuvo con una producción de melón de $\left(55,2 \mathrm{~kg} \mathrm{ha}^{-1}\right)$ en el año 2012 con la dosis $D_{1}$.

La absorción de $\mathrm{N}$ y su acumulación en las diferentes partes de la planta de melón durante su crecimiento, han sido estudiadas por diferentes investigadores, en el caso de algunos grupos de cultivares de melón como Reticulatus en fertirrigación (Purqueiro et al., 2003; Kirnak et al., 2005), Cantalupensis (Pérez-Zamora and Cigales-Rivero, 2001; Fagan et al., 2006), obteniendo resultados diferentes y a veces contradictorios. En la mayoría de los casos, los experimentos fueron llevados a cabo en invernaderos $y / 0$ en hidroponía (Fukutoku et al., 2000; Fogaça et al., 2008). Estos autores informan sobre la dinámica de absorción de $\mathrm{N}$, pero, en la mayoría de los casos, las cantidades de aplicación óptimas no se determinaron. Castellanos et al. (2006) optimizaron la fertilización nitrogenada del melón Piel de Sapo cultivado en condiciones de campo y con acolchado plástico, dando como valor óptimo para esas condiciones entre 90 y $95 \mathrm{~kg} \mathrm{~N} \mathrm{ha}^{-1}$ de $\mathrm{N}$ aplicado o de $160 \mathrm{~kg} \mathrm{~N} \mathrm{ha}^{-1}$ de disponible. En nuestro caso, la aplicación de compost de orujo desalcoholizado incrementó la cantidad de nitrógeno absorbido como consecuencia de la mayor producción obtenida, aunque con cantidades más bajas de nitrógeno disponible.

La adición de fósforo procedente de residuos orgánicos al suelo, puede tener un efecto residual importante. Sin embargo, dado que en las prácticas agrícolas estas enmiendas se suelen aportar anualmente, es importante conocer el efecto de la aplicación "en fresco" en el año del experimento, pudiéndose medir el efecto bien mediante el rendimiento o bien determinando el $P$ absorbido por el cultivo. En experimentos en invernadero, estas dos medidas proporcionan valores similares del valor residual (Barrow and Campbell, 1972), pero no así en experimentos en campo (Mattingly and Widdowson, 1963) donde 
el valor del $P$ absorbido por los cultivos, puede indicar un valor residual más elevado que el indicado únicamente por el rendimiento.

La aplicación de compost de orujo produjo al final del ciclo de cultivo, un incremento en la concentración de $P$ en el suelo proporcional a la dosis aplicada. Se obtuvieron diferencias significativas $(p \leq 0,05)$ los años 2012 y 2013 , entre el control y todos los tratamientos, aunque no entre tratamientos. La adición de fósforo procedente de residuos orgánicos al suelo puede tener un efecto residual importante. Requejo et al. (2016) en un experimento llevado a cabo en suelos calcáreos con el aporte de residuos derivados de la industria vitivinícola y de las destilerías, observaron, que los residuos aportados, tenían un efecto positivo en la disponibilidad del $P$ del suelo y que además el exceso de $P$, se quedaba retenido evitándose así los riesgos de contaminación.

El incremento del fósforo asimilable en el suelo con la aplicación de compost, ha sido observado por otros autores. Bar-Tal et al. (2004) con compost de lodo de depuradora y de estiércol de vacuno en un cultivo de trigo en invernadero durante 4 años y Wong et al. (1999), en un experimento de aplicación de compost de estiércol en dos cultivos diferentes (Brassica chinensis y Zea mays L.).

Al-Rohily et al. (2013), obtuvo que la adición de compost de estiércol de vaca y de lodos a un suelo calizo, proporcionaba altas cantidades de fosforo Olsen. Este incremento de fosforo disponible, podía ser atribuido a la liberación de cantidades significativas de $\mathrm{CO}_{2}$ durante la descomposición de la materia orgánica y a la formación de compuesto con cationes, como el $\mathrm{Ca}^{2+}$, reduciéndose la fijación de $P$ (Tolanur and Badanur, 2003). En suelos calizos, la precipitación de fosfatos cálcicos insolubles es el mayor factor de perdida de disponibilidad de fosforo (Sample et al., 1980; Afif et al., 1993).

Se ha encontrado un efecto sinérgico con la aplicación conjunta de compost y fertilizantes inorgánicos de $P$, siendo dicho efecto proporcional a la dosis de materia orgánica añadida al suelo. Parham et al. (2002), encontraron que el incremento era principalmente debido al incremento del carbón de la masa microbiana, que promueve la actividad microbiana y aumenta la actividad de la fosfatasa y de la deshidrogenasa, responsables de la solubilización del fosforo. El efecto sinérgico de la aplicación de estiércol con la fertilización fosfórica, ha sido estudiada por varios autores (Mkhabela and Warman, 2005; Garg and Bahl, 2008). Delgado et al. (2002), atribuyeron este efecto al hecho 
de que las enmiendas orgánicas consisten en una mezcla de ácidos húmicos y fúlvicos que incrementan la recuperación del $\mathrm{P}$ aplicado.

Akinrinde et al. (2005), estudió el beneficio añadido de la aplicación combinada de fertilizantes orgánicos y minerales en trigo y melón, en dos suelos diferentes, obteniendo incrementos en el porcentaje de recuperación de $P$ por el melón de entre un $3,3 \%$ a un $4,2 \%$, en función del suelo.

Iglesias-Jimenez et al. (1993) en un experimento en invernadero, estudiaron la eficacia de un compost de residuos urbanos como fuente de $P$ en comparación con $\mathrm{K}_{2} \mathrm{HPO}_{4}$, en un suelo con elevada capacidad de fijación. La aplicación de compost a dosis altas $\left(40+\mathrm{ha}^{-1}\right)$, disminuyó notablemente la capacidad de fijación del suelo, al competir en la adsorción los ligandos orgánicos y el ión fosfato. Traore et al. (1999) estudiaron la influencia del tiempo de compostaje en tres residuos: municipales, lodos y residuos vegetales, en la cantidad de $P$ inorgánico soluble en agua, obteniendo una disminución de este en función del tiempo de compostaje y de la estabilidad del compost, y la formación de fosfatos de calcio, magnesio y/o hierro insolubles.

El efecto de la fertilización orgánica sola o combinada con fertilización mineral en el rendimiento de los cultivos y la fertilidad del suelo, depende de la dosis de aplicación y de la naturaleza del fertilizante utilizado. Las dosis de aplicación se obtienen a partir de las necesidades de $N$ del cultivo, sin tener en cuenta el contenido en $P$ y $K$ del residuo orgánico. Dado que la relación N/P en el fertilizante orgánico en general, es significativamente más baja que la relación $N / P$ en el cultivo, se produce una sobre fertilización de $P$. La acumulación en suelos de $P, K$ o metales pesados ha sido estudiada por varios autores. Chen (2006), sugiere que la fertilización basada en el fósforo aplicado con el compost con un suplemento de urea, es la mejor estrategia de gestión para evitar problemas de contaminación a largo plazo.

El aporte de $P$ del compost es uno de los grandes problemas de la utilización de este tipo de residuos en suelos calizos, ya que se producen reacciones de adsorción/precipitación inmediatamente después de su aplicación que hace muy difícil su dosificación. (Vaneeckhaute et al., 2016; Brod et al., 2015). La fijación de $P$ se produce de forma rápida en el suelo, existiendo una mala sincronización con los requerimientos de la planta, fenómeno estudiado por Fouda et al. (2013) en varios tipos digestatos compostados o no y por Grigatti et al. (2015) con diferentes tipos de compost. 
Grigatti et al. (2019), comparando el efecto de la aplicación de distintos tipos de compost (digestato, lodo de depuradora, vegetales y bioresiduos) en un cultivo de ryegrass, encontraron que la disponibilidad de $P$ está directamente relacionada con la del $\mathrm{N}$, existiendo una relación lineal entre la absorción de ambos nutrientes, relación también encontrada en el presente estudio. Aunque la mayoría de los trabajos solo tiene en cuenta el contenido total de $P$, sin considerar su disponibilidad (Jacubus et al., 2016), Grigatti et al. (2019) consideran que en la utilización de compost como sustituto de los fertilizantes minerales, es necesario conocer el $\mathrm{P}$ inorgánico lábil (extraíble con $\mathrm{H}_{2} \mathrm{O}+$ $\mathrm{NaHCO}_{3}$ ), llevando a cabo una especiación de fosforo que permita su dosificación de forma más eficaz.

Se han sugerido muchos métodos para estimar la eficiencia del fósforo (no recuperación): la cantidad de $P$ añadido que permanece en formas lábiles en el suelo a lo largo del tiempo ( Larsen et al., 1965), el efecto de la adición de P en las isotermas de adsorción de P (Fox and Kamprath, 1970), cambios en la concentración de P Olsen en el suelo (Power et al., 1964; Fitter, 1974) o cambios en los pools de $P$ mediante extracción secuencial ( Beck and Sanchez, 1996; Aulakh et al., 2003; Blake et al., 2003).

EI P extraíble, dependiendo del extractante utilizado, puede dar idea de la disponibilidad inmediata o a corto plazo de este elemento. Además, el fraccionamiento del $P$ del compost en inorgánico y orgánico, puede dar idea, de su disponibilidad a corto y largo plazo. En nuestro caso, el compost de orujo desalcoholizado está formado por un $71 \%$ de $P$ inorgánico y un $29 \%$ de $P$ orgánico, representando el $P$ lábil el $22 \%$ del total.

EI $P$ no fue un factor limitante ni en el tratamiento control ni en los de compost, debido a que la cantidad disponible supera en todos los casos considerablemente las necesidades del cultivo (35 kg P ha ${ }^{-1}$ para una producción aproximada de $35+\mathrm{ha}^{-1}$ según Cortez (2005)), por lo que el porcentaje de recuperación del $P$ total disponible por el cultivo fue muy bajo en todos los casos (13 al 25\%). Esto podría representar un problema ambiental al producirse una acumulación de exceso de $P$ en el suelo. Sin embargo, las características del suelo del experimento, y fundamentalmente el valor del pH del mismo, provocan que el exceso de este elemento no se encuentre disponible, lo que disminuiría el riesgo ambiental de la aplicación de este tipo de residuos.

Con la aplicación de residuos orgánicos, la adsorción de fósforo por las partículas del suelo puede ser menor que en condiciones normales, ya que los 
ácidos húmicos que contienen gran cantidad de cargas negativas, compiten por los lugares de adsorción con el P inorgánico (García, 2014; Sui y Thompson, 2000; Iyamuremye et al., 1996 a, b; Von Wandruszka, 2006).

La cantidad nitrógeno mineralizado (NM) en el suelo los tres años de experimentación, aumentó con la aplicación del compost de orujo proporcionalmente a la dosis aplicada, como consecuencia de la mineralización del nitrógeno orgánico, tanto procedente del suelo como del residuo orgánico. Este efecto ha sido observado por otros autores (Iglesias-Jiménez and Álvarez, 1993; Bar-tal et al., 2004) con diferentes tipos de residuos orgánicos. Independientemente del tratamiento, la mineralización fue mayor el año 2011, debido probablemente a que en dicho año tanto las temperaturas mínimas como máximas fueron superiores al 2012 y 2013 (Stanford et al., 1973; Cassman and Munns, 1980). Por otra parte, las mayores entradas de nitrógeno en el sistema los años 2012 y 2013, pudieron retardar la mineralización. Castellanos et al. (2013) encontraron una relación negativa entre el nitrógeno disponible en el suelo y el nitrógeno mineralizado durante el ciclo del cultivo del melón. Otros autores, también han informado del efecto de la cantidad de nitrógeno en la solución del suelo, sobre la velocidad de mineralización de residuos orgánicos (Fangueiro et al., 2012) como consecuencia de un descenso de la actividad microbiana (Fog, 1988).

Hay que destacar, que la materia prima de la industria vitivinícola que se utiliza para obtener compost es variable, lo que implica que el comportamiento de este puede variar. Bustamante et al. (2007), estudiaron la mineralización del $C$ y del $N$ en suelos enmendados con residuos de la industria vitivinícola y alcoholera, obteniendo que la adición de estos residuos al suelo produce un ligero incremento del contenido en $\mathrm{N}$ mineral del suelo, excepto en el caso del raspón o tallos de vid y de las lías, que producen una inhibición de dicha mineralización. Este efecto ha sido observado por otros autores (Flavel et al., 2005). Ello es debido a las características de los residuos de la industria vitivinícola: alta relación $C / N$, presencia de polifenoles y baja concentración de compuestos solubles, todas ellas de gran influencia en la dinámica del $C$ y del $\mathrm{N}$ en suelos (Trinsoutrot et al., 2000).

Por una parte, los materiales carbonosos como los tallos de vid, podrían causar una inmovilización del nitrógeno mineral presente en el suelo al ser usado por la biomasa microbiana (De Neve et al., 2004). Por otra, el bajo contenido de compuestos solubles en el caso del orujo desalcoholizado, está relacionado inversamente con la mineralización del N (Trinsoutrot et al., 2000). El contenido 
en polifenoles presentes en estos residuos (Negro et al., 2003) produce efectos tóxicos en la biomasa microbiana del suelo implicada en los procesos de mineralización de N. Además, la capacidad de estos compuestos de enlazar proteínas a través de su afinidad por grupos amida, hace que puedan formar complejos que son inaccesibles a los microorganismos del suelo (Scalbert, 1991; Mafongoya et al., 1998).

En nuestro caso, no se ha observado este efecto, ya que el proceso de compostaje elimina en gran medida las causas de la inmovilización, fundamentalmente los polifenoles. En todos los casos, se ha producido un incremento en la cantidad de $\mathrm{N}$ mineralizado, partiendo de valores de $\mathrm{N}$ disponible en el suelo muy parecidos, como se observa en el balance de nitrógeno.

Las reacciones de inmovilización-mineralización del $N$ en el suelo, están condicionadas tanto por las características del residuo como por el tipo de suelo. Los altos valores de mineralización de nitrógeno encontrados en el suelo del experimento, pueden ser debidos a su naturaleza ligera (Hernández et al., 2002).

La aplicación de compost de orujo produjo un incremento respecto al testigo, en los valores de los índices relacionados tanto con la producción, (Factor parcial de productividad de aplicación de $N\left(\right.$ PFP $\left._{N}\right)$, Eficacia agronómica de aplicación del $N\left(A E_{N}\right)$, Eficacia de utilización interna del $N\left(I E_{N}\right)$ y Eficacia de uso del $N$ basado en la biomasa $\left(T B N U E_{N}\right)$ ), como con los relacionados con la absorción del $N$ (Eficacia de absorción de $N\left(N U_{p} E_{N}\right.$ ), Eficacia de recuperación de la aplicación de $N\left(R E_{N}\right)$ e Índice de cosecha del $N\left(N H I_{N}\right)$ ), aunque en general no se apreció una clara influencia de la dosis de compost.

En el año 2013, los valores de estos índices fueron en general más bajos, lo que se pudo deber a que el compost que se aplicó era mucho más estable. Sin embargo, en el caso del $P$, la aplicación de compost de orujo no tuvo un efecto marcado en los valores de los índices respecto al testigo. Los resultados de estos índices para el P, como era de esperar son difíciles de interpretar por varias razones. Como hemos comentado, dependen no solo del fósforo disponible procedente de las diferentes fuentes, sino también del $\mathrm{N}$ aplicado. Hay que tener en cuenta, que tanto el rendimiento del cultivo como el $P$ absorbido por el mismo, no dependen únicamente de la disponibilidad del $P$ que se encuentra en el suelo, sino también de otros factores que varían cada año: clima, la disponibilidad de otros nutrientes, $N$ y $K$ fundamentalmente, el estrés 
fisiológico, etc. Además hay otros factores que dependen del tipo de suelo, como es su estructura que mejora con la aplicación de fertilizantes orgánicos, su capacidad de intercambio catiónico, aireación, humedad y capacidad de almacenamiento (Agegnehu et al., 2016; Irineu et al., 2018 y Ozores-Hamptom et al., 2011). Además, en nuestro ensayo, en todos los tratamientos se aplicó una importante fuente de fosforo inorgánico (ácido fosfórico) que cubría con creces las necesidades del cultivo.

En general, para un mismo tipo de suelo y condiciones de cultivo, generalmente la eficacia disminuye al aumentar la cantidad de nutriente añadido o disponible (Cabello et al., 2009).

\subsection{Consecuencias ambientales de la aplicación de compost de orujo} de vid en zonas vulnerables: comparación con fertirrigación

El problema de las fuentes orgánicas de nutrientes, es conocer si el aporte de nitrógeno es el adecuado a los requerimientos de la planta, y si son capaces de suministrarlo aumentando la eficacia del uso de nitrógeno, reduciendo al mismo tiempo las pérdidas por lixiviación y volatilización (Tilman et al., 2002; Poudel et al., 2002). Los residuos orgánicos tienen una gran cantidad de $\mathrm{N}$ orgánico potencialmente mineralizable que aportan el nutriente con liberación lenta, siendo dicho aporte directamente proporcional a su velocidad de mineralización. El compost, formado por materia orgánica estable, presenta en general dependiendo del tipo de residuo del que procede, valores de constantes de mineralización, $\mathrm{k}$ (dias ${ }^{-1}$ ) muy bajas. La aplicación al suelo de compost, incrementa la cantidad de materia orgánica pero también la carga de nutrientes en las aguas superficiales y subterráneas, como consecuencia de la lixiviación de nitratos. Este hecho es importante cuando se aplican dosis elevadas de residuos orgánicos, con un contenido en nitrógeno disponible alto, en suelos bien drenados, $y$ en el periodo donde las lluvias son importantes. (Beckwith et al., 1998, Chambers et al., 2000). La fertilización mineral por el contrario aporta el $\mathrm{N}$ en forma de pulsos.

La aplicación de compost de orujo desalcoholizado proveniente de la industria vitivinícola, disminuyó la cantidad de $\mathrm{N}$ lixiviado entre un $20 \%$ y $50 \%$ dependiendo de la dosis aplicada y del año, respecto a los tratamientos control (apartado 4.4). Este hecho es muy importante en una zona vulnerable, en la cual el principal riesgo es la perdida de una alta cantidad de nitratos en los lixiviados, que contaminen los acuíferos que se usan como agua para consumo 
humano. Una concentración de nitratos en exceso en las aguas de bebida, tiene un riesgo para los animales jóvenes y los niños (USDA, 1991; Tyson et al., 1992; Matson et al., 1997). Además, existe un riesgo potencial de cáncer consecuencia de la formación de nitritos en el agua y los alimentos.

La disminución de la cantidad de $\mathrm{N}$ lixiviado, puede ser debida a la mejora de la estructura del suelo y de la capacidad de almacenamiento de agua del mismo cuando se aplican compuestos orgánicos (Agegnehu et al., 2016; Irineu et al., 2018). Castellanos et al. (2007), usando fertirrigación en melón, observaron el efecto contrario (que las pérdidas por lixiviación aumentaban exponencialmente con la cantidad de nitrógeno disponible aplicado).

El efecto de la aplicación de residuos orgánicos y compost en la lixiviación de nitratos, ha sido estudiado por numerosos investigadores con resultados muy distintos. Leclerc et al. (1995), demostraron una alta eficiencia del compost de estiércol y una disminución importante de la lixiviación de nitratos en un ensayo de 5 años de duración. Otros estudios obtuvieron el efecto contrario, un alto riesgo de contaminación por nitratos cuando se aplica residuos en otoño-primavera en suelos con alto contenido en materia orgánica. (Beckwith et al., 1998; Chambers et al., 2000; Chalmers, 2001; Yan-Wang et al., 2002).

Según De Grazia et al. (2006), el principal efecto beneficioso de los materiales orgánicos compostados, es que disminuyen la lixiviación de los nutrientes gracias a la mayor retención hídrica y al aumento de la capacidad de intercambio de iones. Ozores-Hampton et al. (2011, 2012), observaron un aumenta de la capacidad de retención de agua del suelo de hasta un 35\% con la aplicación de distintas enmiendas orgánicas. En nuestro caso, la aplicación de compost produjo un aumento en la capacidad de retención de agua del suelo ( $2 \%$ $11 \%$, dependiendo de la dosis aplicada) aunque no se encontraron diferencias significativas en el drenaje, en función de los distintos tratamientos y el control. La disminución del $\mathrm{N}$ lixiviado, se debió no solo al aumento de la retención de agua por el suelo, sino también, al aumento de la extracción por el cultivo del nutriente en las parcelas enmendadas (Tabla 4.4.1) (Cameron et al., 2013). Knowles, et al. (2011) tampoco obtuvieron diferencias significativas en el volumen de agua drenada aplicando bioresiduos a dosis de $100+\mathrm{ha}^{-1}$. Basso, et al. (2005), observaron que la aplicación de compost de estiércol, reduce considerablemente las pérdidas por lixiviación de nitratos, respecto a los residuos sin tratar. 
Los valores que se obtuvieron para los diferentes índices de impacto (Índice de impacto II e Índice de impacto ambiental EII) y el Índice de manejo o eficacia de gestión (ME) (apartado 4.6), nos han permitido valorar el impacto ambiental de la aplicación de este residuo orgánico. El Índice de impacto (II) nos permitió determinar si el $\mathrm{N}$ lixiviado a lo largo del ciclo del cultivo excedió los $50 \mathrm{mg} \mathrm{L}^{-1}$, que es la máxima concentración de nitratos permitida en agua de consumo humano por la Directiva Europea, y el índice de impacto ambiental (EII), determinó si la concentración de nitratos en el lixiviado excedió la concentración inicial procedente de los acuíferos. La aplicación de compost de orujo, no presentó ningún riesgo a aumentar la contaminación de los acuíferos. Es evidente que en las zonas vulnerables, donde la concentración de nitratos en el agua de riego es muy elevada, la aplicación de compost de orujo tiende a paliar la contaminación, pero nunca es capaz de anularla. La eficiencia de gestión aumentó con la aplicación de compost de orujo, ya que no sólo se produjo un incremento de cosecha, sino que además, disminuyo la cantidad de nitrógeno lixiviado.

Si comparamos los resultados obtenidos en la producción de melón con la aplicación de compost de orujo desalcoholizado, con los obtenidos por Castellanos et al. $(2012,2013)$ en las mismas condiciones, para el mismo cultivo (melón) pero con fertirrigación, se observó que: con la aplicación de compost se obtuvo mayor producción con menos $\mathrm{N}$ total disponible (apartado 4.6), lo que implica un efecto positivo de la incorporación al suelo de este residuo, además de obtenerse, valores más altos de los índices relacionados con la eficacia del uso del agua (WUE e IRRWUE), respecto a la fertirrigación tradicional (Castellanos et al., 2013) (apartado 4.6). En todos los casos, los valores de los índices de impacto utilizando compost fueron superiores a los obtenidos en fertirrigación, siendo el efecto proporcional a la dosis de compost aplicada. Además, también se produjo un aumento de la eficacia de gestión frente a la fertirrigación.

Como hemos podido constatar, la aplicación combinada de fuentes de nutrientes orgánicas e inorgánicas, puede ser la solución para alcanzar una producción de cultivos sostenible y plantas sanas en zonas vulnerables, ya que, el refuerzo de pequeñas cantidades de fertilizante con compost, reduce la cantidad de $\mathrm{N}$ requerida por el cultivo (apartado 4.2) y produce interacciones favorables para el crecimiento y desarrollo de la planta (apartado 4.1). Estos resultados están de acuerdo con los obtenidos por Yang (2006) y Park et al. (2012). Según Ozores-Hampton (2012), el uso de materia orgánica podría mejorar la calidad del suelo y aumentar la utilización del fertilizante y por lo 
tanto mejorar el rendimiento del cultivo. Hay que tener en cuenta, que según Castellanos et al. (2010), la búsqueda del aumento de rendimiento y beneficios económicos sin tener en cuenta el medio ambiente, puede llevar a hacer algunas practicas inadecuadas, como el exceso de fertilización mineral, que produzcan daños sociales y medio ambientales. El uso de fuentes alternativas de fertilización como el compost de orujo proveniente de la industria vitivinícola, puede reducir el daño ambiental y los costos producidos con fertilizantes minerales. Del mismo modo, Santos et al. (2014) y Agegnehu et al. (2016), aplicando diversos bioresiduos en melón, encontraron que con el uso conjunto de enmiendas orgánicas y pequeñas cantidades de fertilizante mineral, se conseguian mejores producciones respecto al fertilizante mineral, incrementando la rentabilidad, mitigando además la polución medioambiental e incrementando la eficacia de uso del $\mathrm{N}$.

\subsection{Efecto residual del nitrógeno procedente de compost de orujo}

Los cultivos captura se han utilizado para mejorar el reciclado del nitrógeno en el sistema suelo-planta (Thorup-Kristensen et al., 2003), ya que la sobre fertilización es habitual en cultivos irrigados y rentables, por lo que el $\mathrm{N}$ residual en el suelo después de la cosecha puede perderse por lixiviación durante el invierno y primavera, contribuyendo al aumento de la concentración de nitratos en las aguas subterráneas (Isidoro et al., 2006; Quemada et al., 2013).

La cantidad de nitrógeno remanente en el suelo después del cultivo de melón se midió de forma indirecta utilizando un cultivo captura, trigo como testigo. En general, tanto la producción de trigo como la absorción de $\mathrm{N}$ por el mismo, fue más elevada en las parcelas en las que se aplicó compost de orujo en el cultivo de melón, independientemente de las diferentes actuaciones que se produjeran en el cultivo de trigo cada año: aplicación complementaria en la campaña 2011-2012 con el agua de riego de $34 \mathrm{~kg}$ de $\mathrm{N} \mathrm{ha}^{-1}$ y en la 2012-2013 de $47 \mathrm{~kg}$ de $\mathrm{N} \mathrm{ha}^{-1}$ en forma de $\mathrm{N}$ ureico. La incorporación complementaria de otras fuentes de nitrógeno además del compost, aumentó tanto la eficacia de producción de trigo como la eficacia de extracción de nitrógeno.

El efecto residual del nitrógeno ha sido estudiado por otros autores (McCracken et al., 1989; Rufo et al., 2004; Milne et al., 2010) para intentar reducir el exceso de $\mathrm{N}$ en los lixiviados. Así, McCracken et al. (1989) mediante análisis estadístico mostraron que las medidas de la concentración de $\mathrm{NO}_{3}{ }^{-} \mathrm{N}$ 
en la superficie del suelo, reflejaban las técnicas de manejo anteriores realizadas en las parcelas. Milne et al. (2010), estudiaron el efecto de tratamientos previos de nitrógeno en forma de nitrato amónico mediante fertirrigación en la biomasa de trigo, a través de frecuencias espaciales múltiples, para poder determinar la relación dependiente de la frecuencia entre el nitrógeno aplicado, la posición del melón y la biomasa de trigo.

Según el análisis multiescala a través de la entropía relativa $(E(\delta))$ de frecuencias espaciales múltiples, que se realizó en el transecto del cultivo de trigo, los resultados a gran escala (frecuencias altas) ( $q=64 \mathrm{~m}$ y $\delta=128$ muestras recogidas del transecto), no presentan en ningún caso variación apreciable de la entropía relativa. A una escala más pequeña, de 32 a $16 \mathrm{~m}$, en las campañas 20112012 y 2013-2014 los valores de entropía relativa son significativamente diferentes, lo que implica que existe una variación en la producción de grano en función de los tratamientos. La incorporación complementaria en la campaña 2012-2013 de $100 \mathrm{~kg} \mathrm{ha}^{-1}$ de urea, enmascaró el nitrógeno disponible del suelo procedente de los tratamientos de compost.

A escalas de 4-2 y 1-0 metros (bajas frecuencias), hay un incremento significativo de la entropía debida fundamentalmente a la posición de las líneas de cultivo de melón y por tanto de la absorción del nitrógeno. La aplicación de compost de orujo, disminuye la magnitud de las diferencias encontradas.

Las relaciones entre el peso de grano y nitrógeno extraído por el grano y el $N$ mineral disponible en el suelo, muestran que este no es el factor más relevante de los que influyen en la variabilidad. La mineralización del compost de orujo a lo largo del periodo estudiado, y la influencia en dicha mineralización de la adición de fuentes nitrogenadas complementarias, parecen ser factores de influencia más significativos.

Resultados similares fueron obtenidos por Milne et al., 2010. La variación de frecuencia alta está asociada al cambio de paso entre tratamientos y dentro de un mismo tratamiento, a la posición de la línea de cultivo dentro de las parcelas. Resultados parecidos fueron encontrados por Tarquis et al. (2017). 
Capítulo 6

CONCLUSIONES 

Tras el estudio y análisis de los resultados obtenidos, se han llegado a las siguientes conclusiones:

1. El uso del compost de orujo desalcoholizado procedente de las industrias vitivinícolas como fuente de nutrientes en las zonas en que se producen, es una buena opción de manejo de estos residuos orgánicos, desde el punto de vista económico, agronómico y medioambiental.

\section{I - Respecto a la dinámica de crecimiento del cultivo de melón}

2. La aplicación de compost de orujo tuvo un efecto positivo en la acumulación de materia seca de las diferentes partes de la planta respecto al control, efecto que se puso de manifiesto los tres años de ensayo. Sin embargo, mientras que la acumulación de materia seca de la parte vegetativa (hoja y tallo) se vio más favorecida con la dosis mayor $\left(\mathrm{D}_{3}\right)$, la acumulación de materia seca del fruto fue superior con los tratamientos $D_{1}$ y $D_{2}$.

3. La aplicación de compost de orujo no afectó a la distribución de materia seca ninguno de los años de experimentación, siendo todos los años el fruto el que más contribuyó al peso seco del total de la planta, entre un 57-65\% en 2012 y 2011 respectivamente.

4. La aplicación de compost de orujo afectó positivamente a los valores de LAI y LAD los tres años de ensayo, obteniéndose en todos los casos los valores más altos con la dosis $D_{2}$, coincidiendo con la formación y engorde de los frutos. La aplicación del compost de orujo parece retardar la senescencia de las hojas.

5. Respecto a los índices de crecimiento estudiados, el efecto de la aplicación de compost ha producido dos respuestas distintas: No se ha observado una respuesta clara a la aplicación del compost en los índices morfológicos (SLA, LWR, LAR,) mientras que si se apreciaron diferencias significativas en los demás índices: tasa de asimilación neta (NAR), la velocidad de crecimiento de las hojas (LGR), la velocidad de crecimiento relativo ( $R G R$ ), la velocidad de crecimiento del cultivo (CGR) y la velocidad de crecimiento de los frutos (FGR), aumentando todos ellos su valor con la aplicación de compost respecto al tratamiento control. 


\section{II - Respecto al comportamiento del nitrógeno y del fósforo aplicados}

6. La aplicación del compost de orujo no tuvo un efecto claro en la concentración de nitrógeno ni de fósforo, en las distintas partes de la planta a lo largo del ciclo del cultivo de melón, ni tampoco produjo efecto apreciable en la distribución de $\mathrm{N}$ en hoja, tallo y fruto, en ninguna de las fechas de muestreo en los tres años de ensayo. La mayor acumulación de nutrientes, $N$ y $P$ en el fruto se produjo en el año 2011 con la dosis $D_{3}$ en el caso del $N$ y con la $D_{2}$ en el caso del $P$, a los 90 DDT.

7. La aplicación del compost de orujo tuvo un efecto positivo en la absorción de $\mathrm{N}$ únicamente en el tallo, fruto y planta completa frente al control, aunque no fue significativo. Se obtuvo la máxima extracción de $\mathrm{N}\left(142,8 \mathrm{~kg} \mathrm{ha}^{-1}\right)$ con la máxima producción de melón $\left(56,1 \mathrm{~kg} \mathrm{ha}^{-1}\right)$ en el año 2012 con la dosis $D_{3}$. En el caso del $P$, hubo un efecto significativo en la absorción de $P$ por la hoja, fruto y planta completa los tres años de ensayo frente al control, aunque el efecto de la dosis no fue claro. La máxima extracción de $P\left(24,5 \mathrm{~kg} \mathrm{ha}^{-1}\right)$ se obtuvo con una producción de melón de $\left(55,2 \mathrm{~kg} \mathrm{ha}^{-1}\right)$ en el año 2012 con la dosis $D_{1}$.

8. En los tres años de experimentación, el compost de orujo afectó positivamente a la cantidad de nitrógeno mineralizado (NM), produciéndose un aumento proporcional a la dosis aplicada como consecuencia de la mineralización del nitrógeno orgánico tanto procedente del suelo como del propio residuo orgánico.

9. La aplicación de compost de orujo produjo una mayor movilización del $P$ en el suelo todos los años, produciéndose un aumento proporcional a la dosis aplicada al final del ciclo de cultivo.

10. Las pérdidas por lixiviación de nitrógeno en forma nítrica disminuyeron entre un 20-50\% dependiendo de la dosis aplicada y del año respecto a las parcelas sin enmendar. Este hecho es de destacar teniendo en cuenta que nos encontramos en una zona vulnerable.

11. La aplicación de compost de orujo produjo un incremento respecto al testigo, en los valores de los índices relacionados tanto con la producción $\left(P F P_{N}, A E_{N}, I E_{N}\right.$ y TBNUE $E_{N}$ ) como con los relacionados con 
la absorción del $N\left(N U_{N}, R E_{N}\right.$ y $\left.N H I_{N}\right)$, aunque no se apreció una clara influencia de la dosis de compost. En el año 2013 los valores de estos índices fueron en general más bajos, lo que se pudo deber a que el compost que se aplicó era mucho más estable. Sin embargo, en el caso del $\mathrm{P}$, la aplicación de compost de orujo no tuvo un efecto marcado en los valores de los índices respecto al testigo.

\section{III - Respecto a la producción y calidad de melón}

12. La aplicación del compost de orujo produjo una mejora del rendimiento de la fruta en las parcelas enmendadas, debido tanto al mayor número de frutos como a su peso medio. Para conseguir esta mejora fue suficiente la aplicación de la dosis $D_{2}\left(13+\mathrm{ha}^{-1}\right)$. Todos los años la mayor producción se obtuvo en la segunda corta, destacando el año 2012 con la dosis $D_{3}\left(56.1+\mathrm{ha}^{-1}\right)$.

13. La mayoría de los parámetros de calidad de la fruta mejoraron con la aplicación del compost de orujo frente a los obtenidos con el tratamiento control, aunque no se apreciaron diferencias entre las distintas dosis de compost. Sin embargo, en el año 2013, no se apreció dicha mejora frente al control, debido probablemente a la mayor estabilidad del compost utilizado.

\section{IV - La aplicación del compost de orujo versus fertirrigación}

14. Desde el punto de vista económico (producción de fruto), no existen diferencia en los índices de eficacia de uso del $N\left(P F P_{N}\right.$ y $\left.I E_{N}\right)$, entre la fertirrigación tradicional y la aplicación de compost de orujo, ya que estos índices están relacionados principalmente con el $\mathrm{N}$ que dispone el cultivo para su desarrollo y no en la forma (inorgánica u orgánica) en la que este se aplica.

15. Desde el punto de vista agronómico, teniendo en cuenta para este fin los índices relacionados con la eficacia del uso del agua (WUE e IRRWUE), para la misma cantidad de $N$ disponible en el suelo, se obtienen siempre valores más altos de WUE e IRRWUE con la aplicación de compost que con la fertirrigación tradicional.

16. Desde el punto de vista ambiental, utilizando los diferentes índices de impacto (II y EII) y el índice de manejo (Producción/N lixiviado), se observa un comportamiento muy diferente con la aplicación del compost respecto a la fertirrigación. En todos los casos el empleo de 
este residuo, mejora los valores de estos índices siendo el efecto proporcional a la dosis.

$V$ - Respecto al efecto residual del nitrógeno procedente de compost de orujo en un cultivo de trigo

17. En general, tanto la producción de trigo como la absorción de $\mathrm{N}$ por este, fue más elevada en las parcelas en las que se había aplicado compost de orujo en el cultivo de melón, independientemente de las diferentes actuaciones que se produjeran en el cultivo de trigo cada año: aplicación complementaria en la campaña 2011-2012 con el agua de riego de $34 \mathrm{~kg}$ de $\mathrm{N} \mathrm{ha}^{-1}$ y en la 2012-2013 de $47 \mathrm{~kg}$ de $\mathrm{N} \mathrm{ha}^{-1}$ en forma de $\mathrm{N}$ ureico. La incorporación complementaria de otras fuentes de nitrógeno además del compost, aumentó tanto la eficacia de producción de trigo como la eficacia de extracción de nitrógeno.

18. Según el análisis de frecuencias espaciales múltiples que se realizó en el transecto del cultivo de trigo, a bajas frecuencias se obtuvo una fuerte relación tanto de la producción de trigo como de la extracción de $\mathrm{N}$ por este, con la posición ocupada por el cultivo anterior y con la dosis de compost a la que había sido expuesto. Sin embargo, a altas frecuencias, dicha relación fue débil en ambos casos. La variación de frecuencia alta está asociada al cambio de paso entre tratamientos y dentro de un mismo tratamiento, a la posición de la línea de cultivo dentro de las parcelas. 


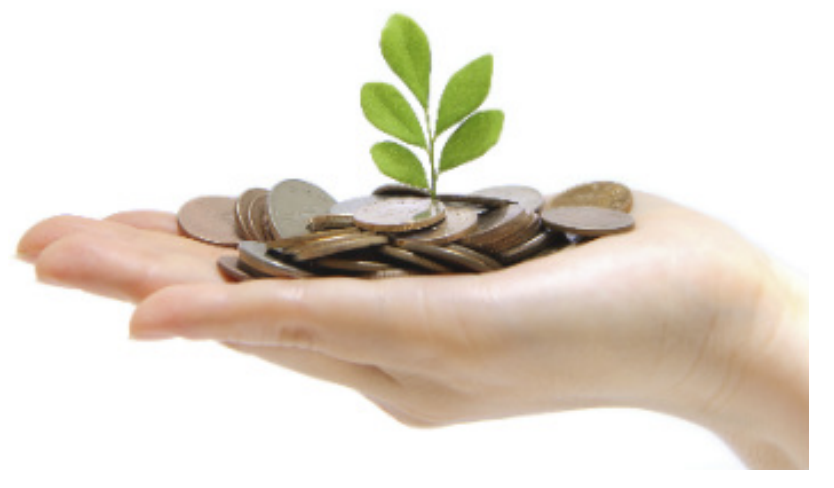

Capítulo 7

\section{BIBLIOGRAFÍA}



Abdelhamid, M.T., Horiuchi, T., Oba, S., 2004. Composting of rice straw with oilseed rape cake and poultry manure and its effects on faba bean (Vicia faba L.) growth and soil properties. Bioresource Technology 93: 183-189.

AENOR 1998. Calidad del agua. Medio Ambiente. Tomo 1. Recopilación de normas UNE. Ed. AENOR N.A. Madrid.

Afif, E., Matar, A., Terrent, J., 1993. Availability of phosphate applied to calcareous soils of West Asia and North Africa. Soil Science Society of America Journal 57: 756-760.

Agegnehu, G., Nelson, PN., Bird, M.I., 2016. Crop yield, plant nutrient uptake and soil physicochemical properties under organic soil amendments and nitrogen fertilization on Nitisols. Soil Tillage Research 160: 1-13.

Ahmed, Y., Shalaby, E., 2012. Effect of different seaweed extracts and compost on vegetative growth, yield and fruit quality of cucumber. Journal of Horticultural Science and Ornamental Plants 4: 235-240.

Akinrinde, E.A., Bello, O.S., Ayegboyin, K.O., Iroh, L., 2005. Added benefits of combined organic and mineral phosphate fertilizers applied to maize and melon. Journal of Agriculture \& Environment 3 (3-4): 75-80.

Al-Rohily, K.M., Ghoneim, A.M., Modaihsh, A.S., Mahjoub, M.O., 2013. Phosphorus availability in calcareous soil amend with chemical phosphorus fertilizer, cattle manure compost and sludge manure. International Journal of Soil Science 8: 17-24.

Allen, R.G., Pereira, L.S., Raes, D., Smith, M., 2002. Crop evapotranspiration. Guidelines for computing crop water requirements. FAO irrigation and drainage paper 56. 3rd edition.

Amendola, D., De Faveri, D.M., Egües, I., Serrano, L., Labidi, J., Spigno, G., 2012. Autohydrolysis and organosolv process for recovery of hemicelluloses, phenolic compounds and lignin from grape stalks. Bioresource Technology 107: 267-274.

APHA, AWWA, WPCF. 1989. Standard Methods for the Examination of Water. Ed Díaz de Santos, S.A. Madrid.

APHA. 1998. Standard Methods for the Examination of Water and Wastewater. 20th edn, American Public Health Association, Washington DC, USA. 
Archila, J., Contreras, U., Pinzon, H., Laverde, H., Corchuelo, G., 1998. Analisis de crecimiento de cuatro materiales de lechuga (Lactuca sativa). Agronomía Colombiana 16 (1): 68-75. Arvanitoyannis, I S., Ladas, D., Mavromatis A., 2006a. Potential uses and applications of treated wine wastes: a review. International Journal of Food Science \& Technology 41 (5): 475-487.

Arvanitoyannis, I S., Ladas, D., Mavromatis, A., 2006b. Wine waste treatment methodology. International Journal of Food Science \& Technology 41: 117-151.

Association of Official Analytical Chemists. [AOAC] 1990. Official Methods of Analysis, Helrich K. Ed. AOAC Arlington VA.

Aulakh, M.S., Kabba, B.S., Baddesha, H.S., Bahl, G.S., Gill, M.P.S., 2003. Crop yields and phosphorus transformations after 25 years of applications to a subtropical soil under groundnut-based cropping systems. Field Crops Research 83: 283-296.

Bai, Z., Jin, B., Li, Y., Chen, J., Li, Z., 2008. Utilization of winery wastes for Trichoderma viride biocontrol agent production by solid state fermentation. Journal of Environmental Sciences 20 (3): 353-358.

Barraza, F.V., 2000. Crecimiento del Chile Manzano (Capsicum pubescensR. y P.) en cuatro soluciones nutritivas bajo invernadero. Tesis de Maestro en Ciencias en Horticultura. Universidad Autónoma de Chapingo, México. 142.

Barrow, N.J., Campbell, N.A., 1972. Methods of measuring residual value of fertilizers. Australian Journal of Experimental Agriculture and Animal Husbandry 12: 502-510.

Bar-Tal, A., Yermiyahu, U., Beraud, J., Keinan, M., Rosenberg, R., Zohar, D., Rosen, V., Fine, P., 2004. Nitrogen, phosphorus, and potassium uptake by wheat and their distribution in soil following successive, annual compost applications. Journal of Environmental Quality 33 (5): 1855-1865.

Bartolo, M.E., Shweissing, F.C., 1998. Yield and quality response of muskmelon to simulated storm damage. Hortscience 33: 34-35.

Basso, B., Ritchie, J.T., 2005. Impact of compost, manure and inorganic fertilizer on nitrate leaching and yield for a 6-year maiz-alfalfa rotation in Michigan. Agriculture, Ecosystems and Environment 108: 329-341. 
Beck, M.A., Sanchez, P.A., 1996. Soil phosphorus movement budget after 13 years of fertilized cultivation in the Amazon basin. Plant Soil 184: 23-31.

Beckwith, C.P., Cooper, J., Smith, K.A., Shepherd, M.A., 1998. Nitrate leaching loss following application of organic manures to sandy soils in arable cropping. I. Effects of application time, manure type, over winter crop cover and nitrification inhibition. Soil Use and Management 14 (3): 123-130.

Bernal, M.P., Paredes, C., Sanchez-Monedero, M.A., Cegarra, J., 1998. Maturity and stability parameters of composts prepared with a wide range of organic wastes. Bioresource Technology 63 (1): 91-99.

Bertrán, E., Sort, X., Solvia, M., Trillas, I., 2004. Composting winery waste: sludges and grape stalks. Bioresource Technology 95: 203-208.

Blake, L., Johnston, A.E., Poulton, P.R., Goulding, K.W.T., 2003. Changes in soil phosphorus fractions following positive and negative phosphorus balances for long periods. Plant and Soil 254: 245-261.

Botella, C., de Ory, I., Webb, C., Cantero, D., Blandino, A., 2005. Hydrolytic enzyme production by Aspergillus awamori on grape pomace. Biochemical Engineering Journal 26 (2-3): 100-106.

Bremer, J.M., 1996. Nitrogen-Total. p. 1085-1121. In: Sparks, D.L., ed. Methods of Soil Analysis, Part 3: Chemical Methods. SSSA Book Series 5; SSSA and ASA, Madison, WI. USA.

Brod, E., Øgaard, A.F., Hansen, E., Wragg, D., Haraldsen, T.K., Krogstad, T., 2015. Waste products as alternative phosphorous fertilizer part $I$ : inorganic $P$ species affect fertilization effects depending on soil pH. Nutrient Cycling in Agroecosystems 103: 16-185.

Brown, R.H., 1984. Growth of the green plant. pp. 153-174. En: Physiological basis of crop growth and development. American Society of Agronomy, Madison.

Bulluck, L.R., Brosius, M., Evaniylo, G.K, Ristaino, J.B., 2002. Organic and synthetic fertility amendments influence soil microbial, physical and chemical properties on organic conventional farms. Applied Soil Ecology 19: 147-160. 
Bustamante, M.A., 2007. Compostaje de los residuos generados en la industria vinícola y alcoholera. Valorización agronómica de los materiales obtenidos. Tesis Doctoral. Universidad Miguel Hernández.

Bustamante, M.A., Paredes, C., Moral, R., Moreno-Caselles, J., Pérez-Murcia, M.D., PérezEspinosa, A., Bernal, M.P., 2007. Co-composting of distillery and winery wastes with sewage sludge. Water Science \& Technology 56 (2): 187-192.

Bustamante, M.A., Morales, R., Paredes, C., Pérez-Espinosa, A., Moreno-Caselles, J., PérezMurcia, M.D., 2008a. Agrochemical characterization of the solid by-products and residues from the winery and distillery industry. Waste Management 28 (2): 372 380.

Bustamante, M.A., Paredes, C., Marhuenda-Egea, F.C., Pérez-Espinosa, A., Bernal, M.P., Morales, R., 2008b. Co-composting distillery wastes with animal manure carbon and nitrogen transformations and evaluation of compost stability. Chemosphere 72: 551557.

Bustamante, M.A., Paredes, C., Moral, R., Agulló, E., Pérez-Murcia, M., Abad, M., 2008c. Composts from distillery wastes as peat substitutes for transplant production. Resource Conservation and Recycling 52: 792-799.

Bustamante M.A., Paredes C., Morales J., Mayoral A.M., Moral R., 2009. Study of the composting process of winery and distillery wastes using multivariate techniques. Bioresource Technology 100 (20): 4766-4772.

Bustamante, M.A., Said-Pullicino, D., Paredes, C., Cecilia, J.A., Moral, R., 2010. Influences of winery-distillery waste compost stability and soil type on soil carbon dynamics in amended soils. Waste Management 30 (10): 1966-1975.

Cabello, M.J., Castellanos, M.T., Romojaro, F., Martínez, C., Ribas, F., 2009. Yield and quality of melon grown under different irrigation and nitrogen rates. Agricultural Water Management 96: 866-874.

Cameron, K.C., Di, H.J., Moir, J.L., 2013. Nitrogen losses from the soil/plant system: a review. Annals of Applied Biology 162: 145-173. 
Cárcela, J. A., García-Péreza, J. V., Muleta, A., Rodrígueza, L., Rierab,E., 2010. Ultrasonically assisted antioxidant extraction from grape stalks and olive leaves. Physics Procedia 3: 147-152.

Carranza, C., Lanchero, O., Miranda, D., Chaves, B., 2009. Growth analysis of 'Batavia' lettuce (Lactuca sativa L.) cultivated in a saline soil of the Bogota Plateau. Agronomía Colombiana 27 (1): 41-48.

Cassman, K., Munns, D., 1980. Nitrogen mineralization as affected by soil moisture, temperature, and depth. Soil Science Society of America Journal 44: 1233-1237.

Cassman, K.G., Dobermann, A., Walters, D.T., 2002. Agroecosystems, nitrogen-use efficiency, and nitrogen management. Ambio 31 (2): 132-140.

Castellanos, M.T., Cabello, M.J., Cartagena, M.C., Tarquis, A.M., Arce, A., Ribas, F., 2006. Absorción de nitrógeno y necesidades de abonado del melón. Vida Rural 231: 22-29.

Castellanos, M.T., Cartagena, M.C., Ribas, F., Cabello, M.J., Arce, A., Tarquis, A.M., 2007. Medidas en campo del balance de agua y de nitrógeno en un cultivo de melón con fertirrigación. In: Estudios de la Zona no Saturada del Suelo. Eds. J.V. Giráldez Cervera and F.J. Jiménez Hornero, Vol. VIII: 217-223.

Castellanos, M.T., Cartagena, M.C., Ribas, F., Cabello, M.T., Arce, A., Tarquis, A.M., 2010. Efficiency Indexes for melon crop optimization. Agronomy Journal 102: 716-722.

Castellanos M.T., Cabello M.J., Cartagena M.C., Tarquis A.M., Arce A., Ribas F., 2011. Growth dynamics and yield of melon as influenced by nitrogen fertilizer. Scientia Agricola 68 (2): 191-99.

Castellanos, M.T., Cabello, M.J., Arce, A., Cartagena, M.C., Tarquis, A.M., Arce, A., Ribas, F., 2012. Nitrogen uptake dynamics, yield and quality as influenced by nitrogen fertilization in "Piel de sapo" melon. Spanish Journal of Agricultural Research 10 (3): 756-767.

Castellanos, M.T., Tarquis, A.M, Ribas, F., Cabello, M.J., Arce, A., Cartagena, M.C., 2013. Nitrogen fertigation: An integrated agronomic and environmental Study. Agricultural Water Management 120: 46-55.

Cayón, G., 1992. Fotosíntesis y productividad de cultivos. Revista COMALFI 19 (2): 23-31. 
Chalmers, A.G., 2001. A review of fertilizer, lime and organic manure use on farm crops in Great Britain from 1983 to 1987. Soil Use and Management 17: 254-262.

Chambers, B.J., Smith, KA., Pain, B.F., 2000. Strategies to encourage better use of nitrogen in animal manures. Soil Use and Management 16: 157-161.

Chen, J.H., 2006. The combined use of chemical and organic fertilizers and/or biofertilizer for crop growth and soil fertility. International Workshop on Sustained Management of the Soil-rhizosphere System for Efficient Crop Production and Fertilizer Use. Land Development Department Bangkok, Thailand 16: 20.

Ciampitti, I.A., Vyn, T.J., 2013. Grain nitrogen source changes over time in maize. Crop Science 53 (2): 366-377.

Conde, E., Moure, A., Dominguez, H., Parajó, J.C., 2011. Production of antioxidants by non isothermal autohydrolyis of lignocellulosic wastes. LWT-Food Science Technology 44 (2): 436-442.

Condron, L.M., Turner, B.L. y Cade - Menun, B.J., 2005. Chemistry and dynamics of soil organic phosphorus in: Stms, J.T. and Sharpley, A.N. editors, Phosphorus: Agriculture and the environment. Agronomy Monograph, 46. ASA, CSSA, and SSSA, Madison WI: 87-121.

Cortez, S.B., 2005. Cultivo del melón: requerimientos nutricionales. Instituto Nacional de Tecnología Agropecuaria, (INTA). Hoja informativa para el sector agropecuario, Serie producción agrícola $\mathrm{N}^{0} .13$.

Costa, C.C., Santos, M.F., Lima, P.S., Lopes, K.P., Silva, R.M.B., 2011. Effect of fertilization of planting supplemented with organic fertilizers on cantaloupe melon production. Horticultura Brasileira 29: 4026-4033.

Costa, F., Moreno, J.L., Hernandez, T., Lax, A., Cegarra, J., Roig, A., 1989. Mineralization of organic materials in a calcareous soil. Biological Wastes 28: 189-201.

Craswell, E.T., Godwin, D.C., 1984. The efficiency of nitrogen fertilizers applied to cereals in different climates. In. Tinker PB, Lauchli $A$ (eds) Advances in plant nutrition, Praeger publishers, New York 1: 1-55.

Cürük, S., Sermenli, T., Mavi, K and Evrendilek, F., 2004. Yield and fruit quality of watermelon (Citrullus lanatus (Thumb.) Matsum. \& Nakai.) and melon (Cucumis melo L.) under 
protected organic and conventional farming systems in a Mediterranean region of Turkey. Biological Agriculture \& Horticulture 22: 173-183.

Dao, T.H., Sikora, L.J., Hamasaki, A., Chaney, R. I., 2001. Manure phosphorus extractability as affected by aluminum and iron byproducts and aerobic composting. Journal of Environmental Quality 30: 1693-1698.

De Groot, C.C., Marcelis, L.F.M., Van de Boogaard, R., Lambers, H., 2001. Growth and dry mass partitioning in tomato as affected by phosphorus nutrition and light. Plant, Cell and Environment 24: 1309-1317.

De Grazia, J., Tittonell, P.A., Chiesa, A., 2006. Efecto de sustratos con compost y fertilización nitrogenada sobre la fotosíntesis, precocidad y rendimiento de pimiento (Capsicum annuum). Ciencia e investigación agraria 34 (3): 195-204.

De Neve, S., Gaona-Sáez, S., Chaves-Daguilar, B., Sleutel, S., Hofman, G., 2004. Manipulating $\mathrm{N}$ mineralization from high $\mathrm{N}$ crop residues using on- and off-farm organic materials. Soil Biology and Biochemistry 36: 127-134.

Del Toro, M., 1988. Use of grape pomace to control nematodes of garlic. Rev. Fac. Ciencias Agrarias, Universidad Nacional de Cuyo 24: 25-34.

Delgado, A., Madrid, A., Kassem, S., Andreu, L., Campillo, M.C., 2002. Phosphorus fertilizer recovery from calcareous soils amended with humic and fulvic acids. Plant and Soil 245: $277-286$.

Devesa-Rey, R., Vecino, X., Varela-Alende, J.L., Barral M.T., Cruz, J.M., Moldes, A.B., 2011. Valorization of winery waste vs. the costs of not recycling. Waste Management (New York, N.Y.) 31 (11): 2327-2335.

Diacono, M., Montemurro, F., 2011. Long-term effects of organic amendments on soil fertility. Sustainable Agriculture 2: 761-786.

Díaz, A.B., de Ong, I., Caro, I., Blandino, A., 2009. Production of hydrolytic enzymes from grape pomace and orange peels mixed substrate fermentation by Aspergillus awamori. Chemical Engineering Transactions 17: 1143-1148. 
Díaz, A.B., Bolívar, J., de Ong, I., Caro, I., Blandino, A., 2011. Applicability of enzymatic extracts obtained by solid state fermentation on grape marc and orange peels mixtures in must clarification. LWT- Food Science and Technology 44 (4): 840-846.

Díaz, M.J., Madejón, E., López, F., López, R., Cabrera, F., 2002. Optimization of the rate vinasse/grape marc for co-composting process. Process Biochemistry 37 (10): 11431145.

Dittmer, U., Budde, K, Stindt, A., Weltzien, H., 1990. The influence of the compost extracts on diferent plants pathogens. Gesunde- Phanzen 42: 219-235.

Dobermann, A.R., 2005. Nitrogen Use Efficiency - State of the Art, Agronomy \& Horticulture - Faculty publications: 316.

Dobermann, A.R., 2007. Nutrient Use Efficiency-measurement and management, International fertilizer industry association. Paris, France, Part 1. General principles of FBMPs: 1-19.

Domínguez, J., Martınez-Cordeiro H., Lores M., 2016. Simultaneous production of a highquality biofertilizer and bioactive-rich seeds. In: Morata A, Loira I, editors. Grape and wine biotechnology. Rijeka, Croatia: Intech Open Science: 167-183.

Domínguez, J., Sánchez-Hernánde, J.C., Lores, M., 2017. Vermicomposting of wine-making products. In: Galanakis CM, editor. Handbook of grape processing by-products: sustainable solutions. London, UK: Academic Press, Elsevier: 55-78.

Doorenbos, J., and Pruitt, W.O., 1977. Las necesidades de agua de los cultivos. Estudios F.A.O. Riego y Drenaje. 24. Ed FAO (Roma), 194.

Dou, Z., Toth, J.D., Ferguson, J.D., Galligan, D.T. and Ramberg, C.F., 2000. Laboratory procedures for characterizing manure phosphorus. Journal of Environmental Quality 29: 508-514.

Duarte, S.R., 2002. Alterações na nutrição mineral do meloeiro em função da salinidade da água de irrigaão. Campina Grande, 70 p. Dissestação (Maestrado em Nutrição Mineral) - UFCG -Universidade Federal de Campina Grande, Campina Grande.

Dufault, R.J., Hester, A., Ward, B., 2008. Influence of organic and synthetic fertility on nitrate runoff and leaching, soil fertility, and sweet corn yield and quality. Communications in Soil Science and Plant Analysis 39: 1858-1874. 
Eckelmann, W., Baritz, R., Bialousz, S., Bielek, P., Carre, F., Houšková, B., Jones, R.J.A., Kibblewhite, M.G., Kozak, J., Le Bas, C., Tóth, G., Tóth, T., Várallyay, G., Yli Halla, M., Zupan, M., 2006. Common Criteria for Risk Area Identification according to Soil Threats. European Soil Bureau Research Report No.20, EUR 22185 EN, 94pp. Office for Official Publications of the European Communities, Luxembourg.

Eghball, B., Binford, G.D., Baltensperger D.D., 1996. Phosphorus movement and adsorption in a soil receiving long-term manure and fertilizer application. Journal of Environmental Quality 25: 1339-1343.

Eghball, B., Power, J.F., 1999. Phosphorus-and nitrogen-based manure and compost applications corn production and soil phosphorus. Soil Science Society of America Journal 63: 895-901.

El-Desuki, M., Shafeek, M.R., Sawan, O.M.M., 2000. Effect of organic and mineral fertilization on growth, yield and quality of cantaloupe (Cucumis melo, L.). Egyptian Journal of Applied Science 15 (12): 585-603.

Evans, G., 1972. The Quantitative Analysis of Plant Growth. Blackwell Scientific Publications. Oxford, England, Great Britain: 733.

Fagan, E.B., Medeiros, S.L.P., Simon, J., da Luz, G.L., Borcioni, E., Jasniewicz, L.R., Casaroli, D., Manaron, P.A., 2006. Evolution and partitioning of dry biomass of muskmelon in hydroponic. Acta Scientiarum-Agronomy 28: 165-172.

Fageria, N.K., Baligar, V.C., 2005. Enhancing Nitrogen Use efficiency in crop Plants. Advances in Agronomy 88: 97-185.

Fangueiro, D., De Sousa, G., Vasconcelos, E., Duarte E., 2012. Influence of nitrogen content in the soil solution on potential nitrogen mineralization of organic residues. Archives of Agronomy and Soil Science 58: S112-S115.

Farinella, N.V., Matos, G.D., Lehmann, E.L., Arruda, M.A.Z., 2008. Grape bagasse as an alternative natural adsorbent of cadmium and lead for effluent treatment. Journal of Hazardous Materials 154 (1-3): 1007-1012.

Faure, D., 1991. The effect of bacterial inoculation on the initiation of composting of grape pulps. Bioresource Technology 37: 235-238. 
Faure, D., Deschamps, A., 1990a. Physical \pm chemical and microbiological aspects in composting of grape pulps. Biological Wastes 34: 251-258.

Faure, D., Deschamps, A., 1990b. Evaluation of the suitability of grape skins for composting. Journal of International des Sciences de la Vigne et du Vin 24: 1-12.

Fernandes, A.L.T., Rodrigues, G.P., Testezlaf, R., 2003. Mineral and organomineral fertirrigation in relation to quality of greenhouse cultivated melon. Scientia Agricola 60: 149-154.

Ferrer, J., Páez, G., Mármol, Z., Ramones, E., Chandler C., Mann, M., Ferrer, A., 2001. Agronomic use of biotechnologically processed grape wastes. Bioresources Technology 76: 39-44.

Ferrer, J.R., Mujica, D., Paez, G., 1993. Composting from grape pomace. Revista Técnica de la Facultad de Ingeniería Universidad del Zulia 16: 191-198.

Fiori, L., 2010. Supercritical extraction of grape seed oil at industrial-scale: plant and process design, modeling, economic feasibility. Chemical Engineering and Processing 49 (8): 866-872.

Fitter, A.M., 1974. A relationship between phosphorus requirement, the immobilization of added phosphate, and the phosphate buffering capacity of colliery shales. Journal of Soil Science 25: 41-50.

Flavel, T.C., Murphy, D.V., Lalor, B.M., Fillery, I.R.P., 2005. Gross N mineralization rates after application of composted grape marc to soil. Soil Biology and Biochemistry 37: 13971400.

Fog, K, 1988. The effect of added nitrogen on the rate of decomposition of organic matter. Biological Reviews 63: 433-462.

Fogaça, M.A.F., Andriolo, J.L., Godoi, R.S., Barros, C.A.P., Janisch, D.I., Braz Vaz, M.A., 2008. Nitrogen critical dilution curve for the muskmelon crop. Ciência Rural 38: 345-350.

Fogg, G.E., 1967. El crecimiento de las plantas. Editorial Universitaria de Buenos Aires (EUDEBA): 327.

Fontana, A.R., Antoniolli, A., Bottini, R., 2013. Grape pomace as a sustainable source of bioactive compounds: extraction, characterization, and biotechnological applications of phenolics. Journal of Agricultural and Food Chemistry 61: 8987-9003. 
Fontes, P.C.R., Días, E.N., Silva, D.J.H., 2005. Dinâmica do crescimento, distribuiçâo de matéria seca na planta e produçao de pimentâo em Ambiente protegido. Horticultura Brasileira 23: 94-99.

Fouda, S., von Tucher, S., Lichti, F., Schmidhalter, U., 2013. Nitrogen availability of various biogas residues applied to ryegrass. Journal of Plant Nutrition and Soil Science 176: 572-584.

Fox, R.L., Kamprath, E.J., 1970. Phosphate sorption isotherms for evaluating the phosphate requirement of soil. Soil Science Society of America, Proceedings 34: 902-907.

Freire, G.M., Medeiros, J.F., Oliveira, F.A., Amâncio, M.G., Pontes, N.C., Soares, I.A.A., Souza, A.L.M., 2009. Application of liquid organic compost via fertirrigation in the melon crop. Bioscience Journal 25: 49-55.

Fukutoku, Y., Koto, S., Teraoka, Y., Kubo, K., 2000. Nitrogen absorption and distribution of muskmelons (Cucumis melo L.) at different growth stages using hydroponics. Japanese Journal of Soil Science and Plant Nutrition 71: 72-81.

García Albacete, M., 2014. Residuos orgánicos como fuente de fosforo. Universidad Politécnica de Madrid. Escuela técnica Superior de Ingenieros Agronomos. Tesis doctoral.

García, C., Hernandez, T., Costa, F., 1990. The influence of composting and maturation processes on the heary-metal extractability from some organic wastes. Biological Wastes 31: 291-301.

García, C., Hernández, T., Costa, F., 1992. Characterization of humic acids from uncomposted sewage sludge by degradative and non degradative techniques. Bioresource Technology 41: 53-57.

García-Martínez, S., Grau, A., Agulló, E., Bustamante, M.A., Paredes, C., Moral, R., Ruiz, J.J., 2009. Use of composts derived from winery wastes in tomato crop. Communications in Soil Science and Plant Analysis 40 (1-6): 445-452.

Garg, S., Bahl, G.S., 2008. Phosphorus availability to maize as influenced by organic manures and fertilizer $P$ associated phosphatase activity in soils. Bioresource Technology 99: 57773-5777. 
Garnier, E., 1992. Growth analysis of congeneric annual and perennial grass species. Journal of Ecology 80: 665-675.

Garnier, E., Laurent, G., 1994. Leaf anatomy, specific mass and water content in congeneric annual and perennial grass species. New Phytologist 128: 725-736.

Glcesner, N., Van der Bom, F., Bruun, S., McLaren, T., Larsen, F.H., Magid, J., 2019. Phosphorus characterization and plant availability in soil profiles after long-term urban waste application. Geoderma 338: 136-144.

Gómez-Brandón, M., Lazcano, C., Lores, M., Domínguez, J., 2011. Short-term stabilization of grape marc trough earthworms. Journal of Hazardous Materials doi: 10.1016/ j. jhazmat.2011.01.011.

Gómez-Brandón, M., Lores, M., Insam, H., Domínguez, J., 2019. Strategies for recycling and valorization of grape marc. Journal Critical Reviews in Biotechnology 39: 437-450.

Gonzalez-Centeno, M.R., Rossel, C., Simal, S., 2010. Physicochemical properties of cell wall materials obtained from ten grape varieties and their byproducts: grape pomaces and stems. LWT- Food Science and Technology 43: 1580-1586.

Gourley, C. J. P., Allan, D. L., Russelle, M. P., 1993. Defining phosphorus efficiency in plants. Plant and Soil 155/156: 289-292.

Gratani, L., Crescente, M.F., Fabrini, G., Varone, L., 2008. Growth pattern of Bidens cernua L: relationships between relative growth rate and its physiological and morphological components. Photosynthetica 46 (2): 179-184.

Greenwood, D.J., Lemaire, G., Gosse, G., Cruz, P., Draycott, A., Neeteson, J.J., 1990. Decline in percentage $\mathrm{N}$ of $\mathrm{C3}$ and $\mathrm{C4}$ crops with increasing plant mass. Annals of Botany 66: 425-436.

Grigatti, M., Pérez, M.D., Blok, W.J., Ciavatta, C., Veeken, A., 2007. A standardized method for the determination of the intrinsic carbon and nitrogen mineralization capacity of natural organic matter sources. Soil Biology and Biochemistry 39 (7): 1493-1503.

Grigatti, M., Boanini, E., Cavani, L., Ciavatta, C., Marzadori, C., 2015. Phosphorus in digestatebased compost: chemical speciation and plant-availability. Waste and Biomass Valorization 6 (4): 481-493. 
Grigatti, M., Boanini, E., Mancarella, S., Simoni, A., Centemero, M., Veeken, A.H., 2017. Phosphorous extractability and ryegrass availability from bio-waste composts in a calcareous soil. Chemosphere 174: 722-731.

Grigatti, M., Cavani, L., Di Biase, G., Ciavatta, C., 2019. Current and residual phosphorous availability from compost in a ryegrass pot test. Science of the Total Environment 677: 250-262.

Gros, A. y Dominguez-Vivancos A., 1992. Abonos. Guía práctica de la fertilización. (4ª edición). Ed. Mundi-Prensa. Madrid.

Hamilton, H.A., Brod, E., Hanserud, O., Müller, D.B., Brattebø, H., Haraldsen, T.K., 2017. Recycling potential of secondary phosphorus resources as assessed by integrating substance flow analysis and plant-availability. Science of the Total Environment 575: 1546-1555.

Harrison, K.A., Bol, R., Bardgett, R.D., 2007. Preferences for different nitrogen forms by coexisting plant species and soil microbes. Ecology 88: 989-999.

Havlin, J.L., Soltanpour, P.N., 1989. A nitric acid plant tissue digest method for use whit inductively couple plasma spectrometry. Communications in soil science and plant analysis 14: 969-980.

Hedley, M.J., Stewart, J., Chauhan, B., 1982. Changes in inorganic and organic phosphorus fractions induced by cultivation practices and by laboratory incubations. Soil Science Society of America Journal 46: 970-976.

Hegde, D.M., 1988. Physiological analysis of growth and yield of watermelon (Citrillus lanatus Thunb. Musf.) in relation to irrigation and nitrogen fertilization. Journal of Agronomy and Crop Science 160 (5): 296-302.

Hernández, T., Moral, R., Pérez-Espinosa, A., Moreno-Caselles, J., Pérez-Murcia, M.D., García, C., 2002. Nitrogen mineralization potential in calcareous soils amended with sewage sludge. Bioresource Technology 83: 213-219.

Hesse, P.R., 1971. A textbook of soil chemical analysis. John Murray Publishers Ltd. London. UK.

Heuvelink, E., Marcelis, L.F.M., 1989. Dry matter distribution in tomato and cucumber. Acta Horticulturae 260: 149-157. 
Huang, X.L., Chen, Y., Shenker, M., 2008. Chemical Fractionation of phosphorus in stabilized Biosolids. Journal of Environmental Quality 37: 1949-1958.

Hubbard, N.L., Pharr, D.M., Huber, S.C., 1990. Sucrose metabolism in ripening muskmelon fruit leaf area. Journal of American Society for Horticultural Science 115: 798-802.

Huett, D.O., 1996. Prospects for manipulating the vegetative-reproductive balance in horticultural crops through nitrogen nutrition: a review. Australian Journal of Agricultural Research 47:47-66.

Huggins, D.R., Pan, W.L., 1993. Nitrogen efficiency component analysis: an evaluation of cropping system differences in productivity. Agronomy Journal 85 (4): 898-905.

Hunger, S., Sims, J.T., Spark, D.L., 2005. How accurate is the assessment of phosphorus pools in poultry litter by sequential extraction. Journal of Environmental Quality 34: 941-949.

Hunt, R., 1982. Plant growth curves. The functional approach to plant growth analysis. Edward Arnold Publishers Ltd., Londres

Iglesias-Jimenez, E., Alvarez C., 1993. Apparent availability of nitrogen in composted municipal refuse. Biology and Fertility of Soils 16: 313-318.

Inbar, Y., Chen, Y., Hadar, Y., Verdonek, O., 1988. Composting of agricultural waste for their use as container media: simulation of the composting process. Biological Wastes 26: 247-259.

INFOVI. Sistema de información de mercados del sector vitivinícola. 2018/19.

INRA-CNRS-Irstea (France). 2014. Valorisation des matières fertilisantes d'origine résiduaire sur les sols à usage agricole ou forestier, impacts agronomiques, environnementaux, socio-économiques. Schmitt, B, Ed.

Irineu, T.H.S., Figueredo, L.F., Figueredo, J.P., Silva, J.N., Paiva, J.R.G., Andrade R., 2018. Agronomic efficiency of 'Cantaloupe' melón under different water blades and organic fertilization. Comunicata Scientiae 9 (3): 421-29.

Isidoro, D., Quilez, D., Aragües, R., 2006. Environmental impact of irrigation in La Violada district (Spain). II. Nitrogen fertilization and nitrate export patterns in drainage water. Journal of Environmental Quality 35: 776-785. 
Iyamuremye, F., Dick, R., Baham, J., 1996a. Organic amendments and phosphorus dynamics: I. Phosphorus chemistry and sorption. Soil Science 161: 426-435.

Iyamuremye, F., Dick, R., Baham, J., 1996b. Organic amendments and phosphorus dynamics: II. Distribution of soil phosphorus fractions. Soil Science 161: 436-443.

Jackson, L. E., Burger, M., Cavagnaro, T. R., 2008. Roots, Nitrogen Transformations, and Ecosystem Services. Annual Review of Plant Biology 59: 341-363.

Jakubus, M., 2016. Estimation of phosphorus bioavailability from composted organic wastes. Chemical Speciation \& Bioavailability 28 (1-4): 189-198.

Jiang, Y., Simonsen, J., Zhao, Y., 2011. Compression-molded biocomposite boards from red and white wine grape pomaces. Journal of Applied Polymer Science 119 (5): 2834 2846.

Jiménez, D.F., Cano, R.P., Maeda, M.C., 1997. Effect of different solarization periods on melon development. ITEA Production Vegetal 93 (2): 116-125.

Johnston, A.E., 2001. Principles of crop nutrition for sustainable food production. Proceedings 459. York, UK, International Fertilizer Society: 39.

Johnston, A.E., Poulton, P.R., Fixen, P.E., Curtin, D., 2014. Phosphorus: its efficient use in agriculture. Advances in Agronomy 123: 177-228.

Kirchman, H., Bergström, L., 2001. Do organic Farming practices reduce nitrate leaching? Communications in Soil Science and Plant Analysis 32: 997-1028.

Kirnak, H., Higgs, D., Kaya, C., Tas, I., 2005. Effects of irrigation and nitrogen rates on growth, yield, and quality of muskmelon in semiarid regions. Journal of Plant Nutrition 28: 621-638.

Knowles, O., Robinson, B., Contangelo, A., Clucas, L., 2011. Biochar for the mitigation of nitrate leaching from soil amended with biosolids. Science of the Total Environment 409 (17): 3206-3210.

Kuck Caciano, L.S., Zapata Noreña, P., 2016. Microencapsulation of grape (Vitis labrusca var. Bordo) skin phenolic extract using gum Arabic, polydextrose, and partially hydrolyzed guar gum as encapsulating agents. Food Chemistry 194 (1): 569-576.

Kvet, V., Mashall, K., 1971. Assessment of leaf area and other assimilating surfaces. Food and Agriculture Organization of the United Nations: 517-555. 
Labrador-Moreno, J., 1996. La materia orgánica en los agrosistemas, Ministerio de Agricultura, Pesca y Alimentación. Mundiprensa. Madrid: 174.

Lambers, H., Poorter, H., 1992. Inherent variation in growth rate between higher plants: $A$ search for physiological causes and ecological consequences. Advances in Ecological Research 23: 187-261.

Lammerts Van Bueren, E.T., Struik, P.C., 2017. Diverse concepts of breeding for nitrogen use efficiency. Agronomy for Sustainable Development 37: 50.

Larsen, S., Gunary, D., Sutton, C.D., 1965. The rate of immobilisation of applied phosphate in relation to soil properties. Journal of Soil Science 16: 141-148.

Le Bot, J., Adamowicz, S., Robin, P., 1998. Modelling plant nutrition of horticultural crops: a review. Scientia Horticulturae 74: 47-82.

Leclerc, B., Georges, P., Cauwel, B., Lairon D., 1995. A five year study on nitrate leaching under crops fertilized with mineral and organic fertilizers in lysimeters. Biological Agriculture and Horticulture 11: 301-308.

Lemaire, G., Gastal, F., 1997. N uptake and distribution in plant canopies. In: Lemaire G, ed. Diagnosis on the nitrogen status in crops. Heidelberg: Springer-Verlag: 3-43.

Lemming, C., Oberson, A., Magid, J., Bruun, S., Scheutz, C., Frossard, E., Jensen, L.S., 2019. Residual phosphorus availability after long-term soil application of organic waste. Agriculture, Ecosystems \& Environment 270: 65-75.

Liguori, L., Pane, C., Albanese, D., Celano, G., Zaccardelli, M., Di Matteo, M., 2015. Compost and compost tea management of mini watermelon cultivations affect the chemical, physical and sensory assessment of the fruits. Agricultural Sciences 6: 117-125.

Lima, A.A., 2001. Absorção e eficiência de utilização de nutrientes por híbridos de melão (Cucumis melo L.). 60 p. Dissertação Mestrado. (Maestrado em Solos e Nutrição de plantas), Universidade Federal do Ceará, Fortaleza.

Lopes, W.A.R., Negreiros, M.Z., Dombroski, J.L.D., Rodrigues, G.S.O., Soares, A.M., Araújo, A.P., 2011. Análise do crescimento de tomate 'SM-16' cultivado sob diferentes coberturas de solo. Horticultura Brasileira 29: 554-561.

Lyamuremye, F., Dick, R.P., Baham, J., 1996. Organic amendments and phosphorus dynamics I. Phosphorus chemistry and sorption Soil Science 161 (7): 426-435. 
M.A.P.A. 1994. Anuario de estadística 1994. Disponible en http://www.mapa.es/es/estadistica/pags/anuario/introduccion.htm\#inicio

Mafongoya, P.L., Nair, P.K.R., Dzowela, B.H., 1998. Mineralization of nitrogen from decomposing leaves of multipurpose trees as affected by their chemical composition. Biology and Fertility of Soils 27: 143-148.

MAGRAMA. Ministerio de Agricultura, Alimentación y Medio Ambiente. 2018. Encuesta sobre Superficies y Rendimientos de Cultivos (ESYRCE).

Maguire, R.O., Sims, J.T., Saylor, W.W., Turner, B.L., Angel, R., Applegate, T.J., 2004. Influence of phytase addition to poultry diets on phosphorus forms and solubility in litters and amended soils. Journal of Soil Science 168: 421-433.

Mandelbaum, R., Hadar, Y., Chen, Y., 1988. Composting of agricultural waste for their use as container media: effect of heat treatments on suppression of Pythiun aphanidermatum and microbial activities in substrates containing compost. Biological Wastes 26: 261-274.

Manios, T., 2004. The composting potential of different organic solid wastes: experience from the island of Crete. Environment International 29 (8): 1079-1089.

Manios, T., Maniadakis, K., Boutzakis, P., Naziridis, Y., Lasaridi, K., Markakis, G., Stentiford, E.I., 2007. Methane and carbon dioxide emission in a two-phase olive oil mill sludge windrow pile during composting. Waste Management 27 (9): 1092-1098.

MAPAMA (2012-2015) https://www.mapama.gob.es/ide/metadatos/srv/spa/metadata.show

Marañon, T., Grubb, P.J., 1993. Physiological basis and ecological significance of the seed size and relative growth rate relationship in Mediterranean annuals. Functional Ecology 7 (5): 591-599.

Marculescu, A., Sand, C., Barbu, C., Babit, H.D., Hanganu, D., 2002. Possibilities of influencing the biosynthesis and accumulation of the active principals in Chrysanthemum balsamita L. specie Roum. Biotechnology Letters 7 (1): 577-548.

Marr, Ch.W., Lamont, W.J., 1992. Fertigation of vegetable crops. Commercial vegetables production. Cooperative Extension Service. Kansas State University, Document $N^{p}$ 92-312-E: 1-4. 
Martin, D.L., Gershuny. G., 1992. The rodal book of composting. Rodal Press, Emmaus, Pennsylvania State, USA.

Masclaux-Daubress, C., Daniel-Vedele, F., Dechorgnat, J., Chardon, F., Gaufichon, L., Suzuki, A., 2010. Nitrogen uptake, assimilation and remobilization in plants: challenges for sustainable and productive agriculture. Annals of Botany 105: 1141-1157.

Matson, P.A., Parton, W.J., Power, A.G., Swift, M.J., 1997.Agricultural intensification and ecosystem properties. Science 277: 504-509.

Matsumoto, S., Ae, N., Yamagata, M., 2000. Possible direct uptake of organic nitrogen from soil by chingensai (Brassica campestris L.) and carrot (Daucus carota L.). Soil Biology \& Biochemistry 32: 1301-1310.

Mattingly, G.E.G., Widdowson, F.V., 1963. Residual value of superphosphate and rock phosphate on an acid soil. I. Yields and phosphorus uptakes in the field. The Journal of Agricultural Science 60: 399-407.

Max, B., Salgado, J.M., Cortés, S., Domíngez, J.M., 2010. Extracción of phenolic acids by alkaline hydrolysis from the solid residue obtained after pre hydrolysis of trimming vine shoots. Journal of Agricultural and Food Chemistry 58 (3): 1909-1917.

McCracken, D.V., Corak, S. J., Smith, M.S., Frye, W.W., Blevins, R.L., 1989. Residual effects of nitrogen fertilization and Winter cover cropping on nitrogen availability. Soil Science Society of America Journal 53: 1459-1464.

Melero, S., Porrasa, J.C.R., Herencia, J.F., Madejon, E., 2006. Chemical and biochemical properties in a silty loam soil under conventional and organic management. Soil and Tillage Research 90 (1-2): 162-170.

Mendes, J.A.S., Xavier, A.M.R.B., Evtuguin, D.V., Lopes, L.P.C., 2013a. Integrated utilization of grape skins from White grape pomaces. Industrial Crops and Products 49: 286-291.

Mendes, J.A.S., Prozila, S.O., Evtuguin, D.V., Cruz Lopes L.P., 2013b. Towards comprehensive utilization of winemaking residues: Characterization of grape skins from red grape pomaces of variety Touriga Nacional. Industrial Crops and Products 43: 25-32.

Mendoza-Cortez, J.W., Cecilio-Filho, A.B., Grangeiro, L.C., Oliveira, F.H.T., 2014. Influence of phosphorus fertilizer on melon (Cucumis melo L.) production. Australian Journal of Crop Science 8: 799. 
Milne, A.E., Castellanos, M.T., Cartagena, M.C., Tarquis, M.A., Lark, M.R., 2010. Investigating the effect of previous treatments on wheat biomass over multiple spatial frequencies. Biogeosciences 7: 2739-2747.

Minjares-Fuentesa, A., Femenia, M.C., Garaua, J.A., Meza-Velázquez, S., Simala, C., Rosselló, 2014. Ultrasound-assisted extraction of pectins from grape pomace using citric acid: A response surface methodology approach. Carbohydrate Polymers 106: 179-189.

Mkhabela, M., Warman, P., 2005. The influence of municipal solid waste compost on yield, soil phosphorus availability and uptake by two vegetable crops grown in a Pugwash sandy loam soil in Nova Scotia. Agriculture Ecosystems \& Environment 106: 57-67.

Moldes, A.B., Bustos, G., Torrado, A., Domínguez, J.M., 2007a. Comparison between different hydrolysis processes of vine-trimming waste to obtain hemicellulosic sugars for further lactic acid conversion. Applied Biochemistry and Biotechnology 143 (3): 244256.

Moldes, A., Cendon, Y., Barral, M.T., 2007b. Evaluation of municipal solid waste compost as a plant growing media component, by applying mixture design. Bioresource Technology 98: 3069-3075.

Molero Gómez, A., Pereyra López, C., De La Martínez Ossa, E., 1996. Recovery of grape seed oil by liquid and supercritical carbon dioxide extraction: a comparison with conventional solvent extraction. The Chemical Engineering Journal and the Biochemical Engineering Journal 61 (3): 227-231.

Möller, K., 2016. Assessment of alternative phosphorus fertilizers for organic farming: compost and digestates from urban organic wastes. http://orgprints.org/29910/.

Montemurro, F., Convertini, G., Ferri, D., Maiorana, M., 2005. MSW Compost Application on Tomato Crops in Mediterranean Conditions: Effects on Agronomic Performance and Nitrogen Utilization Compost Science \& Utilization 13 (4): 234-242.

Moreno Casco, J., Moral Herrero, R. (Edit. Client). Compostaje. Madrid. 2008. Ediciones Mundi-Prensa. 507 p. ISBN: 978-84-8476-346-822: 539-547.

Moreno, J., Perez; M.D., Moral, R., 1996. Análisis y calidad del agua de riego. Ed. Servicio de Publicaciones Universidad Politécnica de Valencia. Valencia. 
Morra, L., Bilotto, M. and Magnifico, V., 2003. Long term effects of soil organic amendment or mineral fertilization on vegetable crops productivity in tunnel. Acta Horticulturae 614: 781-785.

Morris, T.F., Murell, T.S., Beegle, D.B., Camberato, J.J., Ferguson, R.B., Grove, J., Ketterings, Q., Kyveryga, P.M., Laboski, C.A.M., McGrath, J.M., Meisinger, J.J., Melkonian, J., Moebius-Clune, B.N., Nafziger, E.D., Osmond, D., Sawyer, J.E., Scharf, P.C., Smith, W., Spargo, J.T., Van Es, H.M., Yang, H., 2018. Strengths and limitations of Nitrogen Rate Recommendations for Corn and Opportunities for Improvement. Reviews \& Interpretations 110: 1-37.

Muhlack, R.A., Potumarthi, R., Jeffery, D.W., 2018. Sustainable wineries through waste valorization: a review of grape marc utilization for value-added products. Waste Management 72: 99-118.

Murphy, J., Riley, J.P., 1962. A modified single solution method for determination of phosphates in natural Waters. Analytica Chimica Acta 27: 31-36.

Naidu, Y., Meon, S., Siddiqui, Y., 2013. Foliar application of microbial-enriched compost tea enhances growth, yield and quality of muskmelon (Cucumis melo L.) cultivated under fertigation system. Scientia Horticulturae 159: 33-40.

Näsholm, T., Huss-Danell, K, Hogberg, P., 2000. Uptake of Organic Nitrogen in the Field by Four Agriculturally Important Plant Species. Ecology 81 (4): 1155-1161.

Negro, C., Tommasi, L., Miceli, A., 2003. Phenolic compounds and antioxidant activity from red grape marc extracts. Bioresource Technology 87: 41-44.

Nogales, R., Cifuentes, C., Benítez, E., 2005. Vermicomposting of winery wastes: a laboratory study. Journal of Environmental Science and Health, Part B 40 (4): 659-667.

Novoa, R., Loomis, R.S., 1981. Nitrogen and plant production. Plant and Soil 58: 177-204.

OIV. (2019) Organización Internacional de la Viñay del Vino. Balance 2019 de la OIV sobre la situación vitivinícola mundial. http://www.oiv.int/es/actualidad-de-la-oiv/balance2019-de-la-oiv-sobre-la-situacion-vitivinicola-mundial (verificado: 12/09/2019).

Okamoto, M., Okada, K., Watanabe, T., Ae, N., 2003. Growth responses of cereal crops to organic nitrogen in the field. Soil Science \& Plant Nutritio 49: 445-452. 
Olsen, S.R., Cole, C.V., Watanabe, F.S., Dean, L.A., 1954. Estimation of available phosphorous in soils by extraction with sodium bicarbonate. USDA Circ. 939. U.S. Gov. Print Office, Washington, DC.

Ozores-Hampton, M.P., 2012. Developing a vegetable fertility program using organic amendments and inorganic fertilizers. HortTechnology 22 (6): 743-750.

Ozores-Hampton, M.P., Stansly, P.A., Salame, T.P., 2011. Soil chemical, biological and physical properties of a sandy soil subjected to long-term organic amendments. Journal of Sustainable Agriculture 353: 243-259.

Paes, R.A., 2011. Cultivo de melão com agrotêxtil combinado com Mulch plástico. Mossoró: UFERSA. (Tese doutorado).

Panagiotopoulos, L., 2001. Effects of nitrogen fertigation on growth, yield, quality and leaf nutrient composition of melon. Acta Horticulturae 563: 115-121.

Paradelo, R., Cendón, Y., Moldes, A.B., Barral, M.T., 2007. A pot experiment with mixtures of slate processing fines and compost. Geoderma 141 (3-4): 363-369.

Paradelo, R., 2009. Compostaxe de residues da industria vitivinícola e aplicación de compost de bagazo de uva en restauración de entulleiras de lousa. Tesis doctoral, Universidad de Santiago de Compostela.

Paradelo, R., Moldes, A.B., Barral, M.T., 2009a. Properties of slate mining wastes incubated with grape marc compost under laboratory conditions. Waste Management 29: 579584.

Paradelo, R., Moldes, A.B., Barral, M.T., 2009b. Amelioration of the physical properties of slate processing fines using grape marc compost and vermicompost. Soil Science Society of America Journal 73 (4): 1251-1260.

Paradelo, R., Moldes, A.B., Barral, M.T., 2009c. Treatment of red wine vinasses with nonconventional substrates for removing coloured compounds. Water Science \& Technology 59 (8): 1585-1592.

Paradelo, R., Moldes, A.B., Prieto, B., Sandu, R.-G., Barral, M.T., 2010a. Can Stability and Maturity be evaluated in finished composts from different sources? Compost science \& Utilization 18: 22-31. 
Paradelo, R., Moldes, A.B., Barral, M.T., 2010b. Utilization of a factorial design to study the composting of hydrolyzed grape marc and vinification lees. Journal of Agricultural and Food Chemistry 58 (5): 3085-3089.

Paradelo, R., Moldes, A.B., Barral, M.T., 2013. Evolution of organic matter during the mesophilic composting of lignocellulosic winery wastes. Journal of Environmental Management 116: 18-26.

Pardo, A., Perona, M.A., Pardo, J., 2007. Indoor composting of vine by-products to produce substrates for mushroom cultivation. Spanish Journal of Agricultural Research 5 (3): 417- 424.

Parham, J.A., Deng, S.P., Raun, W.R., Johnson, G.V., 2002. Long-term cattle manure application in soil: I Effect on soil phosphorous levels, microbial biomass $C$ and dehydrogenase and phosphatase activities. Biology and Fertility of Soils 35: 328-337.

Park, Y.H., Seo, B.S., 2012. Changes in Growth and Quality of Melon (Cucumis melo L.) and in Soil Nitrogen Forms due to Organic Fertilizer Application. Korean Journal of Soil Science and Fertilizer 45 (6): 1009-1016.

Peak, J.D., Sims, J.T., Sparks, D.L., 2002. Solid-State Speciation of natural and alumamended poultry litter using XANES Spectroscopy. Environmental Science Technology 36: 4253-4261.

Pérez-Zamora, O., Cigales-Rivero, M.R., 2001. Soil moisture tension and nitrogen fertilization on cantaloupe melon. Agrociencia 35:479-488.

Pinelo, M., Arnous, A., Meyer, A.S., 2006. Upgrading of grape skins: Significance of plant cellwall structural components and extraction techniques for phenol release. Trends in Food Science \& Technology 17: 579-590.

Ping, L., Brousse, N., Chrusciel, L., Navarrete, P., Pizzi, A., 2011. Extraction of condensed tannins from grape marc pomace for use as wood adhesives. Industrial Crops and Products 33 (1): 253-257.

Pinto, J.M., Botrel, T.A., Feitosa Filho, J.C., 1997. Efeito do nitrogênio via fertirrigaçao na cultura do melao. Engenharia Agrícola 16: 27-35.

Poorter, H., 1989. Plant growth analysis: towards a synthesis of the classical and the functional approach. Physiologia plantarum 75: 237-244. 
Poorter, H., Van der Werf, A., 1998. Is inherent variation in RGR determined by LAR at low irradiance and by NAR at high irradiance? A review of herbaceous species. p. 309336. In: Lambers, H., Poorter, H., Van, M.M.I., eds. Inherent variation in plant growth: physiological mechanisms and ecological consequences. Backhuys, Leiden. The Netherlands.

Poorter, H.y, Remkes, C., 1990. Leaf area ratio and net assimilation rate of 24 wild species differing in relative growth rate. Oecologia 83: 553-559.

Portilla, O., Moldes, A.B., Torrado, A.M., Domínguez, J.M., 2007. Lactic acid and biosurfactants production from hydrolyzed distilled grape marc. Process Biochemistry 42 (6): 1010-1020.

Portilla, O., Torrado, A., Domínguez, J.M., Moldes, A.B., 2008. Stability and emulsifying capacity of biosurfactants obtained from lignocellulosic sources using Lactobacillus pentosus. Journal of Agricultural and Food Chemistry 56 (17): 8074-8080.

Portilla, M., Torrado-Agrasar, A., Carballo, J., Domínguez, J.M., Moldes, A.B., 2009. Development of a factorial design to study the effect of the major hemicellulosic sugars on the production of surface-active compounds by $L$. pentosus. Journal of Agricultural and Food Chemistry 57 (19): 9057-9062.

Portilla, O., Torrado, A.M., Domínguez, J.M., Moldes, A.B., 2010. Stabilization of kerosene/water emulsions using bioemulsifiers obtained by fermentation of hemicellulosic sugars with Lactobacillus pentosus. Journal of Agricultural and Food Chemistry 58 (18): 10162-10168.

Pospisil, M., Pospisil, A., Rastija, M., 2000. Effect of plant density and nitrogen rates upon the leaf área of seed sugar beet on seed yield and quality. European Journal of Agronomy $12(1): 69-78$.

Poudel, D.D., Horwath, W.R., Lanini, W.T., Temple, S.R., Van Bruggen, A.H.C., 2002. Comparison of soil $\mathrm{N}$ availability and leaching potential, crop yields and weeds in organic, low-input and conventional farming systems in northern California. Agriculture, Ecosystems \& Environment 90: 125-137.

Power, J.F., Grunes, D.L., Reichman, G.A., Willis, W.O., 1964. Soil temperature effects on phosphorus availability. Agronomy Journal 56: 545-548. 
Prata, E.B., 1999. Acumulação de biomassa e absorção de nutrientes por híbridos de meloeiro (Cucumis melo L.). 60 p Dissertação de Maestrado. (Maestrado em Solos e Nutrição de plantas), Universidade Federal do Ceará, Fortaleza.

Pratt, P.F., 1965. Potasium. p. 1027-1028. In: Black, C.A., Ed. Methods of Soils Analysis. American Society of Agronomy, Madison, WI, USA.

Purqueiro, L.F.V., Cecílio Filho, A.B., Barbosa, J.C., 2003. Efeito da concentração de nitrogênio na solução nutritiva e do número de frutos por planta sobre a produção do meloeiro. Horticultura Brasileira 21 (2): 185-190.

Quemada, M., Baranski, M.N.J. de Lange, Vallejo, A., Cooper, J.M., 2013. Meta-analysis of strategies to control nitrate leaching in irrigated agricultural systems and their effects on crop yield. Agriculture, Ecosystems \& Environment 174: 1-10.

Ramesh, S., 2018. Grain yield, nutrient uptake and nitrogen use efficiency as influenced by different sources of vernmicompost and fertilizer nitrogen in rice, Journal of Pharmacognosy and phytochemistry 7 (5): 52-55.

Razza, F., D'Avino, L., L'Abate, G., Lazzeri, L., 2018. The role of compost in bio-waste management and circular economy. In: Benetto, E., Gericke, K., Guiton, M. (Eds.), Designing Sustainable Technologies, Products and Policies. Springer.

Rebecchi, S., Bertin, L., Vallini, V., Bucchi, G., Bartocci, F., Fava, F., 2013. biomethane production from grape pomaces: a technical feasibility study. Environmental Engineering and Management Journal 12 (S11): 105-108.

Reglamento de la European Council Regulation 1493/1999 del Consejo del 17 de mayo de 1999. Requejo, M.I., Fernández- Rubín de Celis, M., Martínez-Caro, R., Castellanos, M.T., Ribas, F., Arce, A., Cartagena, M.C., 2016. Winery distillery derived materials as phosphorus source in calcareous soils. Catena 141: 30-38.

Ribas, F., Cabello, M.J., Moreno, M.M., 1995. Necesidades de riego del melón y respuesta del cultivo a riegos diferenciales en la provincia de Ciudad Real (Castilla-La Mancha). XIII Jornadas Técnicas sobre Riegos (Tenerife) 12-20. 
Ribas, F., Cabello, M.J., Moreno, M.M., Moreno, A., López-Bellido, L., 2000. Physiological response of a melon crop (Cucumis melo L.) to different watering regimes. Investigación Agraria: Producción y Protección Vegetales 15: 195-212.

Rickard, D.A., 2000. Review of phosphorus acid and its salts as fertilizer materials. Journal of Plant Nutrition 23: 161-180.

Rincon, L., Giménez, M., 1989. Fertirrigación por goteo del melón. Fertilización 105: 55-56.

Rincon Sanchez, L., Saez Sironi, J., Pérez Crespo, J.A., Pellicer, C., Gómez López, M.D. 1998. Crecimiento y absorción de nutrientes del melón bajo invernadero. Investigación Agraria: Prod. Prot. Veg. 13: (1-2).

Rincón, L., Sáez, J., Pérez, J.A., Madrid, R., 1996. Growth and nutrient absorption by muskmelon crop under greenhouse conditions. Acta Horticulturae 54: 153-159.

Roberts, T.L., Johnston, A.E., 2015. Phosphorus use efficiency and management in agriculture. Resources, conservation and recycling 105: 275-281.

Rodrigues A.C., Cavalcante If Dantas T.A.G., Campos V.B., Diniz, A.A., 2008. Characterization of yellow passion fruit fruits in soil treated with "biofertilizer Supermagro" and potassium. Revista Magistra 20: 264-272.

Rodriguez, L., Toro, M., Vázquez, F., Correa-Daneri, M., Gouiric, S., Vallejo, M., 2010. Bioethanol production from grape marc and sugar beet pomaces by solid state fermentation. International Journal of Hydrogen Energy 35 (11): 5914-5917.

Roe, N.E., Stoffella, P.J., Graetz, D., 1997. Composts from various municipal solid waste feedstocks affect vegetable crops. II. Growth, yields, and fruit quality. Journal of the American Society for Horticultural Science 122: 433-437.

Ruban, V., López- Sanchez, J.F., Pardo, P., Rauret, G., Muntau, H., Quevauviller, Ph., 2001. Development of a harmonized phosphorus extraction procedure and certification of a sediment reference material. Journal of Environmental Monitoring 3: 121-125.

Ruffo, M. L., Bullock, D.G., Bollero, G.A., 2004. Soybean yield as affected by biomass and nitrogen uptake of cereal rye in winter cover crop rotations. Agronomy Journal 96: 800-805. 
Saha, N., Das, A.C., Mukherjee, D., 1998. Effect of decomposition of organic matter on activities of microorganisms and availability of nitrogen, phosphorus and sulphur in soil. Journal of the Indian Society of Soil Science 43: 210-215.

Sallaku, G., Babaj, I., Kaciu, S., Balliu, A., 2009. The influence of vermicompost on plant growth characteristics of cucumber (Cucumis sativus L.) seedlings under saline conditions. Journal of Food Agriculture and Environment 7: 869-872.

Sample, E.C., Soper, R.J., Racz, G.J., 1980. Reactions of Phosphate Fertilizers in Soils. In: The role of Phosphorus in Agriculture, Khassawneh, F.E., E.C. Sample and E.J. Kamprath (Eds.). ASA, Madison, WI, USA: 263-310.

Sánchez, A., Ysunza, F., Beltrán-García, M.J., Esqueda, M., 2002. Biodegradation of viticulture wastes by Pleurotus: a source of microbial and human food and its potential use in animal feeding. Journal of Agricultural and Food Chemistry 50: 2537-2542.

Sánchez, E., Ferrer, J.R., 1994. Nutritive solution to hydroponic culture from grape pomace. Revista Técnica de la Facultad de Ingeniería Universidad del Zulia 17: 197-206.

Sánchez-Martín, L., Arce, A., Benito, A., García-Torres, L., Vallejo, A., 2008. Influence of drip and furrow irrigation systems on nitrogen oxide emissions from a horticultural crop. Soil Biology and Biochemistry 40: 1698-1706.

Santiago, B., Ferrer, J.R., Colmenares, N., Paez, G., 1993. Industrial use of grape pomace. Revista Técnica de la Facultad de Ingeniería Universidad del Zulia 16: 199-208.

Santos, A.P.G., Viana, T.V.A., Sousa, G.G., Gomes-do-Ó L.M., Azevedo, B.M., Santos, A.M., 2014. Yield and quality of melon fruit depending on types and doses of biofertilizers. Horticultura Brasileira 32 (4): 409-16.

Santos, M., Dianez, F., de Casa, M., Tello, J.C., 2008. Possibilities of the use of vinasses in the control of fungi phytopathogens. Bioresource Technology 99 (18): 9040-9044.

Scalbert, A., 1991. Antimicrobial properties of tannins. Phytochemistry 30: 3875-3883.

Shafeek, M.R., Shaheen, A.M., Abd El-Samad, E.H., Rizk, Fatma A. and Abd El-Al, Faten, S., 2015. Response of Growth, Yield and Fruit Quality of Cantaloupe Plants (Cucumis melo L.) to Organic and Mineral fertilization. Middle East Journal of Applied Sciences 5: 76-82. 
Sharpley, A.N., Sisak., 1997. Differential availability of manure and inorganic sources of phosphorus I soil. Soil Science Society of America Journal 61: 1503-1508.

Shuval, H., Jodice, R., Consiglio, M., Spaggiari, G., Spigoni, C., 1991. Control of enteric micro organisms by aerobic-thermophilic composting of waste water sludge and agroindustry wastes. Water Science Technology 24: 401-405.

Silva, C.F., Arcuri, S.L., Campos, C.R., Vileda, D.M., Alves, J.G.L.F., Schwan, R.F., 2011. Using the residue of spirit production and bioethanol for protein production by yeast. Waste Management 31 (1): 108-114.

Sivakumar, M. V. K., Shaw, R. H., 1978. Methods of Growth Analysis in Field-Grown Soya Beans (Glycine max (L.) Merrill). Annals of Botany 42 (1): 213-222.

Soil Survey Staff. 2014. Keys to soil Taxonomy (811th Ed.). Washington, USA: USDANatural Resources Conservation Service. US Gov. Print Office.

Sorlini, C., Andreoni, V., Balsari, P., Bertoluzza, A., Bonfanti, P., Levi-Minzi, R., Marchetti, R., Masoni, A., Ranalli, G., Sangiorgi, F., Silva, A., Tano, F., 1998. Trattamento e utilizzazione agronomica di reflui e residui di cantine di vinificazione. Rivista di Agronomía 32: 282-287.

Spigno, G., Pizzorno, T., De Faveri, D.M., 2008. Cellulose and hemicelluloses recovery from grape stalks. Bioresource Technology 99: 4329-4337.

Spigno, G., Maggi, L., Amendola, D., Dragoni, M., De Faveri, D.M., 2013. Influence of cultivar on the lignocellulosic fractionation of grape stalks. Industrial Crops and Products 46: 283-289.

Stanford, G., Frere, M., Schwaninger, D., 1973. Temperature coefficient of soil nitrogen mineralization. Soil Science 115: 321-323.

Stojanovic, S., Stojsavljervic, T., Vunurevic, N., Vikicuranjes, M., Mandic, A., 1989. Nutritive and feeding value of dried grape pomace in feeding fattening cattle. Stocarstvo 43: 313-319.

Sui, Y., Thompson, M.L., 2000. Phosphorus sorption, desorption, and buffering capacity in a biosolids-amended Mollisol Soil Science Society of America Journal 64: 164-169.

Sui, Y.B., Thompson, M.L., Shang, C., 1999. Fractionation of phosphorus in a Mollisol amended with biosolids. Soil Science Society of America Journal 63: 1174-1180. 
Svensson, K., Odlare, M., Pell, M., 2004. The fertilizing effect of compost and biogas residues from source separated household waste. The Journal of Agricultural Science 142 (4): 461-467.

Syers, J.K., Johnston, A.E., Curtin, D., 2008. Efficiency of soil and fertilizer phosphorus use. FAO Fertilizer and Plant Nutrition Bulletin 18. Food and Agriculture Organization of the United Nations 107. Rome, Italy.

Tampio, E., Salo, T., Rintala, J., 2016. Agronomic characteristics of five different urban waste digestates. Journal of Environmental Management 169: 293-302.

Tarquis, A.M., Bird, N.R.A., Whitmore, A.P., Cartagena, M.C., Pachepsky Y., 2008. Multiscale Entropy-based Analysis of Soil Transect Data. Soil Science Society. Soil Science Society of America 7 (2): 563-569.

Tarquis, A.M., Castellano, M.T., Cartagena, M.C., Arce, A., Ribas, F., Cabello, M.J., López de Herrera, J., Bird, N.R.A., 2017. Scale and space dependencies of soil nitrogen variability. Nonlinear Processes in Geophysics 24: 77-87.

Teixeira Lobo, J., Da Silva Sales, W., Alves Feitosa, J.F., Costa Junior, J.M., de Fatima, RT., de Almeida Carreiro, D., da Camara, FT., 2019. Yield and characteristics of melon fruits under different fertilization management and soil cover. Journal of Experimental Agriculture International 34 (5): 1-9.

Tekalign, T., Hammes, P., 2005. Growth and productivity of potato as influenced by cultivar and reproductive growth. II. Growth analysis, tuber yield and quality. Scientia Horticulturae 105: 29-44.

Thorup-Kristensen, K., Magid, J., Jensen, L.S., 2003. Catch crops and green manures as biological tools in nitrogen management in temperate zones. Advances in Agronomy 79: $227-302$.

Tilman, D., Cassman, G.K., Matson, P.A., Naylor, R., Polasky, S., 2002. Agricultural sustainability and intensive production practices. Nature 418: 671-677.

Tittonell, P.A., De Grazia, J., Chiesa, A., 2002. Adición de polímeros superabsorbentes en el medio de crecimiento para la producción de plantines de pimiento (Capsicum annum L.). Horticultura Brasileira 20: 641-645. 
Tolanur, I.S., Badanur, V.P., 2003. Changes in organic carbon, available N, P and K under integrated use of organic manure, Green manure and fertilizer on sustaining productivity of Pearl millet- pigeonpea system and fertility of an incetisol. Journal of the Indian Society of Soil Science 51: 37-41.

Tominaga, T., Kawaguchi, K., Kanesaka, M., Kawaguchi, H., Sirillo, E., Kamazawa, Y., 2010. Suppression of type-I-allergic responses by oral administration of grape marc fermented with Lactobacillus plantarum. Journal Immunopharmacology and Immunotoxicology 32 (4): 593-599.

Toor, G.S., Peak, J.D., Sims, J.T., 2005a. Establishing a linkage between phosphorus forms in dairy diets, feces, and manures. Journal of Environmental Quality 35: 1380-1391.

Toor, G. S., Peak, J.D., Sims, J.T., 2005b. Phosphorus speciation in broiler litter and turkey manure produced from modified diets. Journal of Environmental Quality 34: 687697.

Traore, O., Sinaj, S., Frossard, E., Van De Kerkhove J.M., 1999 Effect of composting time on phosphate exchangeability. Nutrient Cycling in Agroecosystem 55: 123-131.

Trinsoutrot, I., Recous, S., Bentz, B., Lineres, M., Cheneby, D., Nicolardot, B., 2000. Biochemical quality of crop residues and carbon and nitrogen mineralization kinetics under nonlimiting nitrogen conditions. Soil Science Society of America Journal 64: 918-926.

Turner, B.L., Papházy, M. J., Haygarth P. M., McKelvie, I.D., 2002. Inositol phosphates in the environment. The Royal Society 357: 449-469.

Turner, B.L., Leytem, A.B., 2004. Phosphorus compounds in sequential extracts of / manures. Chemical Speciation and a novel fractionation procedure. Environmental Science Technology 38: 6101-6108.

Tyson, A., Dixon, M.L., Segars, W., 1992. Your Drinking Water: Nitrates Ext. Publ. 819-5 Univ. of Georgia, Athens, GA, USA.

Tzortzakis, N., Gouma, S., Dagianta, E., Saridakis, C., Papamichalaki, M., Goumas, D., Manios, T., 2012. Use of fertigation and municipal solid waste compost for greenhouse pepper cultivation. The Scientific World Journal, Article ID 973193. U.S. Department of 
Agriculture. 1991. Nitrate occurrence in U.S. waters (and related questions). USDA, Washington, DC.

Valantin, M., Gary, C., Vaissière, B., Tchamitchian, M., Bruneli, B., 1998. Changing sink demand affects the area but not the specific activity of assimilate sources in Cantaloupe (Cucumis melo L). Annals of Botany 82: 711-719.

Vaneeckhaute, C., Janda, J., Vanrolleghem, P.A., Tack, F.M.G., Meers, E., 2016. Phosphorus use efficiency of bio-based fertilizers: bioavailability and fractionation. Pedosphere 26: 310-325.

Varela, M., Castaño, S., 1995. Experiencias para la caracterización del flujo y transporte de nitratos en la zona no saturada de la llanura manchega (Ciudad Real). Jornadas sobre "La zona no saturada y la contaminación de las aguas subterráneas. Vulnerabilidad de acuíferos". (Barcelona).

Vatai, T., Skerget, M., Knez, Z., 2009. Extraction of phenolic compounds from elderberry and different grape marc varieties using organic solvents and/or supercritical carbon dioxide. Journal of Food Engineering 90 (2): 246-254.

Velthofa, G.L., Mosquera, J., 2011. The impact of slurry application technique on nitrous oxide emission from agricultural soils. Agriculture, Ecosystems and Environment 140: 298308.

Von Wandruszka, R., 2006. Phosphorus retention in calcareous soils and the effect of organic matter on its mobility. Geochemical Transactions 7: 6.

Wei, Y.H., Chou, C.L., Chang, J.S., 2005. Rhamnolipid production by indigenous Pseudomonas aeruginosa J4 originating from petrochemical wastewater. Biochemical Engineering Journal 27 (2): 146-154.

Whalen, J.K., Chang, C., 2001. Phosphorus accumulation in cultivated soils from long-term annual applications of cattle feedlot manure. Journal of Environmental Quality 30: 229-237.

Wong, J.W.C., MaK, K., Fang, M., Cheung, C., 1999. Utilization of a manure compost for organic farming in Hong Kong. Bioresource Technology 67: 43-46. 
Xiong, J., Patil, G.G., Moe R., 2011. Effects of diurnal temperature alternations and light quality on growth, morphogenesis and carbohydrate content of Cucumis sativus $L$. Scientia Horticulturae 128: 54-60.

Xue, D., Huang, X., 2013. The impact of sewage sludge compost on tree peony growth and soil microbiological, and biochemical properties. Chemosphere 93: 583-589.

Yamagata M., Ae, N., 1999. Direct acquisition of organic nitrogen by crops. Japanese Agriculture Research Quarterly 33 (1): 15-21.

Yang H.S., 2006. Resource management, soil fertility and sustainable crop production: Experiences of China. Agriculture, Ecosystems and Environment 116: 27-33.

Yan-Wang, Yamamoto K., Yakushido, K., Yan, W., 2002. Changes in nitrate $\mathrm{N}$ content in different soil layers after the application of livestock waste compost pellets in a sweet corn field. Soil Science and Plant Nutrition 48 (2): 165-170.

Zhang, Y.H., Fan, J.B., Zhang, Y.L., Wang, D.S., Huang, Q.W., Shen, Q.R., 2007. Naccumulation and translocation in four japonica rice cultivars at different $N$ rates. Pedosphere 17: 792-800. 
